\title{
AN INTERPRETATION OF FOUR MEN'S EXPERIENCES OF SUICIDALITY
}

by

Brian Phillips

A thesis submitted to the Victoria University of Wellington

in fulfilment of the

requirements for the degree of

Doctor of Philosophy

in Nursing

Victoria University of Wellington

2004 


\section{Acknowledgements}

I would like to express my deepest gratitude to the four participants of this study for their patience and trust. I hope I have been able to do justice to what you have given me. Additionally, I wish to acknowledge the many clients who I have met, trusting me to give something that would help. These experiences have also influenced this study in a multitude of ways. Thank you to you all.

Many thanks go to my partner Shirley Roberson for her love, unflagging support and willingness to debate the abstract stuff of research till the wee small hours during the long journey that is a $\mathrm{PhD}$ study. Similarly, I wish to also thank my parents for their love, support and encouragement throughout the years.

I want to also acknowledge the generosity of my colleagues in the Graduate School of Nursing and Midwifery over this time. Without making room and offering the support that was given to me this would have been a far more difficult journey.

Many thanks also to Dr. Robin Day for his thoughtful feedback in the early part of my PhD supervision. Thank you also to Dr. Alison Kirkman for her feedback on an early draft of the chapter on masculinities. Thanks also to Prof. Jan Duke for her reading, encouragement, and editorial feedback. I am indebted to Dr. Janice McDrury, my primary supervisor, for her experience, guiding wisdom and trust in my exploration. I have greatly appreciated the many hours of reading and feedback that have ultimately extended my learning and writing.

This study was supported by the Faculty of Humanities and Social Sciences' Small Research Grants (Nos. R0141 and 20603) and a Book Grant from the New Zealand Nurses' Organisation. 


\begin{abstract}
Mental health nurses are frequently called upon to care and provide intervention for suicidal men. While there is substantial literature on male suicide, far less is known about the understandings men have of their suicidal experiences. This study draws upon Gadamer's philosophical hermeneutics to explore the understandings that four men have had of their past suicidal experiences.
\end{abstract}

The interpretations developed in this study, as far as possible, make explicit use of my own particular horizon of meaning as researcher and mental health nurse, and as such, seeks to engage with a tradition of mental health nursing. In addition, by consciously bringing an anti-essentialist perspective of masculinity to this process, I explore the way in which gender impacts on men's suicidality. The primary source of information for this study is in-depth, open-ended conversations with four men of European descent in their middle adult years who were asked to talk about their past experiences of suicidality.

The interpretations developed here show that for these men, the hermeneutic fusion of history, language, and sociocultural context, provided limited possibilities with which they were able to construe themselves as "fitting in" with normative standards. These constraints, that are otherwise taken-for-granted and invisible, became explicit through their experience of ongoing victimisation. Furthermore, early understandings of these experiences became a potent horizon of meaning from which they then came to understand later difficult experiences. Victimisation became constitutive of an understanding of self as fundamentally different and (hierarchically) "less-than" other men. Ultimately, suicidality emerged out of a background of ever-present psychological pain accompanying a construction of self as being unable to see themselves as ever "fitting in".

These men did not regard themselves as having recovered from suicidality, but remain in a process of recovering. This process did not mean figuring out how to "fit in", or become "normal" men, but rather, to live meaningfully as men in spite of not "fitting in" with the sociocultural ideal. This involved a process of repeated cycles of revisiting and reflecting on their personal histories from vantage points permitting understandings that opened up opportunities for personal growth and learning. Relationships were significant for either enabling or disabling this process. Recovering was therefore a 
continual and idiosyncratic process, rather than an outcome of a specific technique or knowledge.

The position taken in this study is that mental health nursing seeks to engage with people and work with them in collaborative, respectful, human relationships. It is argued that mental health nurses work with an individual's situated understandings rather than delivering prescribed treatment determined by diagnosis. Hence, viewing suicidality as socioculturally situated and historically emergent suggests mental health nurses must closely attend to the way in which we bring ourselves into relationships with our clients so that we are then able to create opportunities for change. The exploration of suicidality in this study also alerts us to the possibility that through fusion with clients' pre-understandings, mental health intervention can inadvertently further constrain choices to survive. 


\section{Table of Contents}

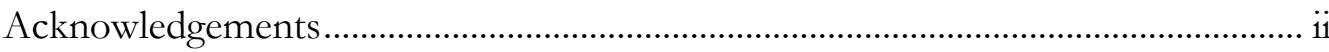

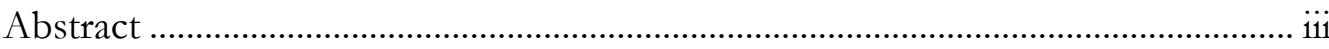

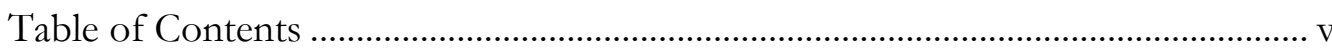

List of Tables ................................................................................................................ ix

\section{Chapter 1}

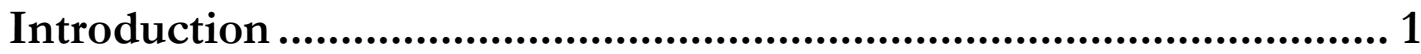

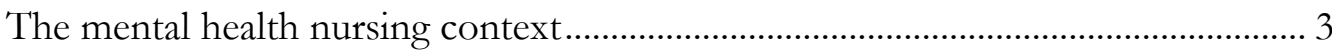

A methodological approach to fit the needs of mental health nursing practice...... 5

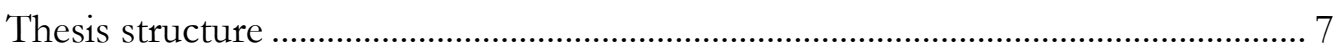

\section{Chapter 2}

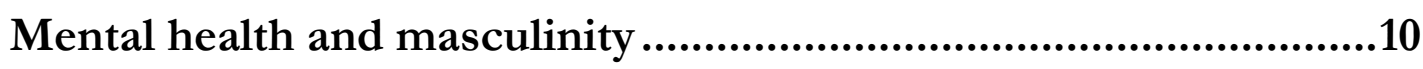

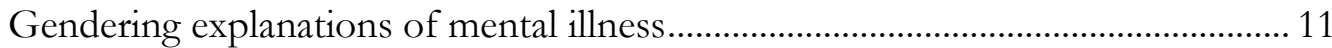

The medical explanation of mental illness..................................................................... 13

Psychiatric legitimisation of stereotypes ...................................................................... 16

Gender bias in psychiatric diagnosis .......................................................................... 17

Gender bias in treating mental health problems ........................................................ 18

Gender bias in access to mental health treatment........................................................... 19

Mental health, men's violence and aggression .......................................................... 20

Towards gendering men's mental health .............................................................. 22

\section{Chapter 3}

Men's suicide and suicidality .......................................................... 24

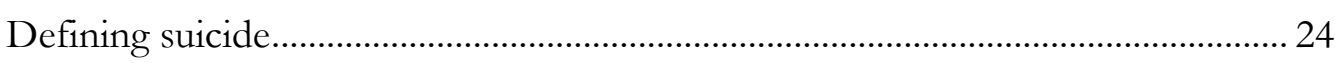

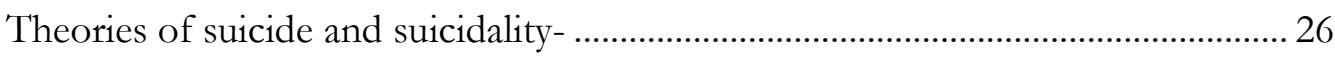

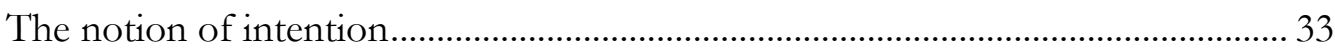

The relationship between non-fatal and fatal suicidality ............................................ 38

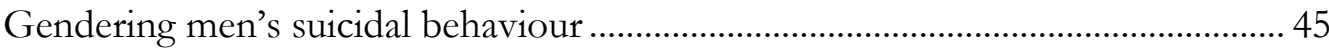

\section{Chapter 4}

Masculinities ............................................................................ 49

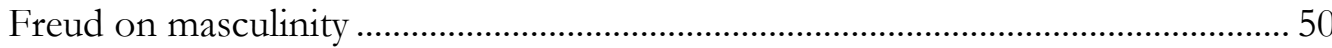




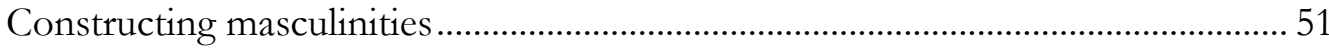

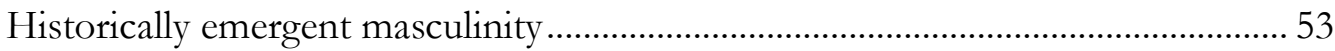

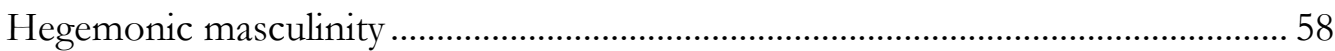

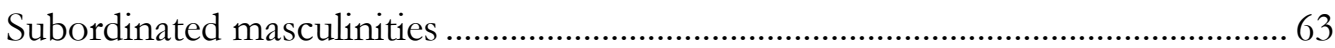

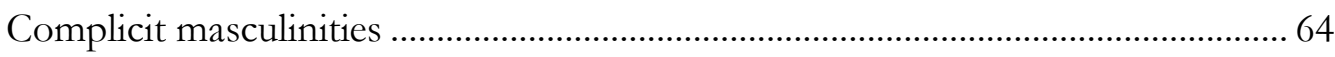

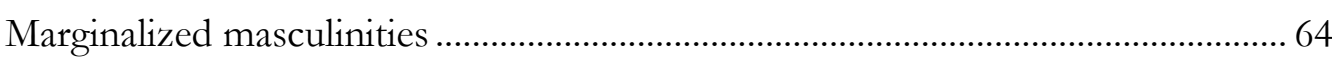

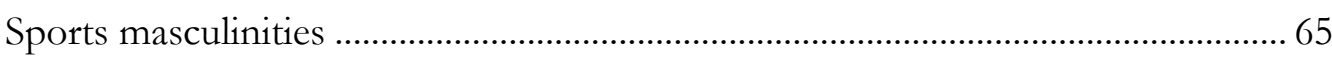

Toward understanding men and suicidal experience ................................................. 71

\section{Chapter 5}

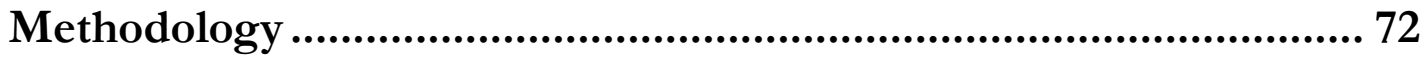

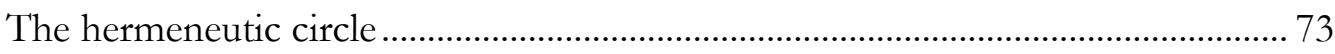

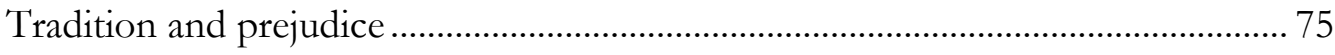

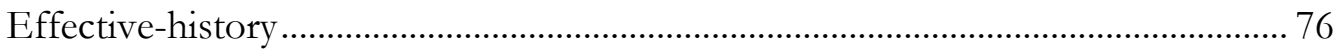

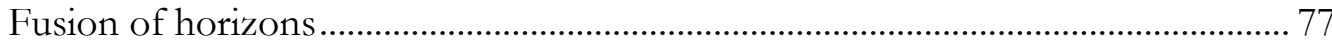

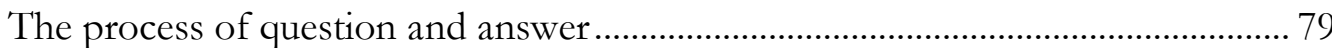

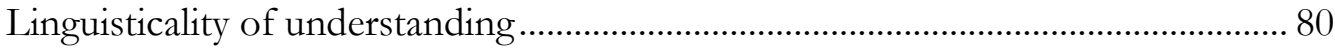

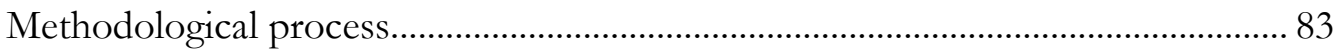

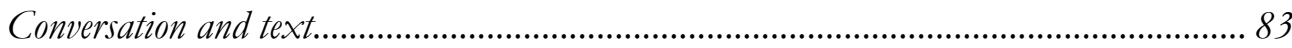

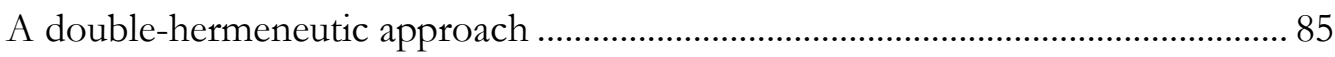

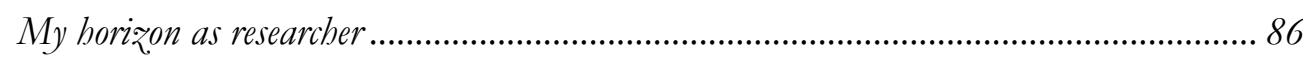

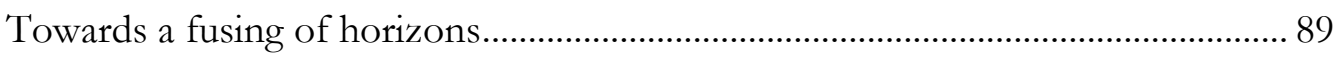

\section{Chapter 6}

Method and analytical process ........................................................... 90

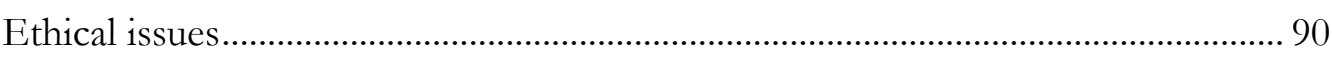

Vulnerability and self-determination ....................................................................... 91

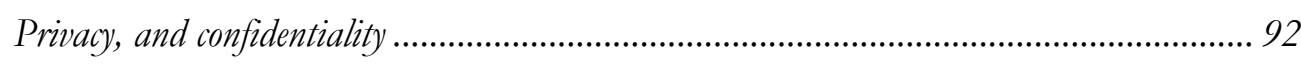

Respectfulness and transparency ...........................................................................93

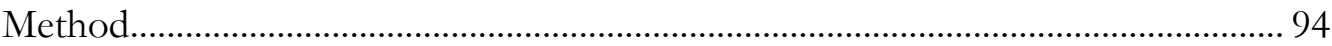

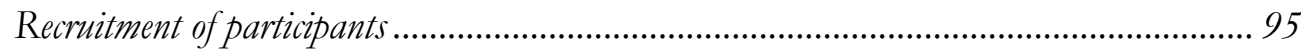

The participants ……………………………………............................................ 96

Positioning the researcher ................................................................................................. 97

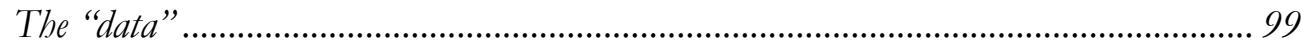




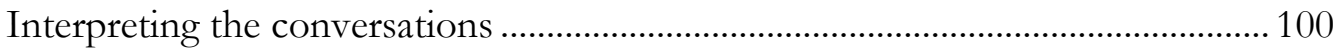

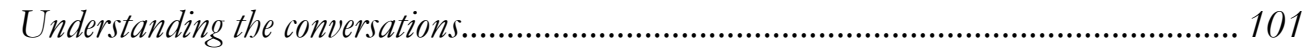

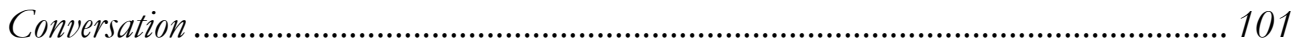

(Re)interpretation through the transcripts....................................................................... 104

\section{Chapter 7}

Conversations with four men............................................................106

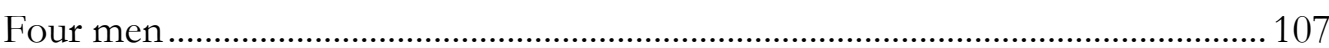

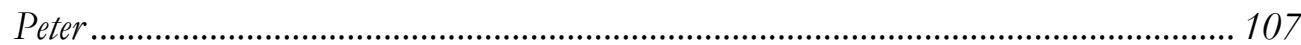

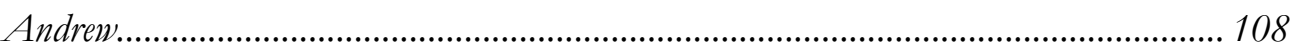

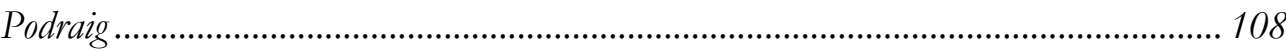

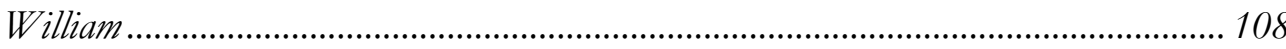

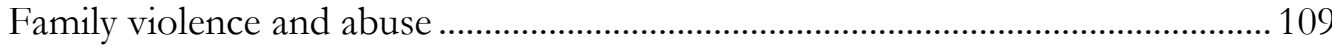

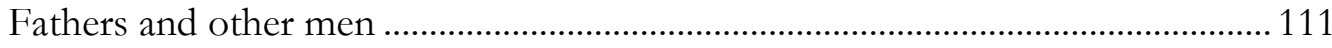

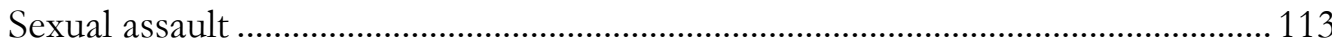

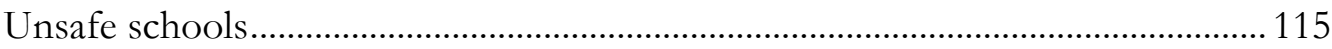

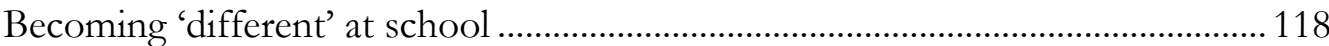

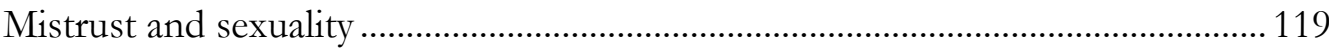

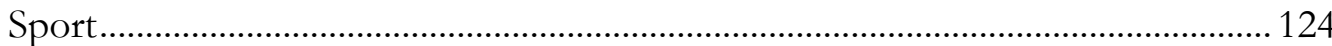

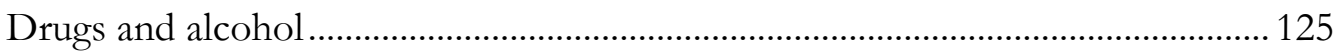

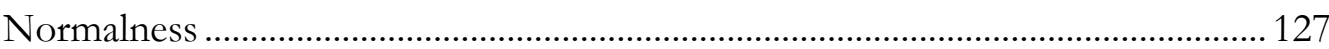

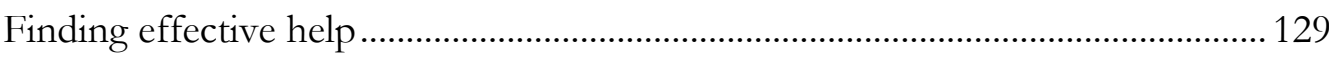

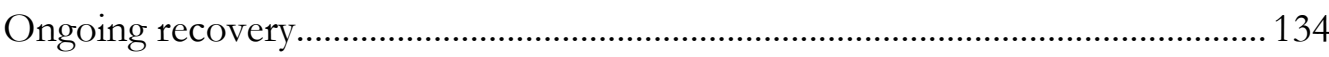

\section{Chapter 8}

A (re)interpretation of four conversations .....................................137

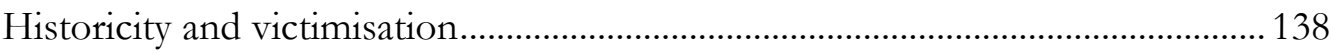

Experiencing re-victimisation ....................................................................................... 141

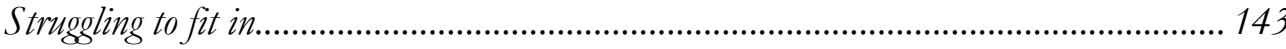

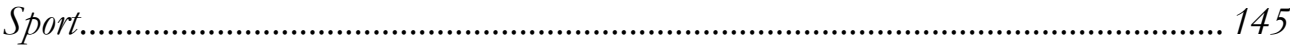

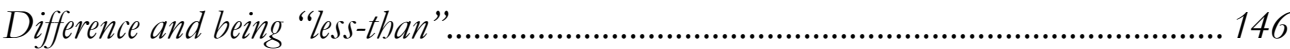

Fathers and heteronormativity.................................................................................. 151

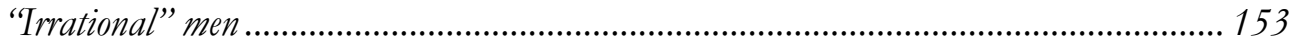

Quelling anxiety: A matter of survival....................................................................... 155 


\section{Chapter 9}

Discussion and implications for mental health nursing practice

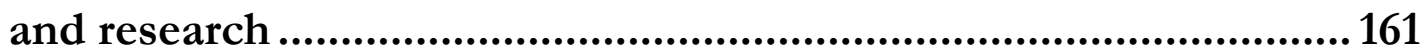

Interpreting suicidal experiences with four men ....................................................... 162

Historically emergent suicidality ………………….................................................. 164

Problematising masculinity in men's suicidal experience ......................................... 166

Implications for mental health nursing practice ......................................................... 170

Implications for mental health nursing research .................................................. 175

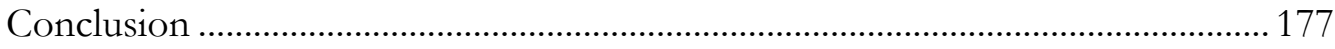

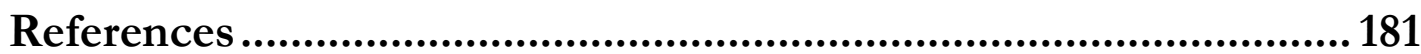

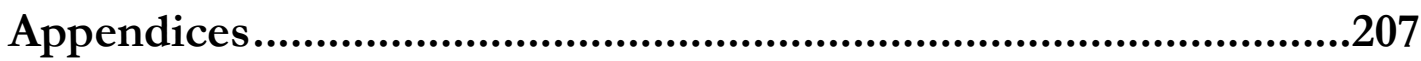




\section{List of Tables}

Table 1. Some key terms used to describe suicidal behaviour.............................................25

Table 2. Baechler's (1975) suicide types and their underlying meanings. ............................31

Table 3. Shneidman's (1985) ten common characteristics of suicide.................................32

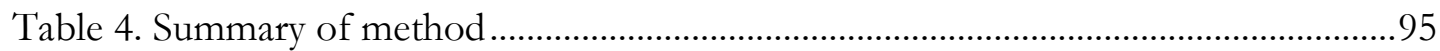

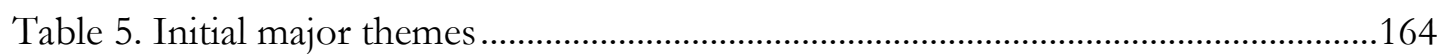

Table 6. A (re)interpretation: Disclosing masculinities in suicidal experience .................166 


\section{Chapter 1}

\section{INTRODUCTION}

Meeting a person who tells of a desire to kill him or herself is regarded as an extraordinarily challenging experience. While there is an abundant research literature on the topic of suicide, and evidence-based guidelines are now available to direct clinical decision-making, the experience of progressively eliciting the story of someone intending to end their life is an inescapably personal experience for both the professional and the suicidal client who is seeking help; and indeed, it is also a deeply personal experience for all those who have a significant relationship to the person.

While assessment and management guidelines are clearly a useful synthesis of knowledge gleaned from the currently available research, the face-to-face encounter as a mental health nurse requires more than an interview for "risk" and "mental status assessment". In the human encounter with a person in a profound state of existential crisis, a meeting limited to an assessment process seems a pallid offering. In confronting such desperate need, risk evaluation and assessment of mental health appears superficial and distant. If nursing is at its core, about nurturance and caring for another person (as well as caring about another person), it is necessary then to answer the question what is it in this encounter that is mental health nursing? ${ }^{1}$ This is one of the questions grappled with through the exploration undertaken in this study.

While each person and their experiences are unique, and each encounter with a person who is suicidal is unique, my own clinical experience as a mental health nurse suggests to me that the person-to-person experience with suicidal men was characteristically different to that with women. The character of the discussion with men; the form of words, the explanation and content of events, the description of feelings (if any), questions of what to $d o$, and so forth, were strikingly different to that I encountered in

\footnotetext{
${ }^{1}$ Except where I refer to practice that has a specific psychiatric focus, I use the broader term of mental health nursing.
} 
my engagement with women who were suicidal. ${ }^{2}$ Reflecting on these encounters, I also noticed that my response to men was likewise characteristically different. What I expected of men and thought was needed in order to engage with men was shaped by my life experiences rather than any clinical text. For instance, rightly or wrongly, I expected an inarticulateness around feelings and considered a certain degree of anger to be normal for men, but not for women. I also expected men to drink and get angry when dealing with personal difficulties. In my risk formulation I also put a high degree of my attention on the risk of violence to myself as well as others (especially family) when dealing with suicidal men in the expectation that angry (and "irrational") men are potentially violent men. When considering potential interventions I also frequently constructed these as things for men to do rather than contemplate, on the basis that solving problems through working harder seemed to be the norm for men. Hence, how I interacted with men and what I expected of men were what my life and professional experience had shown me rather than something taught to me formally from nursing or mental health literature.

Concerns aroused from my reflections upon my clinical practice were left unsatisfied by an exploration of mental health nursing texts and generic clinical guidelines on suicide. These resources did not elaborate on the particular issues for men when in mental health crisis, other than to say that men are at higher risk of suicide than women. They did not answer the questions of what it was about men that left them at higher risk, or what I needed to bring as a (male) mental health nurse to my interventions that would address masculinity in the face of an experience that appeared to force men into contact with services they did want to be associated with. While I felt that one focus of my engagement was quite properly upon the evaluation of risk and mental status assessment, I was unsatisfied with the current practice guidelines for suicide management (e.g. Ministry of Health, 1998; Sumich, Andrews, \& Hunt, 1995). Neither these guidelines, nor mental health nursing frameworks dealt with the meaning of feeling suicidal as a man. Hence, another focus of this study is masculinity in the context of experiencing suicidality, and the implications of this consideration for practice as a mental health nurse.

\footnotetext{
2 At this time I was practicing in drought-stricken rural Australia. A striking example of gender differences at this time was in the process of seeking help from mental health services. Men would rarely approach our service directly, and instead, I or my colleagues would be first approached by their wife or some other community member (or by the local Department of Agriculture representative). The issues would then be discussed from their viewpoint. Eventually, a process would be negotiated to manage my first contact with the distressed farmer in order to provide him with some help.
} 


\section{The mental health nursing context}

To practice as a mental health nurse means to practice within a social context. The advanced practice competencies of the Australian and New Zealand College of Mental Health Nurses (2002) state this clearly naming four areas of relating and relationships situated within the socio-political and cultural contexts: self, consumers, colleagues, and the profession. Hence, there is a clear assumption within these competencies that as mental health nurses we always deal with people in a relationship that is also assumed to be socially situated.

The focus of mental health nursing practice and what mental health nurses are needed for has been the subject of a recent debate (Barker \& Reynolds, 1996; Gournay, 1995, 1997; Lego, 1997; Philbin, 1997; Rolfe, 1996). At issue is a nursing practice driven by a biomedical model or driven by a concern for human living and meaning, and how these two viewpoints are located in a practice framework (Geanellos, 2004). While not necessarily opposing positions, there is an inherent tension between the approaches derived from these two positions.

While the mental health nursing practice context includes consideration of the biological and cognitive aspects of people and responding accordingly, the particular need for mental health nursing is a socially situated one and the interventions mental health nurses provide should necessarily be socially situated. Even if mental health nursing interventions are biological (e.g. administration of medication), this aspect of practice is situated within a social context. That is, the processes of providing medication by mental health nurses is a social one involving a relationship not only with the client, but because medication and being medicated are socially meaningful terms in their own right, this aspect of practice occurs within a larger social context.

Communication or interaction is a social process and takes place in relationships and in social contexts. For those who take the position that interpersonal process is at the core of mental health nursing (Peplau, 1952; Travelbee, 1971), practice is fundamentally a process of engaging with another who is need of what mental health nurses can offer. In this regard, Peplau (1997) has stated "that much of the work of nurses occurs during their interaction with patients" (p. 153). Horsfall and Stuhlmiller (2000) agree, stating that mental health nursing texts investigate communication because that is the foundation of "what nurses do" (p. 23). While language is an important aspect of 
communicating, it is not the only way of communicating. A significant part of communicating is non-verbal and is an essential aspect of interpersonal interaction.

In their study of the "need for psychiatric nurses" Barker, Jackson and Stevenson (1999a, 1999b; Jackson \& Stevenson, 2000) show that people who are in contact with psychiatric mental health nurses need mental health nurses to respond in a flexible process that is responsive to changes in need. In their research, engagement emerged as a "continuous process of 'getting to know' the person and her/his needs, as the person was 'getting to know' the nurse" (Barker et al., 1999b, p. 275). The core of the need for psychiatric mental health nurses was seen as a complex "knowing you - knowing me" process. Knowing you - knowing me was discussed as involving a mobility across what the researchers termed the Ordinary Me to the Professional Me. The knowing aspect of what was needed from mental health nurses within an interpersonal process necessitates an ability to understand the other person. Without the responsiveness, openness, twoway engagement and sharing, that the researchers assert was part of what was needed of psychiatric mental health nurses, understanding would not be able to occur. Accepting that knowing and understanding are embedded within an interpersonal nursing process presumes a concern for socially meaningful relationships. Or to put this differently, mental health nurses are professionally concerned about people as meaningful rather than meaningless. The stories people tell are presumed to be meaningful and able to be comprehended; they are not told because they are meaningless to the person. That is, people care about what they are telling and want to be genuinely heard. There are many distressing stories that people tell. Thoughts of suicide and the personal story of suicidality has long been recognised as one of the more difficult stories to hear and respond to.

Mental health nurses engage in socially situated relationships purposefully. However, the effect is not all in one direction. Insofar as we genuinely hear or attend to others, mental health nurses are also affected by the relationships that we professionally exist within. In this sense, through our engagement with the people we call our clients we become experienced. These experiences enable us to better engage in future relationships and offer help. Through our relationships, in which we are open and sharing, we are able to better understand; that is, through a meaningful interpersonal process in which we seek to understand the other person we become better at meeting the need for mental health nursing in the future. 
Given an interpersonal process as a fundamental underpinning of mental health nursing practice, the current risk orientation provided in nursing texts and generic mental health guidelines do not readily provide an adequate practice framework for mental health nurses who are seeking to meet the needs of men who are suicidal. In order to "address their human responses to psychiatric disorder, rather than the disorders" (Barker, Reynolds, \& Stevenson, 1997, p. 5), concepts such as risk should be located within a framework that helps mental health nurses to understand the person and their experience. As Wilkin (2003) has recently argued, "scientific theory and technical artistry may inform practice, but cannot deliver it" (p. 27), concluding that "the craft of caring is always dependent upon the other, whose own personal growth becomes a catalyst for the incidental development of the nurse" (p. 28).

\section{A methodological approach to fit the needs of mental health nursing practice}

Insofar as mental health nursing is about understanding and responding to "human problems involving his [sic] relationship to himself or others" (Barker, 1997, p. 8) as the central mode of intervention, the task of mental health nursing research should be to address human meaning and interpersonal relating. This position accepts that people are understood to live and move in a world made meaningful through what is shared rather than by a process of universal laws. Likewise, health and ill-health, including mental disorders, are not somehow a separate thing in people's lives. Barker, Reynolds and Stevenson (1997) subscribe to this view stating that:

\section{From birth onwards and throughout life, people are in interpersonal milieu, of one kind or another, in which they have human responses which shape them as persons and which register in the organic body. (p. 5)}

On the basis that socially situated engagement is at the core of mental health nursing practice, a focus for research that seeks to inform mental health nursing practice should include understanding and meaning as a situated activity. That is, psychotherapeutic activity is approached as a "somewhat unique, socially sanctioned interpersonal activity devoted to assisting individual members" (Martin \& Sugarman, 1999, p. 78) in which a collaborative effort brings about change through the client's "internalization of the therapeutic conversations and activities through which their personal theories have been elaborated, interpreted, and analyzed" (Martin \& Sugarman, 1999, p. 78). A focus on 
understanding and meaning as situated also means that the therapeutic encounter is located within a larger social context. Martin and Sugarman note that change is therefore ultimately dependant on the life context of the person before, during and after this encounter. Hence, a research methodology exploring men's suicidality from this position must account for understanding and meaning as socially mediated rather than as stable and discoverable universal notions. The research outcome is therefore interpretive rather than objective.

Cutcliffe and Goward (2000) compare mental health nursing practice to a kind of phenomenological research study in which the engagement with a client operates through a relationship whereby the nurse makes use of themselves to understand the personal meaning and lived experience of another. As with such a research approach, a certain tolerance and embracement of ambiguity and uncertainty that comes with situated meaning is required in this engagement. Such an approach makes explicit the involvement of self in both research and practice. As researcher, or as clinician, I am inextricably bound up in the creation of new understanding through the experience of conversation.

The task set for this study then, is an exploratory one that seeks to further understand the human experience of a specific group of people (i.e. men of European descent) who have experience of a particular phenomenon (suicidality). The methodological premise made here is somewhat similar to that of Cutcliffe and Goward (2000), that by engaging with people who have lived through the experience, then that experience can be better understood by the researcher. Applying this position to men's suicidality, Cutcliffe, Joyce and Cummins (2004) have recently put forward the argument that there is an urgent need to understand suicide "as a result of a person's life, his/her experiences and the situated contextual meaning that the person attributes to these experiences" (p. 309) and advocate a research approach in which "data" is collected using "hermeneutic conversations". This approach is not put forward as a replacement for a positivist method to the study of suicide and suicidal experiences, but to augment or complement current research.

A further consideration is that a methodology concerned with the process of understanding will also inform mental health nursing as a practice that engenders change through social processes. The work of Hans-Georg Gadamer's on 
understanding is particularly pertinent because of his concern with situatedness, the centrality of language, and attention to the unique vantage point that each person brings to the encounter with another person. While Gadamer does not provide a ready-to-hand approach for social science research, philosophical hermeneutics has been variously utilised to undertake nursing research (e.g. Fleming, Gaidys, \& Robb, 2003; Geanellos, 1997; Pascoe, 1996; Thompson, 1990; Walsh, 1996).

\section{Thesis structure}

Having set out the initial motivation for this study and located it in relationship to my position on the "proper focus" (viz. Barker \& Reynolds, 1996) of mental health nursing, this study draws upon the work of Gadamer to explore the past suicidal experiences of four men.

The next three chapters of this thesis explores the initial theoretical position from which this study enters into an exploration of men's suicidality. Chapter 2: Mental Health and Masculinity examines gender in relation to mental health. This chapter examines psychiatry and the broader field of mental health for its relationship to gender in order to develop an argument that clinical intervention in mental health is a potent influence in which psychiatry and mental health services police the boundaries between normal and abnormal for women and men. Whereas diagnosis and intervention are frequently positioned as universal and objective, this argument sets out to show that mental health and disorder are gendered.

In the third chapter, Men's Suicide and Suicidality, the literature on suicide and suicidality is overviewed and specific terminology to the field of suicidology is explained. The discussion then focuses on men's mental health in relation to suicide and suicidality. In particular, notions of risk, intentionality and lethality are critiqued. While men and women are considered in the research on suicide, differences are generally theorised as a category of sex (i.e. female/male dichotomy) rather than as socially engaged meanings related to the body (i.e. gendered). This chapter develops a position from which to explore men's suicidal experience as gendered.

Masculinity is rarely examined within mental health nursing literature as an issue considered for mental health or illness. Where adverse outcomes are seen to be more characteristic of men, that the problem, label, diagnosis or syndrome is gendered is not 
usually examined. Chapter 4: Masculinities begins by overviewing the literature on masculinity in order to develop a non-essentialist position from which to examine the mental health effects of masculinity for men. Drawing on recent research on masculinities, I take the view here that masculinity is a social construction. Rather than biologically determined, masculinity is "problematised" here in an effort to closely examine the taken-for-granteds about men experiencing suicidality.

Chapter 5: Methodology develops an approach strongly influenced by the work of Gadamer. Similar to other nursing studies that have drawn upon Gadamer, the approach developed here attends to understanding as a hermeneutical process in which language and history are central, and that the process of interpretation occurs as a fusion of the horizons of the dialogical participants; in this study, myself as researcher and four men who have had past experiences of suicidality. The notions of conversation and text are discussed in some detail. In attending closely to how a Gadamerian methodology informs the connection between conversation and transcription, it is proposed that understanding has already occurred in the dialogue of the "interviews" and that interpretation of the transcripts is disconnected from, but related back to, the original dialogue. Hence, the methodological approach taken in this study is that of a double hermeneutic interpretation.

Since Gadamer critiques the dominant reliance on method to establish truth, method becomes idiosyncratic to any proposed research drawing upon his work. Chapter 6: Method and Analytical Process develops the methodological approach further to describe the specific processes adopted for this study. This chapter begins with a discussion of ethical issues of particular note to the method used in this study in the context of suicidality. It then traces the concrete, practical processes undertaken to conduct this study as well as the justification for these. In addition, the nature of what is considered to be "data" in the context of Gadamerian hermeneutics is discussed in some detail. The methodological argument set out in Chapter 5 is used to elaborate the process of interpretation for both the conversations and transcripts. In particular, the conditions of understanding are closely examined. In describing the interpretive processes, the personal positioning from which I bring myself into this exploration is briefly described, whilst at the same time acknowledging that this can never be completely explicated. 
Chapter 7: Conversations with Four Men sets out the result of the first interpretive process. This chapter describes the major themes, as I understood them to be, as a result of conversing with the four men who discussed with me their experiences of suicidality. It commences with a brief introduction to each of the four men. The emphasis in this interpretation is upon that understanding formed through the spoken dialogue of the conversations. Drawing upon numerous quotes from the transcriptions, the interpretive effort in this chapter is directed toward a thematic description of my new understanding of these men's suicidal experiences as emerging from the dialogical fusion of horizons.

A (Re)interpretation of Four Conversations revisits the conversational understanding I developed by exploring the records (transcripts, memos, etc.) of these conversations. The transcripts are examined as the primary, but not the only source, of historical records that relate to the original conversations. In this new interpretation the theoretical lens developed in the earlier chapters of this thesis are put fully into play to reveal the gendered nature of four men's past suicidal experiences. A conception of suicidality is understood here to be deeply historical, emergent, and part of a sensemaking process in which suicidality develops against the dominant taken-for-granted (and hence, unseen) ideas of what "being manly" entails.

In the concluding chapter, the interpretive process, and the results of this process are discussed in the context of the position taken in this study, that the "proper focus" of mental health nursing is a situated, interpersonal and purposeful process. Whilst considering generic guidelines for risk assessment and intervention, it is argued that there is a need for mental health nursing intervention to be guided by practice frameworks that are underpinned by nursing theories on interpersonal process such as that articulated by Hildegard Peplau (1952). Gadamer's work on understanding is wellsuited to advancing mental health nursing knowledge given the centrality of understanding to working with interpersonal processes intended to facilitate client growth and development. It is also argued that the consideration of men's suicidality through a nursing lens informed by a Gadamerian approach, shows new possibilities for mental health nursing intervention. In light of the interpretive analysis of men's suicidality, this chapter also discusses the potential risks inherent in an uncritical acceptance of evidence-based guidelines being regarded as sufficient to inform nursing practice. 


\section{Chapter 2}

\section{MENTAL HEALTH AND MASCULINITY}

Until recent years, the interest in men's suicide has been studied as a difference between women and men. That there may be something particular about living as a man that has health effects is a relatively recent issue for the study of suicide. Connell et al. (1998) have argued that a substantial amount of research literature on men's health and mental health focuses upon the differences between the sexes and that such research fails to connect with the existing research on gender. He argues that the consequence of this is that there is a lack of understanding about the causes of health problems from the perspective of the way in which people live their lives as women and men. By gender, I refer to the social meaning attributed to being a woman or a man, whereas a person's category of sex is determined physiologically. Research using positivist methods frequently use the terms gender and sex as if they are synonymous and therefore interchangeable. However, there is a substantial body of literature that shows that the category of sex does not necessarily determine a person's experience of being a woman or man, or the social meaning of woman or man that is attributed by others (e.g. Broom, 1995; Caplan, 1987; Chesler, 1978; Connell, 1985, 1995; James \& Saville-Smith, 1994).

In their review of the literature on men's health Connell et al. (1998) argued that the health research literature is predominantly based on a positivist approach. Through the utilisation of tests of statistical significance, difference becomes the focus of interest whilst similarity is regarded as uninteresting. As the dominant form of health research on men, "sex difference" research exerts a powerful influence on both the definition of health problems and the clinical approaches used to address these issues. The exemplar of the scientific method, the randomised controlled trial (RCT), is seen as the best evidence of efficacy. The premise is that intervention based on scientific evidence will lead to better health outcomes, than intervention based on evidence from research approaches that do not use the scientific method. Both the medical model and scientist- 
practitioner approach of clinical psychology are strongly premised on the scientific method. However, such approaches have been critiqued for supporting dominant social structures and doing little to counter existing inequalities in health (Busfield, 1982; Chesler, 1972), and for emphasising treatment rather than caring within nursing (Barker, 1990; Barker et al., 1997).

As gender is a fundamental division of inequality in our society, it is therefore necessary to critically examine how clinical intervention and gender interact to produce different health outcomes for women and men. This requires commencing with a critique of our understandings of mental illness.

\section{Gendering explanations of mental illness}

Arguably the dominant model by which our society seeks to explain ill health is a medical one (Clarke, 1991). Although the term "medical model" is imprecise, the term nevertheless refers to an approach within medicine premised on science. The medical model takes a person (the patient) from which signs (observable indications) and symptoms (subjective descriptions) are used to formulate a diagnosis. Treatment is prescribed on the basis of the diagnosis and is generally expected to produce a cure.

In the medical model, illness is a natural phenomenon occurring within the body and subject to scientific inquiry in the same manner the natural sciences acquire knowledge about the natural world. It is this very claim to science, Busfield (1986) argues, upon which the legitimacy and authority given to the medical view of health and ill-health rests. It is also upon the claim to science that medicine is open to critique.

In their textbook on research methods, Neale and Liebert (1973) state that science generally refers to the "pursuit of objective knowledge gleaned from observation" (p. 6). Hence, the term science refers to a method and a goal. Research into that which can only be directly observed reflects an empirical approach to science. A pursuit of objective knowledge points to an overarching assumption of objectivism. The epistemology of objectivism holds that "meaning, and therefore meaningful reality, exists apart from the operation of any consciousness" (Crotty, 1998, p.8). Within the scientific approach, objects in our world are assumed to have meaning irrespective of whether or not we are conscious of their existence. It is then the task of scientists to discover the meaning already inherent in objects. The sharp division between science 
and non-science is that of objectivism. The epistemological stance of objectivism separates science from beliefs, values, opinions, feelings and bias (Busfield, 1986; Crotty, 1998; May, 1997). By way of contrast, Crotty points out that while subjective understandings may be important to us, the subjectivist understanding we ascribe to objects are essentially a different knowledge to that established through science.

Being a speciality of medicine, psychiatry is likewise extraordinarily influential in how mental illness is defined, perceived and treated. Beumont, Andrews, Boyce and Carr (1997) state that "although psychiatry uses science, it is not itself a science, directed at the discovery of new facts, but a practical professional activity" (p. xiv). Nonetheless, Busfield (1986) notes that psychiatry is assumed to be rational, objective, and value-free; and hence makes a claim to science for it's authority. Additionally, Busfield makes the point that, like clinical medicine, the purpose of psychiatry is also assumed to be essentially altruistic.

In her review of the thought and practice of psychiatry, Busfield identifies four important characteristics of the medical task. The first is its curative orientation. This curative orientation directs the attention of medicine toward the investigation and treatment of existing illness rather than prevention. The second characteristic is the focus on acute illness rather than chronic illness. This, in part, according to Busfield, directs attention to the preservation of life rather than the amelioration of suffering. The third characteristic is one of individualism. Here, Busfield observes that "individualism permeates every aspect of the medical orientation to sickness, including the explanations and treatments it offers" (1986, p. 25). According to this view explanations for illness reside within the individual and consequently so does treatment. That is, an individual has a disease, and an individual is treated. Social changes or conditions, such as workplace, clean water and sanitation, social practices, or poverty are not usually examined as explanations. The fourth characteristic mentioned by Busfield is that of voluntarism. An assumption of medicine is that medical intervention is sought out rather than compelled by law or other authority. It is assumed that patients will seek out help when and if it is needed, and that treatment offered is accepted free of compulsion. Thus, practitioners only treat those who have sought to consult them. 


\section{The medical explanation of mental illness}

The dominant view of mental illness and disorders is that these can be understood in the same way as the natural sciences view any phenomenon occurring in nature and therefore amenable to investigation by scientific methods. Being based upon science, psychiatric knowledge shares the same assumptions inherent to science, in particular assumptions of objectivity. ${ }^{3}$ Guba and Lincoln (1994) critique the conventional approach (post positivist) to research and the basis for its privileged status, arguing for the utility of qualitative, or non-positivist, approaches. In their critique of the conventional view of research, they assert that "human behaviour cannot be understood without reference to the meanings and purposes attached by human actors to their activities" (p. 106). Doing science, or the using the scientific method, requires a hypothesis about selected variables to be posited and then tested for falsification of the hypothesis (hypotheses may only be disproved). There is frequently an omission to acknowledge the process for the development of a priori hypotheses before proceeding to test them. The scientific approach therefore privileges the method used to test the hypothesis over the development of the hypothesis (Guba \& Lincoln, 1994).

Within the language of objectivism, human behaviour (and even cognition) is reduced to the status of variables. In experimental and quasi-experimental research, all variables, except those selected for hypothesis testing are controlled or excluded. Inclusion of such information may in fact greatly alter the findings (Guba \& Lincoln, 1994). To the extent these variables are decontextualised, the objective view may bear little resemblance to that of the individuals being studied. Moreover, the assumption that hypotheses can be stated in a way that is independent of the facts used to test them is questioned by Guba and Lincoln who argue that facts are facts only within a particular theoretical framework. While the presumption in science is that observation is a passive uninvolved receipt of sensory information, Harvey (1992) argues that in fact science takes place within the context of the scientist's language, culture and theoretical perspective, which are necessary to enable science to be understood.

A general assumption is that the acquisition of scientific knowledge is linear and progressive and will eventually, through its methods, converge upon the "truth".

\footnotetext{
3 Although my focus here is upon psychiatric medicine as it has historically been significantly influential for psychiatric and mental health nursing, the critique can equally be applied to clinical psychology on the basis of its scientist-practitioner model.
} 
However, the possibility that the same set of facts can equally support different theories undermines this assumption. Scientific theories are held to be tentative and tested in an effort to support or more correctly, fail to support a hypothesis. In this sense, hypotheses can never be proved or disproved absolutely, rather, "when research provides regular support for the hypotheses derived from a particular theory, scientists will tend to accept the theory as useful" (Neale \& Liebert, 1973, p. 13).

Busfield links science to psychiatry, not so much due to any appraisal of its worth, but through its adoption as a professional ideology. Of this, she states "psychiatrists generally believe in the scientific, rational and humane basis of psychiatric work, and justify their demands for power and autonomy in these terms" (1986, p. 19). The claim to science is a potent rhetoric. For instance, Neale and Liebert state that "because of their insistence on objectivity, the social sciences command a respect that philosophy and theology alone never did" (1973, p. 6).

The medical model is therefore privileged and powerful. Through the practice of medicine, the way people think about their bodies, minds, health and illness and come to decisions about other people's health or illness, are all influenced (Busfield, 1986). This is most readily seen, for example, in the interaction between the field of medical practice and industry, whereby the medical practitioner has the authority to decide if the employee is to be labelled sick and therefore entitled to be paid while absent from work. Likewise, it is largely medical practitioners who decide if an illness is present for insurance and legal purposes. ${ }^{4}$

How medicine comes to determine what is an illness is therefore important. Busfield describes three features that are the focus of medicine: (1) bodily processes, (2) a mechanistic conception of the body, and (3) it is devoted to technology. The act of diagnosis (and its technology) is central to medical practice as it both explains the disease and (mechanistically) determines the treatment. The central focus of clinical intervention is therefore on obtaining the "correct" diagnosis.

In their handbooks on The Management of Mental Disorders, Sumich, Andrews and Hunt (1995), state that "the central function of any mental health service is to treat people who have mental disorders", and further, that the aim of any programme of

${ }^{4}$ It is worth noting that clinical psychology, which likewise is founded on a positivist science, also has legal authority to label if someone has a mental disorder or not. 
management is "to change symptoms and reduce disabilities" (1995, p. 2. Original emphasis). They go on to state that "treatment will be most effective if it is based on the correct diagnosis, not on the complaints" (1995, p. 4). Hence, diagnosis is linked inextricably to treatment, but not necessarily a cure. The emphasis here is palliative. It is also removed from the person's subjective complaints through the (objectivist) mechanistic process and outcome.

In psychiatry diagnosis does not necessarily equate to disease with its distinct, linear relationship between cause (germ) and effect (illness). Illness or disease in psychiatry are more accurately described as syndromes (Beumont, 1997; Busfield, 1986; Kaplan \& Sadock, 1991). This distinction is important. Kaplan \& Sadock define a syndrome as "a group of signs and symptoms that occur together and constitute a recognizable condition" (1991, p. 214. Emphasis added). Signs are "objective findings observed by the clinician", while symptoms are "subjective complaints listed by the patient" (Kaplan \& Sadock, 1991, p. 214). Where a disease is a pathological change to anatomy, physiology or biochemistry (Beumont, 1997, p. 18) and can be directly observed, the pathology of psychiatric syndromes are hypothesised from observation of clusters of signs and symptoms that deviate from normative values. Because the same method is used to establish diagnosis in psychiatry as in physical medicine, there is a tendency to treat a psychiatric diagnosis as if it were a disease, rather than its lesser status of a syndrome. However, in the case of psychiatry, deviations from the norm are measured against a psychosocial and ethical standard rather than deviations in anatomical or physiological structure (Szasz, 1970).

Thus, what constitutes a recognisable condition has varied historically and culturally across time and place in accord with what is currently accepted as the range of normal. Arguably, recognition of abnormality of the mind through the science of psychiatry is a complex reification of the social perceptions of abnormality or stigma as a symptom of mental illness. For instance, prior to 1973 homosexuality was considered a mental disorder by the American Psychiatric Association, and therefore had a diagnostic classification in the Diagnostic and Statistical Manual of Mental Disorders (DSM) and was similarly recognised as a disorder of the mind by the World Health Organization's International Classification of Diseases (ICD) prior to 1980. 
Given the link between psychosocial and ethical standards, the psychiatric notion of mental illness, through a claim to the objectivity of science, reproduces social norms in a manner that obscure its social origins and grounding in value judgements. As treatment is also inextricably linked to the diagnosis of mental "illness", treatment reinforces social norms. The impact is society-wide as other professions utilise the psychiatric notion of mental illness; for instance, social workers, mental health nurses, lawyers, journalists, psychologists.

\section{Psychiatric legitimisation of stereotypes}

The profession of psychiatry, and the practice of clinicians in mental health or psychiatry, is arguably much more involved with ethics than perhaps any other health profession. I state this because it is through the clinical decisions made in everyday practice that what is normal and what is deviant thinking and behaviour, is explicitly defined. These boundaries of normality or deviance are most immediately defined for whoever the clinician is communicating with at the time; often the patient, friends and family. However, as a collective group, mental health clinicians are a powerful definer and reinforcer of these boundaries for all of society. Thus, what it is that constitutes normal thinking and behaviour for women and men becomes defined, reinforced and reproduced, through the concepts and notions used by mental health clinicians.

Arguably, much of how clinicians come to understand the mental health problems of women, children and men is through research conducted within a conventional scientific paradigm using quantitative methods. Such data for instance, typically yields prevalence information about particular diagnoses on the basis of age and sex showing difference between men and women across the lifespan (the degree of similarity between the sexes is unimportant in this approach). Uncritical interpretation of the data will tend to support dominant social norms that "men are naturally like this" and "women are naturally like that". This data tends to reinforce the notion that there are "women's problems" and "men's problem's" drawing upon the authority of scientific method. Conclusions drawn from the statistical data are constructed in a manner that remains consistent with pre-existing dominant views, or stereotypes, of women and men. Such conclusions are carried through to clinicians as objective evidence to support judgements of deviance and normality in women and men on the basis that numbers and scientific method is unbiased. 
The impact of an uncritical acceptance of dominant social norms regarding the sexes by psychiatric and other mental health clinicians is shown in a much reported study by Broverman et al. (1970) who examined the impact of sex-role stereotypes on clinical judgements. This study concluded that clinician's views of health are no different to the stereotypes prevalent in society. They found that clinicians' concepts of a healthy adult did not differ from their views of a healthy, mature (White) man, and that clinicians were less likely to attribute adult "healthy" traits to women. On this basis, the researchers' speculated that

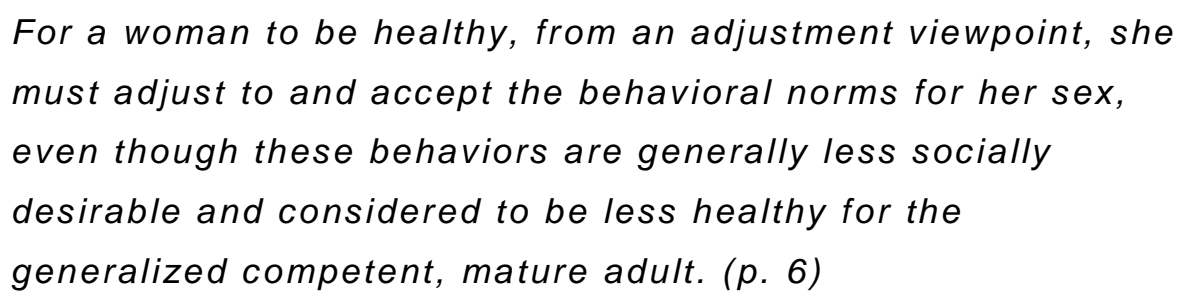

Clinicians have considerable influence on social standards and attitudes. This early piece of research lends support to an argument that acceptance of stereotypes by mental health clinicians reinforce current dominant views of women and men. The authority of psychiatry (and psychology), through its claim to medical science, legitimises stereotyped views by its ability to define what is unhealthy or abnormal thought and behaviour for the sexes.

\section{Gender bias in psychiatric diagnosis}

There is a sense of circularity to the argument I have proposed here. Scientific social norms are merely an interpretation of statistical data in a manner consistent with dominant beliefs about women and men. This "finding" in turn reinforces pre-existing clinical notions of normality for women and men. Hence, clinicians make clinical judgements on the basis of scientific conceptions of normality and deviance, in turn legitimising the wider society's conceptions of normality and deviance, thus completing the circle.

The reproduction of social norms through clinical practice can occur through a multitude of mechanisms, one of which is the act of diagnosis. The diagnosis of mental disorder is dependent on the assessment of symptomatology; that is, the interpretation of reported subjective experiences. The transformation of the person's report of their subjective experiences into the symptoms of psychiatry is an active interpretation on behalf of the clinician, and not simply a passive receipt of knowledge. The clinician is 
required to consider how what is expressed matches with his or her learning about deviance from normative values. The active involvement of the clinician's interpretive efforts undermines the assumption of objectivity inherent in the labelling, or not, of the person's experience as symptoms of mental illness.

Comparatively less reliance is made on clinical signs in the form of laboratory tests in psychiatry compared to physical medicine as the aetiology of mental illness is rarely established as a result of anatomical or physiological pathology, but rather, hypothesised syndromally from deviant behaviour or thinking. Nevertheless, deviant behaviour or thinking might be considered accessible to objective observation. Observation however, involves an act of interpretation whereby what is observed is made comprehensible through the clinician's language, theoretical perspective, and cultural norms. Even where clinical signs are available as laboratory tests, the clinician is also required to judge and interpret the observation within the context for which the test was requested. A brain scan showing some abnormality may or may not support a provisional diagnosis of mental illness. Such support for a diagnosis of mental illness occurs only within the context of a great deal more information; that is, a context against which the laboratory data is interpreted.

Given that mental illness or disorder is broadly defined as a significant deviation from social norms with respect to a person's behaviour or thinking, what is considered to be deviant is dependent upon the clinician's normative expectations for women and men. In this regard Busfield (1982) suggests that:

If fear, anxiety, and emotional sensitivity are considered more appropriate in women than in men, then it is not surprising that it is women rather than men who become overanxious, fearful, depressed, and so on. Conversely, if drinking, drug taking, and sexual activity are more acceptable among men than women, then we should expect to find pathologies of these behaviours among more men than women do. (p. 57)

\section{Gender bias in treating mental health problems}

Development and implementation of treatment programmes occurring without a critical consideration of gender may also serve to reinforce inequities along a gender division. For instance, consider the communication of emotion for women and men. Due to dominant beliefs regarding how a man conducts himself, expressions of 
emotion are less likely to be elicited from men, if elicited at all (David \& Brannon, 1976; Warren, 1983). Explanations of a problem in the form of a rationale, rather than expression, may well be preferred by both the clinician and men presenting with an issue that is substantially emotional (Seidler, 1989). When feelings are expressed by men they are more likely to be interpreted as symptoms and excessively pathologised; and accordingly treated. Anger is one such example. While being regarded as "natural", expressed anger from men is also feared due to its strong association with violence and aggression rather than being regarded as a normal aspect of a range of emotions available to both women and men (Novaco, 1994). Expressed anger may therefore be vigorously treated by psychotherapy and/or psychopharmacology with the aim of reestablishing "control". A multitude of treatment programmes exist to improve men's anger management; for instance, social skills programmes like the Aggression Replacement Training by Glick and Goldstein (1987). On the other hand, a lack of affective expressiveness may well be met with minimal response by the clinician because it is seen as congruent with expected social norms for men and therefore interpreted as being "in control" of his emotional state (Warren, 1983). Thus, depression may well be minimally treated for men.

\section{Gender bias in access to mental health treatment}

There are many and varied factors that influence why a man would or would not consult a mental health professional. Kessler et al. (1981) suggest help-seeking be considered as three stages: (1) recognition that the person has a problem, (2) belief it is serious enough to seek professional help, and (3) the act of seeking help. Taking each stage in turn, men may firstly not perceive there is a problem, or alternatively it might be denied. For instance, men may not report depression because it is incompatible with masculine socialisation as "men may experience depression as a more aversive condition than women because of the values and behaviors associated with the male sex role" (Warren, 1983, p. 150). Feelings and behaviours such as crying, vulnerability, loss of competence at daily tasks, and dependence are perceived as stereotypically feminine, self-indulgent, a failure, and weakness, and are therefore intolerable (Warren, 1983).

The second stage of help-seeking requires the discomfort or problem to be regarded as sufficiently serious to seek help. What is meant by sufficiently serious may well be different for women and men. Rational control of the mind over the body tends to mean that men's understanding of the body is much like that of a machine and so 
respond to it in this context (Pease, 1997; Watson, 1983). A fitting mechanistic colloquialism is that "if it isn't broken, then it doesn't need fixing". Research into men and sport, such as bodybuilding or rugby, shows that men will clearly sacrifice health status in an effort to achieve ideals of masculinity, such as "defeating" pain, risk-taking, or inflicting violence (White, Young, \& McTeer, 1995). The very fact of injury, rather than being understood as detrimental to health or a sign of ill-health, may also be construed as a valued symbol of masculinity. "Sufficiently serious" may mean problems become noticeable only when exercising instrumental control over their daily lives is impaired (Pease, 1997).

The third help-seeking stage, the act of seeking help, may also be different for women and men. Mental health services may not be provided in a manner congruent with dominant forms of masculinity and therefore discourage men who hold to these beliefs about themselves. Insofar as masculinity is understood to be consistent with economic productivity, being manly is generally associated with paid employment, services only available during business hours may be perceived as services for women rather than men (Adams, 1997). Mental health services may also be perceived as women's services (i.e. for emotional problems) and therefore men who hold to notions of masculinity as "no sissy stuff" (David \& Brannon, 1976) will be discouraged from considering psychiatry as a source of help. Adams has suggested that the nature of this sort of bind for men is one between sexism and homophobia, depending on the clinician being a women or a man.

\section{Mental health, men's violence and aggression}

Until recent years, discussion of the mental health issues to do with the perpetration of violence appear to be largely restricted to forensic psychology and psychiatry, and hence viewed as pathology within the individual. The individual pathology hypothesis appears to be inconsistent with the endemic nature of the issue; that is, that men's violence seems global and socially prevalent (Heise, 1994). Gilbert (1994) writes that "male violence may even outrank disease and famine as the major source of human suffering [and] if one wanted to instigate one mental illness prevention programme, then targeting male violence would possibly be the single most significant one” (p. 352). Male violence is a global phenomenon (Heise, 1994). There is an immense but disparate data supporting Gilbert's assertion. Nonetheless, some studies suggest that male violence may be underreported. For instance, a recent New Zealand survey by Moris (cited in 
Ministry of Justice, 1999) found that $24 \%$ of female respondents with a current partner, and $73 \%$ with recent partners, reported at least one incident of physical or sexual violence from their partner. Of these, only $8 \%$ of women who disclosed abuse by a current partner, and 21\% who disclosed abuse by recent partners, had informed the police. Heise cites reports showing $80 \%$ to $90 \%$ of homicides are perpetrated by men. The Ministerial Committee of Inquiry into Violence (Roper Report) (Roper et al., 1987) estimates child abuse in New Zealand to be in the order of 25 per 100,000 some studies show children are physically abused by men and women at somewhat similar rates, child sexual assault is perpetrated predominantly by men (Wyatt \& Powell cited in Heise, 1994). That much of violence against women and children is seen simply as a part of the natural right for men to dominate (Heise, 1994), clearly demonstrates that violence and aggression are embedded within masculine beliefs and culture, rather than disorders or illness located within individual deviant men.

Violence and aggression are an essential aspect of male identity, connected at many different points in social life. For instance, White et al. (1995) examined the connection between masculinity, combative sport and injury. Their research showed that both the commission of violence and the resultant injury become means of affirming masculinity by exemplifying mastery over the body. In combative sport, the masculine ideology of physical mastery and opposition to femininity are essentially connected to violence and notions of risk and courage acted out and celebrated on the sports field. The defeat of pain becomes one means of disciplining the body by the masculine mind at the cost of health. Combative sport sanctions and celebrates the act, as well as the effects of violence, by men. Much of what it means to be a male is constructed upon violence and aggression. For instance, the act of heroism in combative sport and war is a highly regarded form of being a man. To view these very same acts of violence and aggression as forms of clinical pathology would not be possible without also questioning dominant forms of masculine identity. Only when violence steps outside of socially acceptable constraints is the act of violence regarded as pathological. Issues of violence and aggression embedded within masculine identity are not made problematic from the current psychiatric perspective that dominates the mental health field. The application of psychiatric labels, meaning that one is "sick", also can have the effect of absolving the individual of responsibility for his actions. The diagnostic label therefore serves to

\footnotetext{
5 This is likely to be a significant underestimate. See Kotch et al. (1993) for a more recent discussion of this issue.
} 
confirm notions of the uncontrollability of violence and aggression by locating the cause as individual rather than social. However, it does so in such a way as to leave unchallenged, the privilege and status of male violence. By locating the problem of unsanctioned violence and its treatment within a disease model, the social link between masculine identity and violence remains unproblematic.

Violence and aggression are thought to be linked to suicide as an inward turning of aggression, and as an easily associated attribute of masculinity, is readily accepted in the aetiology of men's suicide. Many theorists have considered that suicide and homicide to have a common origin in violence (Cantor, 1993; Durkheim, 1897/1952; Gold, 1958; Henry \& Short, 1954; Palmer, 1968). By and large these theorists view suicide either as a form of violence or destructiveness turned inward toward the self or as arising out of the social meanings of violence, particularly that related to masculine identity. That is, ideas that originate in psychoanalytic theory or the psychosocial-cultural and political perspectives.

\section{Towards gendering men's mental health}

An underlying theme of this chapter is that clinical intervention in mental health is a powerful influence in maintaining the existing social structure, and thus the gendered status quo within society through its authority to label what is deviant or abnormal. Equally, what is not deviant or abnormal is defined as appropriate to the sexes by default. Much of psychiatry's influence comes as a result of its status as a speciality of the medical profession that makes its claim to authority on the basis of science. Equally, the scientist-practitioner model for clinical psychology exerts its increasing influence through a similar claim to science. The claim of scientific objectivity in the practice of psychiatry is however, flawed. At many points in the process of diagnosis and treatment clinical intervention in mental health is an act of interpretation that is inextricably bound to the social context. Likewise, the argument of scientific evidence supporting claims about the differences in women's and men's mental health is similarly socially situated. An uncritical approach to mental health intervention simply reflects and reproduces the dominant social gender structure. Through the professions that subscribe to the dominant theories about mental disorder and illness, notions of mental disorder become commonly held ideas about the boundaries of normality. 
The discussion within this chapter has important implications for the examination of suicide as gendered. Themes I have raised here, such as the flawed assumption of objectivity in psychiatry, the gendered nature of diagnosis, men's violence and aggression, and masculine identity, I shall carry through into an examination of suicidality. 


\section{Chapter 3}

\section{MEN'S SUICIDE AND SUICIDALITY}

Le Suicide (1897/1952) was published by Emile Durkheim over a century ago and is regarded as marking the beginning of modern research into suicide. Since then, a vast research literature on the subject has been produced in an effort to explain, predict and control this form of death. One of the most enduring features of suicide data, at least in Western countries, has been the consistency with which the rate of men's suicide has been higher than that for women. Insofar as suicide is socially situated, it seems likely that from this observation alone, suicide rates are impacted upon by the gender structure of Western society.

In order to discuss suicidality, I begin by defining suicide and then briefly overviewing major theories from the last 100 years. This overview is necessarily selective as this literature is immense. My intention is to open up to question the underlying assumptions that suicide, and hence, suicidality, is best regarded as pathology unaffected by gender.

\section{Defining suicide}

The terminology surrounding suicidal behaviour can become particularly complex within the clinical and research fields. There is therefore a need to clarify at the outset how I shall use these terms in the following discussion. I have listed many of these in Table 1 (p. 25).

Although at first glance, a definition of suicide might seem self-evident, a definition for suicide that suites research and clinical utility has been the subject of considerable debate. Colloquially, the Oxford English Dictionary definition of the term "suicide" is “...an act of taking one's own life, self-murder" (Simpson \& Weiner, 1989). However, establishing the fact of suicide post mortem, for official statistics or for research purposes, has been fraught with difficulty (McIntosh, 2002; O'Carroll, 1989; Shneidman, 
1985). This difficulty arises from the need to establish that death was intended. The issue of intent is pivotal to much of the debate for what defines a death as suicide. Particularly problematic is that intent is personal and private, and can only be inferred from circumstances surrounding the death (e.g. suicide note).

In an everyday sense of the word, suicide is generally understood to be a particular form of death in which someone has consciously intended to bring about their own demise. As such a death is intended, those who have a significant relationship to the person, including clinicians, also frequently ask the question "why"? This questioning is often deeply personal and can raise spiritual, moral, and ethical issues that further complicate the grief and sorrow accompanying the death of someone who has been closely known. From the perspective of mental health services, the issues of "intent" and "why" are important to the understanding, treatment and prevention of suicidal behaviour. Undoubtedly, an understanding of the motivations for suicide and how this could be prevented is likely to be also important for friends, family, and others who had a significant relationship to the person.

Table 1. Some key terms used to describe suicidal behaviour

\begin{tabular}{|c|c|}
\hline $\begin{array}{l}\text { Nonfatal suicidal } \\
\text { behaviour }\end{array}$ & $\begin{array}{l}\text { Usually a term used by clinicians to refer to any act that is thought } \\
\text { to be part of an intended suicide. }\end{array}$ \\
\hline $\begin{array}{l}\text { Near-fatal suicide } \\
\text { (serious attempt, } \\
\text { clinically serious, etc.) }\end{array}$ & $\begin{array}{l}\text { Same as "nonfatal suicidal behaviour" but the injuries present are } \\
\text { evaluated as likely to have caused death without urgent medical } \\
\text { intervention. }\end{array}$ \\
\hline Parasuicide & Deliberate self-harm irrespective of the intention that risks death. \\
\hline Self-harm & $\begin{array}{l}\text { Any form of deliberate injurious behaviour. In practice, the label } \\
\text { "self-harming behaviour" generally means the clinician believes } \\
\text { the injury was not a conscious intention to die. }\end{array}$ \\
\hline Suicidal threat & $\begin{array}{l}\text { May be verbal or nonverbal but is evaluated as a communication } \\
\text { of the possibility of suicide in the future. }\end{array}$ \\
\hline $\begin{array}{l}\text { Suicidality (suicidal } \\
\text { ideation, thought, } \\
\text { behaviour, etc.) }\end{array}$ & $\begin{array}{l}\text { Thoughts, actions, or behaviours that are evaluated by clinicians } \\
\text { to be indicative of potential suicide. May be self-reported or } \\
\text { clinician evaluation. }\end{array}$ \\
\hline Suicide attempt & $\begin{array}{l}\text { Defined by the person as survival of activity they had consciously } \\
\text { enacted to end their life. Some authors argue that high-risk } \\
\text { behaviour could be included here. }\end{array}$ \\
\hline Suicide gesture & $\begin{array}{l}\text { A pejorative term used to define an effort that is thought (by } \\
\text { clinicians or others) to have the appearance of an attempt to } \\
\text { suicide. }\end{array}$ \\
\hline $\begin{array}{l}\text { Suicide intervention } \\
\text { (prevention, etc.) }\end{array}$ & $\begin{array}{l}\text { Any form of intervention (often claimed to be the province of } \\
\text { clinical professions) to prevent death by suicide. }\end{array}$ \\
\hline Suicidology & The study of suicide and its prevention. \\
\hline
\end{tabular}


Observing that suicide involves many people and the cultural context (e.g. parents, family, language, cultural heritage, etc.) Maris (1997) suggests that suicide might be better regarded as a social event rather than an individual one. Even the very meaning of the word "suicide" is social. Citing Durkheim, Maris argues that social facts constrain individuals and therefore, individual traits are unable to explain suicide rates. Maris goes on to conclude that "suicides result because of social forces and pathologies acting in concert with individual characteristics... some suicides are committed to preserve society, not to weaken it”' (p. 48).

\section{Theories of suicide and suicidality-}

Killing oneself has been variously positioned by the different moral laws of the era; for instance, it was not until the fourth century that St Augustine (354-430 A.D.) deemed that killing oneself was forbidden and then later by St Thomas Aquinas (1225-1274 A.D.), that it was a Christian mortal sin (Shneidman, 1985). In contrast, for the Greeks and Romans of antiquity, killing oneself was a means of restoring honour (van Hoof, 2000). The word "suicide" is of comparatively recent origin, first used by Sir Thomas Browne in 1642 (Shneidman, 1985).

What has become labelled as suicide has therefore been written about and subjected to various investigations for many centuries. In more recent decades, suicide has become increasingly a public health concern. In parallel with this increasing concern there has been a burgeoning literature seeking to explain and prevent suicide. Rather than the spiritual or religious intervention of the middle ages, suicide is now seen as the province of scientific research and intervention from a variety of clinical professions. I summarise some of the major theories below. This is not an exhaustive listing, but an attempt to summarise those theoretical approaches in suicidology that have been utilised within the clinical field. ${ }^{6}$

\section{Emile Durkheim}

Originally setting out to demonstrate the application of natural science methods to $19^{\text {th }}$ century sociological problems, Durkheim developed what was to become a seminal work in the study of suicide. Durkheim (1897/1952) defined suicide as being:

${ }^{6}$ A number of attempts have been made to review this substantial field. For instance, see Lester (2000b). Why People Kill Themselves: A 2000 Summary of Research on Suicide for a comprehensive review of the scientific and sociological research literature on suicide since 1897 and Shneidman (2001) Comprehending Suicide: Landmarks in 20 th Century Suicidology for a selection of key works. 
applied to all cases of death resulting directly or indirectly

from a positive or negative act of the victim himself [sic], which he [sic] knows will produce this result. (p. 44)

For Durkheim, suicidal behaviour is a measure of the degree to which a society is integrated. The greater a society is integrated the less death by suicide will occur, so that the rate of suicide varies inversely to the level of social integration.

Under adverse social conditions, when individuals' social contexts fail to provide them with the requisite sources of attachment and/or regulation at the appropriate level of intensity, then psychological or moral health is impaired, and a certain number of vulnerable, suicide-prone individuals respond by committing suicide. (Hassan, 1995, p.3)

In Le Suicide, Durkheim developed an aetiological typology of suicide that has continued to be used and debated through to today. He has argued that three main types of suicide exist: egoistic, altruistic, and anomic. It is worth noting that he also developed a fourth, fatalistic suicide, but described this only briefly as a footnote. Due to the enduring currency of Durkheim's theorising, it is worth summarising his typology.

Egoistic suicide is about excessive individualism. The individual is not sufficiently integrated into society and consequently depends only on themselves to decide appropriate rules of conduct. The person is alone. To statistically demonstrate this Durkheim cites the different rates of suicide for Catholicism, asserting that compared to Protestantism, the lower rate of suicide for Catholics is due to the greater degree of invariability and solidarity that Catholicism demands. In contrast, with its greater emphasis on individualism, free will and learning, and therefore a lesser degree of common beliefs, the higher suicide rate for Protestants is attributed to a lesser degree of social integration.

Altruistic suicide occurs when there is too great an integration of the individual into society, so that the individual is lost and has no autonomous existence apart from the group or society. The individual has little value compared to the group. Duty or obligation may require the individual to die and will likely condemn the person if they do not meet this expectation. Alternatively, suicide may be an option for the redemption of shame and humiliation, such as the Japanese seppuku (as cited in Hassan, 1995). 
Anomic suicide occurs as a result of sudden change in the circumstances of the individual resulting in a loss of social regulation of the person. Such a crisis occurs with dramatic changes in the economic cycle. A lack of social regulation can occur with both a loss of wealth and its consequent downward spiral in social class, or a sudden accumulation of wealth and consequent sudden lack of restraint upon social aspirations. However, anomie is not only of economic origin. Changes in the individual's overarching form of social regulation may result in anomie. Durkheim suggested that for men, this could occur through widowhood and divorce. Unlike some later writers who saw common psychological origins for both murder and suicide, Durkheim did not see suicide as a derivative of homicide turned against oneself. However, he did see a common origin for the two forms of death in the social cause of anomie. For Durkheim, the explanation for a person committing homicide was primarily about individual morality.

The fourth type of suicide developed by Emile Durkheim was that of fatalistic suicide which he thought to be due to excessive regulation. Fatalistic suicide may occur in circumstances such as slavery, where excessive physical or moral despotism is encountered and no hope of escape is foreseen.

Other writers have followed Durkheim's sociological approach and theorising. For instance, Cavan (1928/1965) holds a similar view to that of Durkheim insofar as she relates suicide to social phenomena. Like Durkheim, she hypothesises a relationship between personal and social disorganisation and the incidence of suicide. However, while Durkheim undertook a statistical approach, Cavan develops her hypothesis on the basis of an analysis of a multitude of in-depth case studies, linking the psychological to the sociological as an important contextual influence. In a similar vein to Durkheim, Cavan emphasises the role of social disorganisation. Douglas (1967) also followed Durkheim but took a different view critiquing Le Suicide by arguing in detail the necessity for attending to social meaning in the pathway to suicide, concluding that:

The statistical-hypothetical approach fails to take into consideration the fact that social meanings are fundamentally problematic, both for members of the society and for the scientists attempting to observe, describe, and explain their actions. (p. 339) 
Like Cavan, Douglas argues for the construction of a theory of suicidal actions through intensive observation, description, and analysis of individual case studies. Douglas however, goes further than Cavan's attention to social context, taking the position that before assuming that suicide statistics can be understood, such careful observation and description is necessary in order that the situated meaning of suicide is understood before an abstract understanding may be obtained. That is, suicide needs to be understand firstly as a socially situated and meaningful phenomena.

While Durkheim was a strong early influence for the sociological view of suicide, the psychoanalytic theories of Freud also had an important and similarly early impact on clinical intervention for suicidal individuals.

\section{Sigmund Freud and Karl Menninger}

In Mourning and Melancholia Freud (1917/1925) saw suicide as hostility directed inward against the ego. Suicide is the result of "aggression turned inward against an introjected, ambivalently cathected love object" (Kaplan \& Sadock, 1991, p. 555). Hostility, once directed toward another person, who is also usually close to the person concerned and to whom they are now unable to openly express their hostility, is now directed against the self.

However, Freud did not elaborate the detail of suicide, this was taken up later by Menninger in his work Man Against Himself (1938). Menninger proposed that suicide arose out of the interaction of eros (life-instinct) and thanatos (death-instinct) in a particular circumstance. According to Menninger normal development of the personality is a process whereby these two forces, originally directed inward and concerned with the self, become progressively directed outward toward other objects. A failure of normal development is an incomplete turning outward of these two forces. Suicide becomes possible when the destructive (thanatos) and constructive (eros) impulses fail to be directed outward and instead are forced inward toward the self. If the destructive impulse is overwhelming then suicide can occur.

From the psychoanalytic perspective of Menninger there are three components (or three wishes) within the suicidal act. Firstly, there is the wish to kill; that is, the murder of the self by the self. Secondly, there is the wish, or desire, to be killed. Thirdly, there is the wish to die. In suicide, the wish to kill, or murder, is unable to be directed outward to an object, but becomes turned inward through introjection. The distinction between 
wishing to die and wishing to be killed or murdered lies in the necessity for some form of violence in the latter, whereas wishing to die can be a passive surrender of the self.

\section{Andrew Henry \& James Short and Martin Gold}

Henry and Short (1954) proposed a theory of external restraint to explain homicide and suicide. They tested this hypothesis against the cyclical nature of economics. According to Henry and Short external restraint exists in two forms: horizontal and vertical. Horizontal restraint equates to the strength of a relational system such as marriage, while vertical restraint equates to a relationship of subordination to authority. Their hypothesis was "that the reactions of both suicide and homicide to the business cycle can be consistently interpreted as aggressive reactions to frustration generated by the flow of economic forces" (p. 14-15). Their view is that the cyclical nature of capitalist economies causes frustration due to interference in achieving goals. However, they assert that status rank differentiates between the two outcomes of aggression. From their study, they offer the conclusions that: firstly, "a positive relation exists between suicide and status and a negative relation between suicide and strength of the relational system" and secondly, that there is "a negative relation between homicide and status and a positive relation between homicide and strength of the relational system" (p. 17). Furthermore,
When behaviour is subjected to strong external restraint by virtue either of subordinate status or intense involvement in social relationships with other persons, it is easy to blame others when frustration occurs. But when the external restraints are weak, the self must bear the responsibility for frustration. (p. 18)

Gold (1958) extended the work of Henry and Short by hypothesising a preference for homicide or suicide based on childhood socialisation and class. On the basis of his research he hypothesised that working class socialisation results in a tendency for homicide that he attributes to early experiences of physical punishment and aggression in working-class families, whereas the early experience of middle class families instead produce a tendency for suicide.

\section{Jean Baechler}

Baechler (1975/1979) produced a typology of suicides hypothesised on the basis of the meanings of the individual's suicide, echoing the earlier work of Douglas. Like Douglas, 
Baechler offers a different definition of suicide to that of Durkheim, reflecting their different orientations to the social and psychological. Baechler states that "suicide denotes all behavior that seeks and finds the solution to an existential problem by making an attempt on the life of the subject" (p. 11). He emphasises that suicide "is a solution to bear on a problem" (p. 443) grounded in a lifelong pattern of responding to adversity.

Baechler hypothesised four types of suicide that clustered together eleven different underlying meanings of suicide set out in Table 1, below.

Table 2. Baechler's (1975) suicide types and their underlying meanings.

\begin{tabular}{ll}
\hline Suicide type & Underlying meanings \\
\hline Escapist suicides & Flight, grief, punishment \\
Aggressive suicides & Crime, revenge, blackmail, appeal \\
Oblative suicides & Sacrifice, transfiguration \\
Ludic suicides & Ordeal, game \\
\hline
\end{tabular}

While the personality is central to Baechler's analysis, as it was earlier for Freud and Menninger, Baechler is concerned to understand suicide as individually meaningful within the historical context of the person concerned. Baechler's typology emphasises an individual's rationality toward her or his own suicide and provides a means for others to comprehend the action. This is a theme that was also of concern for Shneidman.

\section{Edwin Shneidman}

Edwin Shneidman is regarded as the founder of the discipline of suicidology, creating the American Association of Suicidology in 1968 with the aim of developing an interdisciplinary field of suicidology and providing a professional journal, Suicide and LifeThreatening Behavior (Leenaars, 1993).

In an early classificatory approach to suicide, Shneidman (1968) conceptualised suicide as egotic, dyadic, and ageneratic; in turn, focussing on intra-psychic and social issues, and issues around the loss of belonging. In a later work Shneidman attempts to produce a clinically useful definition of suicide arguing for far less concern for classification and more emphasis on developing clinically useful understanding (1985). To this end he has developed the following definition of suicide: 
Currently in the Western world, suicide is a conscious act of self-induced annihilation, best understood as a multidimensional malaise in a needful individual who defines an issue for which the suicide is perceived as the best solution... in an ambivalent individual. (Shneidman, 1985, p. $203 \& 227)$

The addition of the qualification of ambivalence has become clinically significant (Cardell \& Horton-Deutsch, 1994; Shneidman, 1988) for it describes a point where the individual is between dichotomous thoughts and feelings; at this point caught between hostility and love, wanting to die and wanting to be rescued, to cut one's throat and yet call for help. Shneidman's definition asserts that while the perceived current best solution is suicide it is not the only solution. Ambivalence describes the state of mind whereby the person may choose to live if a better solution is found. Elaborating further, Shneidman (1985) has described ten common characteristics to all suicides which can then be clustered into six aspects of suicide: situational, conative, affective, cognitive, relational, and serial. These are summarised in Table 3, below.

\section{Table 3. Shneidman's (1985) ten common} characteristics of suicide.

\begin{tabular}{ll}
\hline Aspects of suicide & Common characteristics \\
\hline Situational & $\begin{array}{l}\text { Unendurable pain } \\
\text { Frustrated psychological needs } \\
\text { Conative }\end{array}$ \\
& $\begin{array}{l}\text { Purpose is to seek a solution } \\
\text { Cessation of consciousness } \\
\text { Affective }\end{array}$ \\
& $\begin{array}{l}\text { Hopelessness and helplessness } \\
\text { Cognitive }\end{array}$ \\
Relational & Constriction \\
& Communication of intent \\
Serial & Aggression or escape \\
\hline
\end{tabular}

Shneidman (1992) later produced a clinically useful model that he calls the cubic model of suicide. This model, in the geometric shape of a cube, has three visible faces, each of which is divided into five increments so that each face is divided into rows and columns. The three faces of the cube are called pain, perturbation and press. Pain arises out of thwarted psychological needs. Perturbation includes perceptual constriction and the need for action. Press refers to that which presses in on the person. These faces are each 
then divided into five rows and columns. Therefore, the cubelet at 5-5-5 has maximum pain, maximum perturbation, and maximum press. According to this model, only people in cubelet 5-5-5 are at risk of committing suicide. It is important to note that Shneidman also points out that not everyone at 5-5-5 commits suicide, stating "he or she may commit homicide, 'go crazy', become amnesic, or destroy a career; but in this conceptual model no one commits suicide except those in the 5-5-5 cubelet" (Shneidman, 1992, p. 11). The model aims to focus clinical intervention on the three components of psychological pain, perturbation and press. Accordingly, immediate clinical intervention needs to focus on shifting the person out of the triple- 5 cubelet; even just a little movement will prevent suicide.

\section{The notion of intention}

The concept of intent is a key issue for labelling what is, and what is not, suicidal. However, the term is rarely defined in the literature and tends to assume certain understandings depending on the disciplinary field in which it is being used.

Hjelmeland and Knizek (1999) suggest that part of the confusion lies in differences of perspective between a phenomenological-subjective explanation to the scientificpsychological explanation of behaviour. Buss (cited in Hjelmeland \& Knizek, 1999) argues that generally subjects explained their actions in terms of reasons rather than causes. Reasons imply that the explanation of the act lies in the expected future (teleological) whereas causal explanations imply the explanation lies in the past. Hjelmeland and Knizek (1999) argue that distinctions must therefore be drawn between "motives", "intentions" and "reasons". Motives are more closely associated with causal explanations and the perspective of the observer, while reasons are more closely associated with intentions and is likely to be from the suicidal person's perspective.

Related to the notion of intent is the term "attempted suicide". An attempted suicide is generally applied to an individual who is thought to have tried to commit suicide and has survived. This definition has at least two essential components to it: a behaviour causing injury, and an intention of self-destruction. Such a definition attempts to distinguish suicidality from hazardous but deliberate behaviour. The key issue in drawing this distinction therefore is to ascertain the intent of death. 
However, Diekstra (1989b) suggests this may be a complex issue. On the basis of a study of self-reports following overdosing, Diekstra suggests motives in non-fatal suicidal behaviour may include the following three motives:

- Cessation (death, stopping conscious experience now and forever);

- Interruption (to interrupt conscious experience for a while, to sleep, not to feel anything for a while); and

- Appeal (to mobilize or change others).

Diekstra goes on to argue that a significant proportion of nonfatal suicidal behaviour would be some combination of these three motives. He also argues that behaviour constituted by interruption or appeal would be more accurately labelled deliberate selfharm rather than "attempted suicide" as there is not a conscious intent to deliberately bring about one's own death. The tenth revision of the International Classification of Diseases (ICD) (World Health Organization, 1993) adopts this approach using the label intentional self-harm. In contrast, the earlier ICD-9 (World Health Organization, 1975) 7 did not address nonfatal suicidal behaviour. These distinctions are important in the context of current clinical practice as the response to someone attempting suicide is viewed as warranting greater urgency than someone evaluated as inflicting "deliberate self-harm".

If the distinction between the categories of "attempted suicide" and "deliberate selfharm" revolve around the notion of intentionality, then the interpretation of behaviour is a key issue for clinicians (and others such as coroners, epidemiologists, etc.). While this issue has been emphasised in reviews of the quality of statistics on suicide (McIntosh, 2002; O'Carroll, 1989; Shneidman, 1985), it has also been an issue for clinicians and for clinical research.

At first glance, it would seem that to determine the purpose of a person's injurious behaviour, the person could simply be asked. However, while the nature of the injurious behaviour may be ascertained through any number of means, such as reports by others, Stengel (1969) has suggested that not everyone will wish to accurately report their intention of suicide for reasons of guilt or shame. Indeed, an attempt to suicide may not be reported at all in order to prevent the thwarting of a further attempt. Further complicating the issue of intent for Stengel and others (Farber, 1968; Maris, 1981) is the

7 The later clinical modification of ICD-9 (ICD-CM) (World Health Organization, 1978) provided additional E-codes under the label "suicide and self-inflicted injury". 
apparent variability in the degree of intent at self-destruction. They hypothesise that some people deliberately create the appearance of an attempt to end their lives while their "real" intention is to survive. This argument is used to privilege the clinician's (or researcher's) interpretation over the explanation of the injured person. Of course, this argument presumes that the clinical interpretation of the self-inflicted injury is an accurate proxy for the private thoughts and meanings of the (possibly) suicidal person.

Some writers have proposed that an alternative approach to dealing with the issue of the person being "not quite genuine" (Stengel, 1969, p. 77) is to judge the degree of intention upon an assessment of the lethality of the method being used by the person. Such judgements are made on the basis that the lethality of method equates to levels of intent (Shneidman, 1985). For instance, gunshot is seen as indicating a greater level of intent than self-poisoning. The conclusion from the degree of lethality approach is that, if the overall method is judged to have a low risk of death then low levels of intent can be safely assumed. However, rather than an indicator of intent, self-poisoning presents a greater amount of time for discovery and opportunity to medically intervene than gunshot (Marks \& Abernathy, 1974; McIntosh, 1992). As a consequence, the person may then be seen as not "really" intending to suicide and instead is seen as being "manipulative" or "attention-seeking" (Lester, 1972). The labels of manipulative and attention-seeking are frequently used pejoratively and are considered to be character flaws in the person, and on this basis may result in the diagnosis of personality disorder.

A further consequence of the lethality of method hypothesis is the conclusion frequently drawn in research and clinical settings that males are potentially more suicidal than women, as males tend to use more lethal methods (Buckley, Dawson, Whyte, Hazell, \& et al., 1996; Carter, 1997; Ikeda et al., 2001; Kral \& Sakinofsky, 1994; Lester, 1996; Rich, Ricketts, Fowler, \& Young, 1988). However, Marks and Abernathy (1974) critique the equating of lethality of method to intentionality. Firstly, they make the observation that "all the methods used by completers [of suicide] are deadly" (p. 5. Original emphasis). Secondly, that what is being evaluated by this approach is actually the time span available for possible intervention, rather than the degree of intent. On this basis they suggest that choice of method is instead, "a consequence of the constellation of values, beliefs, and social pressures" (p. 10). The socio-cultural hypothesis proposed by Marks and Abernathy suggests that instead, different choices of suicide method are made by women and men according to their social and cultural 
context, rather than varying degrees of intent. Additionally, Kushner (1985) argues that acceptance of the lethality of method hypothesis has led to a distortion of official statistics through a determination of suicide being made on basis of method, in lieu of knowing intent. Kushner argues that it is therefore likely female suicide deaths may in fact be underdetermined, and likewise, male nonfatal suicidal behaviour has been underreported.

From the socio-cultural perspective, several further problems arise from the equating of lethality to levels of intent. Firstly, there is a focus in research and clinical settings on the fatal outcome (suicide) to the exclusion of the range of self-destructive behaviour and thought (suicidality). The language surrounding this focus positions a fatal outcome as a successful behaviour and a nonfatal outcome as an "attempted" or "failed" suicide. Terms used to describe nonfatal suicide outcomes, such as: "failed attempt", "not serious", "manipulative behaviour", and "suicidal gesture", are all pejorative terms that are value judgements labelling the person as having fallen short of some valued status. On the other hand a fatal suicidal outcome is positioned as an achievement or success. By way of comparison, Lester (1989) argues that if we were to focus on the full range of self-destructive behaviour, the statistical norm would be survival and a fatal outcome becomes statistically deviant. Lester further suggests that such a perspective would regard the nonfatal outcome positively as an adaptive behaviour that permits survival and should therefore be regarded as successful.

Secondly, given the distrust of the person's self-report inherent in the lethality of method hypothesis, pejoratively labelling nonfatal outcomes as not serious, manipulative, an attempt, attention seeking, failed, and so forth, tends to minimise the critical assessment of future risk of harm (Clark \& Fawcett, 1992). As $25 \%$ of fatal suicidal behaviour is preceded by nonfatal suicidal behaviour (Maris, 1981), such language disguises the increased risk of harm. ${ }^{8}$ As well, such pejorative language discounts the subjective distress and pain experienced by the person making a respectful working relationship with the person unlikely.

Thirdly, clinicians influence how others come to understand the behaviour of themselves and others (Busfield, 1986; Clarke, 1991). Such stigmatising language will

${ }^{8}$ It is worth noting here that Stengel (1969), and more recently, Diekstra (1989a) suggest a higher range of 30 to $40 \%$. 
reinforce any existing negative perspective of themselves as well as reinforcing negative stereotyping by others. The experience of stigmatising language may inadvertently contribute to increasing the risk of suicide. That is, if a nonfatal outcome is perceived as less socially acceptable than a fatal outcome, then the choices available for survival become restricted (Linehan, 1973).

Kushner (1985) argues that the basis for differential beliefs about women's and men's suicidality is deeply historical. He notes that the dominant perception of the nineteenth century was that women "cling to life" because "her courage [to kill herself] is apt to fail" and men suicide due to external pressures while women suicide due to inner troubles. Kushner is suggesting a link between the different social spaces women and men were expected to occupy in $19^{\text {th }}$ century society. That is women were expected to occupy private domestic social spaces and whereas men were the dominant figures in public space. That these beliefs remain current suggests a well-established stereotyped association between the social expectations for the sexes and fatal suicidal behaviour. Hence, men's suicide becomes construed as some sort of heroic solution to insurmountable pressure (Canetto, 1992). However, the term "failed suicide" is easily associated to the "failed courage" of women, and hence, does not meet the stereotypical masculine standard.

Similarly, Sanborn (1990) and Canetto (1994, 1995, 1997, 1998) assert that surviving suicidal behaviour may be unacceptable for men. Dominant forms of masculinity are defined as the negative of femininity; that is, masculinity is not-feminine (Connell, 1995; David \& Brannon, 1976; Pease, 1997). For men who hold strongly to the not-feminine view of masculinity the option of surviving an attempt to kill himself is severely constraining. Perhaps as importantly, this may also prohibit the acceptability of acknowledging and dealing with suicidal thinking. Warren (1983) takes a similar view in her review of men's depression, arguing that much of the behaviour, ideas and feelings associated with depression are also associated with femininity. Where dominant forms of masculinity are associated with strength, control, and rationality; the experience, ideas and behaviours characteristic of depression (e.g. crying, confusion and lethargy) are associated with being emotional, a lack of control, and weakness. These characteristics of depression are easily associated with femininity from the perspective of men who subscribe to the not-feminine view of being a man. One possible conclusion to be drawn from this argument then is that for men who subscribe to a strongly not- 
feminine (or to use David \& Brannon's [1976] words, "no sissy stuff") view of masculinity, having ideas about suicide and experiencing symptoms of depression may be so disturbing that awareness of symptoms, including thoughts of suicidality, must be rejected in order to retain their sense of being a man. Such a denial of the experience of depression prevents all possibility of communication and consequently excludes the acceptability of support and intervention.

\section{The relationship between non-fatal and fatal suicidality}

Reading the literature on suicidal behaviour, one encounters a debate about the relationship between non-fatal (including deliberate self-harm) and fatal suicidal behaviour. From my reading of the literature four broad positions emerge. Firstly, suicidal behaviours are understood as symptoms of mental disorder; secondly, nonfatal and fatal suicidal behaviour are viewed as two separate but possibly related populations; thirdly, that nonfatal suicidal behaviour and suicide are all different aspects of a continuum of self-harm; and fourthly, an emerging position that self-destructiveness is best understood through the cultural and gender meanings of the person as part of how the person makes his or her world meaningful.

This latter position offers a critique of the first three, which tend to be premised on a traditional scientific worldview and hence, tend to be medicalised and consequently viewed as mental illness or disorder. I shall briefly overview the first three positions before turning to the latter sociocultural position in more detail.

\section{Mental disorder}

Neame (1997) argues that suicide must reflect a mental disorder, on the basis that to kill oneself one has to overcome the basic instinct to survive. From Neame's standpoint, "suicide is never a normal or rational choice" (p. 14). The link between a diagnosis of mental illness and suicidality becomes tautological. To be suicidal means one must be mentally ill or disordered because it is irrational. It follows from this position of irrationality that the individual can be presumed to have no capacity to seek help as “"seeking help' is a rational choice, it almost totally excludes the seriously mentally ill" (Neame, 1997, p. 5). Furthermore, it assumes behaviour is without meaning on the basis that the person is not rational. On the basis of Neame's argument it makes little sense to engage in a relationship with a suicidal person as any communication, like their behaviour, is meaningless. This position ignores studies of suicide that show a multitude 
of reasons for killing oneself; for instance the theorising of Jean Baechler or the more recent work of Edwin Shneidman (1998). It also ignores the multitude of people who seek out help on the very basis that they feel suicidal (Barnes, Ikeda, \& Kresnow, 2001; Kessler et al., 1981).

Arguably, in recent years suicide has increasingly become understood to be a symptom of a mental disorder. This is the position taken by recent New Zealand guidelines for the Assessment and Management of People at Risk of Suicide (New Zealand Guidelines Group, 2003). A formidable array of evidence in support of the mental illness notion of suicide can be found in epidemiological studies and psychological autopsies (Barraclough, 1985; Berman, 1993; Brent, 1989; Clark \& Horton-Deutsch, 1992; Durkheim, 1897/1952; Klerman, 1987). Tanney (1992) sums up the status of the mental disorder hypothesis, saying that

The conclusions are unequivocal: (1) Mental disorders are more common in populations of persons completing suicide, and (2) suicide and suicidal behaviors occur much more frequently than expected in populations of psychiatric patients. (p. 287)

Tanney concludes further, that the affective disorders are those most commonly associated with suicide followed by schizophrenia, while organic disorders have little association. However, he also cautions that association with mental disorder is not the same as a direct link to suicide (Tanney, 2000). Nonetheless, he estimates the "increased risk of suicide for persons with active mental disorders converges around 7 to 10 times that of the general population" (2000, p. 339). Similarly, other writers report that probably less than $1 \%$ of people who suicide did not have a diagnosable psychiatric disorder at the time (Fremouw, de Perczel, \& Ellis, 1990). In a variation of the role of mental disorders, Maris (1981) makes a distinction between trigger factors and the more remote causes for fatal or nonfatal suicidal behaviour stating that

Depression and hopelessness were still most important as precursors of completed suicide, but physical problems, general interpersonal problems, and work problems all seemed to be slightly more important as situational precursors than they were as major causes. For the nonfatal suicide attempters, depression and hopelessness were the most important situational precursors, with general interpersonal problems a close second. (p. 274) 
Studies using the psychological autopsy method have also proposed a strong relationship between suicide and mental illness (Berman, 1993; Brent, 1989; Clark \& Horton-Deutsch, 1992). On the basis of his findings in a study of 100 suicides, Barraclough (1985) argued for a medical approach to suicide. He found that 93 of those who died by suicide were diagnosed mentally ill and of those, 83 would fit criteria for diagnoses of depression and alcoholism. He also notes that 75 had seen a doctor in the previous month.

A large body of research exists that lists variables correlated to fatal and nonfatal suicidal behaviour that appears to support the link between depression and suicidal behaviour (Tanney, 1992). However, as suicidality is one of the behavioural criterion for a diagnosis of major depression (American Psychiatric Association, 2000), this association should be unsurprising and seems to be somewhat tautological.

Cognitive psychology theorises a relationship between suicidal behaviour and the cognitions of depression. According to Rudd (2000) cognitions are the private meanings assigned by the individual that consist of the meaning-making structures termed schemas. There is a linear, reciprocal and deterministic relationship between cognitions and outcomes. According to Freeman and Reinecke (1993),
The relationship between early negative experiences and current symptomatology is not through the invocation of a descriptive personality structure, but is mediated by the activity of specific assumptions and schema. These beliefs are understandable within each individual's personal meaning system, and although highly personal and idiosyncratic, are available to conscious awareness. The cognitive therapy model postulates that depression may be seen as a manifestation of these enduring belief systems, assumptions, and schema. (p. 18)

Building on cognitive theory, Rudd uses a specific elaboration of Beck's (1996) modal theory of psychopathology in which he proposes a cognitive-behavioural model that integrates psychotherapeutic approaches to suicidality in which he takes the approach that views cognitive therapy as mediational. That is, Rudd's model is premised on seeing the individual as living in "a dynamic context, with reciprocal influence, interaction, and interdependent outcome” (Rudd, 2000, p. 21). 
Although there appears to be a strong statistical association of mental disorders with suicide, Diekstra (1989a, 1989b) concludes that the current evidence suggests suicide has complex causes rather than any single responsible agent or disorder. Diekstra (1998) states further, that although mental illness is clearly a risk factor, and a non-specific one since it crosses many disorders, why it is a risk factor remains yet to be explained.

\section{Suicidality as a continuum of self-harm}

There is an ongoing debate in the literature as to whether there is, or is not, a relationship between fatal and nonfatal suicidal behaviour; that is, whether they represent two different populations. Those who argue for theorising two separate populations with little or no relationship, do so mostly on the basis of population-based statistical comparison. For instance, in their review of the literature, Hawton and Catalan (1987) conclude that the rates of attempted suicide and suicide vary independently of each other. Tanney (2000) agrees, arguing that nonfatal suicidal behaviours have a characteristically different set of diagnoses. Maris (1992) also reports research showing that suicide attempts are a poor predictor of future suicide as only 10 to $15 \%$ of people who attempt suicide go on to kill themselves. However, the same data cautions that, of those people who commit suicide, 30 to $40 \%$ have made prior attempts (Maris, 1981).

Other researchers proceed from the premise that suicidal behaviours are but one end of a continuum of self-harm. From this perspective, a common element exists connecting non-fatal behaviours to those that end in an intended death. For instance, like Shneidman, Farber (1968) also draws on Freud's notion of ambivalence, hypothesising that within a suicidal state the person experiences a kind of existential ambivalence; that is, they exist in a contradictory state of "to die or not to die" (p. 7). The psychoanalytic perspective also differs to that of epidemiologists in that the starting point is a detailed examination of the individual rather than that of populations. From the psychoanalytic perspective self-mutilation is a psychological process that parallels suicide in so far as it is "hate directed against an external object... turned back upon the self and reinforced with self-punishment" (Menninger, 1938, p. 233). Like Farber and Shneidman, this process is also thought to do with both the past, present and future, and has deep symbolic and real values: 


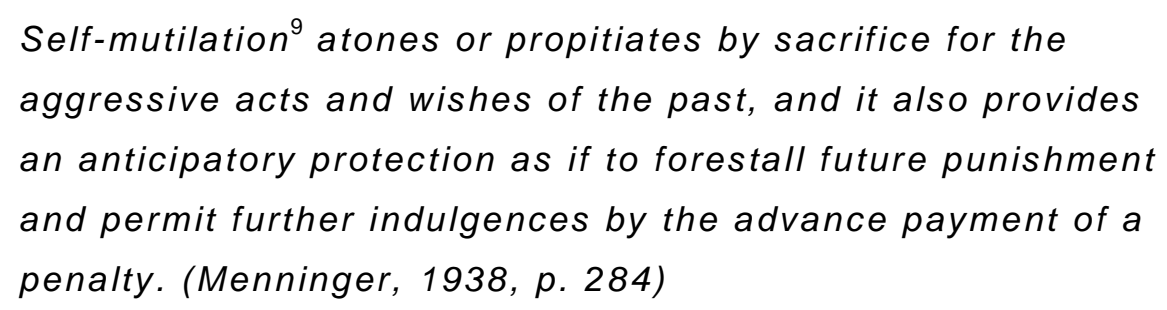

The relationship of self-mutilation to suicide within the psychoanalytic thesis is that self-mutilation is a form of suicide in which death is averted; albeit at times at great cost to the person. Within the personality, the life and death instincts are not necessarily in harmonious balance. To avert death, eros must overcome thanatos. Menninger considers self-mutilation as the death of a part of the self, in order that survival is made possible through a sacrifice of a part of the body; as a substitute for killing the self.

Frankl (1984) casts the issue of suicidal thought into a question of existential meaning. Frankl's use of the term "meaning" is paradigmatically different to how it is used within cognitive theory. In cognitive theory (such as Rudd, previously discussed), meaning is to do with logical-rationality and as a consequence the meaning of a behaviour can be discovered through scientific method. However, meanings can involve human qualities that go beyond that of the empirical world, such as "the ability to self-transcend, to observe the self in a detached manner, and to draw upon our "noetic ${ }^{10}$ dimension"' (Long, 1986, p. 97). Frankl views the normality of life as full of different tensions, suffering, or of crises. In fact he suggests they are ever-present as a fact of human existence. Life or living is assumed to include what he terms the "tragic triad" of pain, guilt, and death. From Frankl's perspective it is not enough to simply have the means to live, but necessary to have something to live for. In this sense, lives are lived toward an intention or purpose.

A purposeful or intentional living changes the tragic triad by: "(1) turning suffering into a human achievement and accomplishment; (2) deriving from guilt the opportunity to change oneself for the better; and (3) deriving from life's transitoriness an incentive to take responsible action" (p. 162). There are three major paths to creating meaning in life according to this view: “(1) creating a work or doing a deed; (2) by experiencing something or someone; and (3) by the attitude we take toward unavoidable suffering” (p.

\footnotetext{
${ }^{9}$ Karl Menninger uses the term self-mutilation rather than the term self-harm. To the extent that self-harm is a deliberate and purposeful injury inflicted upon the body by the self, I believe the terms can be considered synonymous.

${ }^{10}$ From the ancient Greek noös, meaning mind or soul (Gadamer, 1996).
} 
133). On this third part, Frankl states that it is not necessary to suffer in order to find meaning, this would be masochism; but when unavoidable, it is what one makes of the experience that is important.

From his observation and experience of living through the concentration camps of Nazi Germany, Frankl saw in others that moment when "meaning orientation had subsided, and consequently the seeking of immediate pleasure [e.g. a secreted cigarette] had taken over" (p. 164). In the context of the concentration camps it was a signal that death was accepted and perhaps desired. Frankl attributes much of the current-day depression, aggression, addiction and suicide to "an existential vacuum, a feeling of emptiness and meaninglessness" (p. 166).

In Frankl's form of existential analysis, logotherapy, a spiritual dimension (noös) is brought to the physical and psychological aspects of being human. Suicidal thoughts are seen to arise out of a loss of, or inability to find a meaning for living. Suicide occurs, not so much as a loss of hope, but as a loss of the ability to find meaning or purpose to life (Long, 1997). Suicide, suicidal thought, nonfatal suicidal behaviour, and so forth, are not seen as separate phenomena from this perspective but as behaviour arising out of the person's own circumstances and is meaningful within their worldview. Although Frankl draws links between the social and suicidality through the centrality of meaningfulness to living and dying, how it is that cultural and gendered understandings contribute to meaning remains invisible.

\section{Suicidality as gendered}

In the early 1970s Linehan (1971) proposed that the differences between women and men's rates of suicide and choice of method could be explained as an outcome of sexrole expectations. In a study of college students that examined attitudes toward suicide and attempted suicide, Linehan found that, consistent with the expectations of sex-role theory, suicide was more often regarded as a masculine act than attempted suicide.

Marks and Abernathy (1974) proposed a socio-cultural perspective, arguing that using the lethality of method hypothesis to explain the difference in female and male suicide rates is misleading. They point out that both sexes actually use the same methods, but differ in the proportion. They re-examine the relationship between intent and method through a socio-cultural perspective asserting that 
An individual is subject to social and cultural norms that help

him[sic] define acceptable and nonacceptable forms of

behavior, including methods of self-destruction... these norms

are internalized and, to varying degrees, relatively consistent

with other values and beliefs, such as bodily appearance,

avoidance of pain, assumed effectiveness of method, and

moral and religious convictions. (1974, p. 10)

From the socio-cultural perspective of Marks and Abernathy, a relationship would be expected between particular methods of suicide and:

- the person's evaluation of self,

- the person's knowledge of methods,

- the person's familiarity with these methods,

- the person's personal and social acceptability of these methods, and

- the actual availability of these methods.

More recently, a focus on the socio-cultural dimension of suicidal behaviour has led to consideration of what part the sex role of men might have in suicidal behaviour. For instance, Canetto (1991) compared substance abuse to the rate of suicide attempts. While both are life-threatening behaviours and encompass a range of conscious selfdestructive intent, impulsivity and appeal for help, there are different outcomes for women and men. While men usually have increased rates of drug and alcohol abuse, women have increased rates of overdosing (Battersby, O'Mahoney, Beckwith, \& Hunt, 1996; Hall, 1996; Nightingale, Beatrais, Joyce, \& Mulder, 1994; Paton-Simpson, 1999).

Canetto and others have argued that gender roles are a key factor to understanding the different outcomes for women and men (Canetto, 1991, 1995; Chesler, 1972). They argue that stereotypical masculine gender beliefs lead to non-fatal suicide attempts being considered feminine because they are seen to be the result of personality problems, implied helplessness, indecisiveness; additionally, an expectation of rescue may mean that surviving suicide is equated to failed masculinity. Such understandings of what an "attempted suicide" or "failed suicide" may mean, could lead to men taking greater care to ensure a fatal outcome (White \& Stillion, 1988).

On the other hand, alcohol and substance abuse may be easily accessible and socially acceptable for men (Canetto, 1991; Griffiths, 1993; Hill, 1999; James \& Saville-Smith, 
1994; Paton-Simpson, 1999). If we subscribe to Menninger's view that deliberate selfinjury is a form of sacrifice (of a part of the body) in lieu of suicide, drug and alcohol abuse may be seen as options to avoid death while also managing to conform to socially acceptable behaviour for men. Support for this view may be seen in the strong statistical correlation with suicide, alcoholism and substance abuse (Lester, 2000a, 2001; Nightingale et al., 1994).

\section{Gendering men's suicidal behaviour}

The review of suicide and suicidality in this chapter shows that suicide and suicidality have complex causes. It is argued here that both are essentially human acts which require a consciousness to conceive of the purpose of death and move toward bringing it to fruition. From this perspective each person and each community will understand a person's suicide differently. Kerkhof and Diekstra (1995) have suggested that there are multiple pathways to suicide and not every pathway necessarily ends in suicide. A fruitful approach to suicide prevention might be found by focussing on the pathways rather than attempting to isolate a single variable. In contrast to the reductionist approach, a significant contribution to the understanding of suicidal behaviour may then be made through theoretical frameworks that attend to the dynamics within the complex social contexts and meanings in which people live and die. It is likely therefore that different understandings are attributed to suicide in differing cultural contexts. For example, suicide may be culturally meaningful as a means to restore honour, or as a courageous act in the face of external stress, or to cover up personal dishonour, or regarded as a blasphemy against God, or as a result of a (Western) medical condition such as depression, or a means to go to a higher form of existence, and so forth.

Different approaches to theorising suicide and suicidality have been canvassed here that preserve complexity, meaning, and social context. While the sociological approach, exemplified by Durkheim, considers issues of social structure, such a perspective minimises the agency of the individual by focussing upon larger social groups. For instance, the central premise of Le Suicide is the relationship of the individual within society. As a sociological theory, Durkheim's typology of suicide has been a valuable contribution towards explaining suicide. Other more recent writers support Durkheim's sociological approach. In Suicide Explained, Hassan (1995) argues for the consideration of social factors in the explanation of suicide, basing his research on an extensive review of Australian data. He echoes Durkheim stating that 
In social theory suicide is viewed fundamentally as a product

of the nature of the relationship between the individual and

society. The relative degree of regulation, control, isolation

and oppression of individuals in society are among the primary

causes of varying degrees of suicide in different societies. ( $p$.

156)

Hassan (1995) concludes that a sociological analysis of Australian data reveals that the aetiology of suicide is that "about half of the suicides were primarily 'anomic'... [and] the other half were primarily "egoistic"' (p. 161). In addition, he concludes relational, instrumental, and health problems, are the major circumstances preceding suicide. Of note is that in Hassan's interpretation the data demonstrates the significance of symbolism and social forces in suicide, saying that

The empirical evidence examined in this volume shows that suicidal behaviour, like other forms of social behaviour, has important symbolic content and in the final analysis it is shaped by the same social forces which influence and regulate the other general patterns of social life. (p. 162)

The psychoanalytic perspective provides a much more dynamic and complex process to suicide than the objectivist and deterministic worldview of positivist science upon which psychiatry and clinical psychology are grounded. However, by focussing on individuals, the psychoanalytic approach of Freud and Menninger fail to problematise social structures and the environment that influences each individual's suicidality. Additionally, by hypothesising mental structures of the personality, psychoanalytic language is itself objectivist and deterministic leaving little latitude for personal agency. As a result, personal meanings become pathologised through a language that assumes what it has labelled as "normal" development is a universal standard.

Shneidman also remains clearly focussed on the individual. However, rather than emphasising cause, he places an emphasis on need. His description of the common characteristics of suicide (Table 3, p. 32) defines problems and needs in terms of thinking and behaving. This approach is not dissimilar to the cognitive-behavioural and medical views of suicidality. Whilst he provides a clear path for intervention, it is limited by its universalism; being suicidal is reduced to ten different components which are regarded to be the same for all regardless of age, sex, class, and so forth. 
Arguably the current dominant form of understanding, or attempts to understand suicide, in Western societies is that suicide is a result of mental illness, and consequently ultimately comprehendible and preventable through the efforts of medical or psychological science. This view is influential across all clinical disciplines within mental health services who have a role to manage suicidal people. This view has the individual as its focus rather than society and takes a mechanistic (and objective) view rather than a concern for meanings derived in the context of social relationships.

Each of these positions discussed in this chapter provide a useful way of explaining suicidal behaviour, and each has its limitations. Except for the existentialist perspective (e.g. Viktor Frankl) each of these theoretical positions seek a causal explanation by looking to the past. As Hjelmeland and Knizek have argued, this is consistent with the psychological-scientific position of observation. On the other hand, a teleological explanation of suicidal behaviour looks to the future asking "what is intended?" and as a consequence, the private thoughts and meanings of the individual are important to understand their suicidal behaviour. A scientific explanation of suicidal behaviour then can only provide only a partial understanding of a person's suicidality; it cannot answer the question Jean Baechler (1975/1979) set out to answer: "what are people doing when they set about ending their lives?” (p. 443). As a human answer to a human problem, Baechler hypothesises it is "a solution brought to bear on a problem" (p. 443). In this sense, suicide is ultimately meaningful to the person. How men come to act the way they do requires an understanding of historical experience, relationship to the present context, a view of the future, and the personal meaning of life and death. Importantly, it also includes a sense of morality and ethics; being questions of how things should be and how he is prepared to live and act. These questions are meaningful only in a social context and involve an appreciation of how "being a man" exerts an influence over expectations and experiences.

Positivist theorising of gender as sex-roles is insufficient for an adequate exploration of the relationship of masculinity to suicidal experience. Furthermore, building on the work of feminist theorists, positivist theorising on gender has now been comprehensively critiqued as being static, unable to explain diversity, failing to examine power relationships, unable to grasp social meaning and history, or men's relationships to institutions and technology, and does not provide a means to theorise change (Connell, 1995; Kimmel, 2000; Mac an Ghaill, 1994; Seidler, 1994). Moreover, a 
theorising of masculinity for the purpose of this study will need to be congruent with the position on mental health nursing argued earlier as meaningful and socio-culturally situated and therefore requires an approach somewhat more criticalist in orientation rather than that of a positivist social science. This is the subject taken up in the following chapter. 


\section{Chapter 4}

\section{MASCULINITIES}

The position I have outlined earlier is that what is understood as normal or abnormal (e.g. mental illness), is an interpretation situated within a social context. Moreover, I have argued that claims to an objective science leave existing gender constructs unproblematised. Premised on science, clinical intervention in psychiatry and mental health acts to police the boundaries between current norms and that which is "inappropriate". As a taken-for-granted and universal norm, masculinity is both unseen and unchallenged. However, to ask the question of masculinity in mental health issues demands masculinity to be made visible. To do this requires a theorising of masculinity.

The position I have developed in the previous chapters is an explicit rejection of the essentialist or mythopoetic position on men and masculinity that has been adopted in recent years by some writers and researchers (e.g. Biddulf, 1995; Bly, 1990; McCann, 1999). The essentialist position holds that there is a fundamental (that is, "essential") core to men's character that has always been part of being a man, whilst the mythopoetic position is both a political and a therapeutic-spiritual movement (Fee, 1992; Hearn, 1992; Kimmel \& Kaufman, 1994). The "central assumption of the mythopoetic vision is an ontological essential difference between women and men" (1994, p. 269). The essentialist and mythopoetic movement is concerned with addressing what is perceived to be a loss of manhood generally assumed to begin with a "loss of fathering" (Biddulf, 1995; McCann, 1999).

An essentialist position has enabled some writers to argue that a variety of social problems involving young males, including mental health problems, to be explained as a loss of fathering or other male role model (McCann, 1999); thus enabling an antifeminist discourse and closing off a critical self-reflection by men. The question of “how 'being a man' might affect and influence their expectations and experiences, in a multitude of settings" (Whitehead, 2001, p. 352) does not get asked. The mythopoetic 
and essentialist responses therefore seem to be less about self-awareness and instead a response to a perceived threat to men's power, privilege and control over women and children. Hence, it is intended to retain the status quo.

To the extent that there is an absence of critical self-reflection by men, health and power remain entwined and unseen. While there is a well-established feminist literature examining men's power at the expense of women and women's health, it is only recently that some effort from men has been directed toward examining the impact of masculinity upon men's health. Much of this effort has been built upon the work of feminist scholarship.

A rejection of essentialist notions of masculinity introduces the idea that masculinity has a history and social structure. One of the earliest theorising, linking masculinity and psychological dis-ease has been Freud who's writings have prompted prolific discussion, debate and further theorising.

\section{Freud on masculinity}

Although Freud did not write a theory of masculinity, Connell (1994) points out that his thinking on masculinity can be traced through his writings, in particular the Three Essays on the Theory of Sexuality (Freud, 1905/1986), as well as the "Rat Man" (Freud, 1909/1955) and "Wolf Man" (Freud, 1918/1955) case studies. Freud's writings hypothesise that heterosexuality and masculinity are formed through the oedipal complex in which, at an early age, the boy is confronted by his father's competition for the attention and affection of his mother. In successful resolution of this crisis, he separates from his mother to eventually identify with his father (i.e. the aggressor). In doing so, this also enables the boy to (symbolically) have a sexual union with a mothersubstitute (Kimmel, 1994). Through a Freudian model, masculinity is irrevocably tied to heterosexuality, independence, and fear; that is, the fear of (symbolic) castration - the fear of being cut off from his mother. Freud also ties masculinity to separation from the mother. Psychosexual development requires separation from one's mother as a male as an essential and ongoing proof of manhood (David \& Brannon, 1976).

Both Victor Seidler and Bob Connell draw upon Freud to support the argument that the dominant conception of masculinity is based upon a separation from the feminine. Seidler draws upon Freud to connect desire and control to masculine identity, describing 
the oedipal crisis as a time where boys learn to "crush their feelings of need, dependency, and emotionality to achieve a masculine identity" (1987, p. 98). Hence, the denial of these feelings and desires establishes male identity (Connell, 1983). Freud's description of male psychosexual development is not one of steady progression, but a conflict-ridden process in which sexuality is formed and reformed in a state of tension between the masculine and feminine self (see for instance, the "Wolf man" case study). Seidler (1987) argues that paradoxically, learning to repress these feelings and basing a sense of masculinity on this denial, leaves boys in a continuous struggle with themselves, always fearful of revealing the "femininity" that they are denying within themselves. The preferred resolution then is to utilise reason as protection from an emotional world that is unfamiliar and not well understood. In learning to value independence, men have difficulty showing and exploring their emotional needs as it raises questions of dependency made even more profound by a separation from the feminine (Seidler, 1997).

\section{Constructing masculinities}

By removing the notion of a deterministic relationship between sex and gender, we can acknowledge the agency of the person in the creation of gender. That is, irrespective of how a person's gender becomes a reality, the person is actively involved. Gender can therefore be said to be accomplished by people; hence, people do gender (West \& Zimmerman, 1991). This premise means that merely because a man observes he has a penis he does not then passively accept a prescribed (and proscribed) social existence or role in accord with his culture. While a point of difference may be noted, the social meaning of the body becomes worked through in relation to the social world in which he lives. As Kessler and McKenna (cited in, West \& Zimmerman, 1991) have noted, genitalia are conventionally hidden, and it is the presumption that they are there that is the basis for public categorisation of a person's sex. Although it is individuals who do gender, "the enterprise is fundamentally interactional and institutional in character... doing gender is unavoidable" (West \& Zimmerman, 1991, p. 23-24).

While this position acknowledges individual agency in how a man may wish to see himself and how he socially exists, it also draws attention to the interactional space in which gender is accomplished and as a consequence, individual agency is not unlimited. Having stated that choices exist, they may not however, be readily accessible. Choices for gender accomplishment can be made more or less accessible by others through 
various strategies, such as: the use of stigma, stereotyping, knowledge, religious and cultural expectations and obligations, fear, persecution, and legal prohibition. Ultimately, the use of overt violence continues to be a mechanism of social constraint. For instance, in a study of male school students by Town (1998), some of the gay men he interviewed described a strategy of managing their fear of homophobic persecution at school by maintaining a façade of heterosexuality; that is, engaging in sex with women as well as participation in assaults on boys who were identified as being feminine and therefore assumed to be homosexual. Town's interviewees show that heterosexuality or homosexuality ${ }^{11}$ are not objective facts to which they variously conformed, but are subjective experiences of self that may or may not be consistent with observed behaviour or even self-report; particularly as circumstances may mean that to "come out" is unsafe. As an attribution of gender identity is made by the individual as well as others, it is entirely possible that there can be an inconsistency between how others see us compared to how we experience ourselves. Put another way, how we are seen objectively may not be the same as how we experience ourselves subjectively. Drawing on a poststructuralist perspective, hetero- or homo-sexuality are therefore not biological "things", but ideas and meanings that relate to the body and have material effects on the body.

The view that masculinity is socially constructed holds that what we call masculinity is not a "thing" in the material sense, but an idea constructed out of beliefs about what constitutes "being a man". Connell (1996) progresses this conceptualisation of masculinity by defining gender as a configuration of social practice. He does not set out to suggest that such a configuration of practice is passively received but that gender is a "social practice that constantly refers to bodies and what bodies do" (p. 159). Although the body is the point of reference for this definition, gender is not derived in a deterministic way from the observation of anatomy or any other biological status. Instead, Connell argues that masculinity should be seen as a life-long personal project rather than a "stable object of knowledge" (p. 33).

Connell argues that gender needs to be understood as a body-reflexive practice because "bodies are both agents and objects of social practice" (p. 159). As an agent, for example, a body can act to do violence, or provide comfort to another. As an object, a

11 Although I speak here in polar terms of homosexuality or heterosexuality, the discussion could easily refer to any number of sexualities, including but not limited to, bisexual, intersexual and transgender. 
body can be the site of social practice and be dressed, injured or be cared for. Such events do not occur in isolation but take place within a pre-existing social structure. Take boxing and nursing as two different examples. The social institution of the sport of boxing is predominantly a practice of males, where males injure other males and are also in turn, have injury done to them. The institution of nursing remains predominantly a practice by women where nurses (amongst other activities) have regard for and provide physical and emotional care for people who are "patients". Where this is disrupted, say by men doing nursing, the term "nurse" becomes qualified and people will refer to the "male nurse" precisely because the norm for nurse has an expectation of women. Similarly, the reverse applies in boxing. That men predominate in boxing and women predominate in nursing shows gender produced and re-produced within the existing social and institutional structures of sport and nursing. These examples also show social constraints operating against women in boxing and men in nursing, are never quite fully overcome.

\section{Historically emergent masculinity}

Seidler argues for an understanding of masculinity as an "historically-emergent experience" (1989, p. 3). According to Seidler (1989, 1994), many accepted traditions have arisen out of a rationalist inheritance formed in the Enlightenment. ${ }^{12}$ The public world of men was identified with reason and morality set in opposition to the superstition and religious dogma that preceded it. He argues that it was during this time when the power of religion to control intellectual life began to give way to individualism and the scientific view of the world that the cultural prerequisites for modern forms of masculinity were set in place. It is Seidler's $(1989,1994,1997)$ contention that it is from within Kantian philosophy and the Protestant Reformation ${ }^{13}$ that current conceptions of masculinity have emerged. This history has been made invisible through a 300 year long process of normalisation and naturalisation of the masculine character now embedded in modern society.

\footnotetext{
12 The Enlightenment (also known as the "Age of Reason") marks the beginning of the Modern Age for the Western world. The Enlightenment covers the two centuries from approximately 1600. In this time, the deeply religious Renaissance (approx. 1450 to 1600) world was attacked and replaced by a mechanistic worldview of science (Leahey, 1987).

13 The period of the Renaissance includes the Protestant Reformation. The Reformation is the $16^{\text {th }}$ century religious revolt that split the Christian Church in Western Europe into Protestants and Catholics. It occurred against a background of social unrest and effectively began when Martin Luther nailed his Theses to the door of Wittenberg Cathedral in 1517 challenging the Roman Catholic hierarchy seeking to de-emphasise ritual, the priesthood, and the authority of the Pope (Leahey, 1987).
} 
Seidler argues that within the Enlightenment "reason" was claimed by men, and regarded as separate to the emotional world. Reason was defined by Descartes (15961650) and then Kant (1724-1804) as setting humanity apart from and superior to nature (Seidler, 1994), or as Stern (1965/1985) phrases it, "the subject must leave the stage of the world so that the world can be mathematically elucidated" (p. 76). Cartesian dualism was a prerequisite for positivist science, separating the observing and the observed, bringing about the possibility for scientific objectivity. For Kant, morality was a matter of internal reasoning, and as such, questioned the traditional relationships of power and authority of the Church. No longer did religious authority define right and wrong and how to live, individuals could now do this through their own capacity for reasoning. However, when power held by the Church (who were men) gave way to reason, men did not lose power, rather men appropriated reason as their own. It is upon the capacity to reason that the basis for men to position themselves as superior to the natural world of beasts has been formed; and as women and children have been defined as closer to nature, it is through men that they are able to "anchor themselves in the new world of reason and science" (Seidler, 1989, p. 14).

According to Seidler, the "Age of Reason" (Enlightenment) institutionalised a new relationship between reason, science, progress, power and masculinity, and frequently did so through violent means (such as the witch trials of Europe and North America). ${ }^{14}$ Using his insights into the world of the military physicists Easlea (1987) connects science, masculinity and power in a profound way to nuclear arms. He points to the exclusion of women from science as "temperamentally unsuited" to the aggressive, competitive nature of scientific endeavour that locates greater masculine value on "hard" and objective science than the creative, intuitive and emotion-linked "softer" subjective sciences. Similarly, the pervasive notion of the conquest and mastery over nature and the view of nature as matter that has no inherent value other than what science gives it. Easlea uses language familiar to scientists to describe the scientific investigation of nature in terms that deliberately invoke the image of rape, asserting that "hard" science "attacks", "probes" and "penetrates" to reveal "her" secrets in an endeavour resulting in the "military paternity" of weaponry.

${ }^{14}$ See for instance, Midlefort (1981) for brief explanation of this period in history. 
It is through reason that men often make a claim to rightness and frequently do so through the instrumental use of language (Seidler, 1989) on the basis that it is only through reason that claims to truth can be made. Agreeing with Seidler, Pinar (1997) asserts that "reason is political and gendered. Reason is the regime in which and through which, our voices are raised, the medium we are coded as intelligible or not" (p. 93). It can then be argued that equality can be granted to others if men's claims are considered rational (Seidler, 1989). Based on rational terms, issues of justice, equity and fair play are able to be problematised, and as problems these issues are shifted to a rational worldview able to be solved through reasoning. Through an Enlightenment inheritance men assume that experience can be constructed according to how it is thought things ought to be. It then becomes difficult to acknowledge emotions and feelings that go against these images (Seidler, 1994). In a rationalist worldview, the intention of an act becomes crucially important for men. For instance, it is the intention of an act to which men turn when evaluating if what is happening in their relationships is right or wrong, rather than anything to do with the personal feelings or the subjective experience of partners (or even men's own feelings for that matter) (Seidler, 1994). Shifting the issue to a worldview of reason denies the legitimacy of the other person's experience (and men's own experience). This in turn frequently provokes a response of hurt and confusion; which are emotional experiences men then seek to further distance and devalue.

In dealing with "problems" of justice, equity, and fair play, anxiety arising out of ambivalence is not easily dwelt upon as there is an imperative to decide what is right and then act. The anxiety arising out of ambivalence or indecision is relieved by reaching a decision through the autonomous reasoning of the mind that exists as separate but within the corporeal self. This can lead men to reject, discount, or minimise the points of view of others as unreasonable, emotional, or irrational. Emotional life, being of the natural realm, is to be distrusted as it can lead men away from reason. Being closer to nature, emotions and feelings are seen as signs of weakness, as these "things" of nature are meant to be under control; "we fear that if we allow our softer feelings to surface, we shall never be able to regain control of ourselves" (Seidler, 1989, p. 161). This makes it difficult for men to take note of emotional needs of themselves and others. Emotions, being part of the natural world, are distanced and devalued; feelings are distanced, devalued and subordinated through men's instrumental use of language and the pre-eminence of reason. 
The distancing of emotion and privileging of reason presumes a Cartesian dualism of mind and body in which the body belongs to the natural world. Belonging to the natural world, the body is devoid of meaning and value other than what human thinking assigns it. That is, we attribute meaning to or discover the meaning of the body. It is only in the tasks the body can be caused to accomplish that the body has meaning. From this mechanistic position, the body, like the natural world, can be used as we see fit. It is there to be controlled, as that is the process through which the body (and the natural world) becomes valued. It is men's relationship to their bodies, as if separated in the first instance, that is so important to masculine gender practice and consequent health outcomes.

Duroche (1990) argues that the Enlightenment marks a time in history where bodily experience, and the body's perception, changed to serve or support other social changes. How the body is perceived and how the body perceives the world through bodily senses, is not fixed but a product of history. For instance, he argues that prior to the $19^{\text {th }}$ century there was an emphasis on "strong and close, often deeply intimate, male friendships" replaced later by "a muting of the emotions, a transforming and often dulling of male perceptual awareness, and an increasing homophobia" (1990, p. 172). The expressiveness of Romanticism began to be increasingly associated with the feminine as part of a redefinition of masculinity. In this sense there was an intellectual move by men to negate or transcend the body; to "get out of the body [and] into the head" (1990, p. 174).

A transcending of the body also involved a privileging of some senses over others (Duroche, 1990). The sense of sight became ranked highest and was associated with assertion, while smelling, hearing, and tasting came to be considered as passive and receptive. Sight also came to be considered as a "masculine" sense through its association with distance, cognition and abstraction, whereas the ability to distinguish flavours and fragrances were considered to be "feminine". The social meaning of bodily perception shifted, congruent with the turn toward science.

Discussing the hearing of sound, Duroche also draws on the work of Attali to argue that whilst men hear subtle differences in the mechanical noises of car engines, which "our wives" rarely hear, the noises that children and other people make are blocked out whilst they read the newspaper (cited in Duroche, 1990, p. 176). It is an argument that 
suggests that men have been socially trained, or disciplined to attend to certain sounds, so that some sounds are not heard or are dismissed as "noise." Similarly, he argues that beliefs about smell have also changed. While the pathogenic nature of smell had been disproved, there began an association between the "crowd" and a "putrid" smell, and a connection with lack of (male) public space that encroached on an increasing awareness of himself as an individual. Duroche traces an historical path that first deodorised public space and then later, private and domestic spaces. Not only has the mind been separated from the body through the scientific turn of the Enlightenment, but gradually the body's senses have become socially constructed to support a decorporealised sense of a masculine self.

Seidler (1989) argues that as the Enlightenment has cast the body as a natural object and therefore to be controlled by the mind, the prerequisites were set for deep divisions between men and their bodies. The body, being the corporeal thing that men exist within, has emerged as the most immediate natural object to be dominated and controlled; that is, self-control. In a very immediate and omnipresent sense, self-control enables men to be positioned as superior to nature. Uncontrolled emotional experience has become equated to a descent into the natural realm and "a loss of control"; a phrase frequently heard as a rationale for violence after the fact. Indeed, Seidler argues that it is frequently "the fear of losing control that accounts for the instrumental nature of men's actions as well as the power of theories which marginalize emotional life" (p. 44). The imperative to be in-control has shaped the nature of men's relationships with women and children. Through instrumental use of language, emotional distance, women and children can be positioned at a distance, as objects closer nature, to be controlled and subordinated. Similarly, Phillips (1986) saw evidence of this in a large-scale study of men's relationships. As a result of his observations he comments that wives were rarely regarded as "friends", and that most interview responses about women generally were "gratuitously hostile" (p. 331). Women were positioned by men as natural objects; for instances, as a prize in competition with other men, or as possessions to be displayed. In part, he concluded that:

Most married men have little physical or psychological contact with their wives. They talked of their wives largely as possessions proclaiming their virtues as cooks, interior designers, or child development specialists... Most 
respondents reported they had little recreational or social

contact with their families. (p. 331)

While an enlightenment inheritance has equated emotion to nature and set it in opposition to rationality, Hearn (1987) has pointed out that this has not mean that emotion goes unrecognised. He states that men are actively involved in the "selective control of the emotions of themselves and others" (p. 139). For instance, men in wellestablished male-dominated professions deal specifically with emotions as a career choice (e.g. psychiatry, psychology, mental health nursing, etc.). Hearn's argument, however is that control characteristises these professional relationships. That is, being professional means being "in control". "Being emotional" can undermine claims to rationality and consequently calls masculinity into question. Emotions are talked about rather than expressed. An important distinction arises therefore between men's emotions and men's emotional needs. To assert that control is a central issue in men's emotional lives, men necessarily have to deal with emotions. As the traditional masculine role is in part, defined as self-reliance and a rejection of vulnerability, a lack of independence and control becomes associated with femininity. To acknowledge a need for approval, love, nurturance, and unconditional acceptance, then could risk a claim to masculine identity. Stern $(1965 / 1985)$ casts this in terms of love and power as a moral antithesis. That is, to love is to relinquish power over another.

Men's relationship with men, while frequently held up as the important and treasured mateship, is perhaps, paradoxically, the greatest potential threat to a claim to masculinity through risking an association with homosexuality (Kimmel, 1994; Plummer, 1999). As Kimmel (1994) put it, "the great secret of American manhood" is that "We are afraid of other men" (p. 277. Original emphasis). As something that pervades all of men's thinking and doing, fear and denial of the emotional world inevitably shapes all relationships to such a degree that homophobia is the foundation on which masculinity itself is constructed (Kimmel, 1994; Plummer, 1999; Stoltenberg, 1992).

\section{Hegemonic masculinity}

Drawing on Gramsci's concept of hegemony, Connell has introduced the term "hegemonic masculinity" (1995) to describe the notion of masculinity that is socially exalted and to which other forms of masculinity are subordinated. According to Connell, hegemonic masculinity is: 


\section{The configuration of gender practice which embodies the currently accepted answer to the problem of the legitimacy of patriarchy, which guarantees (or, is taken to guarantee) the dominant position of men and the subordination of women. (1995, p. 77)}

That is, hegemony is "about the winning and holding of power and the formation (and destruction) of social groups in that process" (Donaldson, 1993, p. 645). Hegemony involves imposing the definition of terms and understandings, ideals, moralities, and issues that are deemed to be legitimately debated (Donaldson, 1993). The establishment and maintenance of hegemony then, requires mobilisation of ideological resources in order for people to accept that the current hegemony is "natural", "ordinary", "common sense", and "normal". A vast and diverse number of institutions and social sites are involved in this endeavour (Beynon, 2001); for example, work (Collinson \& Hearn, 2001; Kerfoot, 2001), family (Morgan, 1994), advertising (Hill, 1999; Lövdahl, Riska, \& Riska, 1999), organised sport (Bryson, 1987; Fougere, 1987), friendships (Messner, 2001; Seidler, 1992), psychiatry (Busfield, 1982; Chesler, 1972), film (Donald, 2001; Nicholls, 1999), the Family Court (Ellard, 1999), prison (Toch, 1998), and schools (French, 1999; Mac an Ghaill, 1994; Mills, 2001). Hegemony is therefore a complex process whereby one social group (in this case, men) "maintain[s] consent for its rule through both domination and intellectual and moral leadership, which is taken for granted because it defines social understandings" (Phoenix \& Frosh, 2001).

The importance of Connell's use of the concept of hegemony is that it makes visible the processes by which male domination is effected by all men without all men explicitly subscribing to it. He argues that this is more often a collective project to which individual men rarely need to overtly defend in any self-conscious way (Connell, 1995). Silence then becomes sufficient to support the status quo (Kimmel, 1994; Rutherford, 1992). Hegemony is therefore, not necessarily established by force, although "at its most brutal it is predicated on raw coercion" (Beynon, 2001, p 16) but is rather, a strategy that can be seen in large cultural movements and social networks as a collective practice (Connell, 1990, 1991) and is visible in the "associated practices, relationships and supporting projects" (Campbell, Law, \& Honeyfield, 1999, p. 169). While this does not require individual men to accept and embody hegemonic masculinity, all men obtain a benefit from the "patriarchal dividend" (Connell, 1996, p. 162). Hegemonic masculinity is therefore not a "type" but is the "most honored or desired in a particular context" 
(Connell, 1995, p. 77). In this sense it is fluid, "historically mobile", multiple, and contestable. Hence, Connell argues that hegemonic masculinity is only ever the currently accepted strategy for (heterosexual) male power (Connell, 1995).

Hegemonic masculinity exists in relationship to other forms of masculinity and in relationship to women. These relationships, being about power, are ones of domination and subordination (and therefore also become visible as sites of resistance). While gender is the way in which social practice is organised, it is not a singular structure. Connell $(1987,1995)$ proposes a three-fold model of gender relations: (a) power relations, (b) production relations (division of labour), (c) cathexis (emotional relations); to which he later adds a fourth (d) symbolism (Connell, 2000). Although he describes this as a structure of relations he cautions against perceiving this as an orderly system that operates in such as way as to make a unitary whole. Instead, using an orchestral metaphor, he suggests it is an historical composition of many composers with a less than perfect meshing of the four elements (Connell, 1987).

\section{Power relations}

The major axis of power in the Western gender order is the subordination of women by men (Connell, 1995). Feminist scholars have named this as patriarchy (e.g. Walby, 1989).

Connell conceptualises power as a reality of people's lives embedded in practice, and as a consequence, is something that is struggled with, and through this struggle it is experienced as a material "reality" that impacts on or constrains bodies as a bodyreflexive practice. The material effects of power are not experienced in the same way by all men:

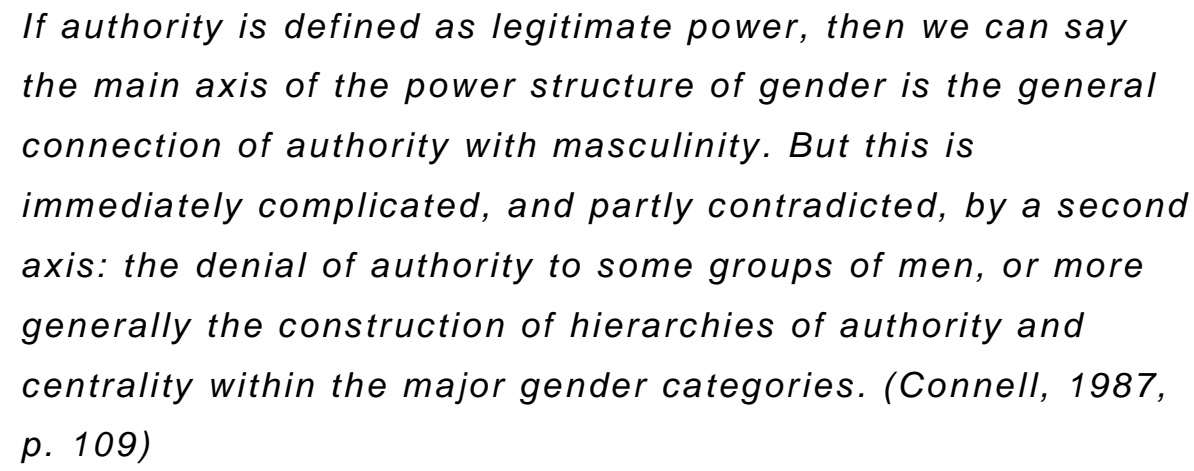

Here, Connell points to a complex, multi-layered system that while granting power to men generally also imposes a hierarchy of power between different groups of men. While exemplars of manhood hold out images of power and control, the relations of 
power between groups of men also mean that men also experience a contradiction of powerlessness in their lives (Kaufman, 1994). Connell's (1990) case study of a champion Australian "iron man" 15 shows that even those who are held out as exemplars of hegemonic masculinity experience powerlessness; in the case of the iron man champion, this took the form of constraints on his behaviour and the limits placed on his aspirations and lifestyle from the image required by his sponsors. By definition, heroes and exemplars that meet the exalted qualities of hegemonic masculinity are likely to be very small in number and even then, as Connell's iron man shows it is more likely to be only a partial achievement. Kimmel (1994) agrees, drawing on David and Brannon's (1976) well-known description of the male sex role, suggesting that the "rules" of manhood are constructed so that:

Only the tiniest fraction of men come to believe they are the biggest of wheels, the sturdiest of oaks, the most virulent repudiators of femininity, the most daring and aggressive.(p. 138)

\section{Production relations}

Production relations refer to the gendered division of labour in the home, industry, and the accumulation of wealth that overwhelmingly favours men over women (Connell, 1995). Connell argues that the connection between capitalism and patriarchy is "constituted out of the opportunities for power and profit created by gender relations" (1987, p. 104). From this perspective, instead of examining the sex division of labour, an examination of production relations seek to show the re-production of masculinity and femininity in economic activity (including the family). For instance, that the language of business management is replete with masculine terminology reflects the particular interpersonal style that is expected, which in turn, reconstitutes the domain of a particular masculinity within the organisation of production.

In another area of industry of particular interest to this study, that of nursing, the same deep-seated gendered nature of production may also be seen. Again, Connell's argument draws attention to the femininities and masculinities involved in the organisation of the "industry" rather than whether or not women or men perform nursing "work." That the profession of nursing has a deep-seated gender structure can be seen, for example, in the way in which nursing is positioned against medicine through

15 A specialty of surf sports. 
a variety of mechanisms; for example, the laws and institutional hierarchies providing for medical authority over what nurses can or cannot do, the generally lower levels of salary, a media depiction of women in daytime "medical soaps" as professionally and sexually subservient to male medical practitioners, and the strong association of homosexual masculinities with male nurses.

\section{Relations of cathexis}

Cathexis, or desire, is a term that draws upon the Freudian meaning of emotional energy attached to an object (Connell, 1983). Connell argues that those practices surrounding desire are an aspect of the gender order. From Connell's position, all social relationships have an emotional and possibly erotic dimension, and to the degree that one's relationships are organised on this basis constitutes the "structure of cathexis" (1987, p. 112). He points to the laws and taboos attached to age of consent, incest, and homosexuality, as examples of some of the most obvious social organisation on the basis of relations of cathexis that occurs through the prohibition and sanctioning of certain activity. An Enlightenment (and Seidler would argue, also Protestant) history has positioned men's sexuality as a temptation back to nature and hence, a threat to reason (Seidler, 1987). Associated with immorality and sin, sexuality has become a great source of unease for men.

In a study of men's submissions to the Australian Family Court, Ellard (1999) has argued that for men, an ability to demonstrate a material connection to the family is a public confirmation of sexual identity, power, and possession of property. An inability to publicly show this connection is likely to be experienced as emasculating. As Kimmel (1994) has argued, it is from other men that men fear the humiliation of being perceived as not-masculine. Additionally, Foucault's (1975/1979) notions of discipline and surveillance suggests that this evaluation becomes internalised as if they stand before the gaze of other men; and in this sense, men become disciplined as men.

\section{Relations of symbolism}

Gender symbolism, particularly that portrayed in the mass media, reflects and reinforces depictions of women and men. Such gender symbolism is pervasive and global. Media portrayal depicts masculinities and femininities as dichotomous rather than analogous. Advertising takes advantage of the current dominant beliefs of men and women to promote their products. Images of men and women are represented in a diverse media, 
such as literature (Sear, 1999), beer advertisements (Campbell et al., 1999; Hill, 1999), pharmaceutical advertising (Lövdahl \& Riska, 2000), cinema (Nicholls, 1999), style of clothing (Comaroff, 1997), linguistic practice (Holmes, 2000), heroic achievement (Morin, Longhurst, \& Johnston, 2001), and political resistance (Peteet, 2002).

Connell theorises masculinities as organised in a hierarchy in which all men gain from male power, using the term patriarchal dividend to describe the benefit it obtains. However, as a hierarchy concerned about power, it is likely that all men will experience varying degrees of privilege and powerlessness whilst all men gain from patriarchy (Kaufman, 1994). While the principle axis of power revolves around the relationship between men and women Connell (1995) also theorises relations of dominance and subordination between groups of men.

\section{Subordinated masculinities}

For Connell, the use of the term hegemony relates to the subordination of all of society to the currently dominant cultural group. Multiple masculinities means that there is a structure of subordination and domination amongst different groups of men. One of the most important relationships of domination and subordination between groups of men is that of the subordination of gay men to heterosexual men (Connell, 1995; Donaldson, 1993; Herek, 1987; Kimmel, 1994; Plummer, 1999; Stoltenberg, 1992). Connell makes the point that homosexual masculinities are positioned at the bottom of the gender hierarchy among men, stating that "gayness, in patriarchal ideology, is the repository of whatever is symbolically expelled from hegemonic masculinity" (1995, p. 78). From the viewpoint of hegemonic masculinity, gayness becomes associated with femininity and threatens the current order.

The power relationship involved in subordination is brought into stark relief by researchers such as Town $(1998,1999)$ and Plummer (1999) whose studies explicitly describe participant accounts of physical assault and terror as defining aspects of growing into adulthood as gay. Suicide becomes a real consideration in order to escape the psychological pain (Town, 1998, 1999). In these studies, relations of cathexis and power are explicit organising structures of the gender order amongst schoolboys. On the basis that gayness is associated with femininity, persecution of boys exhibiting feminine characteristics or behaviour (or not engaging in masculine activity such as rugby) is a strategy that confirms masculinity as not-femininity. Additionally, these 
studies show the power of a discourse of silence in which sexuality (especially homosexuality) is rarely discussed in the school curriculum; heterosexuality is "just a basic rule that you learn, you're brought up with, you don't even consciously think about it" (A participant quoted in Town, 1999, p. 144); that is, (hetero)sexuality is learnt in the silence of a taken-for-granted.

\section{Complicit masculinities}

Connell's concept of complicit masculinities is that masculinities are constructed in such a way that men support the hegemonic project without necessarily meeting the hegemonic ideal themselves, or even having to take conscious steps to promote patriarchy. For instance, a man does not need to be an All Black, ${ }^{16}$ he can support the dominance of rugby masculinities by participating as a spectator. Complicity however, can also mean doing nothing. By not taking steps to change the status quo, silence and inaction become supportive of hegemony. In this way men who do not meet the masculine ideal participate in its maintenance and obtain the patriarchal dividend that accrues to all men.

\section{Marginalized masculinities}

Marginalized masculinities are formed through the interplay of gender relations with other social structures such as race and class. Race and class interact with gender relations to limit access to the hegemonic ideal for many groups of men. For instance, Messner's (1991) study of athletic careers shows that Black men were acutely aware of their oppression. While in their struggle to construct a masculine identity in such a context they were able to establish "respect" through "physical presence, personal style and expressiveness" (1991, p. 70), this did not bring about any change in social equity at large. Marginalization is relative to what Connell (1995) calls the "authorisation" of the dominant group.

Connell's concept of hegemonic masculinity and its relationship to subordinated, complicit and marginalized masculinities is not a deterministic one, nor are these names for fixed character types, but what he calls configurations of practice. Rather than viewing subordinated, complicit and marginalized masculinities as types of masculinity that, but for a certain number of character traits would achieve hegemonic status, these

${ }^{16}$ The All Black's are the New Zealand national rugby union team, known as such by their black uniform. 
have a role to play in the maintenance of the hegemonic ideal. In this sense masculinities, as "configurations of practice", are always in dynamic relationship within other social structures of inequality.

While Connell has a substantial focus on social structures, at the personal level he also theorises masculinity as a lifelong gender project that is both an individual and collective endeavour. That is, "through body-reflexive practices, more than individual lives are formed: a social world is formed" (Connell, 1996, p. 159). That is, men do masculinity, and this doing is always socially situated (West \& Zimmerman, 1991). While acknowledging individual agency this suggests that the potential for free will is constrained within already existing social and cultural traditions and institutions. As a hierarchy, the masculine gender order makes it clear that it is men who oppress other men and hence, limit individual agency. Body-reflexive practices respond to situations in which certain ways of being and doing, and not others, are legitimated (Connell, 1995). Likewise, body-reflexive practices are not purposeless. Something is being achieved in the doing. Through this process a situation that previously existed is changed into another. In this sense, the interaction of body, the social and configurations of practice create a world (or ontology) that not only refers to the body but also has effect on the body (Connell, 1995). It is through body-reflexive practice that health effects can be considered as gendered.

\section{Sports masculinities}

Sport is "a powerful institution through which male hegemony is constructed and reconstructed" (Bryson, 1987, p. 349). Sport is a key issue for this study because of its health consequences for participants. Similarly, the importance of sport to the construction of masculinities is demonstrated in the adverse consequences for those boys who do not conform (Grieve, cited in Fitzclarence \& Hickey, 2001, p. 121). By examining sport through a gender lens, particularly organised sport, one important instance of the impact of masculinity upon health becomes visible.

Sport has a particular potency for the construction of gender because of the pervasive media depiction of sports imagery to which almost all of society is exposed. Some organised sport, more than others, has assumed national importance. Fougere (1987) argues that for New Zealand, the sport of rugby "in part facilitated, the emergence of the New Zealand nation itself" (p. 113). As symbolism of a nation, rugby presented 
particular images of New Zealand men that, although the imagery has shifted with social change, symbolically linked men with nationhood (Phillips, 1996). In contrast to men's participation in organised sport, women's participation in sport is often trivialised, ignored, and frequently controlled by men (Bryson, 1987). Fougere (1987) states that while rugby has always "been a game for men and boys, ... women's rugby teams remain a sports-page joke" (p. 113).

In contrast to essentialist and determinist notions of masculinity the considerable time, effort and energy devoted to teaching boys to become men through sport, and the struggle that boys encounter in finding "success" at sport, belies any notion of masculine biological destiny (Whitson, 1990). Men's sport constructs relationships to other men in ways that are deemed manly. While sport "makes boys into men", it does so by providing an organised potent (and public) experience for the construction of a particular relationship between men's (and boys') bodies and bodily experience. Sport teaches an intentional use of men's bodies in which violence, pain and injury are valorised in this process.

Crossett (1990) sees modern sport arising out of a backlash to $19^{\text {th }}$ gains by women. As a social institution, modern sport reaffirmed the naturalisation of men's privileged position over women through "inherent connections between sport, morality, and manliness" (p. 45). Through sport, men's relationship to their bodies is constructed in such a way that the ideological notion of superiority over women through strength, skill and assertion of force is supported. Moreover, as the sporting arena is a public domain, these attributes are on display for men, women and children to participate. Participation involves more than those playing on the field, "rugby may involve spectatorship, but more importantly, it demands participation" (Fougere, 1987, p. 113). Bryson (1987) demonstrates the potency of sport as a spectacle using a vivid media portrayal of the father-son relationship from an advertising campaign run during the 1983 Sydney rugby season. The camera's focus was upon an excited (i.e. emotional) father in close contact with his young son in the middle of the crowd. The music consisted of stirring (strong) lyrics (sung by Tina Turner) accompanied by an orchestra, choir, with imagery that cut back and forth from roughhouse football to the father and son:

Feel the roar of the crowd,

This is men against men, doing it proud,

Show him the courage, show him the skill, 
What it means to be part of a team, someday he will,...

(Cited in, Bryson, 1987, p. 358)

Sport has been increasingly seen as an essential aspect of a male child's development of manly attributes such as "courage, nerve, pluck, and endurance" (Adelman cited in Crosset, 1990, p. 52). In contrast, without sport, intellectual boys have been thought of as weak, not having their passions under control, having perverse sexual thoughts, and were believed to masturbate (considered in this context to be negative) (Beynon, 2001; Crosset, 1990):

Without sport, then, boys became womanlike, delicate, and degenerate. Without sport, men could lose control over their own sexual desires, become susceptible to sexual excesses, and eventually suffer from sexual exhaustion. (Crosset, 1990, p. 53)

The cure for these "deficits" was physical exercise, or trips to the country to experience a more "hardy" life. The notion that "a boy's mind could be kept pure and free from temptation through the pursuit of 'manly' pastimes such as sport' (Town, 1999, p. 139) remains prevalent.

Violence and injury serve to construct masculinity, affirming conceptions of sports masculinities (White et al., 1995). Schacht (1996) has argued that rugby situates men in a hierarchy of athleticism, strength, tolerance of pain, and distance from femininity. Similarly, Phoenix and Frosh (2001) have found that boys' claims to the hegemonic or masculine ideal was frequently through sporting prowess. Even where competitive sport is unavailable boys formulate other strategies that embody athleticism and physicality through ritualised verbal abuse known as "cussing" (Swain, 2002). In their study of Australian Rules football, Fitzclarence and Hicky (2001) draw a link between masculinity and violence within mass media depicting the "hardness" of the game and valorisation of "damage, abuse, and intimidation" (p. 129).

Such an investment in claims to a hegemonic masculine identity through sport means that being removed from sport through injury leaves little room to reclaim a masculine sense of self and construct different relationship to their body that is seen as masculine (Sparkes \& Smith, 2002). Sport provides an arena in which emotion and competitiveness are linked to violence and masculinity. Hutchins \& Mikosza describe rugby league as a 
"cultural exemplar of hegemonic masculinity" (1998, p. 250) for this very reason. Their study of rugby commentary in Australian sports magazine shows the active involvement of the media in this process citing headlines such as: "Rugby League: 80 Minute Hate', 'Jump On His Head, Big Jimmy', 'Kill! Kill! Kill!', 'Slaughter!' and 'King hit!”' (Cited in Hutchins \& Mikosza, 1998, p. 252).

Phillips (1996) also notes the culture of violence linked to rugby masculinities in New Zealand:

The violent insensitivity to pain and injury, the incredible crudeness of language, the misogyny, the drunken boorishness. (p. 271)

While the headlines cited by Hutchins \& Mikosza depict a perpetration of explicit violence, not only is the ability to "hand it out" "“it" being an objectification of physical assault) as a required aspect of the male athlete, but also the ability to "take it" ("like a man"). The question of how to "take it" is about the manner of accepting injury and pain as a man. "It" is to do with violence, and like the perpetration of violence, "it" is similarly full of manly meaning. Through organised sport "the concern with force and skill becomes a statement embedded in the body" (Connell, 1987, p. 85). Acknowledging pain is indicative of "being something that one is supposed to always guard against being vulnerable, potentially weak, and feminine" (Schacht, 1996, p. 560). If David and Brannon's (1976) description of the male role of "no sissy stuff", success, strength, and aggression is a guide to the desired form of masculinity, then disabling injury can be experienced as emasculating.

In their study of Canadian athletes, White et al. (1995) have shown that pain was normalised, hidden, disrespected, concealed, and depersonalised. Showing pain or injury, in so far that it compromises physical power, also compromises the masculine conception of self. Disabling injury compromises the public ability to display power and control. The athletes interviewed in the study associated incapacitation with weakness, passivity, incompetence, impotence, and vulnerability. By becoming incapacitated through injury or pain, the athlete is marked as deviant, unable to "take it like a man." Incapacity becomes associated to femininity through vulnerability and weakness. In this respect, injury is gendered. Crosset links the gendered nature of injury to longer term health issues, arguing that: 
Such pressures are powerfully insidious however, because the fear of having one's masculinity questioned [by other men] can threaten the long-term health of an athlete who might stop listening to pain signals from his body and return to the team. (1990, p. 177)

Just as manliness is enhanced by (violently) defeating the opponent, little is diminished in losing if it is assumed all competitors are manly men (Crosset, 1990). The battlefield metaphor, so often used to describe combative sport, historically links male violence to the restoration of honour through the "duel" (Spierenburg, 1998) and echoes Easlea's (1987) comments on militarised science. Sport is a highly ritualised means of learning courage, heroism, and violent combat that "could be stopped at the blow of a whistle" (Phillips, 1980, p. 231). In this regard, the exclusion of women as credible athletes is critical to the masculinist project of rugby and other combative sports (e.g. boxing). That is, to defeat women at rugby would undermine the construction of masculinity as not-feminine through sport.

Attempts by women to enter the arena of combative sport have provoked severe public backlash to protect male exclusivity as "proper". A recent example has been efforts by women to enter as boxers in Oceania boxing championships. Australian boxing administrator Arthur Tunstall opposed the idea on the grounds that "a woman is a petite person, not to be knocked around" (McMorran, 1998, p. 45). In a more sophisticated assertion of men's exclusive claim to combative and violent sport, journalist Bob South (1996) constructed a parody of the woman boxer:

[Fathers] can buy those wee boxing gloves for their little darlings, then get down on their knees and trade blows in the faint hope that their sweetie might grow up to be some rough, tough pugilist named Terminator Tina, Sugar Rose, or Hit Woman Harriet. Maybe Pumpkins will even become the Baddest Woman on the Planet. Wow. (p. 9)

That a combative team sports such as rugby league is a "masculine exemplar" shows that public demonstration of physical strength and skill, such as that required for ballet, is not sufficient to affirm masculinity. It is the male exclusivity, utilisation of violence, and men in competition with men, that is exalted above all else; or as James and SavilleSmith have put it, it is "the group dependency, the risk, the violence, and the virility" (1994, p. 52). 
Rugby holds its high status in countries such as Australia and New Zealand as the epitome of hegemonic masculinity because it captures the disparate elements of hegemonic masculinity in a highly public way. Success on the sports field is echoed in other arenas of male dominance, such as the company boardroom:

Toughness in making difficult decisions replaced physical toughness; a ruthless will to win around the board table replaced mateship; power and money replaced good blokemanship as the key attributes of the go-getting cellphone man. (Phillips, 1996, p. 276)

Sport, as well as other social sites (e.g. pubs, clubs, military, etc), are an arena where men learn to relate to men and also exclude, objectify, and demean women (Whitson, 1990). Through sport, male superiority is naturalised and connected to the physiology of the male body so that taken-for-granted assumptions of men as bigger, stronger, faster, become part of the public structure of women's oppression by men. Our focus is rarely drawn to the many women who are stronger, bigger, and faster than many men; or that few other men could measure up to most professional sportsmen. Echoing Freud's theory of psychosexual development, to do so may deeply disturb the foundation of the male psyche grounded in men's separation from women (Kidd, 1987, p. 257).

As sport is a crucial site (in all likelihood because it is one of the few sites men can be overtly emotional without provoking homophobia) for linking masculinity with particular positively sanctioned skills, behaviour and ways of being men, sport becomes a potent location for naturalising the male assertion of violence, aggression, force, competitiveness, and the passivity of women (Bryson, 1987); and as a powerful symbolic form propagated by mass media, this connection extends well beyond the action on the field. By virtue of its extensions into wider public life through the mass media, courts, pubs and club life, it is also a potent force in the naturalisation of what it is that is bounded by the term "masculine". The sports field puts on public display a potent image of masculinity to which other men, women and children engage with as spectators (Connell, 1990; Drummond, 2002; Messner, 1991). Importantly, it is also a social site where violence is controlled (and sanctioned) through sophisticated mechanisms (referee, media, courts, spectator approval, etc.), so as not to be a threat to the established social order. 
At first, organised (combative) sport appears to contradict the general assertion of Seidler $(1989,1997)$ that masculinity rejects emotion and dependency or any appearance of emotion and dependency. The team however, is an acceptable experience of dependency on each other and there are strict rituals around such behaviour. It is a site where young men are initiated into a sharing, or solidarity, of manliness, where particular behaviours and the language of manliness are absorbed within an emotionally charged setting that is publicly exalted. High levels of emotion and dependency are not usually permitted for the hegemonic masculine character, yet these can be experienced and expressed within this particular and tightly constrained domain of male homosociality.

\section{Toward understanding men and suicidal experience}

Freud describes masculinity as a conflict-ridden process in which a boy's father is depicted as somewhat terrifying and dominating figure. As other men enter and continue to feature in men's lives, violence becomes ever-present and immanent in its various symbolic or physical forms. Violence then becomes a defining feature of masculinity. The critical theorising of Connell, Seidler and others, depicts masculinity as the physical embodiment of the rational mind controlling the body to forcefully occupy social space. In doing so, the Enlightenment project of rationality and mind-body split is brought into the present with consequences for men's health and well-being. This suggests that the material effects of masculinity must also be mental ones in which violence also features; both real and symbolic.

Social relationships for men, and even relationships to self, are constructed around a hierarchy of domination through patriarchy and relationships between different groups of men. The internal structure of masculinities has material effects at the level of the individual man. Men's individual experience of this is a fractured and conflicted one; on one hand obtaining the patriarchal dividend, and on the other, an experience of subordination. Boys and men thrown into this pre-existing gender structure and Freud's work suggests that from their earliest moments they are always doing and working at a personal project of masculinity, in both their relationship to their body and in relationship to others. Hence, if men are always engaged in the doing and working out of gender, including in health and ill-health, then the way in which men are socially engaged in the doing and working out as men is central to a complete understanding of men's suicidal experience. 


\section{Chapter 5}

\section{METHODOLOGY}

The research approach proposed in this study is one that has a focus on understanding an other; where that other may be a person or a text. Understanding others is of central concern to the practice of mental health nursing. The term understanding can have several meanings. Understanding another person's distress might mean to define and label the issue as an objective fact irrespective of that person's experience of it. However, in this sense of the term understanding, we would not be understanding the person as a person but as an object. The power to define the meaning of the experience is located with the expert rather than the person experiencing the distress. In contrast, the position taken in this study on mental health nursing has been that mental health nursing is about a human encounter with the person. From this position, understanding is about grasping the meaning of the experience for the other person. Wilkin (2003) states this as "primarily 'being' and 'becoming' with people who are suffering (either directly or indirectly as carers) the effects of mental dis-ease or distress" (p. 26). As he goes on to elaborate, Wilkin argues that this involves the mental health nurse taking up the position of learner, and being taught by the other person. This requires an active participation rather than distant uninvolved observation. It is a process, a conscious and deliberate activity, rather than passive receipt of "data".

The issue of understanding is of central concern to the work of Hans Georg Gadamer in his major work Truth and Method. He does not set out to elaborate a system of rules by which correct understanding is established, but rather, to investigate "what happens to us over and above our wanting and doing" instead of what we do or ought to do (Gadamer, 1965/1975, p. xvi). Grondin (2002) suggests that for Gadamer, understanding has three connotations: 1) understanding as an intellectual grasp, 2) understanding as practical knowledge, and 3) understanding as agreement. As an intellectual grasp Gadamer is following on from Wilhelm Dilthey in that understanding is a comprehension or insight; that is, to make something intelligible. As practical knowhow rather than a possession of facts or knowledge in which activity is a calculation, a 
person is able to exercise a practical skill; for example, as a musician in "knowing" how to play music. Practical knowledge is more about "know-how" rather than theory and hence, involves some degree of self-understanding. To understand is also to agree or to concur. Such a meaning therefore involves partnership around the subject-matter. For Gadamer, agreement is dialogical and occurs through the medium of language. This does not mean that all dialogue reaches understanding. As Grondin points out, "of course, understanding often fails" (2002, p. 42). The notion of agreement is not intended as a perfect consensus, but instead is meant to emphasise that each participant be taken seriously in what is said.

Gadamer's rejects the conception of "knowing" as an act of merely sensory perception and cognitive knowledge as cognition. Instead, he meticulously argues for an "historical and dialectical concept of 'experience', where knowing is not simply a stream of perceptions but a happening, an event, an encounter" (Palmer, 1969, p. 194-195). An experience of understanding is an awareness of not-knowing; that is, "experience is first of all experience of 'not-ness' - something is not as we had assumed" (Palmer, 1969, p. 195. Original emphasis). Basic hermeneutic experience is that our anticipations of understanding have been shattered (Grondin, 2002). Hence, experience has a negative character. We learn by what it is not. From this we learn to leave things open. On this basis it can be said that the accumulation of experience leads to a capacity for better understanding. As an apprehension of expectations being confronted, experience is also an experience of one's finite-ness or limitations.

\section{The hermeneutic circle}

Historically, hermeneutics was developed for the purpose of correctly interpreting biblical texts. The nineteenth century saw hermeneutics drawn into the philosophical debates of the human sciences. With Edmund Husserl (1859-1938), Maurice Merleau Ponty (1908-1961) and Martin Heidegger (1889-1976), hermeneutics took a phenomenological, ontological and existential turn. More recently with Hans-Georg Gadamer (1900-2002), history and language has taken central place in philosophical hermeneutics.

Drawing on the work of Heidegger, Gadamer asserts that the hermeneutic circle is not a formal geometric or logical circle as such, nor a method, but rather is the ontological structure of understanding itself. The notion of circularity is used here to emphasise 
coherence rather than geometry (Grondin, 2002). The circle "describes the form in which the interpretation which produces understanding is accomplished" (Gadamer, 1959/1988, p. 71). The structure of hermeneutical understanding is "the circular relation between the whole and its parts: the anticipated meaning of a whole is understood through the parts, but it is in light of a whole that the parts take on their illuminating function" (Gadamer, 1963/1987, p. 126). The constant shifting between the parts and whole is how an experience is understood. For instance, to reach an understanding of a sentence each part is made sense against the whole sentence. The whole sentence makes sense only when each part is in harmony within the whole. Both the understandings of the parts and the whole are adjusted in a to-ing and fro-ing against each other until there is a harmony between the parts and the whole. It is in the harmony of all the parts and whole that lies "the criterion of correct understanding" (Gadamer, 1965/1975, p. 259).

The circularity of hermeneutics means it is not possible to be outside of the circle. That is, we are always already within the hermeneutic circle of understanding. There is not a beginning or an end. Heidegger uses the term "thrown" to express the historical situatedness of our existence that both constrains and makes possible our understandings. We are "thrown" into a world where language and culture already exists. Understanding a sentence then, to use my earlier example, is an act of projecting ahead to an anticipated whole. From the first moment of reading a sentence it is anticipated that it will be meaningful. The anticipation of meaning that governs our understanding proceeds from our historical situatedness. Understanding a text "begins with foreconcepts that are replaced by more suitable concepts: exactly this constant re-designing constitutive of the back and forth of meaning in understanding and interpreting, is the process which Heidegger describes" (Gadamer, 1959/1988, p. 72). In this, the task then is the working out of the correct fore-concepts and replacing or amending these with more suitable ones. Gadamer goes on to say that "methodologically conscious understanding will be concerned not merely to form anticipatory ideas, but to make them conscious, so as to check them and thus acquire right understanding from the things themselves" (1965/1975, p. 239).

New understanding is always a dynamic project of anticipating, modifying or replacing already existing concepts: 
...every revision of the fore-project is capable of projecting

before itself a new project of meaning, that rival projects can

emerge side by side until it becomes clearer what the unity of

meaning is, that interpretation begins with fore-conceptions

that are replaced by more suitable ones. This constant

process of new projection is the movement of understanding

and interpretation. (Gadamer, 1965/1975, p. 236)

\section{Tradition and prejudice}

Gadamer disagrees with the Enlightenment positioning of reason in opposition to prejudice, asserting that reason cannot operate outside of tradition. For Gadamer, the very possibility to understand is formed on the basis of prejudice. Prejudices, or prejudgements, are our initial standpoint or expectations and assumptions on something. This initial position is relative to a tradition of language, culture and history. The "knowledge that an individual or community has of a particular object domain is not that individual's or community's product alone but that of history" (Warnke, 1987, p. 79). Wachterhauser puts it similarly, stating that "tradition sets the normative context of inquiry for a community of learners" (2002, p. 58. Original emphasis). Wachterhauser further explains that as a normative tradition it sets the boundaries, at least initially, for what is acceptable in terms of, for example, research questions that can be asked and even the acceptability of answers. Traditions of inquiry also have their own conceptual language that is itself historically constituted:

We are always already biased in our thinking and our knowledge of the world. To grow into this linguistic interpretation means to grow up in the world. To this extent, language is the real mark of our finitude. It is always beyond us. (Gadamer, 1976, p. 64)

While prejudice enables the possibility of understanding, all that we bring with us to the task is not conscious or fully knowable. Hence, prejudice cannot be fully articulated and therefore we are not free to separate productive prejudices from hindering prejudices in advance. Gadamer states instead, that this separation must take place in the process of understanding itself. It is the task of hermeneutics to ask how this happens. In doing this, critical reasoning cannot be set aside; that is, not any understanding will do. Gadamer argues that the task of hermeneutics is not to simply passively accept prejudice in the process of understanding, nor to develop a procedure of 
understanding, but to "clarify the conditions in which understanding takes place" (Gadamer, 1965/1975, p. 263).

\section{Effective-history}

In Gadamer's view we belong to history. By effective-history Gadamer is referring to a "history of influence" (1959/1988, p. 78) Gadamer sees all understanding as determined by the past and that all understanding takes place in tradition. Effectivehistory is present in all understanding whether we are aware of it or not. Understanding is therefore an historical experience in the sense that the past determines the future. Gadamer takes the position that we do not rationally calculate the world but rather, that we experience our being-in-the-world, and that this experience is historical. For science, facts stand outside of time and place whereas for Gadamer all knowledge proceeds from what is historically pre-given as "essentially, an effective-historical relation" (Gadamer, 1965/1975, p. 267). In any process of understanding, we are unable to achieve some objective point outside of history so as to look down upon it, because we are already in it the moment we try to grasp at comprehending something.

Understanding and meaning is therefore not fixed, but bound to history through prejudice and tradition. Understanding is an historical experience in which history has a productive effect. The power of effective-history does not depend on it being recognised. It is rather, an element in the act of understanding already at work, for instance, in the anticipated understandings brought to bear on something to be comprehended. The effects of effective-history also mean that it is determined "in advance both what seems to us worth enquiring about and what will appear as an object of investigation" (Gadamer, 1965/1985, p. 268). Gadamer calls attention to the fact that in all understanding there is this historical element and that we will "miss the whole truth of the phenomenon when we take its immediate appearance as the whole truth" (Gadamer, 1965/1985, p. 268). The task of hermeneutics must therefore be conscious of the effectivity of history in understanding.

However, because we are already in an historical situation and unable to look from the outside, effective-historical reflection cannot be completely achieved (Gadamer, 1965/1975). This is not due to a lack of reflection, but is the nature of historical being. That is, being historical, we can never completely know ourselves. Since we cannot fully know all of history, our agency is limited by what we can make explicit and therefore 
subject to critical reason. We are therefore autonomous within historical tradition even when we do not know where it has come from or what its ultimate goal is (Wachterhauser, 2002, p. 62-64). Gadamer uses the term "finitude" to describe this experience of our "dependency of knowledge on conditions the human knower can never fully know" (Wachterhauser, 2002, p. 56). That is, historical experience is the experience of our limits or finite-ness to our knowledge.

While inappropriate or hindering prejudices come to nothing in the to and fro process of understanding, the full potentiality of that understanding is reached when their use are not arbitrary. This is not to imply that prejudices are freely chosen, but a call to consciously examine the legitimacy, or origin and validity, of these initial understandings (Gadamer, 1965/1975, p. 237). While understanding is an everyday event, what Gadamer proposes here is a radicalisation of the everyday. That is to say, while hermeneutic understanding occurs as an everyday automatic and unexamined event, for hermeneutic enquiry, a consciousness of meanings and history is needed. Rather than adopting some attitude of "neutralness", Gadamer calls for the "conscious assimilation of one's own fore-meanings and prejudices" and to be "aware of one's own bias, so that the text may present itself in all its newness and thus be able to assert its own truth against one's own fore-meanings" (Gadamer, 1965/1975, p. 237). This presumes a preparedness to be open to modify, reject, or maintain the initial standpoint in a conscious way. To do this involves the development of an awareness of the "newness" or "otherness" of the thing. For instance, "a person trying to understand a text is prepared for it to tell him [sic] something. That is why a hermeneutically trained mind must be, from the start, sensitive to the text's quality of newness" (Gadamer, 1965/1975, p. 238). This happens through consciously standing in one's own (historical) tradition, rather than attempting to stand outside of it or bracketing it aside. To do either would be a denial of historical reality. Gadamer (1963/1987) cautions that prejudices can dominate us and impair true recognition of the historical past, however, without prejudice and a readiness for self-criticism, historical understanding would not be possible nor meaningful.

\section{Fusion of horizons}

For Gadamer, horizons are a metaphor for the range of meaning that has come out of one's own history, language and culture. An horizon is the range of view that encompasses all within it from a particular vantage point. From an horizon, the relative 
significance of everything in view is established. Hence, to acquire an horizon also means looking beyond what is close in order to see in better proportion what is close at hand (Gadamer, 1965/1985). By way of contrast, if a person does not have an horizon then that which is nearest tends to be overvalued. Hekman (1986) notes that as horizons are particular points of view, and encompass a range of meanings, they are therefore also finite. Nevertheless, an horizon can also be expanded through what Gadamer terms a "fusion of horizons." Gadamer construes understanding as a dialogical event in which one's own horizon is expanded through a conscious assimilation of an other's horizon (Gadamer, 1965/1975). This is a continual process that is always happening and always relative to what is historically pregiven through prejudice and tradition.

However, by fusion, Gadamer does not mean simply understanding the other's historical horizon in terms of knowing the standpoint of the other, nor is it merely stepping into the situation of the other as if to "see through their eyes". In doing either of these, there is no seeking of an agreement in which our own standpoint is consciously brought into question. To understand the other as a fusion of horizons then, does not mean leaving our own horizon, nor making the horizon of the other into an object. The notion of fusion means to let into our ontology something alien, unfamiliar, or something that is other. In the interplay, or to-ing and fro-ing, between the two horizons of unfamiliar (i.e. otherness) and familiarity, the claim to the truth of the other emerges. Taylor (2002) states that to be challenged by others means that we also see our own peculiarity for the first time, rather than simply remaining taken-for-granted and invisible. In being challenged we will also see a corresponding aspect of the other as undistorted. It is to hear the other undistorted that Gadamer means by "truth"; the truth of the other. Nonetheless, these new understandings will not be perfect; they remain open to refinement.

For Gadamer, the prerequisite for understanding is to therefore have our own horizon rather than abandoning it for the other. The hermeneutical task is to make the fusion a conscious act. In Gadamerian terms, the meaning of "placing ourselves" in the situation of the other in order to understand, is to "become aware of the otherness, the indissoluble individuality of the other person" (Gadamer, 1965/1975, p. 272). This requires a commitment to openness:

In human relations, the important thing is, as we have seen, to experience the 'Thou', truly as a 'Thou', i.e. not to overlook 
his [sic] claim and listen to what he [sic] has to say to us. To

this end openness is necessary. (Gadamer, 1965/1975,

p. 324)

An important concept within interplay of understanding then is the putting of our prejudices at risk in the fusion of horizons; as prejudice is only properly in play when put at risk of being rejected or amended. Again, this is not to say that we give up our own prejudices, but rather, to be consciously situated in relation to the horizon of the other (Gadamer, 1963/1987). The requirement here is for an effective-historical consciousness. The experience of understanding is "to have insight into the limitations within which the future is still open to expectation. Thus, true experience is that of one's own historicality" (Bleicher, 1980, p. 113). While a range of understandings are therefore possible, understanding can legitimately only occur within the limits dictated by the fusion of horizons. Openness and awareness of the newness, otherness, or unfamiliar in the text, as well as a readiness to put our own prejudices at risk in a question and answer dialogue with the text, permits an effective-historical consciousness.

\section{The process of question and answer}

Bleicher (1980) describes Gadamer's explication of understanding as hermeneutic and dialogical. This is because Gadamer explains understanding using the model of conversation whether the experience of a fusion of horizons is with a text or a person. The development of understanding is analogous to the dialogue of question and answer. That is, there can be no understanding without questions. Once questions cease, so does learning (i.e. understanding). In particular, Gadamer is arguing that the question-answer dialogue has as its foremost task to find the question to which the text (or person) presents an answer. Putting this another way, if something is not as first expected then there is an implicit question about the object. In this sense, the text (or other) poses questions from its own horizon. However, hermeneutically, to answer the text we must ask questions.

The process of question and answer however, is not proposed as a method as "there is no such thing as a method to learning questions" or of "learning to see what needs to be questioned" (Gadamer, 1965/1975, p. 329). It is more that the text evokes the question in the experience of understanding. The other, be it a text or person, demands 
to be recognised and listened to and agreed with in the process of understanding, and in this way both are tied together; fused. The logic of question and answer means that the very meaning of a sentence is relative to the question to which it answers; and therefore the comprehension of the sentence is as open or as limited by the horizon of meaning of the question. There is a demand then for a form of partnership and openness in the process of dialogue. The openness of what is questioned is in the fact that the answer is not settled; the to-ing and fro-ing continues. Once settled (including to agree to disagree) it may be said that the object in question is understood; hence, learning ceases once questions cease. The question to which the text (or person) has an answer however, is derived from an horizon and is therefore as open or limited as its horizon dictates. Hence, a question can be right or wrong. A question can also be false when it fails to achieve a state of openness, or may be distorted when there can be no real answer. From Gadamer's perspective, the question must bring the object into a state of indeterminacy if it is to be a true question. The purpose of questioning is to make a thing indeterminate.

\section{Linguisticality of understanding}

The dialogical process of question and answer becomes possible only through the medium of language. Gadamer asserts that it is language that mediates any access to the world. Hekman (1986) argues that it is the linguisticality of understanding that is the most important aspect of Truth and Method. It is in the medium of language that the mediation of past and present occurs in the fusion of horizons (Bleicher, 1980). For instance, the language I use to understand things is mine and belongs to the present context even if it is some ancient text before me and comes out of a past context. The experience of understanding, as linguistic, is an experience of our limitations. All contexts are at least partially constituted by language; we therefore understand ourselves in the world through language (Wachterhauser, 2002). That is, we grow up within the world. As our language is particular to our place in history our grasp of the world will be limited. However, Wachterhauser notes that the "fact that we cannot attain certainty, it does not follow that we cannot attain knowledge" (2002, p. 70). Gadamer has termed this human "finitude". This does not mean that with language everything is understandable and can be expressed in words; but rather, that words are sought for everything that is to be understood (Grondin, 2003). 
That we start with anticipated meanings and our own language in the hermeneutic of understanding, means we are at risk of using words that we see are proximate to the other and erroneously carry through all that the word means without opening the meanings of words up to question. This can be difficult because of our investment in our current understanding of self and consequently an investment in the distorted image of the other. To understand the other would require a changed understanding of self (Wachterhauser, 2002). What is critical then is the nature of participation in the event of conversation where words are searched out to convey meanings and then put to the test in dialogue.

For Gadamer, language is the mediation of past and present and all understanding without being in a fixed position: "language is the fundamental mode of operation of our being-in-the-world and the all-embracing form of the constitution of the world" (Gadamer, 1966/1980, p. 147). While we understand the world in an automatic way, Gadamer asserts that we understand it through our own language and not an other's language. Language is not fixed, it develops and changes over time. Our language is different to an other's language because of the particular challenges and hurdles taken to achieve understanding within each tradition. Within language is therefore history; and so, language gives effect to history.

Contrary to our Enlightenment inheritance, particularly through positivist science, it is clear that Gadamer does not see language used as a tool, such as a system of signs that represent the world, or through which we are able to somehow manipulate our world. There can be no point of view outside the world of language so that the world can become an object of language. Gadamer sees a relationship between words and the world, for Gadamer, "words make the world more intelligible and accessible than it would be without words" (Wachterhauser, 2002, p. 67), so that words do more than mirror the world as a representation. The world is interpreted as if the word and the world are in dialogue due to some degree of common intelligible meaning. The world, and objects in the world, are unintelligible without words. At the same time, Wachterhauser argues that Gadamer asserts a compatibility between the word and the world where experience acts as a corrective for "getting it right":

Judgements of correspondence between word and world are possible because we don't need to stand outside of language to make them. Instead our experience can mediate between 
language and the world because all three are in principle "intelligible." If this is so, we can speak again about "getting it right" even though "getting it right" is relative to interpretation. (p. 77)

Clearly then, Gadamer argues that a text cannot be viewed with regard to the author's intentions, but for what the text addresses to us at an historical distance; that is, the subject matter within the text. Gadamer argues that the interpreter understands in a different way to the author and, if understanding has occurred at all, understands differently. In this sense, "the meaning of a text goes beyond its author" (Gadamer, $1965 / 1975$, p. 264). Through the activity of the interpreter, the text has meanings the author may not have been aware. Through interpretation the text is reconstructed, not as a repetition or replication, but emerges as something different. Interpretation is not a duplication, but a creation in the present. The past then is forever being re-interpreted, that is to say, understood differently. In this way the text is not so much an expression of life, but is taken seriously in its claim to truth. Bleicher (1980) summarises the process as follows:

The interpreter is, therefore, first aware of a distance between the text and his [sic] own horizon which leads, in the process of understanding, to a new, comprehensive horizon transcending the initial question and prejudices. The experience he [sic] makes in the course that leads to a new understanding is a hermeneutic one and essentially different from the experience that underlies the formulation of scientific methods. (p. 112-113)

Gadamer (1984/1989) asserts that what makes understanding possible is "the forgetfulness of language, a forgetting of the formal elements in which the discourse or text is encased" (p. 32). Gadamer is arguing that we do not calculate the words to understand an other but understand through language in an automatic kind of way. Hence, for understanding to be possible at all speech must be intelligible and a text be readable. Where this is not the case, interpretation is necessary, arising as a mediating process between the text (or other) and the reader when the text is in some way unintelligible or in dispute. The requirement is for the interpreter to be inserted in between the text and the reader in order to convey "not what the speaker or writer originally said, but rather what he [sic] would have wanted me to say" (Gadamer, 1984/1989, p. 35. My emphasis). In arguing this, Gadamer regards the text as a phase in 
the process of communication that the interpreter facilitates, and does so by referring back to the original communicative event; the interpreter "serves" the text. In overcoming the difficulty in the readability of the text too, is a hermeneutic fusion of horizons as the interpreter is involved in mediating understanding.

\section{Methodological process}

As the discussion above shows, Gadamer's work is a philosophical investigation rather than an exposition of method for the human sciences. Accepting Gadamer's position on understanding then requires a different approach to that of the natural sciences and, according to Hekman, "calls into question the very notion of method" (1986, p. 95). The kind of understanding that Gadamer asserts is one that is always historically and linguistically positioned and includes both parties (e.g. the text and the reader, interpreter and interpreted, etc). This position then is one that seeks to "comprehend", "have insight" into, and "make intelligible", the human world.

\section{Conversation and text}

Although Gadamer argues very strongly against a methodical approach to truth, this does not mean the study of human sciences is not possible, nor does it mean that hermeneutics is not relevant to the methodology of human sciences (Hekman, 1986). Gadamer's ideas have been usefully explored by, for example, Ricoeur (1971), and more latterly by Hekman (1984) as a methodology for the exploration of social action. However, in this study I am not seeking to explain or understand social action as such but rather, to comprehend or understand the experience and meaningfulness of suicidality through dialogue with others (i.e. men).

Gadamerian hermeneutical understanding, understanding a text or spoken event, involves speech-partners in dialogue out of which communal life is created:

The ability to understand is a fundamental endowment of man [sic], one that sustains his [sic] communal life with others and, above all, one that takes place by way of language and the partnership of conversation. (Gadamer, 1984/1989, p. 21)

Understanding then is not something that we plan and control but is participated in with others. We experience understanding in dialogue when it runs counter to what we think; bringing us up short, forcing us to think, at the same time bringing something into a state of indeterminacy. For Gadamer, "the extension of the concept of text to include 
oral discourse is hermeneutically well grounded" (1984/1989, p. 33). The term "conversation" signals a verbal to-and-fro process that is more organic than in say, a rule-based (therefore structured) face-to-face interview designed to eliminate variation between interviews.

A "text" is not simply intelligible letters on a page, it is "a phase in the execution of the communicative event" (1984/1989, p. 35). In the hermeneutical process of understanding then, a text is not the beginning and ending of understanding, but a part of the whole. Texts become a central point for Gadamer through the relationship to interpretation and language:

\section{The point that must be firmly adhered to is that only on the basis of the concept of interpretation does the concept of the text come to constitute a central concept in the structure of linguisticality; indeed, what characterized the concept of text is that it presents itself only in connection with interpretation and from the point of view of interpretation, as the authentic given that is to be understood. (1984/1989, p. 30)}

In the task of interpretation, Gadamer cautions that something understood should lead back to the original communicative situation. With spoken conversation, intonation and gesture are part of the check and balance between participants used to assist understanding that are not fully communicated with spoken conversation fixed as text; say, as a transcript. Insofar as the checks and balances are part of the dialogue, such conversations are not writings to be later read as text; so that "writing is more than a repetition in print of something spoken" (Gadamer, 1984/1989, p. 34). Hermeneutical understanding occurs at the time of the communicative event as a text. The openness and indeterminacy in hermeneutical understanding are not fully revealed in transcripts of conversations. This is because in writing that is intended to be read, the author is already aware of the reader and conscious of the need to communicate in such a way that the work can stand on its own. While understanding of a text must involve referring back, "it must equally look forward; for all that is said is always already directed toward understanding and includes the other in itself" (Gadamer, 1984/1989, p. 34). In reading a text, which is, of course, separated from its author, the reader engages in a dialogue with the text in itself. In a sense, the text talks to the reader evoking questions. However, texts can be regarded in this way. Conversation transcripts do not possess the additional non-verbal interaction that made the original speech intelligible. Nonetheless, 
transcripts (e.g. of researcher-participant conversations) might be regarded as an historical record of the conversations that have taken place though requiring interpretation. As historical records conversation transcripts cannot be regarded as equivalent to the original communicative event. Clearly there are two historical events: firstly, the original communicative event of the conversations, and secondly, a reading or dialogue with the transcripts; that is, an interpretation.

\section{A double-hermeneutic approach}

Although as researcher I would be present in both the original communicative event and the later interpretation, my horizon of understanding progressively widens as I am transformed (i.e. a fusion of horizons) by ongoing understanding. However, the horizon of the other person also changes in a critical way. In the first instance, the horizon of meaning is that of the participants which they bring to the conversations, while in the second instance, the horizon of meaning is that of the transcripts as an historical record. To understand transcripts of these conversations, because they are unable to stand on their own as "writings", there is a necessity for interpretation. Correct interpretation must consider the historical horizon of the text (and researcher) and cannot merely consider the literal meaning of the words. It is worth noting that in any case it is usual for transcripts of spoken conversation to require "cleaning" in order to be intelligible, and have therefore already undergone a preliminary form interpretation. To make transcripts then understandable Gadamer calls for this to be done in a conscious hermeneutical way.

Hermeneutically, it does not make sense to speak of a beginning to understanding so even as I refer here to an original communicative event (being that of the research conversations), these are not an actual beginning to an understanding, entry into research conversations is intentional, with a view to their future significance and hence sit within history. Research interviews such as took place for this current study, were preliminary conversations by telephone; even preliminary "warming up" talk prior to settling down to a recorded conversation. To say that the recorded face-to-face conversations are the original communicative events then is merely an historical reference point.

As the conversations for this study are recorded and then fixed through transcription, the transcripts provide a further opportunity to consider these conversations differently. 
Considered as historical (textual) records, there are two phases of hermeneutical understanding which need to be made conscious: firstly, an understanding of the participant conversations, and secondly, an interpretation of the transcripts. In the process of understanding, my horizon as researcher will already be widened prior to interpretation of the transcripts.

\section{My horizon as researcher}

The motivating force throughout understanding is derived from the researcher's horizon of meaning because the hermeneutical situation "is determined by the prejudices that we bring with us" (Gadamer, 1965/1975, p. 272). Such prejudices constitute the horizon of a particular present. Accordingly, if the horizon of the enquirer shifts, then questions evoked by the encounter with tradition will also shift. There is therefore, more than one "right" horizon and more than one "right" interpretation. An horizon is not something that we can freely choose, nor something we can be outside of and completely see. An horizon is not fixed; as history doesn't stop, our horizon moves with us as our situation changes. Horizons then are in motion:

through the testing of our prejudices in the encounter with the past and the attempt to understand parts of our tradition. An horizon is therefore not something there to be discovered, but instead, is always happening. It is therefore inadequate to conceive of an isolated horizon of the present since it has already been formed through contact with the past. (Bleicher, 1980, p. 112)

Or, as Gadamer phrases it: "the horizon is, rather, something into which we move and that moves with us" (1965/1975, p. 271). An horizon then is one's historical situatedness; the situation from which one meets the other. The task in conversation or in reading is to experience the tension or temporal distance between the "text" and the present. That is, we must recognise the text in its otherness and therefore having its own horizon. In the process of dialogue, a fusion of the two horizon produces a widening of my own horizon as interpreter/researcher. That is, a new understanding is formed.

Gadamer's position reverses the methodical process of the natural sciences in that the prejudices upon which an experience of understanding takes place are only known historically and cannot be set beforehand; as an historical experience, we "stand in the midst of an event without knowing what is happening to us before we grasp what has 
happened in looking backwards" (Gadamer, 1984/1989, p. 24). Although it cannot be fully known what constitutes the horizon of meaning beforehand, "methodological conscious understanding will be concerned not merely to form anticipatory ideas, but to make them conscious" (Gadamer, 1965/1990, p. 239). This is accomplished in the interpretive process in which "explicit reflection is required on the conditions that enable the text to have one or another meaning" (Gadamer, 1963/1987, p. 90). The formation of new understandings can reveal something of the old through the challenge or confrontation of prejudices in the working out of a new understanding. The experience of understanding something entails a confronting and questioning, suggesting that new understanding would not be new unless it was asserted against something that had been expected. It is in this being brought up short that what had been anticipated is revealed; at least as a shadow of the new understanding.

The task then is to hold open to challenge as much as possible on what is to be understood through dialogue. In this regard, Gadamer suggests that there must be "good will" on behalf of both speech-partners to be open to hearing the truth of the other. In contrast, understanding does not occur when seeking to have one's own opinions upheld by stridently overwhelming the other's words. Although different in each hermeneutic phase, the task in this study is to approach participants' suicidal experience as "unfamiliar" or "foreign"; to ask questions that cast my own opinions with doubt, requiring understanding to be considerate of the horizon of meaning of the other, be it the participants or the transcripts. As understanding a "thing" is a process of modifying anticipatory ideas, preliminary ideas form the foundations of the situatedness of interpretation. The discussion above clearly shows that such pre-conceptions need to be put at risk to be modified, rejected, or elaborated upon. In this way, seeking to get behind the everyday taken-for-grantedness of these anticipatory understandings.

Hermeneutically, this study has no clearly defined beginning. The process of understanding is already happening without knowing the process of it, and its anticipatory ideas have historical origins from many directions and cannot be fully known beforehand. Which of these are hindering or facilitating prejudices is worked out through the hermeneutical to-ing and fro-ing of understanding.

My personal life history, and the culture and language into which I have been "thrown" is likely to be important as anticipatory understandings that I bring into this study. The 
specifiers to my own historical, linguistic and cultural background can be endless. To attempt an autobiography, as a means of describing my history and culture would only ever present only a partial picture. From an hermeneutic viewpoint, there is no means to step outside of this history in order to look down upon it in its entirety, so my beginning awareness is itself derived from within the history I am would be attempting to explicate. It is also important to recognise that my historical background extends beyond my lifetime in the culture and linguistic tradition I have grown up in. For instance, to say that I am a white, university-educated, adult male calls upon a particular history. I have benefited in manifold ways from this history that has privileged white, educated, heterosexual, adult males.

As a study that seeks to inform mental health nursing, a strong body of anticipatory understandings are likely to derive from being personally embedded within a tradition of mental health nursing. A strong motivation for this study is that the experience being explored is important to this profession. Mental health nursing has its own history and worldview, that is in turn, influenced from many other traditions, for example, medicine and psychology.

Not only is the interpretive horizon of meanings constituted by my own personal and professional history and the traditions in which these sit, but also the horizon formed by the theoretical conceptualisation of the study itself. In opposition to the deterministic view of masculinity I have taken the view that masculinity is a social construction in which men are active (and also constrained) agents. "Problematising" masculinity is political in the sense that mainstream health research does not usually view masculinity of itself as an issue, instead it is usual to view adverse health outcomes as a problem associated with being a male (e.g. by statistical association to sex categories).

Being a man attempting to "trouble" the notion of masculinity is fraught with political difficulty. There is a political and personal struggle that needs to be acknowledged here. This revolves around an uneasy tension between my conscious focus on men's experience and the effort to uncover the taken-for-granted within suicidal experience. Feminist writers have clearly shown the taken-for-grantedness of men's centrality in such diverse aspects of social life as: scientific endeavour, marriage, religion, language, the courts, employment, and psychiatry. Indeed, it has been proposed that one cause of men killing themselves is marital breakdown (Durkheim, 1897/1952), and to support 
this assertion, writers such as Durkheim have turned to the so-called "breakdown" of taken-for-granted social structures such as marriage. Difficulty too is encountered, in the use of language to argue out the thesis. Spender (1980) has for instance, highlighted the gendered nature of language, asserting the male-centricity of language. However, such male-centricity poses challenges when talking about men as men. By this I refer to the hermeneutic position that I can never be outside the circle; I cannot use any other language (and subsequently, a particular linguistic and cultural history) than that into which I am thrown. As man-made language (to draw on the title of Spender's book), in which men are the normative reference, there is no other language available to step outside and look upon men.

\section{Towards a fusing of horizons}

The methodological concern here, drawing on Gadamer's philosophical investigation of understanding, has been to develop an overarching approach from which to explore experiences of suicidality. In doing this, and at the same time remaining centrally concerned with a position on mental health nursing in which understanding is about engaging with the other person meaningfully, the way in which understanding happens is the focus of concern. As researcher and as a mental health nurse, I am part of the process of understanding; in Gadamerian terms, I bring my horizon to the encounter and a preparedness to put my prejudices at risk. Gadamer's draws attention to the hermeneutical task rather than a particular method. For me as researcher, the requirement is to make the conditions in which understanding takes place as explicit as I am able.

Insofar as method is applicable, the requirement from a Gadamerian perspective is for a dialogical partnership in which speech or text presents the horizon of the other. In the case of this study, a double hermeneutic approach is proposed in which both forms of dialogue occur. The following chapter details the way that dialogue occurred in this study in which I set out to understand four men's experience of their past suicidality. 


\section{Chapter 6}

\section{METHOD AND ANALYTICAL PROCESS}

Drawing on the methodological position outlined in the preceding chapter, this chapter describes how a methodology informed by Gadamer's philosophical hermeneutics was enacted for this current study. In doing this, the discussion will cover ethical issues, the method adopted for the conduct of the research, and the process of interpretive analysis. In practice, there is only a notional separation between methodology, ethics, method and interpretive process. Each is informed by the other and there is no clear dividing line.

\section{Ethical issues}

To achieve the aims of this study, a proposal was put to the Human Ethics Committee of Victoria University of Wellington to recruit a small number of men who had past experience of suicidality to participate in in-depth interviews about their experiences.

The proposal for this study was approved by the Human Ethics Committee of Victoria University of Wellington (Appendix A) on $22^{\text {nd }}$ March 2002. This approval was later extended to 31 December 2004 (Dr. A. Kirkman, personal communication, March 17, 2004). As a Registered Nurse, the ethical application also encompassed the Code of Conduct for Nurses and Midwives (Nursing Council of New Zealand, 1998) and the Standards of Practice for Mental Health Nurses in New Zealand (Australian and New Zealand College of Mental Health Nurses, 1995).

In the light of ethical principles and the professional standards of conduct, this study raised several particular ethical issues of note: a) the potential vulnerability of participants, b) the particular consent, privacy, and confidentiality issues for this group of people, and c) the moral standpoint and ethical requirements to conduct the study in a respectful and transparent manner. These are discussed in more detail below. This is 
not to say that these were the only ethical issues, but were particular to the nature of the issues involved in the conduct of this study.

\section{Vulnerability and self-determination}

The earlier review of suicidality and men's mental health shows that the nature of this study required exploration of an issue that is currently viewed within a medical model to be the result of a mental illness or as equivalent to mental illness. Consequently, suicidal men are seen as a vulnerable group requiring special precaution around their mental health status. From this perspective it is thought that discussion of past suicidal experience might exacerbate risk, and hence, require special precautions. The design of the study sought to ameliorate such possible risk by firstly, seeking participants from the general public rather than clients of mental health services who were already assumed to be at a higher level of risk due to diagnosed mental illnesses and secondly, excluded men who felt they had been suicidal in the last three months, irrespective of intervention or not.

Men who had recently experienced major depression or a psychotic illness were also excluded for methodological reasons; that is, the recency of such a profound experience would potentially overwhelm reflections on the focus of this study. The meaningfulness of understandings would be expected to be markedly influenced by the power and recency of psychotic events; their horizon of meanings would, in all likelihood, be dominated by the experience of psychosis.

As well as these exclusions written into the Information Sheet (Appendix B), they were also specifically discussed within the information and consent process. Additionally, I discussed the necessity to monitor risk of serious harm to self or others. At the same time, discussing resources the resources available for participants to obtain counselling for any distress arising out of our conversations. I offered an initial counselling session at no cost to participants. Although the research conversations could be ceased at any time by participants, the availability of some level of support in the event of later distress was also considered. To this end, our preliminary discussion also explored the social networks immediately available to participants (including telephone counselling services). Ultimately each of the four men who participated in this study requested these services. Additionally, in my follow-up with these men, they each expressed some initial concern that they may experience serious distress, but that this had not occurred. 
A further mechanism to assure the well-being of participants was the engagement of a clinical supervisor experienced in the mental health field for the duration of the fieldwork phase of this study. The primary purpose of supervision was to reflect on the interactions with each of the participants in order to review issues that may need further attention. Supervision also served the additional purpose of providing self-care for me in the event that the exploration with participants provoked unresolved issues for me.

While the purpose of the initial meeting with participants was for me to assure the safety and well-being of participants and ascertain if both the inclusion and exclusion criteria were met, it was also a point in time where the potential participant also sought to assure his own safety and trust in me. Participants therefore had their own questions and ways of evaluating my trustworthiness. The issue of trust became a major theme within the study itself.

The initial meeting with participants was also an important point to set up the openness and dialogical character of our interactions which the successful conduct of a Gadamerian approach required. Additionally, without openness and a willingness to facilitate understanding, genuine choice to participate or not, cannot occur. The explanations and discussion of the Information Sheet and Consent Form (Appendix C) were important features of this process, setting up a basis for creating dialogue and openness. Given the likelihood of contact with mental health services and the possibility of past experience with compulsory treatment, transparency of processes around confidentiality, voluntariness, and how suicidal risk would be approached, were considered essential features and explicitly discussed. I discuss these issues further, below.

\section{Privacy, and confidentiality}

To assure privacy and confidentiality, the presumption put to participants was that pseudonyms would be used in the thesis and within any further publication, and that this name could be of their own choosing if they wished, or I could choose a name. Ethical approval was granted on this basis. However, this presumption of protecting identity and the means to address it raised a particular issue for one of the participants. One participant preferred his real name to be used rather than a pseudonym. The assumption of protecting identity is argued to be particularly important for marginalized and stigmatised groups (Kirkman, 2001; Peterson, 1998). He wanted to use his real 
name on the basis that a major factor in the history and perpetuation of his abuse was the secrecy and silencing around it. This posed a dilemma, as disclosure of his identity would in turn identify others involved in this history without their consent. Given the relatively small size of the population of New Zealand and the depth of detail in the interviews, care was particularly needed around contextual detail to not only protect participants, but also to maintain the privacy of others (Tolich, 2001); in this case, people who were abusive to him. Alternatively, excluding him from the study on this basis would again be an experience of being silenced. As well as discussing the issues extensively beforehand, this subject also arose during the recorded conversations as part of the focus on suicidal experience.

Given that the methodology used in this study is personally situated and there is a depth detail to potential quotes, identifiability through the context of the conversations is a potential risk. In addition to the use of pseudonyms, both the identity of locations and circumstances have therefore been either modified or deleted from the quotes used in this study. These changes were also made in the transcripts that participants received for review. In conversations with clinical and academic supervisors, only pseudonyms were used; and as far as possible, no identifying events or contexts are mentioned. Nonetheless, even with these precautions there is a small possibility of identifiability and the Information Sheet acknowledges that the use of quotations in the study does carry with it some level of risk to the maintenance of confidentiality.

\section{Respectfulness and transparency}

The underlying philosophical tenets of "understanding" as dialogical, emphasise the need for respect and transparency. Gadamer's philosophical hermeneutics have an inherent ethical sense in that the truth of what the other has to say cannot occur if the other is kept at a distance and one's own prejudice or presuppositions are not put at risk; "both partners must have the goodwill to try and understand one another" (Gadamer, $1984 / 1989$, p. 33). There is a necessity to acknowledge one stands within tradition in order to extend it through dialogue. Equally, this demand to put preunderstandings at risk does not exclude the possibility of agreeing to disagree.

For instance, my history as mental health nurse was a significant aspect of my horizon as of understanding suicidality; while at the same time, mental health professionals have significant power with respect to people with a mental illness. One aspect of respect and 
transparency therefore needed to include how I, as a mental health nurse and researcher, would impact on the dialogical relationship. Questions arise as to how what is said and not said, will be interpreted during our contact, both clinically and analytically. What is the nature of my connection to mental health services? Ethically and methodologically, respect and transparency necessitated explicit discussion of these issues from the moment of first contact with potential participants, including through the Information Sheet and Consent Forms. Thus, both forms included disclosure of my profession and how my perception of clinical risk would be managed.

In this study, it is methodologically explicit that my "personal biography" influences the research design, process, and content. However, as the earlier discussion of methodology also shows, this cannot be fully known. Whilst good ethical conduct necessitates a careful and self-conscious identification of this influence, a Gadamerian perspective suggests that this task cannot be fully achieved. Nonetheless, the hermeneutic (and ethical task) is to continue to make explicit those presuppositions upon which my understandings are constructed as explicit as is possible.

A Gadamerian hermeneutic approach demands putting pre-understandings at risk; to open these up for question wherever possible. As an ethical practice, openness as well as historical consciousness cannot be restricted to specific tasks of the research conduct (e.g. Information and Consent Forms, recruitment, "data collection", etc.), but must inform the total process of the research endeavour. At the same time respect and transparency are methodological issues, they are also ethical issues. This means that issues of method are also issues of the application of ethics.

\section{Method}

Gadamer critiques methodical prescription as the pathway to truth and does not prescribe a method or process to understanding and instead, argues that hermeneutics transcends method. Rather than a focus on method, Gadamer calls attention to the conditions of understanding. Insofar as the notion of method may be applied to this study then dialogue, how it occurs and is then recorded, become the methodical issues. As may be seen in the summary of the method set out in Table 4 (p. 25), the second column describing how Gadamerian hermeneutics is translated into the conduct of this study, is centrally concerned with dialogue. 
Table 4. Summary of method

\begin{tabular}{ll}
\hline Research dimension & Gadamerian approach used in this study \\
\hline Participants & $\begin{array}{l}\text { Men who have an understanding of self as having been } \\
\text { suicidal. }\end{array}$ \\
Researcher & $\begin{array}{l}\text { Explicitly engaged within a process of understanding others. } \\
\text { Sensitivity to the "otherness" of suicidal experience. } \\
\text { Mode of data collection }\end{array}$ \\
$\begin{array}{l}\text { Spoken dialogue, conversational, question and answer style. } \\
\text { Researcher and participants are focussed on understanding } \\
\text { "suicidality". }\end{array}$ \\
"Data" for analysis & $\begin{array}{l}\text { i) spoken conversation, ii) researcher memos, iii) } \\
\text { conversation transcripts. }\end{array}$ \\
Mode of interpretation & Double hermeneutic. \\
\hline
\end{tabular}

\section{Recruitment of participants}

A small number of men were sought for in-depth, focussed dialogue on their past experiences of suicidality. A follow-up interview was planned; firstly, to offer participants the opportunity for reflection and contribute further if they wished, and secondly, to provide an opportunity to clarify issues arising from consideration of the earlier interview. Two interviews also permitted the process to be broken up into smaller lengths in what was potentially an emotionally draining exercise for both the participants and myself as interviewer. These interviews were recorded and transcribed. In addition, I made supplemental notes following each interview recording my impressions of physical context, my personal response, and of any notable events that occurred.

As the issue of concern for both myself and the participants was experiences of suicidality, and not characteristics of the men themselves as such, the aim of recruiting participants was to seek men who could inform me of their suicidal experiences. That is, it was not different men that were required for the study but rather, men who have had different pertinent experiences. However, the problem was to recruit such men without predetermining what constituted suicidal experience. For example, I did not want to assume that being suicidal was fully defined by behaviour labelled "suicide attempt." In recruitment I was therefore careful to give permission for participants to define for themselves what constituted "being suicidal."

Recruitment was reliant on personal networks rather than any particular sampling framework based on the methods of positivist science. This approach is sometimes termed an "incidental" or "opportunistic" approach to recruitment (Minichiello, Aroni, 
Timewell, \& Alexander, 1990). The study was not advertised; although some third parties did put up notes about the study in public locations. Potential participants, or some other trusted person on their behalf, was asked to contact me in order for me to then contact the potential participant. In some instances a request for further information about the research was needed before this contact was made. I had no means of knowing if the person contacting me was a potential participant or third party unless they chose to tell me. These approaches therefore involved much discussion in which the Information Sheet was frequently used as a reference document to read later.

\section{The participants}

As this study draws upon a Gadamerian approach, interpretation rests upon a fusion of horizons between the participants and myself. Central to Gadamer's concept of horizon is that it is an historical, cultural, and linguistic vantage point. This fusion of the horizons is enabled (and constrained) by what is common to us both. Both myself and the four participants in this study were men of European descent between the ages of 30 and 60 years. English was the first language for each of us. In common with these men, albeit as a mental health nurse, I was familiar with the culture and language of mental health. This degree of commonality provided a useful common horizon of meaning from which to enter into dialogue.

\section{Meeting the participants}

Contact was initially by telephone or, in one instance, by email. Invariably, more details about myself and the study were requested. In all but one instance, arrangements were then made to meet in order to go through the Information Sheet and Consent Form. As one participant lived at a considerable distance, much of the initial discussion took place by email.

A number of options for meeting the participants was considered. As an aspect of feeling safe, the location for the interviews was a negotiated process. For instance, quiet cafés and rooms at the University were initially considered and offered to participants as possibilities. Eventually, participant's homes and workplace offices were the locations mutually decided.

A detailed explanation of the study was provided at the first meeting. This included explanations about the Information Sheet and Consent Form, as well as a rationale for each aspect of the interview process. This included discussing the following: 
- A brief introduction to who I was;

- How and for what reason the interview was to be taped and transcribed, including who had access to the tapes and transcriptions;

- Other details that I would be noting during and outside of the interviews;

- The reasons for the follow-up interview;

- The reasons for my clinical supervision;

- How I would assess risk during our contact and what process I would use in this event;

- Exclusion criteria;

- The full transcript would be provided to participants with the option of adding further information in the follow-up conversation and sections could be marked with a request for these not be quoted; and

- An opportunity to ask questions of me.

Although I did not provide participants with the Interview Guide (Appendix D), the process and focus areas of the guide were made explicit and briefly discussed. In the initial meeting, it was inevitable that such discussions with participants approached the proposed content of the interviews. This was difficult to restrain for myself and participants, and was then revisited at the earliest opportunity within the recorded dialogue.

\section{Positioning the researcher}

As researcher, achieving understanding required active participation without privileging my presuppositions. Rather than seeking a narrative or chronological story, the approach taken here was to engage in an interaction characterised by an active to-ing and fro-ing, and a back and forth, around topics that emerged as meaningful within the exploration of suicidal experience. The Interview Guide was utilised to maintain a focus on the topics of interest in order to facilitate increasingly greater detail and clarity about the focus topic, check understandings, and elicit greater contextual data. Instead of the focus being upon a list of questions asked in an uninvolved way, the dialogical process becomes a priority. As the researcher, I am therefore not positioned as disengaged and somehow unbiased but instead, actively engaged as a dialogical partner asking question, listening to responses, and offering my own understandings for checking. Through this 
active participation and contribution, my own horizon of meanings is overtly brought into play.

It is therefore more accurate to use the term "conversations" to describe the dialogue rather than "interviews." Geanellos (1999, p. 40) uses the term "participative conversation" to describe the character of interviewing guided by Gadamerian hermeneutic research. At the same time, it was a conversation guided by the agreed purpose; accordingly, dialogue was continually directed back to illuminate suicidality from a multitude of angles. This process enabled increasing detail about suicidal experience to be brought into question for me as researcher to learn more and hence understand better.

Entry into the conversations began with an introduction that recapitulated the purpose of the interviews and that it would be audiotaped. In addition, a reminder was provided that emotional supports, both formal and informal, need to be considered. This included an offer of a debriefing session with a psychotherapist, ${ }^{17}$ if it was needed for any distress or discomfort. Consistent with the overall research approach this introduction was conducted in a conversational style. That is, from the moment of introduction onward the interaction was recursive and open-ended, although guided by the explicit focus of the research.

Given the emotional energy of such an active engagement on a topic area that was important to the participants, closure was an important process. Closure included a conscious slowing down of the process, turning off the tape recorder, followed by an opportunity to reflect on the experience of the discussion. This reflection was also an opportunity to check on the well-being of participants. Again, this purpose and the requirements for this process were made explicit. Closure included making arrangements for a debriefing or counselling session if required and a reminder of the supports that were available. Additionally, arrangements for the follow-up meeting were discussed, and checked that participants remained agreeable. Sometimes, further information arose during closure. Permission to note this was obtained.

\footnotetext{
17 The availability of a group of psychotherapists who were prepared to be available at short notice and also had extensive experience of psychiatric and mental health issues was organised prior to the fieldwork (I would pay the initial session fee). Ultimately, this arrangement was not called upon.
} 


\section{The "data"}

The "data" for this study was in various forms and is shaped by the dialogical hermeneutic character of the study. These are listed as follows:

- Audiotaped recordings of each conversation;

- Transcripts of the conversations;

- Memos on the conversations; and

- My own experience of the conversations.

These different forms combine to create a relatively comprehensive historical record of what was used to inform an exploration of these men's suicidal experiences.

The text for this study was obtained from the transcription of the audiotaped conversations with the four participants. While it was originally intended to have all initial conversations completed before entering the follow-up conversations, this did not occur. Conversations occurred on the basis of the timing of recruitment and seeking to intrude as little as possible on the participant's lifestyle and work commitments. Insofar as the purpose of dialogue was to expand my horizon, the sequence of conversations was methodologically unimportant.

Transcriptions included notation of prolonged pauses and unintelligible sections. The recordings of these conversations were made using a professional quality tape recorder from which the majority of the conversations were later transcribed by a secretarial service; excepting the first conversation which was transcribed by myself. As far as possible all identifying information was then removed from the transcripts before returning these to the participants for review. At this point participants also had the option of requesting that parts be never quoted. This option was taken up by one participant. Additionally, place names and some characteristics of events were modified. A check with participants for identifiability resulted in only one further change to one of the transcripts.

Another form of text drawn upon to support the analysis were notes that I made throughout the fieldwork aspect of the study, and following the suggestion outlined by Minichiello et al. (1990), consisted of a form of personal log. These notes included observations about the context, my own personal responses to the conversations, and my general perceptions of the nonverbal responses of participants (for example, expressiveness or lack of expressiveness where it might have been expected). In part, 
this was facilitated by reflections during clinical supervision sessions. This "memoing" also included reflection on the research process itself (for example, engagement and closure).

From the two conversations with four men, more than 10 hours of audiotape were produced. Following transcription and checking, the text was then imported into N6 (Qualitative Solutions \& Research, 2000). N6 is a qualitative software programme designed to hold text data and provides a number of tools to aid in qualitative analysis. N6 enabled convenient storage and a systematic means of retrieving particular text in the process of analysis. Unlike say, utilisation for a grounded theory methodology (Amankwaa, 2000; Plass \& Schetsche, 2000), coding was used within N6 simply as an aid to text search and retrieval rather than to facilitate the development of themes or build theory (see St. John \& Johnson, 2000 for further discussion of issues). Only the intelligible spoken words were put down in transcription text. A basic level of tonal variation, silence, overtalking, and so forth was also noted.

Transcripts are substantial documents and awkward to read because of the spoken nature of the text. They are not "writings" intended to stand on their own to be read. It is therefore not an insignificant task to be asked to read them. This was offered to participants as an option, depending on their interest. Nonetheless, every participant did indeed read them. Entry into the follow-up conversations started from a response to reading the transcripts (e.g. "what did you think about the transcript?").

\section{Interpreting the conversations}

In Truth and Method Gadamer (1965/1975) has argued that insofar as people communicate with one another and exist in communities, then understanding occurs. While understanding is therefore an everyday thing, he argues that the task of human sciences becomes to understand with greater deliberateness and consciousness of the hermeneutic nature of understanding and the "conditions under which understanding takes place" (p. 263). This is a radicalisation of an everyday event; and in the case of mental health nursing, a radicalisation of an integral aspect of practice - communicating with and understanding mental health nursing clients.

Two hermeneutic processes are undertaken in the interpretation of the conversations with participants. Understanding firstly occurs within the conversations with 
participants. Understanding is then further developed through an interpretive analysis of the transcripts. I have termed this approach a double hermeneutic.

\section{Understanding the conversations}

Before the conversations with the four men in this study were fixed as transcripts, understandings were formed in conversational dialogue. That is, although the transcripts are a form of historical record, understanding was first created within the living dialogue of the conversations. The purpose of examining the conversations themselves, is to elaborate what it was that was conversationally understood. To put this another way, through the conversational partners being held by the focus of conversation - that is, the suicidal experiences of each of the men - the task is to describe what was illuminated in the dialogue as I understood it to be. I emphasise here that I have my own understanding. Each of the men would have somewhat different, albeit significantly related, understandings of the same conversation.

Hermeneutically, insofar as understanding has occurred, presuppositions have required modifying, accepting, or rejecting in the to-ing and fro-ing of the dialogue. Such conversation are a temporal living thing, always situated and always moving. Analysis of conversations then is always too late, as understanding has already occurred and moved on (Gadamer, 1984/1989). Hence, to examine the conversations for the "conditions" in which new understanding has emerged cannot occur as part of the conversation itself (as it would then become the conversation). However, this is made possible in dialogue with transcripts. Transcripts offer the advantage over the conversations in that they are fixed. An interrogation of the transcripts however, is to engage in a different dialogue to that which has already occurred in conversation. In that they refer back to the original conversations, a different understanding of the conversations occurs.

\section{Conversation}

Conversation may seem to be something to be taken-for-granted as it is so much of daily social life. In Gadamer's work, conversation is the key to understanding, and the key to understanding further about something. In this study, conversation begins the process of exploring four men's experiences of suicidality.

While Gadamer doesn't specify how to dialogue he makes frequent reference to conversation as a model for understanding a text. To the degree that conversation results in understanding, means that one has learned something. However, not all 
conversation leads to understanding. An interaction in which the purpose is to succeed in getting one's opinion accepted by another is not a conversation in this sense intended here. In "successful conversation" both partners in dialogue put their preunderstandings at risk to truly hear the other person. Such a conversation then is dependent on holding the object of conversation open to question. That is, there is something not expected about the object thus provoking dialogue. Proper questions result in bringing the object into a state of indeterminance. These questions cannot be known beforehand as it is not known what will emerge to hold open to question.

Drawing on a Gadamerian methodology means that as researcher I am positioned as learning through recursive dialogue, rather than as an uninvolved knowing expert. If I am to understand I must be fully engaged in the conversational process; consequently, if understanding has occurred, I am transformed as a result. The nature of the research "interview" then will be characterised by an attitude of good will to understand the other and to ask and be asked questions and offer my own understandings for questioning. As researcher, understanding will depend on reciprocal participation (but also, not taking over), rather than sinking into the background of the dialogue. Equally, this does not mean a pretence of not knowing, as understanding requires putting preunderstandings properly into play.

Hence, effective conversation depends on the balance reached in order to consciously put prejudice properly into play. The intention here therefore, is not to obtain bis understanding - in which my understandings are made inaccessible - but to truly understand through putting my preunderstandings at risk. In her application of Gadamer to interviewing, Geanellos (1999) describes the hallmark of this sort of dialogue as "a speculative, undogmatic openness and a willingness to be instructed to another point of view; to another horizon" (p. 41). As an active participant in this dialogical process I will influence the other as he will influence me. The issue is not to eliminate the process of influencing, but to make it a conscious process and address it as such.

Any analysis that seeks to make explicit the "conditions of understanding" must account for understanding having already occurred within the conversations that produced the transcript data. The process I have undertaken here is to write out a form of autobiographical "story" of each conversation that tells the "reader" of my 
understanding of suicidality arising from the conversation. This story writes out the understandings I have reached within the conversations in a narrative form as if to an imagined audience (e.g. as in writing a letter). In addition, as far as possible preserving contextual understanding including what I took to be the pivotal meanings and events important to the construction of my understanding. Hence, this writing is not simply a definitional statement nor a chronological narrative; as an historical record of the conversations, they do not attempt to capture chronology as if a detached observer, but instead, are written as a participant in the creation of that history. That is, in a literal sense it is my point of view. Equally, the intent here was not to abstract the essential social phenomenon, nor to explain what gave rise to this understanding, but to summarise the conversation in such a way as to faithfully capture in writing the way in which I understood each of the conversations on suicidality. While this writing cannot capture everything, it begins a process of interpretation by fixing in writing something of the current state of my understanding.

These stories therefore convey my understanding rather than bis. A different story would be written by each of the research participants. Although the expectation would be that there would be a substantial commonality in each of the stories, reflecting the fact that the conversations were co-created, the stories would nevertheless be different as they are different authors.

In an effort to stay close to the original event and the language of each conversation, the "story" of each conversation was constructed using substantial quotes from the transcripts. However, these were pieced together within a narrative in order to convey the context of my understanding. As the experience of the conversation also contributes to understanding (i.e. it is not a social act independent of my presence), the narrative portrayal was facilitated by memos and reflection.

As well as a story for each conversation, the production of these gave rise to a metastory consisting of the collection of stories. Reflecting across all conversations, a summary was written that attempted to tell what I understood to have been my understanding of suicidality as a result of these many hours of conversation and story writing. A thematic summary of this meta-story is set out and discussed in the following chapter. 


\section{(Re)interpretation through the transcripts}

The purpose of an interpretation of the transcripts differs to that of the conversations. Having the transcripts available as an historical record of the original conversations offers the possibility of a different understanding to emerge from dialogue with the text. Understanding no longer develops in dialogue with another person, but instead, in dialogue with a fixed text. This is not simply a different interpretation of the conversations, as the transcripts are an historical record and are not the conversations themselves which, of course, occurred in the past and therefore no longer exists. Yet, the significance of analysing the transcripts lies in the fact is that an interpretive analysis of the transcripts relates back to the conversations and therefore has the possibility of saying something about the original event. To put this another way that is closer to Gadamer's words, the conversations were the historical influence from which the transcripts were produced (i.e. effective-history).

The interpretation of the transcripts is therefore a kind of interrogation from a specific horizon of meaning. This horizon of meaning is consciously informed by the earlier review of masculinity, mental health, and suicidality, as well as historically effected from understanding developed from the earlier conversations. The transcripts are therefore examined in order to provide a different interpretation about the conversations in which an understanding of suicidal experience as men was reached.

This theoretical horizon was one in which the everyday taken-for-granted meanings are seen as imbued with gendered meaning in which power operates in certain ways. Such a positioning is therefore one in which the taken-for-granted and "natural" are regarded with attitude of suspicion; for example, suspicion is directed toward those aspects of the text that depict social contexts and outcomes as "natural". This position could not be put into play through conversation in which understandings are constructed on the basis of their everydayness. Gadamer (1984/1989) has argued that the invisibility of language enables the very possibility of communication, so that it is only when "the process of understanding is disrupted" that questions are asked about meaning. However, the written text can be interrogated in such a way as to bring meanings once again into a state of indeterminacy by asking questions from a particular theoretical horizon. In this way meanings beyond the taken-for-granted are illuminated in these texts. Through an explicit, and therefore conscious, attitude of suspicion then, the text is made distant, other, and somewhat unfamiliar. Questions were put to the text such as: 
Why this meaning? Why say it this way? Why this meaning now? Where did this meaning come from? What other meaning could there have been?

The first step in the analytical process is to conversationally understand the past suicidal experiences of the four men in this study. The following chapter provides a discussion of my understandings as a result of the dialogue produced through the processes outlined above. 


\section{Chapter 7}

\section{CONVERSATIONS WITH FOUR MEN}

Four men participated in initial, and follow-up conversations on their past experiences of suicidality in accord with the process set out earlier resulting in eight transcripts. Transcribed conversations do not necessarily proceed in grammatically correct prose, but are frequently overlapping, hesitant or rushed, change topic in mid-sentence, and are supplemented by the use of um's, ah's, and silences. In natural conversation non-verbal behaviour is frequently used to facilitate communication. Additionally, the environmental context may influence the interaction, such as the pet cat coming over for a pat. Memoing was therefore also utilised to facilitate later interpretation.

The quotes used in the following analysis use commas and periods to approximate hesitations in the flow and three periods (...) to indicate silence or unfinished sentences. The mathematical 'less than' $(<)$ and 'greater than' $(>)$ brackets are used to insert such events as laughter or crying, or to show where identifying people or places have been removed to prevent identification. The source of the quote is identified by a notation of name and paragraph number. This notation takes the form of (Namen, $₫ n)$. The number $n$ following the name indicates if the transcript is from the first or second conversation with person. For example, the notation of (William2, 950) would therefore mean the quote is from paragraph 50 from the follow-up conversation with William.

This chapter sets out an overview of these conversations. It describes my understanding of what was told to me at the conversational level; that is, it sets out my understanding of what was conveyed to me by all four participants. This chapter is therefore a thematic retelling of the story as faithfully as is possible, but in a summary form. I do not do this from an uninformed or neutral position, but rather, do so from standing within the tradition of my profession as a mental health nurse.

The retelling of an other person's story of their troubles is a common occurrence in mental health settings between clinicians and across teams. For instance, a clinical 
parallel can be found in the retelling (or documenting) of an assessment interview. The original interview is told in as raw a form as it is possible to remember in an attempt to convey the client's understanding of their troubles. However, such a retelling of an interview is not the end of the process of understanding the client's issues. The retold story would then be reflected upon by the team and an understanding (clinical analysis or hypothesis) is then developed and written up. A different understanding of the client's story is developed, but related to the original interview. In all likelihood this understanding is regarded as provisional and investigated further.

Having transcribed the recordings of two conversations with each of the four men in this study and then written summaries of each, common issues and pivotal events stand out. This chapter describes these key themes or issues that, out of all the other possible life events to be recollected, appear to have been emphasised. This is not a retelling of a story in the sense of a chronology instead, it is told according to a set of themes. In this regard, what it is that constitutes the theme guides the description.

The chapter commences with a short outline introducing the four men. This description is necessarily brief in order to reduce the risk of identifiability. The following chapters revisit these key issues, building further on this initial point of understanding.

\section{Four men}

All four men were European, spoke English as their first language, and were aged between 30 and 60 years old. They each had an option to choose a pseudonym or leave this for me to choose for use in this study. Although they each identify New Zealand as home, they were not all born in New Zealand and in our conversations they related experiences from other countries as well as that encountered in New Zealand. Some details have been changed to further protect identity in the biographies set out below.

\section{Peter}

Peter was the first of the four men whom I met to talk about suicidal experiences. On first meeting Peter, he was welcoming, appeared pleased to meet me, and very comfortable talking about people, living and life in general. Peter had been hesitant upon hearing of my study topic as he did not think he met the criteria for previously being suicidal stating that he had never tried to kill himself. However, it became clear very early in our preliminary discussion that indeed he had been suicidal across a 
number of years; for instance, at one point, planning how his death might be brought about. Once into the process of our conversation, retelling his experiences alternately brought enthusiasm, passion, and tearfulness. Many cups of hot tea were consumed keeping the winter cold out of his sitting room and time seemed to rapidly evaporate.

\section{Andrew}

Andrew was the youngest of the four men. He was currently undertaking further tertiary study. He had previously run a successful business. We met at his home, which was light and airy with wonderful scenic views from the lounge room where we sat each time. He was passionate about telling his experiences, though much of it was difficult for him to tell. There was an obvious determination at times to confront the telling of the story. He later told me it was a conscious effort to be honest with himself. At the same time, like the other three men, Andrew was also warmly welcoming and eloquent in what he wanted to put to me.

\section{Podraig}

Podraig was the oldest of the four men. Like Andrew, Podraig had also successfully run a business and then gone on to university, studying as a mature-age student. In this he was also successful. Unlike the other three men, I first met Podraig by email and then by telephone, before eventually meeting at his home. It was a warm and friendly home in a quiet and peaceful setting that matched his expressed desire to keep stress to a minimum. It was a great setting in which to engage in unhurried conversation without intrusion. As with the other men, conversation brought out passion and tearfulness as well as a strong desire to 'tell it as it is' in all its rawness. I felt that it was important to him for me to understand where he came from. Some of what we talked about was full of recollected pain that continues to have the power to provoke real anger many decades later.

\section{William}

William was of a similar age to Podraig and the last of the four men I met up with. We met in an office at his workplace. I didn't at first notice he limped until later when it became a central aspect of what he had to tell me. William too, had been successful in middle management and like Peter, his children and partner (and previous partner) became a central part of his story. Although I was late to our first meeting, William was nevertheless generous in the use of his time and willing to permit the conversation to 
explore some very difficult areas of his personal history. While some of what he told had been told many times during hospital admissions and seemed to be familiar territory to tell a psychiatric/mental health nurse, there remained certain aspects that were clearly painful to tell; and perhaps less often told. Like Podraig, it was important for William to impart the wisdom of painful experience to me for others to learn.

\section{Family violence and abuse}

Each of the four men had strong recollections of experiencing traumatic experiences in their childhood homes. This trauma was ongoing and extended into their school years.

While Andrew and Podraig spoke of their own physical abuse as children, our conversations show that they were acutely aware of the violence directed toward their mothers and siblings. It was also apparent that the violence that pervaded the home was experienced as ongoing until well into their school years. Podraig is clear about the violence in his childhood home, saying:

My father was, an alcoholic, and he was pretty violent with alcohol. I lived in a very nice place until I was four <sarcastic tone>. From when I was six months old, simply because he used to pick me up by the head and throw me against the wall. (Podraig1, आ3)

Andrew also comments that:

There was a lot of violence in the family as well and I know that there is a lot of other people worse off than I had it, but the thing is the damage. (Andrew, \$13)

The "damage" Andrew speaks of is evident in Podraig's later remarks the bind he found himself in with the relationship to his father as a child:

I was frightened of him. Frightful. It's really confusing when you're a little boy and you just really love your father and you're scared of him as well. You love and hate him all at the same time. And I, the thing you're desperate for is for him is to show affection but he doesn't. Then the little glimpses of it when he's in a good mood come occasionally in the evening, but they can disappear in a flash. Keep going back and try to grasp onto that little bit. (Podraig1, \50) 
The fear and terror expressed by Podraig also meant learning at a young age to manage behaviour in such a way as to avoid provoking the violence. At other times, it could mean taking on adult roles. For Andrew, this included becoming the "man about the house" as a 10 year old child:

I have to go back to my early childhood, and I had a toolbox, and I did all the home maintenance for mum you know. I had a toolbox at the age of ten. Dad I don't think had two screwdrivers. (Andrew1, \75)

Peter's story seems at first to be different initially suggesting an absence of childhood trauma or victimisation. Perhaps because, unlike Podraig or Andrew, his story does not reveal physical abuse. However, Peter gradually reveals the emotional impact of the volatile nature of his parents' marital breakdown:

So I felt like okay things had happened in the past which were about these stresses and things and I would just become a helpless child basically in the face of that, because I was, a big part of me was a pained, you know, distressed child from some of the fundamental grief and pain of my childhood which was around my family... the very distressed nature of my family. (Peter1, \$101)

The depth and extent of the distress for Peter comes through in statements like the following that show the long-lasting impact of the disintegration of his harmonious nurturing home:

I think basically all of the grief the grief was the grief and loss of family really, because the family blew apart and the depression and the anger have arisen out of, yeah, a very small person you know, and beginning in life, and all the undercurrents of distress and fear and anguish and torment that were around in my emotional kind of home. And that was, clearly I couldn't deal with it and didn't deal with it. You know it's haunted me really. (Peter2, \84)

While Peter was not physically assaulted. His description shows that he experienced the effects of exposure to family violence as a young boy as emotional abuse, rather than physical abuse. The trauma is real in his descriptions of his parents' marital breakdown when he remarks that it was: 
really scary and awful and hysterical. You know, it was

horrible really. (Peter2, $₫ 38$ )

He contrasts this experience to earlier experiences of his family as being "warm", "fun", and "lots of nurturing". He makes a special point about the loss of connection and relationship with his father, and the silencing from his mother.

William's childhood trauma came from multiple sources. William suffered from an injury to his leg at age $1 \frac{1}{2}$ years that resulted in multiple hospitalisations for painful reconstructive surgery to his foot and ankle over many years. It is unclear how the injury originally occurred. In addition to repeated traumatic hospital experiences, his father died when he was $2 \frac{1}{2}$ years of age. Seen as being too young to understand or cope, William did not attend the funeral. He doesn't recollect his father's death ever being discussed. He feels that at the age he felt that his father had simply vanished. The death of his father also resulted in other changes to his home life. William describes moving around a lot, school absenteeism, and a remoteness to his mother, stepfather, and siblings. His story portrays a sense of emotional disconnection and neglect for William during these years. He seems to confirm this later in a discussion about trust:

I guess I wanted to be nurtured. I wanted to make up for the fact that you know, mum wasn't there. (William2, \62)

At age eleven, William tried to kill himself with his mother's sleeping tablets. Discovered by his stepfather and mother, he was made to vomit. This incident was never discussed within the home, nor does he recall ever being taken to a doctor as a result.

\section{Fathers and other men}

Fathers and stepfathers appear in these conversations as significant figures to the traumatic events of their childhood years. In contrast, they feature minimally in the adult years; if they feature at all.

Andrew describes a childhood with a violent alcoholic father and similarly Podraig describes his experience of childhood as a tense and terrifying relationship with his abusive father:

So I didn't have much idea of or much value of self from a pretty early age. I was a quite isolated lonely kind of little boy. Spent all my time in my home with pretend friends for a long time. He was actually sexually abusing my two eldest sisters 
at the time. But I didn't come to find that out until many years

later. And I kind of found if I did function with other guys, other human beings if you like, they were generally people who just you know, gave me heaps of affection and I didn't have any idea of whether that affection had, you know, what kind of motives might have been behind the affection. I didn't really care. Just any kind of affection if you like. So I found myself in the situation <garbled $>$, where I was abused by somebody outside the family. (Podraig1, П3)

Podraig and Andrew both describe their childhood as "isolated". Podraig spent much of his time playing with "pretend friends", while Andrew became "mum's little helper" at age 10 with his own toolbox doing the house repairs.

Fathers have also appeared to significantly influence the quality of relationships with their mothers:

\section{My relationship with my mother is very strong. But I think I had held some resentment at her when the family was very dysfunctional that she didn't take us out as children. She didn't take us out of that environment. So I had to deal with that later on. But that didn't come about until just recently. (Andrew1, \19)}

While there was an awareness of the ongoing exposure to violence and threat to their siblings and mothers from fathers or stepfathers, mothers were nevertheless blamed for not removing them from their childhood fear and terror, or were instead blamed for the disintegration of the family. This impact is long-lasting. While Andrew speaks of resolving this with his mother, this did not happen for the other men.

Peter and William had different experiences. They did not experience the violence and fear that beset Andrew and Podraig. The earliest childhood years appeared to be idyllic for Peter. He describes a happy, loving, "hippy" lifestyle. However, by the time he was into his early teenage years his parents' relationship was disintegrating in a frightful way. This had a lifelong traumatic impact on Peter.

In contrast to the others, William experienced great loss associated with significant change in the home. Other than mentioning his stepfather to make him throw up the Mogadon overdose at age eleven, William is silent about his stepfather. Silence was a 
feature of the trauma these men experienced as children. William experienced silence from his mother in the context of his father's death, and then, again, from his mother and stepfather after overdosing on his mother's Mogadon. Peter experienced silence from his mother after his father left home, refusing to speak to him about it. Andrew talked about the silencing of his sexual assault, and stated that as a Catholic family, sexual abuse was never spoken about. Equally, violence in the family was never spoken about because of the fear of more violence. Similarly, Podraig described his father's (and later, his stepfather’s) sexual abuse of his sisters as "the family secret” (Podraig1, ๆ20). In this context then, silence and silencing was used as a means to control and victimise.

In their early adult years, these experiences of their fathers and step-fathers left them wondering what they would themselves be like as fathers and partners. Andrew expresses this doubt when he states:

I'm thirty-seven, I'm still not married <laughs> and no children. And that's a conscious decision because I wonder what sort of... I'm sure I'd make a good father, but... (Andrew1, П41)

He continues, clearly worried about sexual abuse, saying:

Am I going to be able to trust myself in raising children the way they should be raised? You know, are they going to be safe? Am I going to be safe? (Andrew1, \114)

\section{Sexual assault}

While Andrew and Podraig experienced physical abuse as children, they were also made victims of sexual assault. Andrew talks about the impact of being sexually assaulted at age 10 by his older brother that took some years to understand and connect to his emotional distress and relationship issues. His family's strong Roman Catholic beliefs seemed to further complicate the impact of this trauma:

Well there was one particular incident I think kind of took up the um, to the suicidal thinking and that was at the age of ten then um sexually abused by a family member and of course coming from a Catholic family that was, ah, put the cat among the pigeons, and it was also the case the family they never, never spoke about things anyway. (Andrew1, П3) 
He eventually connected this event to a recurring nightmare. The intensity of the trauma and its current effect on him is still recollected, decades later:

After that incident at the age of ten I had this recurring dream of um, if you could envisage like just a white light with a black surround, and you can't see anything of the blackness and that there was this like a leather ball rolling down taking up more of the light. And it's getting closer and closer to you to the point of suffocating you. And I eventually equated to that as being grabbed from behind with a hand held over my mouth and being told to shut up and don't scream. And because of that the feeling that was associated with that dream is coming to me during the day, I could be walking down the street and then all of a sudden I just get this overwhelming sensation of that of the feeling, of that dream. And ah, you know, I knew I was not in a good state. And I had... Had panic attacks at different stages out in public, and my temperature, blood pressure, would skyrocket, and be completely red in the face and sweating and l'd have to get away, get home. (Andrew1, \187)

Podraig attributed his sexual assault as an 11 year old child to what he believed to be his need for affection, linking this to the lack of affection he experienced at home:

I was rather confused at the time I think. Because I mean, the difficulty was having no ideas, boundaries or moral value or you know, just from my upbringing, just having violence around me and that sort of thing. You know, the confusion was probably more over you know, was it such a bad experience? Was it even pleasurable, to some degree? You know, I had no distinction in my mind of what was pleasurable and what wasn't. But I isolated even more. (Podraig1, \5)

Although at first he states that the experience was confusing rather than frightening, because “it didn’t hurt, he didn’t do anything nasty to me” (Podraig1, $\$ 48$ ), he later goes on to say that as a result he further isolated himself. He also bitterly reflects that from this experience he learnt that "sex and love aren't freely given" and that "it became quite a pattern for life" (Podraig1, ๆ5). 


\section{Unsafe schools}

While home life was a location in which, as children, these men were victims of traumatic experiences, school was also an unsafe place. Their school experience became an extension of their victimisation. School was another social setting in which they encountered this experience. Moreover, their recollections show that there was an absence of people or places mentioned as safe and secure. School continued to provide experiences of victimisation until they left. All four men left school as soon as they were able. This is not to say there were elements or times at school that were indeed safe, but that the overall experience was of a lack of safety and security.

Peter described his early high school as a "torment". Andrew found he was wary of other boys in the change rooms and of the priests. William described being persistently teased about his different walk and later, his weight. Podraig described his response to peers at school as an awareness of vulnerability and threat:

I would attach myself to a teacher. [Brian: To a teacher?]

Yeah. [Brian: Rather than...] because I'd feel protected. The

girls seemed threatening, and in fact the guys seem

threatening too. To me you know, they seemed to have a secret about manhood that I didn't know about, or something that they had that I didn't. They seemed to like, they were real men. I didn't like that you know. (Podraig1, ๆ8-10)

While teachers were sometimes seen as offering temporary safety, and indeed Podraig and Peter sought out the presence of teachers for protection, this did not stop the victimisation. The company of teachers did not stop the nastiness, jibing, and feelings of inadequacy. In combination with feeling small and less physically developed than his age-peers in early high school Podraig found himself bullied. The bullying was nasty and sexual, with taunts about incest. It was an experience that eventually led to a prolonged emotional collapse:

But that's not, not much fun when you go through school and you're feeling really different anyway, and I was a very tiny boy, and I felt victimised a lot, and the kind of taunts that were, the kind of victimisation was, you know, your old man fucks your sisters. And its not fun stuff. You know, maybe you're just one of your sisters' sons! (Podraig1, \20) 
At thirteen years old and almost catatonic at home, and being cared for by his mother, Podraig's sisters also verbally abused him. He recalls them yelling at him day after day:

...just like your fuckin' old man, lay down and have life done for you. (Podraig1, \38)

Although this was yet another experience of victimisation for Podraig, it is also clear that his sisters felt they were also being re-victimised by the care and attention that he was receiving from his mother, while unbeknown to Podraig, they were continuing to be raped by their father.

Peter was bullied because he also was seen as different to the other boys. Peter recalls that throughout the third and fourth form he was:

...really knocked around every lunchtime and playtime [...and]

I mean it was, sort of lives in my memory. It was torment you

know. (Peter2, \6)

He attributes this to his appearance; although he also feels that not playing rugby was a significant and compounding factor. While he says he had a lot of adult support from teachers and family, it is also clear that this support did not stop the bullying or the trauma of the experience.

For Andrew, teachers were never seen as possible supports; in particular, he was suspicious of the motivations of the male teachers. Andrew felt that as a result of his sexual assault he became suspicious of the motivations of all males. And elsewhere in his life, particularly at school Andrew was watchful of the sexual motivation from the males around him:

Basically I was always very wary of males. And I wouldn't go in the scouts because of being worried about the Scoutmaster. I was worried about priests. (Andrew1, \15)

He also remembers being acutely aware of the other boys in the sports dressing room before and after playing soccer:

Well I played soccer for most of those years, and was always worried about, I don't know whether it's was just a normal thing to be worried about, in that being scared of being in the changing rooms, and you know, keeping your, don't want to expose yourself to anybody, and you know, it's I suppose 
that's a natural thing, but it was just a case of, so aware of it that it was uncomfortable. (Andrew1, \21)

In some instances, teachers were the source of their victimisation. For Podraig, there was a connection between victimisation from the school and the bullying in the playground.

And twice a year in those days at Sunday Mass the priest would read out the names of everybody in the parish and how much they'd pledged and if you came from a poor Irish family like I did, that would be read out. That would be read out that they got nothing. So within that small school environment that I was in I'd hear the taunts about that too. (Podraig1, \32)

The failure of his family to pledge any money became a potent source of shame and became yet another means to taunt him. This continued on into his later school years.

And everybody would know that you had to apply, that you had to apply for a kind of special dispensation from the church to get funding if you hadn't been able to provide the kind of money that was required for tuition. Now you were expected to go into this school but you were classed even by the other students as kind of like the charity case of the school. So the stuff just continued. (Podraig1, ॠ32)

William provides a different example of the impact of victimisation within the school. William clearly recollects giving up on school at a very young age knowing he would never be able to write like the other children because of his left-handedness. This was a point of difference in the classroom from a very early age.

I remember very clearly as a five-year-old sitting in the classroom looking at our writing lessons. And at the end of the lesson we held our writing up and the teacher would have a look. Whoever had the neatest writing got a jelly baby. Of course I was busy trying to learn to write with my opposite hand. I never got a jelly baby. I gave up. I thought what's the

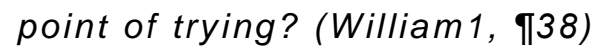

In the playground, William too was subject to bullying, first for the limp produced by the surgery, then later for his weight. This evaluation of himself as being unable to fit in (and hence, unable to succeed) seemed confirmed for him when later on at school teachers labelled him as a troublemaker and ringleader; yet William saw himself as a 
loner, picked on by his peers. He was eventually dismissed from school for punching the Deputy Principal after feeling that he had been shoved in the back during the school assembly. As he saw it, he made an unconscious, albeit violent response, to a physical taunt.

Each of these men regarded themselves as unsuccessful at school. Any success that they had (for instance, William's horse riding, Andrew's athletics, etc.) was quickly discounted against the overall negative school experience. Academic failure became yet another experience of an ongoing experience of victimisation.

\section{Becoming 'different' at school}

These conversations show that their realisation of difference from their peers did not occur until they were at school. Until school, their home experience constituted normality. At school, difference meant deficiency and vulnerability. Difference became feared because it was the target of victimisation. Victimisation was both constitutive of, and constituted by, difference. That is, they learnt what it was that was different from what it was that they were victimised about. Difference was always related to the body.

Difference was a pervasive aspect of their consciousness of everyday life at school.
I would be aware of it 24 hours a day. Was different. Their
voices were deeper, I didn't have as big a chest, I wasn't as muscular. I didn't have that muscle just above my knee that the other boys seemed to have or, I felt these things! I somehow hadn't developed properly sexually or in a physical sense. (Podraig1, \18)

Unlike the other three men, Andrew didn't describe being bullied or isolated from his peers and instead, describes being very much involved with his peer group through his sporting activities. However, he also becomes profoundly aware of being different in other ways:

But with regards to having this feeling of being different. When I was growing up I knew certain things had happened and the thing was I actually wanted to be the same as everyone else. And I think even to this day I struggle with the fact that I didn't play rugby. You know this whole kiwi thing about you know, blokey, and you know I played soccer and ended up. It was meant to be the more gentler of the sports 
and ended up having a horrendous ankle through it with the insertion of screws and whatnot, which I still carry. But I was never big enough to play rugby because I was only a small fellow then and light weight and I used to get absolutely pummelled you know. Some of the Polynesian boys lined me up and that was it. (Andrew2, \11)

While Andrew bases his feelings of difference relative to his physical form, he also describes historical experience as a mark of difference. He was conscious that his experience of rape somehow meant that he could not be like other boys. This experience separated him from the other boys in a profound way and physical difference added to his feelings of difference. Like the body, he was helpless to change or undo this experiential marker of difference.

Each of the men describe their experiences of bullying as a consequence of being somehow different. Difference was to be vulnerable and unsafe.

I got teased a lot as a child because of my foot, which made me feel like an outsider. We came to New Zealand when I was ten. And then I was teased not only about my limping, but being <foreign> and felt even more an outsider. And eleven, had my first suicide attempt. I took a whole bottle of mum's Mogadon sleeping pills. (William 1, \$11-13)

Each of the men attributed their leaving school to the belief that things would be better outside of school.

\section{Mistrust and sexuality}

As these men entered their later teenage and early adult years various experiences were encountered of feeling unsafe, vulnerable, and mistrustful. A particular aspect of this experience was related to sexuality and intimacy.

Exploring intimacy and attempting to engage in meaningful relationships was fraught with difficulty. There was a fear of intimacy and a complete lack of any experience that approximated what was needed in order to form intimate emotional and physical relationships. Intimate relationships were then a source of tremendous angst.

Podraig stated his situation in his mid-teens bluntly and painfully: 
I never have relationships. <laughs> I never had partners. I

only had prisoners and hostages. (Podraig1, \68)

Despite the level of control that his previous statement might portray, he goes on to add:

I just didn't feel that thing that I knew was, yeah, I'd be excited about seeing women, then when I was with them. It was like I was desperate for something, and then, I was desperate for some kind of a feeling and I expected them to be able to provide it, and they, I had no idea that it was. What I did know was that it was me that was not really functional on an emotional level. But I did what I could do to avoid taking that responsibility. (Podraig1, \68)

Each of these men talked about heterosexual relationships as the expected norm. There was no doubting the heteronormative standard. In addition, there was an unquestioning acceptance of homophobia. In various ways they each expressed their unacceptability of homosexuality in their teenage years. It is clear in their recollections that homosexuality was viewed as a defect (and therefore, different) and as a consequence, the vulnerability that being associated with homosexuality brought was to be greatly feared. Nevertheless, each of the men described a period of time where they were very aware, and very worried, about attributes or behaviours of themselves they saw might be construed as evidence they were homosexual. For instance, the choice of different dress style and expression of creativity (Peter), the experience of male sexual assault (Andrew, Podraig), or disinterest in rugby (all), they each considered this to be evidence that they may be homosexual.

The fear of homosexuality in these conversations is also linked to religious and moral beliefs, as well as feelings of guilt and shame:

Well there was, because I thought, because of what had happened at an earlier age that you know, in my early thinking, I thought, god maybe I'm gonna become a homosexual you know there, and of course some of the intimacy which goes on with a normal heterosexual relationship I felt tremendous guilt over certain things when I shouldn't. And I think it's that fact of, struggling with your own ah, belief system and what's right and what's wrong.

(Andrew1, \$104) 
Nevertheless, although expressing some ambivalence about the degree of his awareness of exploration of sexuality at the time, Peter remembers actively pursuing a more "feminine" presentation of himself, that on reflection, he now sees as an exploration of an alternative sexuality to a macho masculinity:

But it is interesting that I was exploring gender. I was certainly physically manifesting, if you like, my feminine nature in my late adolescence early twenties by, you know, wearing a lot of the kind of accoutrements of femininity if you like, earrings, necklaces, and very long hair. And wearing clothes that were expressive of softer, you know, just not overtly male clobber <laughing > by any means, you know. And yeah, and actually, because l'd always felt more comfortable with female company than I had with male company, you know, I'd always found that. So there's something there. It was, I think I felt less under threat. Yeah, that's what it was. I felt less threatened by women than I did by men. (Peter2, \$14)

Even in this part of the conversation with Peter, his concluding point about threat from men indicates the ever-present awareness of risk in connection with a different expression of maleness to what was expected by other males.

Mistrust and fear had a serious impact on the development of intimate peer relationships. All four men experienced difficult relationships with women causing great emotional pain for all involved. None of the men spoke about intimate or sexual relationships with men.

Andrew states that as a teenager he was "totally dysfunctional", and directly attributed this to the experience of being sexually assaulted by his brother:

I think um, trying to be a teenager at the best of times is hard enough. But like, I was completely scared of getting into any sort of relationship with a female. And, ah. And I just had these feelings that I just wasn't good enough. And ah, yeah, I didn't realise how normal incest is you know. (Andrew1, 凤7)

Andrew goes on to state that his fears were particularly around physical intimacy because of the shame of feeling "unclean".

Similarly, Podraig attributes relationship difficulties to being sexually assaulted as a child: 
So, the real problems came along and difficulties with young women. I started feeling my oats as it were, and had difficulties relating because I really wanted the affection but, I started to question you know, if I touched on any sexual thing, that there is, that there must be a price to it. And from my first sexual experience, I think that's what I gleaned you know, that there's something instinctive. That it's not, sex and love aren't freely given. It became quite a pattern for life. (Podraig 1, \7)

For Podraig then this experience taught him that sexual intimacy didn't occur in a reciprocal partnership. Instead, he goes on to express a sense of desperateness or neediness within himself that couldn't be met within sexual relationships that he "manages":

It was like I was desperate for something and then, I was desperate for some kind of a feeling and I expected them to be able to provide it, and they. I had no idea that it was. What I did know was that it was me that was not really functional on an emotional level. But I did what I could do to avoid taking that responsibility. I didn't want that admission to myself. I didn't want to be confirming the kind of things that l'd had confirmed to me by all the guys as I went through secondary school and primary school and stuff like that. I didn't need to be doing that to me too. Because when I finally started doing that, and did finally start doing it, then all I wanted to do was die. Because then I was a total failure to me as well. (Podraig 1, \68)

William found he was unable to seek out intimate relationships in the same manner as his male peers. He found that he was unable to:

sort of go out and chase women the way the rest of the boys could. To chase girls. So even though l've had a number of relationships, I guess I missed a lot of opportunities.

(William 1, ף205)

As with the other three men, William also was unable to trust male peers or adult men. William connects this to what he sees as the emotional absence of his mother as well as a lack of shared interests in things that are particular to men:

I guess it was a total lack of trust of men and boys in particular in my past. The fact that I wanted that, I don't know, 
I guess I wanted to be nurtured. I wanted to make up for the fact that, you know, mum wasn't there. You know, I've always felt closer to women than what I have to men especially when it comes to rugby, racing and beer, none of which I have a passion for. (William2, \62)

William eventually marries, twice. However, reflecting back on these relationships he feels that these choices were influenced by a belief he was an unlovable person saying: “I guess because I felt I didn't deserve to be loved I chose somebody who wouldn't love me" (William1, 976). His first marriage produced a child and when he and his partner separated the description of his time as a single parent is regarded as the happiest time of his life. Unfortunately, this ended in a bitter custody battle in which he lost. This traumatic time resulted in several attempts to take his own life and subsequent psychiatric admissions.

It is very clear to Peter that his "failings" around relationships are due to his early traumatic experiences of victimisation, particularly the trauma of the dissolution of his childhood family home:

Well I mean, you know, I know that I have in past relationships lived out a lot of the muck, that was emotional muck that was in my family in terms of the relationships and the behaviours. And I certainly made a decision to change that. It's been bloody hard. But I've never yeah, I've always felt yeah, I've felt afraid of anger, of other people's anger at me and my own anger you know, and through down the years. So l've kind of wanted to be in a world that's gentle and loving and nurturing <laughing >. I've had to acknowledge my own anger and actually do some expressing of it too. And I've had to also accept that the world isn't always going to be that way. But I certainly seek out and you know, want to be in more environments that are about, you know, about warmth and loving and goodness between people than people feeling at odds with each other. (Peter2, \36)

In these remarks, Peter is particularly concerned about his anger. It is not an image of himself that he wants to be associated with. Like Peter, anger (even "rage") was also a feature of events related by Andrew, and although Podraig did not discuss perpetrating 
violence directly, he describes taking his "rage out against the world for a couple of years" (Podraig1, \$73) through serious criminal behaviour.

\section{Sport}

While various strategies were used to deal with increasing distress, including avoidance (e.g. absenteeism, truanting, etc.), sport featured prominently as a strategy for alleviating ongoing distress in their teenage years. However, non-participation in sport was also significant. Each of the men mention that not playing rugby was seen as important to them being targeted as being-different. Rugby exerts a strong life-long influence that, even now, continues to position them as being different. As Andrew puts it:

I think even to this day I struggle with the fact that I didn't play rugby. You know this whole Kiwi thing about, you know, [being] blokey. (Andrew2, \$11)

Nonetheless, while not playing rugby, each of the men seemed to make some attempt to claim inclusion through involvement in sport as teenagers - that is, except Peter who instead, took up using cannabis. For instance, Andrew chose to compete in triathlons and play soccer. To some degree, playing soccer meant that he was involved in a team and was therefore included in a peer network. Although Andrew might be marginalized elsewhere, his inclusion in a male team sport ameliorated against his isolation. Like Andrew, Podraig sought refuge in the solitude and "confrontation" of marathon running.

The running was really the thing that was my drug at that time. It got the adrenaline that got things moving. It was a kind of fight against the world when I was out there and it would get, it was sort like of when the adrenaline comes up and you either flee or you confront. The running was my confrontation to it and the adrenaline would pump. And before I really started drinking at about 18 or 19 and I found that there was a quicker way to it, that was my answer. (Podraig1, \26)

Running seemed to be an important test for Podraig, affirming something about his existence. At the same time the solitude offered by long-distance running avoided the psychological pain that otherwise seemed ever-present.

William's strategy was to be "independent" of his peers, like Podraig, generally choosing individual pursuits. Although his isolation was somewhat tempered by his horse riding, 
for which he prided his skill at dressage. An additional, and important strategy for William, was to simply absent himself from school. While William chose to name his separateness as "independence" and "aloofness", his school experience was clearly one of being excluded even though he chose to claim responsibility for this as his choice. While William continued his love of horse riding after leaving school, he became strongly involved in a biker group. Although at first glance this appears unusually sociable for William, the rules of bikers emphasise the separateness, "independence", and emotional isolation with which he was already familiar. However, his lack of trust was reflected in the "code" of the gang, or "way of life", that excludes intimacy:

I mean, I suppose one of the things too, one of the reasons why I felt safe when I was with that bike crowd was basically we were all people looking for solace without questions being asked. (William 1, П248)

Similarly, Andrew continued to be involved in individual sports following school through fishing, hunting, driving, triathlons, and tramping; all of which were individual pursuits, but with a social element. Podraig did not speak about any involvement in sport after leaving school. Peter did not seek out any sporting activity, stating that he has never been comfortable with competition. Instead, Peter immersed himself in artistically expressive outlets.

\section{Drugs and alcohol}

Drugs (mostly cannabis) and alcohol were important features of these men's lives from their early teenage years. While alcohol and drug abuse variously complicated these men's lives as teenagers and young adults, they see a link between their entry into heavy drug and alcohol use and the level of distress and anxiety present in their everyday lives. They do not portray their drug and alcohol use as some sort of "youthful" or developmental risk-taking experience. Additionally, their remarks point to a kind of relationship with sport, in that sport appears to be an alternative form of relief or escape from distress; albeit inferior in terms of speed and efficacy. In this sense, alcohol and drug abuse are constructed here as a form of self-medication using substances that were accessible to them at the time.

Unlike the other three men, Andrew did not abuse alcohol or drugs in his youth. Nonetheless, it remains significant to his story that he explicitly considered his position 
on alcohol abuse, making a conscious decision to be abstinent. In this sense, alcohol was a significant presence in his teenage years with which he struggled. This becomes clearer in his rationale. The choice of abstinence was due to the highly adverse impact of his father's alcoholism on his family and childhood home. Instead, Andrew states that threw himself into sport, eventually extending his athletics into such arduous events as the triathlon.

The significance of alcohol for Andrew is also shown later in his early adult years when he began to drink alcohol as part of a relationship. In his remarks about his initial experience of drinking, he found alcohol to be:

a godsend, [providing] a place I could go to. Under the

influence of alcohol was just bliss. (Andrew1, \41)

So, rather than drugs and alcohol having not had an impact on Andrew until his early adult years, it had already been a long-standing issue for him through the conscious consideration of abstinence. It is the very fact of this awareness, and what he chooses to do with it (i.e. abstinence) that has already made alcohol an issue for him.

For the other three men, abuse of drugs and alcohol appears to have occurred as soon as they were old enough for it to come within reach of their social context. Except for Andrew, these men were bingeing and using drugs from their earliest high school years. While alcohol was the substance of choice for William and Podraig, for Peter, it was drugs; predominantly cannabis. However, like William and Podraig, abuse escalated throughout his teenage years.

There were some times in my late adolescence I would put it down to where I experienced what is fairly common I think, which is some self-destructive tendencies, which is around wipe-out with alcohol. Sometimes with other drugs. Marijuana and yeah, mostly marijuana which I used to use to an extreme degree where I would be unable to kind of I would be in a pretty ragged state at times. And I often wondered why did I need to go that far because it actually got past being pleasant you know. It's just sort of, feeling bloody awful really. (Peter1, \12)

When Peter reflects back on this period he expresses puzzlement at the extremes he now sees that were involved, labelling it self-destructive, and wondering what it was that 
drove him. However, while he names this behaviour as self-destructive, Peter states that it was not specifically suicidal:

\section{But that to me that wasn't about specifically suicidal but it was it was, you know, I think that's a fairly common experience of people to have some of those times where we they we just want to self-destruct. A nihilistic kind of thing really. (Peter1, \12)}

While Podraig's alcohol abuse was heavy in his late teenage years, the death of his first partner resulted in an extraordinary level of cannabis use and very little else, including food and water. Unlike Peter however, Podraig did end this period by an explicit act to end his life. He was discovered hanging and admitted into the local general hospital for medical and psychiatric care.

While William relates some use of cannabis, his concerns focus almost exclusively on his experience of drinking heavily from age 13 to try:

...drowning it [feelings] out, or trying to drown it out.

(William 1, П285)

He left school the next year, and at age 16 had his first psychiatric admission following an attempt to shoot himself. His first experience with psychiatry was "horrendous". His drinking escalated, and he recollects that he often mixed alcohol with his prescribed medication.

Although substance abuse appears to have been initially used as a means to relieve the anxiety of day-to-day life, it eventually added another layer of difficulty to already complex issues for these men. For Andrew and Podraig, substance abuse (including alcohol) led to violence and crime. Andrew relates violent rage associated with his binge drinking. He also attributes drinking to the ending of his first relationship and loss of work. Similarly, Podraig entered a career of crime and started abusing "hard" drugs.

\section{Normalness}

A common thread for each of these conversations was that throughout their childhood and school years these men recollected understanding their emotional state to be "normal". While they understood themselves to be different, there is a complete absence of recollection of understanding themselves to be anything other than normal. 
This stands in stark contrast to their detailed descriptions of distress and the growing awareness of being different. While an awareness of being different to their school-age peers grew, these men were silent on being other than normal. As William says,

I knew no other way, that's just the way I felt. (William1, \11)

Each of the men seemed to draw complex, and apparently contradictory distinctions between normal and different. For instance, the following part of the conversation with Andrew shows one view of difference and normality.

Andrew: I would always start the year off in a higher stream of class but then always end up down in $C$ or $D$ and it just kind of indicated to me that I wasn't as intelligent as some of the people thought I was, you know, that thought I was intelligent.

Brian: So you saw it that way rather than...

Andrew: Oh, it was reinforcing the whole time, and it was knowing that the school certificate, that a certain percentage had to fail.

Brian: So in that sense you wouldn't have seen yourself different to the other kids, just not as intelligent?

Andrew: Yeah. Yeah.

Brian: So no idea you were depressed either probably?

Andrew: No. Just living it.

Brian: That was normality for you. There was not something particularly a problem here, so no reason to even ask for help?

Andrew: No.

(Andrew2, 凤37-44)

In this excerpt of my conversation with Andrew about his deteriorating academic performance, he puts forward a view in which he positions his poor intelligence as something separate or distant. He does not see himself as fundamentally different from the norm of his peers. There was simply no prompt or motivation to seeking help. His experience of the world had led him to understand that others simply got their assessment of his intelligence wrong. While Andrew describes his emotional experience as "just" lived, in a taken-for-granted way. Until others, or other circumstances named them as abnormal, the need for help was not prompted for their increasingly distressed psychological state. The adults around them in their childhood years also did not see 
cause to intervene; at least until a crisis point was reached (e.g. Podraig's emotional collapse).

While help for emotional needs remained unrecognised at school, the help of teachers was sought out for physical threat (i.e. bullying). However, in other circumstances adults were also the source of their distress; for instance, Podraig's humiliation at school assembly for his family's poverty and his description of his search for affection as causing him to be vulnerable to further victimisation through sexual assault.

Peter provided a somewhat different example about help. At school, Peter described his teachers and other adults as supportive of his "Bohemian" difference and desire for creative expression.

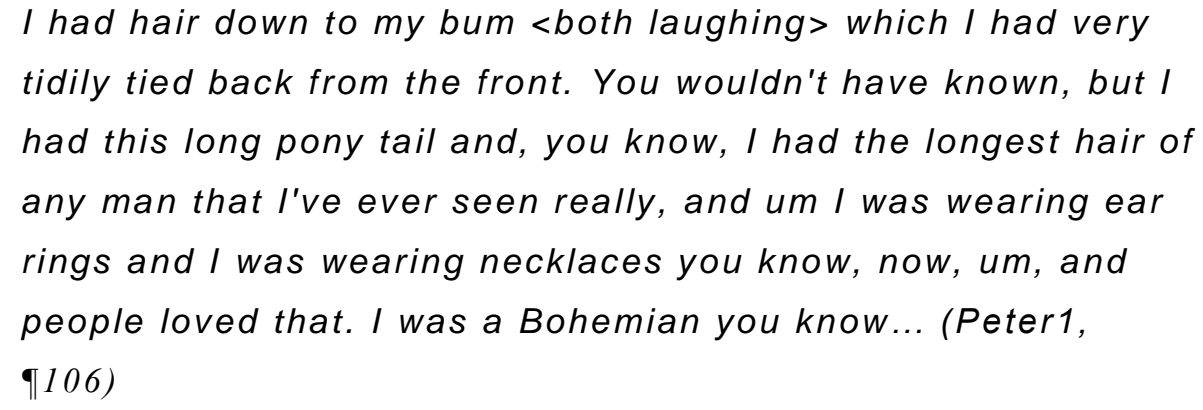

In particular, his school principal stood out for modifying requirements of the curriculum to suit Peter. However, reflecting back on this showed that this "help" made him even more different to his peers through the special arrangements. As a result, Peter became increasingly aware that he was inadequate, unable to cope with the "hard" subjects of maths and science, and not up to playing sport. The help seemed to emphasise the problem rather than stopping it or making the problem go away for him. Similarly, Podraig appreciated the attention and care his mother paid to him, but his problems too, appeared to get emphasised through the vociferous accusatory responses from his sisters.

\section{Finding effective help}

Looking back on their school years, what was purported as help then was variously ineffective at resolving the issues that it was sought out to deal with and appeared to exacerbate the underlying issues or even result in a further a further breech of trust. While peers were frequently the source of psychological pain, the company of girls was somewhat preferred to that of boys. By the time these men left school there appeared to 
be little experience of effective help and support for their distress. Where resources were discovered that ameliorated their distress (e.g. truanting, sport, drugs, etc.), it was as a result of their own efforts.

In their later teenage and early adult years two different paths were taken in which these men encountered the help of health professionals. Prompted by crises, Andrew and Peter sought out professional "help" from their general practitioner (GP). Many years of repeated crises of emotional distress. For instance, Andrew described a cyclical spiral downward of binge drinking, involving deterioration at work and loss of relationships. For some time he had also endured increasing panic attacks. He eventually moved back to his parent's home. While this was a refuge for him, it was also a place of bad memories.

\section{It was hell to live with them and I would just stay in my room, and I remember some days for quite long, you know, months, consecutive months, sometimes not even going outside the house. (Andrew2, \25)}

At this stage, Andrew felt that a crisis point had been reached, feeling that he was in a much more dangerous place than he had previously coped with, visualising himself deliberately driving into a specific bridge. A recognition that he was stepping over his "line in the sand" beyond which he did not have self-control forced him to seek help from his GP.

While for a time in his early adult years Peter had been mostly enjoying life using cannabis and partying. However, he increasingly began to experience debilitating panic attacks that left him overwhelmed, scared, unable to move, and wishing he wasn't there. These were associated with day-to-day stress (e.g. raising a child) that, while difficult, he saw other people managing. However, stressful circumstances could leave Peter sobbing, cold, terrified, and unable to remain on his own. Peter sought support from friends and family (not his birth family). He recollects that thoughts of killing himself seemed "too horrific" to inflict on everyone; he did not want "to do violence to those people" (Peter1, 979). Nevertheless, he found himself planning how to bring about his own death in such a way that those around him would consider it an accident. This thinking prompted Peter to seek professional help from his GP. 
Andrew and Peter were both prescribed medication from their GP. They were also referred to various forms of counselling and psychotherapy. For both of them, medication was viewed as a means to enable them to work on their problems rather than as a cure. However, both Andrew and Peter also experienced counselling that was both, effective and not effective for them. This included different therapeutic approaches from both health service professionals as well as others (e.g. counsellors, psychologists). Looking back, Andrew regards that the most effective help and support has come from Alcoholics Anonymous (AA). Another effective strategy for him was to confront his brother about sexually assaulting him as a child. While he expected a denial, and this is what happened, he came away feeling sufficient closure was achieved in order to move on.

The notion of what has been effective help is unclear. Peter seems to come close to defining the difference in the following remarks:

Well ah, the psychotherapeutic work has, you know, through articulating a kind of understanding the history, my history and my experience. I've, actually there's a whole lot of things about my relationships $\langle\ldots>$ there's been a lot of healing through that. It hasn't required me to storm and rave and, you know, and gestalt and you know, cathart <laughs>. And l've been really surprised at that cause you know I talk a lot and I'm quite an expert talker <laughter>. And I always felt I was an expert in what was wrong with me if you like, but actually the talking of the psychotherapy has been very very effective in chipping away at some of that stuff. And actually you know, the way it was described to me when I asked what the process was, cause I got impatient with it <laughs>, the way I think anyone does you know, was very much about that thing of bringing into conscious understanding the real guts of the story basically, I mean to have some power over it in my life instead of being at its mercy. (Peter1, \$100)

From this description, effective therapeutic "work" involves an historical exploration of the trajectory to suicidality in a way that in turn, leads to a shift in understanding. The result of effective help then appears to have been a way of thinking historically and critically in order to develop a different construction (i.e. "the real guts") of himself 
from these events. In changing his view of himself in his past, Peter has found that he changed his present circumstances.

Finding help was however, a very different story for William and Podraig. In response to attempts to take their own life they were compulsorily admitted for psychiatric care; William was admitted into an institutional setting in his mid-teens, and Podraig into a medical unit of a general hospital in his early adult years. This "help" was experienced as traumatic, leaving them both to conclude they would have nothing to do with psychiatric services ever again. Decades later, the anger at the earlier experience is still very apparent in the conversation I had with William:

At sixteen I tried to blow my head apart with a rifle. That time

I was put into <institution> I hated it. I was drugged to the

eyeballs. I really don't remember that much about it but what I

do remember yeah, I swore I'd never have anything to do with

mental health services again. I mean nobody told me what was

wrong with me, luckily, because apparently I was labelled

schizophrenic. But then back then everybody was

schizophrenic. (William1, \50)

Nonetheless, William has had ongoing experiences with mental health services since that early admission. He has experienced various medications as well as electro convulsive therapy (ECT). He has had various diagnostic labels attributed to his repeated hospital admissions. In contrast to his first psychiatric admission, his regard for mental health services has become much more positive. William attributes this change to good relationships with his psychiatrist and GP. Furthermore, he now has access to much longer consultations and good follow-up after discharge from hospital. He contrasts this to previous times when he has felt abandoned in times of crisis, when he could only get the answer phone at mental health crisis services.

Unlike William, due to serious medical complications, Podraig was treated in a medical unit. He recollects feeling treated differently. The nursing staff communicated to him that his problems were simply an issue of "mind over matter" (Podraig2, ๆ39). He says he was not helped, but instead, stigmatised and neglected. He left the hospital after "recovering" feeling an intense anger at the world that decades later remains present in our conversation:

Brian: Did that anger start while you were in the ward? Podraig: Yeah. 
Brian: Just left to think?

Podraig: Yeah, because I thought you know what was the point of hauling me down from the road? Why not just leave me? I mean what have they done? Where's the intervention? What's happened? Nothing's changed.

Brian: What did they do?

Podraig: Nothing.

Brian: Not even anti depressants?

Podraig: Nothing.

Brian: No?

Podraig: They ended up giving me an anti depressant after I left.

Brian: Oh, okay. I was going to ask because...

Podraig: Which was absolutely useless. It was one of these things where you had to take about twelve a day and then it gradually goes up to about 24. And it did nothing. I had it for weeks and weeks and weeks and it changed nothing. All I got was angrier. Nobody was dealing with the issue. With me. All they were doing was trying to <? get> me out of the <? way > So my anger just increased till I threw the whole bloody lot away. (Podraig2, \55-67)

While Podraig feels certain that the deep anger kept him from killing himself, it was also an impetus for entering a long period of serious crime which, in turn, produced further experiences of violence and victimisation as well as drug abuse. This in turn, led to further attempts to take his own life, sometimes with the antidepressants that he had been prescribed. Again, attempts to take his own life led to other hospital admissions during which, like William, he acquired different diagnostic labels. The multiple experiences with psychiatry over these years have continued to leave him feeling unhelped, invalidated, frustrated, and angry.

Podraig has also explored alternatives to psychiatry; in this he has traversed the range from meditation gurus to self-help literature. He recollects that in some ways there seemed to be something in each experience that was helpful. At the suggestion of his partner at the time who expressed her confidence in his abilities, Podraig has since successfully undertaken a degree programme. He was surprised to find not only was he successful, but that the subject area deeply interested him. 
Nonetheless, during his time at university he experienced a number of crises in connection with his relationship, as well as discovering he had a chronic physical illness. These events eventually led to him being drawn once again into a period of heavy drug use. However, unlike earlier times, he sought out a clinic for drug and alcohol abuse and was admitted for a prolonged period of rehabilitation. Here, he underwent a very different process to his experiences of psychiatry. He describes what happened as having the layers of his identity stripped back:

\section{I got an assessment done at $A$ and $E^{18}$ at <hospital>. And I went in there on the <exact date>. For the first two years I couldn't really <inaudible>. The onion had been stripped. The trouble with onions is that their skins are right to the centre and if you peel back the skins you end up with nothing there. That's what I felt. And I didn't know who I was or what my identity was. It was really quite a lonely time. It was a really lonely time. I got depressed quite a bit and I filled it up by having my phone number available as a contact for anybody who was having alcohol or drug problems and wanted to ring} AA. (Podraig 1, \105)

He regards this admission as a turning point in his life, setting him on a path of ongoing recovery.

\section{Ongoing recovery}

At the time these conversations took place, each of these men had found strategies to relieve their psychological distress that they believe are working. At the same time, this positive self-evaluation is tempered by a realisation that each of them has previously felt that they were on top of their issues, and yet experienced further psychological crises. To get to this point in their history, many different approaches to "help" have been tried and experienced throughout the intervening years. In their reflections on this history there appears to be no single outstanding point at which recovery commenced, although a number of key events are identified as influencing the path they have taken.

All four men have very clearly stated that, although not wishing their experiences on others, the path they were set upon has meant that "I [have] learnt a lot about myself" (William1, ๆ196). Podraig's remarks about stripping away the onion layers of his sense

\footnotetext{
18 Accident and Emergency unit of the public hospital. Elsewhere called an Emergency or Casualty department.
} 
of self describe the profound levels of experience to which this comment refers. They each also point to the importance of being resourceful by learning as much as possible about what was happening. In this regard, these men do not point to one reliable source, but rather point to multiple sources of information and to different people and different services. The range of resources includes health professionals, self-help resources (e.g. books) and groups (e.g. AA), as well as people within their day-to-day relationships. William in particular, argues the importance of seeking to be informed. Podraig highlights that it is not known what will become useful until later, and only upon reflection that it can be seen what has contributed positively and what didn't, so he suggests to be broad in selecting resources.

Developing positive relationships with people was highlighted as a key issue. This took different forms. For William, Andrew and Peter, their partners (and their children) provided a means to continue living in times of great psychological pain. Peter describes this connection quite powerfully to me a number of times; for instance:

The reason I wouldn't do it was because the loving of my partner and her family. My very, very, intimate friends who were around me. (Peter1, \88)

Other relationships were also important. William regarded a relationship with his psychiatrist and GP, as a key reason for accessing mental health services. Andrew and Podraig also found that involvement in Alcoholics Anonymous (AA) was a critical part of their ongoing strategy. It was through AA, that they discovered other people needed them on the other end of the telephone, and that their knowledge and experience was valued. This is reciprocated, for they both rely on their AA connections to guide and maintain their recovery process.

They each emphasise the necessity to "work" on their problems. While Andrew and William frame their problems, in part, as a biological (i.e. as genetic and organic changes to the brain) problem, they both strongly assert that:

I'm sorry, but I think counselling is really important. I mean handing out pills is not enough. (William1, \272)

"Work" then, meant revisiting the history and developing a different understanding of "the real guts of the story" (Peter1, \100). Medication on the other hand was valued as a means to enable the work to happen. 


\section{Chapter 8}

\section{A (RE)INTERPRETATION OF FOUR CONVERSATIONS}

Having previously set out the key points of my understanding of my conversations with the four men in this study, this understanding is revisited at a deeper level in this chapter. Through an interpretive analysis of transcripts (supported by memos), this chapter undertakes a further (and different) understanding of the conversations. Transcripts are a link back to the original conversational events in a similar way that medical records serve to connect a clinical analysis to the original interview with a client. Transcripts are an aide memoir and audit trail. As a fixed historical record, they are made available to many more people than were present at the original event. While separate from the original event to which they refer, these texts serve to enable a deeper understanding to be developed through further interpretation. In this way, the horizon of the clinical lens is imposed upon the client's story and consequently becomes the clinician's interpretation. Similarly, while referring to the original conversation, the interpretation in this chapter is not the same as that from the conversations themselves, yet provides further information about the original conversation through the opportunity provided by the transcripts. In the process of (re)interpretation ${ }^{19}$ a different horizon of meaning is imposed on the text, consequently a different story is told, and a different set of issues is revealed as significant.

Home and school are shown to be key social contexts for the construction of understandings that become significant for these men. As children and young people, they understand their victimisation as "normal" until, in the social context of school, they are increasingly excluded on the basis of difference. In this chapter, this process, and the trajectory leading from this process to suicidality, is shown to be a gendered one. In revisiting these conversations, bringing the taken-for-granteds into view, this

${ }^{19}$ I use the parentheses in (re)interpretation to indicate that while it is a new interpretation, it is another interpretation of the original to which it refers back to. That is, it is both an interpretation and reinterpretation at the same time. 
chapter will focus on the way in which masculinity influences the meaning-making processes in the pathway that these men have taken in their experiences of suicidality.

\section{Historicity and victimisation}

The social "fact" of what actually happened in these men's lives as a discoverable truth is not at issue here but rather, the way in which their history was experienced and then reinterpreted in an ongoing attempt to better understand themselves and their world. Specific events in their lives stand out as significant, even life-changing, according to this meaning-making process. Historically, certain events are viewed as having been influential while others are barely noticeable.

Heidegger (1962) has said that the world is already replete with ready-to-hand meanings through our cultural and linguistic heritage, and that we are "thrown" into this world. These already existing meanings remain tacit and unexamined insofar as assumptions are not interrupted in some way that requires our conscious attention (Martin \& Thompson, 2003). Seidler $(1989,1994,1997)$ has for instance, argued that our present understanding of masculinity is historically linked to our Enlightenment heritage. While these already existing meanings make it possible for the world to be intelligible, it correspondingly constrains the range of possible meanings (Gadamer, 1965/1975). In this regard, the body is already endowed with taken-for-granted gendered meanings. Within the hermeneutic perspective, to understand suicidality then is to understand it as

a deeply historical and embodied endeavour, inextricably tied to the social context through language and culture. Through temporal distance, some events will stand out for these men as having been influential; this of course, is from the vantage point of the present and as such is a viewpoint that is culturally and linguistically situated in the present.

To relate their understandings, these men commence their sense-making story from their childhood, describing what they now comprehend as traumatic events. This understanding is from the vantage point of their present horizon of meaning. The experience of victimisation in the home as children was understood in the past context as "normal"; and as such, was invisible and unquestioned. Construed as normal, there was no impetus to question the taken-for-grantedness of their experiences of violence or neglect. Also as children, their experience was also likely to be one in which there was no experience of being able to cause change. Their father, or father figure, embodied 
power within their childhood home. As children, their experience was likely to be one of powerlessness, and understood as such in a tacit unacknowledged way. For Podraig, this understanding of powerlessness had been put to the test resulting in the practical experience of being overpowered (i.e. violently assaulted) by his father or stepfather. This somatic and emotional experience of powerlessness then, had become embodied at an early age and understood as normal.

School brought experiences that challenged existing understandings. At school, they began to make sense of themselves as "different". However, being different, necessitates something against which to be different. What it was that they were different to did not become clear for many years.

With respect to health, Gadamer (1996) has said that well-being, as a state of equilibrium, is an equilibrium within the world and not simply an absence of physiological dysfunction. Well-being is well-being within the world. That which is normal and taken-for-granted is not usually conscious to us until something is experienced as "wrong" or not as it should be, or as Gadamer has said, that "something is lacking"; he states that "in its very freedom from disturbance, [well-being] almost completely escapes our attention" (p. 73). As children, difference was experienced negatively in quite material ways, for instance, through the violence of bullying and exclusion from peer groups. The notion of difference makes sense only in relation to something else. The contrast between presence and absence, discloses that something was there. Through its relativity to something else that is taken-for-granted, the pain of being different, of being victimised, and of being excluded, discloses something of what had been taken-for-granted. In this case, through what bullying achieves, bullying discloses something about when bullying does not occur.

Understanding these experiences of "difference" did not occur independently of what had gone before. In repeated cycles, unexpected events are cause for reflection, that in turn also shift and extend previous understandings. Becoming "different" at school then occurs in a dynamic between past and present, whilst also situated within institution of school, as well as peer relationships in the playground. The "struggle" to make sense of this experience includes the practical working out of it in both the playground and classroom. In other words, not just any understanding will do. For instance, Podraig's consciousness of his small stature constrained his ability to locate himself 
socioculturally. He could not for instance, construe himself as one of the First $\mathrm{XV}^{20}$ Clearly, being different was also construed as being less-than.

The past also both provides possibilities and constraints to understand future experiences. For instance, experiences of powerlessness, violence, or neglect in the childhood home become ready-to-hand understandings upon which to make sense of later experiences at school. Against their historical background, the experience of other boys targeting them is readily associated with their past experiences, and therefore readily interpreted in an almost taken-for-granted way. However, that their experience is not the same as others in the school ground is a new experience and hence, stands out as "difference".

Fathers are complex and contradictory figures in these men's reflections on their childhood. Early memories of a home milieu of "happy" relationships "goes to crap" in later childhood. Fathers leave and step-fathers enter their lives. Fathers who are drunk, violent and threatening are feared and also loved. Their narratives show that their experience of fathers and stepfathers bequeathed a tradition that remained something that they struggled with from a very early time in their lives. This is evident in their narratives of the following years, showing that the struggle around these issues are the basis for later understandings of their life experiences. In a real sense, as these men look back, the trauma they experienced are foundational experiences upon which later understandings are constructed.

Trauma, and consequently fear and terror, may be as a result of family violence or loss, but the central figure in this experience is their father or step-father. The distressing experiences created by their fathers occur within particular contexts of childhood. However, significant to what they related that was influential to the development of their understandings was also what was absent; that is, what was not mentioned that I had expected to hear about. In these conversations, until their school years these men do not mention any other adults except for their mothers. This doesn't mean there was no other adult present in their lives, but that for some reason they are not significant to what these men attempt to convey to me.

${ }^{20}$ The First XV is a term used to mean the first 15 members of the rugby union team. 
In their childhood home, these men do not appear to have had access to adult help except for their mothers. Yet, mothers are blamed for not protecting or preventing the terror and fear or neglect experienced from their fathers and step-fathers. Mothers are variously seen as inaccessible and remote, silent, and also subjected to fear and violence. Podraig draws this picture vividly when saying that as a child he states:

...[I] spent all my time in my home with pretend friends for a long time. (Podraig 1, \३3)

A picture of isolation and powerlessness appears from a very early age. Similarly, school brought further related experiences of violence, fear, and an absence of adult help. As in their home, the teachers at school did not stop the bullying. As Martin \& Dawda (1999) have stated, experience shapes understanding, therefore understanding is also an embodied experience. Hence, self understanding must be congruent with its practical working out. The practical day-to-day experience and understanding was that of victimisation.

\section{Experiencing re-victimisation}

Consistent with the current literature that demonstrates the significance of school in shaping the development of young masculinities (Connell, 2000; Mac an Ghaill, 1994; Mills, 2001) these men relate significant events from these years in the context of school rather than any other social location. The construction of their school-boy masculinities involved the school as an institution, teachers, sport, curriculum, and their peers (both male and female). Mac an Ghaill (1994) has argued that schools are institutionally gendered, arguing that the authority of the school is generally held by and serves the interests of heterosexual men. Institutional expectations are therefore gendered. This may be seen for instance, in the gender-based expectations in sport and curriculum. Institutionally, there was an expectation on boys to play rugby as a sport. Other sports were regarded as "sissy". Similarly, in the curriculum there are "hard" subjects and "soft" subjects. Boys were expected to do the "hard" subjects. That boys sometimes undertake the so-called softer sports or subjects does not necessarily challenge the accepted norms of masculinity. For instance, while Peter undertook the soft subjects, this did not serve to bring these subjects into the hegemonic masculine domain, but rather, Peter was excluded from legitimate masculinity leaving the hegemonic standard uncontested. 
Masculinities are constructed in the playground through peer and teacher dynamics (Mac an Ghaill, 1994; Mac an Ghaill, 1996; Phoenix \& Frosh, 2001; Swain, 2002). In particular, bullying had a profound impact at school upon these men. School ground violence was used to exclude certain attributes from school ground hegemonic masculinity. This included smallness of stature, passivity, "being sensitive", creativity, accent, and styles of dress. A hierarchy was being enforced within the school ground culture based on excluding the expression of certain emotions and emphasising physical control. This was congruent with school authority in setting the curriculum and the privileging of certain sporting activity over other sports. As Connell (1995) has argued, hegemonic standards are not necessarily determined by any particular group but requires some degree of correspondence between the cultural ideal, institutional power, and individuals. So, while there may be obvious differences between playground expectations of peers and those of teaching staff, at some point, there is also a convergence. While not necessitating an explicit agreement, the convergence of interests is range generally acceptable to all. In this interplay between scrutiny, reward, and punishment, lies the power of disciplinary processes (Foucault, 1975/1979).

As children entering school with pre-existing understandings of what constituted normal in a taken-for-granted way; that is, the presence of violence and fear was unquestioned (as were their responses to this). However, what was previously their unexamined assumptions about their home life were constructed as "different" through the wider social interactions of school. In particular, encountering the expanded social context of school life brought an awareness of things about their bodies and thinking that they began to understand as a differentness from that of other boys in the school.

In their stories of their school years, it was from their male peers that they feared violence and exclusion. Being victimised was of itself a reason to be marked as different; "normal" boys were not victimised. Part of this process of understanding their differentness was an emerging awareness that, what marked them as different, were also associated with femininity through homophobia. That is, being victimised, not fighting, not playing rugby, physical deformity, being sensitive, dressing differently, doing art or music, associating with girls, seeking the protection of teachers, and so forth became associated with femininity. Soccer was "sissy" (Andrew), and music rather than maths, was defined as taking "softer subjects" (Peter). Through a process of ongoing victimisation their differentness became embedded in their historical background. This 
was built on their previous understandings of violence and bullying in relationship to women and men, as well as other hierarchies; such as age. There is an absence of any influence from within and without the school that seemed to significantly question their understanding of these experiences in any other way.

At school, fear of violence and the experience of victimisation is extended into a wider social context. In a sense, as children, the experience of victimisation in their lives is now global. The social context of school brings further experiences of victimisation of male violence, and significantly, also now connects male violence to sexuality through homophobia. By their later school years, the meanings of differentness and violence are interpreted as an expulsion of homosexuality. For Podraig and Andrew, male violence is additionally linked to sexuality through their experiences of sexual assault.

\section{Struggling to fit in}

At the same time as realising themselves to be different, there was a struggle to fit in. There were different aspects of themselves that these men mentioned that indicated what it was that made them different: appearance, dress style, grooming, behaviour, social skills (e.g. being quieter than other boys), sport, relationships to peers and teachers, and choice of school subjects. Through their engagement with the sociocultural context of the school, these boys understood themselves to be deficient and less-than other boys. They were aware that it was these attributes that were targeted in the bullying and exclusion they experienced. However, during their school years, the external constraints of physical violence that targeted specific attributes or behaviours became internalised so that upon leaving school, these boys had internalised the hierarchical structure, knew their place in it, and monitored themselves for signs of transgression. As Foucault has argued, through the internalisation of surveillance, they had been disciplined in accord with the dominant cultural view (Foucault, 1975/1979).

Motivated by their distress, their school years were characterised as a period of struggle. This was crystallised as a quest "to fit in". Like Podraig's earlier portrait of himself as a little boy seeking his father's love and at the same time terrified of his violence, these boys were grappling with the challenge of fitting in while at the same time fearful of the rejection and threat of violence from their peers. The institution of school was not separated from this struggle. This struggle took place within an institutional context that helped shape the struggle to make sense of difference and an inability to fit in. 
An extensive history, and consequent understanding of self as a victim, existed by the time they grappled with issues of sexuality and sexual intimacy in their teenage years. Furthermore, Podraig and Andrew had both experienced sexual assault from older males. They remained wary of males around them and the potential for further sexual assault. This impacted widely on their relationships with male peers and adults, causing them to be persistently vigilant for potential sexual vulnerability. The ever-present need to be watchful meant that the opportunity to develop and experience trusting relationships was severely curtailed. In their teenage years, developing sexual intimacy was therefore fraught with these additional tensions.

In the case of these men, it is clear from these discussions that heterosexuality was the dominant norm. As the dominant cultural form, heterosexuality was simply not questioned by these men. On the other hand they were highly aware of what constituted the trigger for homophobic responses as severe negative sanctions existed to curtail homosexuality. Being homosexual was discussed in these conversations as something that was greatly feared due to the vulnerability, threat of violence, and ostracization. As a result of working through his experiences in different sociocultural contexts at home and at school (e.g. religious beliefs, home violence, school ground homophobia, and sexual assault) Andrew positioned homosexuality as some sort of disease or personality defect of the body that might occur contrary to his will: "I thought god, maybe I'm gonna become a homosexual” (Andrew1, 『108). Ashamed of his body, and believing he was undeserving of affection and care, Andrew rejected physical intimacy until his early adult years. By being so closely connected to the body, exploration of sexual intimacy was a powerful signifier of conformity (or not) to heterosexuality. At the same time intimacy was desired, it was also feared.

Yet, conformity to the heterosexual standard through sexually intimate relationships was additionally complex because of already present understandings (prejudice) about themselves developed from earlier experiences of victimisation, fear, sexual assault, and isolation. While both Andrew and Peter worked this tension through by avoiding sex, Podraig took from his experience of sexual assault the understanding that intimacy was a transaction; that to obtain affection, sexual intimacy had a personal cost. In his sexual relationships with young women he describes a distancing and control over the transaction by "managing" intimacy. 


\section{Sport}

As school boys, these men described being highly conscious that not playing rugby marked them as different in important ways that no other sport could address. Somehow, it marked them as less than other boys. The role of rugby in shaping school boy masculinities in New Zealand (Fougere, 1987; Pringle, 2002; Rout, 1992; Town, 1999) and elsewhere (Edley \& Wetherell, 1997; French, 1999, 1996; Phoenix \& Frosh, 2001) has also been observed by others as significant. Such an emphasis on rugby is not isolated from the larger sociocultural context. Phillips (1996) has described rugby as defining the identity of a nation. He argues that rugby brought together the "muscular virtues of the pioneering heritage" and the need to contain that spirit within civilised boundaries (p. 86). Not playing rugby then, marked them as unable to meet the hegemonic standard, not only for the present, but is a significant constraint upon their view of themselves as men into the future. Not playing and not even liking rugby were further markers of their difference to which they were acutely aware.

Nonetheless, except for Peter, these men emphasised the role of sport in their school life. Of the four men, Andrew was the only one to play a body-contact sport. In his discussion of soccer he shows he is aware of the role rugby had as a proving ground for a physical masculinity. While he points to the severity of his soccer injuries as a claim to masculinity through "taking it", he recalls that this was insufficient, as soccer was the game for "sissies". In this, Andrew clearly connects injury and pain to the hierarchy of maleness. The degree of injury was insufficient to lift Andrew's claim to fit in.

Athletics provided a different set of tensions. Although athletics does not have the privileged status of rugby, the comments from these men suggest that in doing longdistance running, the relationship of the mind as being in control of the body was a private affirmation of masculinity. Furthermore, the success of Andrew and Podraig at athletics emphasised this meaning-making in that they related experiencing little other success in their school years. Podraig perhaps best captured the significance of this meaningfulness in athletics when he talked about the adrenaline, and confrontation he experienced in long-distance running. His language well captures the dominant masculine ideals of competition, rationality (of the mind), and physical strength. However, unlike rugby, athletics does not privilege the controlled violence and exclusion of women (Fitzclarence \& Hickey, 2001; Hutchins \& Mikosza, 1998; Schacht, 1996). 


\section{Difference and being "less-than"}

Consistently, these men expressed a childhood in which they said they discussed experiences of not fitting in. As an experience of something lacking or "wrong", difference and feelings of inadequacy point to what it is that is considered normal, as it is this that they differed from in a negative way. While their interactions as children (and later as younger teenagers) undoubtedly included a multitude of forms of communication, explicit victimisation provided unmistakeable experiences through which they rapidly became aware of the motivations for their exclusion. That is, they were aware of what it was about them that was being targeted. The nature of what it is that is different or shameful therefore begins to define the shape of what is currently accepted as "normal" from which they are excluded. To put this another way, the range of normal did not include certain attributes for which they were targeted. Victimisation begins to answer the implied question of "fitting in"; that is, it answers the question of to what did they not fit in with?

Through threat and overt violence their victimisation taught what it was about them that meant they were different and inadequate. The normal that these men identified from their childhood was that they were different from other boys. They differed from "normal" boys in a negative way. Their differences were associated in various ways that could be easily associated with femininity; smallness, passivity, clothes, etc. Additionally, at some point during their school years, being a victim itself became a target for further exclusion.

There is a distinction between victimisation and losing a fight. If men are to be consistent with David and Brannon's (1976) oft-quoted four themes of the "sturdy oak", "big wheel", "give "em hell", and not do "sissy stuff"; then men cannot also be victims, as it is women who must be the victims of men's violence (Gilligan, 2004). Yet, both victimisation and losing a fight involve violence and men both win and lose. Of itself, losing is not necessarily victimisation. However, school-ground bullying is not doing battle nor doing sport. What it is that defines bullying is the social context, the spectacle (even when others are not directly present, someone getting "done over" becomes "known" throughout the school). Difference is both constitutive and constituted by the violence. Bullying is a policing of the boundaries between different and not-different; and it is perpetrated by males on other males. The meaning of 
violence in the arena of the school-ground is to repel the feminine attributes of males, and preserving the dominant masculine image.

Notably these men did not question this status quo. Instead, they became highly adept themselves at a process of self-surveillance for signs of transgression to the hegemonic standard. Such self-surveillance, finding many faults in physical appearance, dress, behaviour, lack of success, and social relationships, confirmed their understandings of difference to the other boys. Foucault describes this process as disciplinary; whereby “discipline produces subjected and practiced bodies, 'docile' bodies" (1975/1979, p. 138). For Foucault, disciplinary power constantly surveys the body for transgression, it is anonymous, and at the same time everywhere. Such scrutiny brings about ever increasing detail to light, and in doing so, subjects bodies to increasing constraint.

Sport was one domain in which these men worked out an identity as less than other males. As an explicitly competitive physical test (and spectacle), sport emphasised a hierarchy between winners and losers. While rugby might be regarded as entertainment, the importance of rugby for constructing male identity cannot be underestimated. Rugby has had an historically significant place in national identity for men in New Zealand (Phillips, 1996). This hierarchical positioning extends beyond the teams involved to all men. As the First IV are at the pinnacle, all other men are measured against this standard. Not playing rugby at all is at the lowest point of the hierarchy; as is expressing complete disinterest. The privileged position of rugby men, means that playing rugby provides a potent means for a claim to masculine status.

While significant, rugby was not the only means of constructing male identity. The school curriculum was similarly hierarchical, distinguishing between those that did well and those that did not. Even as a very young child, William recognised this in the system of rewards for handwriting. Instead of being encouraged to do better, he understood that he would never be rewarded. As older children, subjects at school were also divided between "hard" and "soft". Soft subjects were those with substantially feminine attributes.

By the time they leave school in their mid-teens, these men had a vast history of victimisation upon which to resource further understandings of new experiences of violence, threat and fear. Understanding these experiences differently than as confirmation of inadequacy (and therefore responding differently), was not possible. 
While providing a rich means of possible understandings as victimised, and what this meant for a sense of identity, this background did not provide for a view of self as other than victimised. They knew their place as subordinated to the other boys; they knew they did not "fit in". By the time they left school their difference to other ("normal") boys was known to them in great detail. They were excluded, and knew this to be correct. They knew they were not "a proper bloke" (Peter2, $\mid 17)$.

Insidiously, exclusion and the knowledge that they were not "proper blokes" brought about a sense of angst. There is no single event to which they are able to point as the beginning to this angst. Nonetheless, each of the men look back now and see their distress as evidence they had been depressed as children and teenagers. Leaving school as early as possible was described as an effort to reduce their distress. While this removed them from direct day to day contact of the proving ground of the school yard it did not remove the need to deal with the issue of fitting in; leaving school simply changed the social context and did not of itself change their sense of self.

Before reaching their adult years, Andrew and William both tried to shoot themselves, while Peter and Podraig initially turned to drugs. However, as Peter notes with the benefit of hindsight:

But I never, I didn't deal with the grief basically, and the pain, you know. (Peter1, \47)

In their teenage and adult years, intimate relationships became an important context in which varying levels of crises were precipitated. Relationships became a key focus for crises because of the anxieties that arose out of the expectations or demands that they experienced and were historically ill-equipped to resolve. Fused with the understandings of self that these men carried on leaving school, these new crises became understood as further confirmation of their individual faultiness and not-belonging in the world. Within relationships (and in their choice of partners, or of consciously not choosing partners) these understandings were worked through further, ultimately confirming an understanding that they did not fit in. Crises were multiple and occurred at different times and in different social contexts in their histories, that at times were precipitants to suicidality. As well as the location in which these crises tended to occur, these men also made it clear that partners, children, families, and friends were also people that they highly valued during those times. So, for instance, while Peter describes raising his child 
as stressful, pushing him beyond his capacity to cope, he also held onto the presence of his family as a source of comfort from the terror and fear of his personal "abyss".

While psychiatric services may be thought of as a resource for psychological pain, Podraig and William describe a different experience. They described their experience of involuntary intervention by mental health services as traumatising. Their recollections of compulsory treatment and perception of interactions were understood as "invalidating". From Podraig's perspective, there was nothing he could say that was accepted as valid.

Felt as if I didn't have a voice. I felt as if I could scream from the top of the tallest building in <city> and for some reason nobody would hear it. They could hear everybody else's babble but they could not hear me. I wasn't allowed to be heard. That's how I felt. I felt as if I just wasn't allowed to be heard, that my voice didn't matter... (Podraig2, \152)

Fused with the horizon from which they viewed the world, Podraig and William viewed involuntary treatment as the removal their last claim to fit in; the removal of their right to speak with a rational voice. As Podraig put it in the quote above, he was not "allowed to be heard". Moreover, the assumption of the right to be heard - to participate in society - was no longer a given but accorded to them by the authority of specialist health professionals. The experience of loss of control and isolation was further compounded in a profound way. Podraig and William were now authoritatively labelled as not normal. Their diagnosis was scientific "proof" of their individual faultiness and provided the reason for their exclusion. Whereas at school the bullies had faces and were known personally, and in a sense were local and personal, diagnosis on the other hand, is universal and unassailable. They understood themselves to be examined objectively using universal rules and were found to be not normal compared to universal norms. There was no claim to some higher authority that exceeded psychiatry. The universality of diagnosis meant that rather than not fitting in to their social context, their exclusion took on a universal perspective.

On their discharge, William coped by resorting to familiar means of dealing with anxiety and increased his drinking. However, Podraig did something different and instead took his “rage out against the world” (Podraig1, 973). In Podraig’s view he was excluded from the world and used this as a justification to embark on a career of serious crime, feeling 
that the world did not care for him. In the years that followed, both men had multiple encounters with psychiatric services for attempts to take their own lives.

Another mechanism of policing the boundaries of different and not-different was through labelling. While psychiatry imposes labels, an earlier label attached to these men at school was of being "sensitive". Being sensitive meant apprehending emotional and somatic experience in a way that was qualitatively different to that of other boys and easily associated with femininity. There was a difference in their responses, such as being quiet and creative, rather than sporty, not forming friendships, and a preoccupation about safety (including sexual vulnerability). Sensitivity may also have been a sense of reflection, self examination, and introspection. Yet, to avoid violence targeted at personal attributes, a certain degree of sensitivity appeared necessary to know what it is that is targeted so as to avoid it. On the other hand, in that sensitivity is associated with femininity, it becomes a target of the same violence. Reflection and sensitivity then, or knowing what it is that is targeted (i.e. knowing what is and isn't manly), is in part, also constitutive of being a victim.

The experience of difference was not one of an uninvolved observing mind, separate to the body it controls; difference was meaningful in the sense that it mattered. These men cared very deeply that they were cast as different. Difference was also a felt difference through the senses of the body. These men experienced the pain of violence and injury. They could see and feel the muscles and bones through which they were small or tall. They could hear their quietness of their voice or the accent with which they spoke. They could feel and see their different dress style, and the way the walked or moved. Additionally, the anxiety and fear they spoke about, rather than "in the mind" are physical experiences able to be located somatically; for instance, as that tight knot in the abdomen, the horrible nausea in the stomach, or tightness of breathing in the chest. Guilt and shame mark the body through the slumped posture and slowness of movement. ${ }^{21}$ For these men at school, these were prolonged experiences over many years in which difference, and being less than other men, becomes painful and embodied in a multitude of ways that in turn, becomes confirmatory of being less-than. That it matters is at the same time experienced through the body. The way in which

${ }^{21}$ A contemporary depiction of the physical manifestation of psychological pain is the changes that the character of Golum undergoes in the film Lord of the Rings (Jackson, 2001). 
difference becomes meaningful is not simply intellectual (i.e. separated from the body), but is worked through in an embodied and historically situated context.

As the embodied apprehension of difference is ongoing, so is the project of self understanding. While these men identify a prolonged period of working out the experience of difference, what they desired was to "fit in". Their exclusion was never absolute or uncontested or stable but rather, they grappled and struggled with doing what was necessary to fit in; or at least minimise the psychological pain. This grappling was always in reference to their body, and always socially situated. As such, coming to grips with gender.

\section{Fathers and heteronormativity}

Fathers (and step-fathers) are central figures in these conversations. They are depicted as feared, terrifying figures who perpetrate violence. They are also central figures even when absent. Paradoxically, fathers are feared, loved and needed all at once. Fathers and step-fathers are the central figure around which all other relationships in the family revolve. Mothers and siblings emerge only in the reflection of fathers. This is a complex and conflicted picture whereby fathers are placed as a potent influence. The potency of fathers is through fear; both fear of violence and fear of absence. As children, these men managed their emotions and behaviour so that tension and violence (and even absence) were not provoked. The impact of these experiences is enduring, and is depicted for instance, in the lyrics of the rock singer Meatloaf (Steinman, 1993):

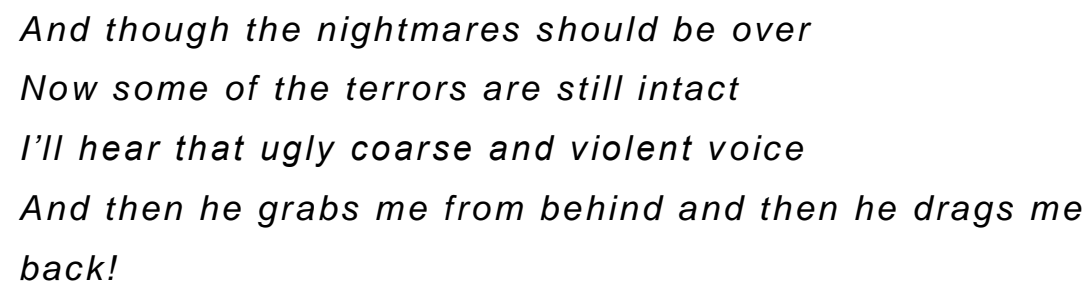

But it was long ago and it was far away

Oh God it seems so very far away...

Later, as adults their fathers return in the shape of their fears of perpetrating upon their own children the experiences that damaged them as children. Andrew worries that he will be unsafe with young children, unwilling to care for young children by bathing them. With shame, guilt, and great sadness Peter relates raging against his child in times of stress, although quickly adding that he has done a lot of work to address this. William 
also relates that doing the "family thing" overwhelmed him. These tensions are worked through in times of feeling suicidal in the way in which Peter and William relate taking great care to minimise the impact their manner of death would have on their children. While this thinking helps Peter from acting on his suicidal thinking (although he had planned how to make his death "accidental”), William makes attempts to kill himself while his children are absent and chooses to gas himself rather than using violent and bloody means.

Understandings are also developed about their own experiences in relationship to their father; and as a consequence, to their mothers and siblings. These understandings were carried forward into their school years. Understandings about emotions, behaviour, and power are first understood in the context of the childhood home. ${ }^{22}$ While they do not label their experience as abuse, their reflections are consistent with descriptions of chronic child maltreatment (Erickson, Egeland, \& Pianta, 1989), children who have experienced the death of someone close to them (McCloskey \& Walker, 2000), and of the childhood experience of parental discord (Depner, Leino, \& Chun, 1992; McCloskey \& Walker, 2000).

At school, authority figures were easily associated with the fear of their fathers and stepfathers. Even after these men had left home in their teenage years, the impact of fathers continued on in the authority figures of other "successful" men and different authority figures. Adult men, in different forms, are pervasively associated with fear, heterosexuality, and authority. Adult men are variously feared in these conversations for their ability to humiliate, threaten and do violence, sexually assault, change the school curriculum, privilege rugby over other sport, leave home, determine employment, and diagnose psychopathology.

The heterosexual norm is taken for granted and unquestioned in the content these men discuss. A certain patriarchal way of relating to women and children is described in their reflections of their earlier years. Andrew and Podraig particularly describe their childhood homes where patriarchal control was maintained through fear and violence. As an institution, school is a deeply gendered regime, affirming relations of domination and subordination (Mac an Ghaill, 1994). School was a social location of male privilege.

22 Piekarska (2000) describes four types of abuse: physical, emotional, sexual, and neglect. Of note is that while there was recognition of intentional physical abuse in the early 1960's, recognition of other forms of maltreatment did not get attention until at least a decade later. 
While they were in a position of greater power than the young women they "chased" or with whom they "managed" their relationships, they were also victims of male power.

To have sex with women then was primarily about proving heterosexual masculinity to other males. Like the rugby field, sex with women was a proving ground for masculinity. This was also a contradictory experience on another level. While desiring to be near women, there was also a fear and need for distance. Intimacy was unfamiliar and threatened masculine control of emotion. While in one sense sex could be conceived of as the proper mechanistic functioning of the body with the mind in control, intimacy was an experiential dwelling in the body and provoked feelings of vulnerability threatening to overthrow heterosexual accomplishment (Allen, 2002). Podraig expresses this conflict, and the tremendous angst it produced, when he talked about being a great lover in control of these relationships yet feeling something important to him is amiss.

Contradictions were also experienced in relationships with other males. At the same time as seeking to fit in, relationships with other males were carefully scrutinised for homosexuality. Behaviour that could be construed as indicative of homosexuality would be a target of homophobic response from other boys. Heterosexuality was mandatory and unquestioned (Mac an Ghaill, 1994). So, while hugging in the context of winning the match was acceptable affirming male bonding, hugging in the school ground would acquire homosexual meaning. These tensions between possible meanings are expressed by Andrew in the dressing room, watchful of the other boys. Andrew is uncertain if his vulnerability is a recollection of his sexual assault, or some sense of shame about his body's development.

\section{"Irrational" men}

Crises that have an emotional aspect to them or are about relationships are more often construed to be within, or as a characteristic, of the individual. That is, these crises are thought of as internal to the individual rather than between people. A person can also be thought of to be in crisis if they relate to others in ways inconsistent with the normative expectations of society (McNamee, 1992). McNamee points out that society also has to recognise it as a crisis to be labelled as such. This is demonstrated by the existence of services that are specifically designed for events regarded as crises (e.g. Mental Health Crisis Teams). Such services exist on the assumption that such relational crises are a result of a disturbance in an individual's mental functioning. Furthermore, to the degree 
that this view is taken-for-granted, individual's will seek out the services of a health professional in the event of a feeling "in crisis". That is, the crisis is construed as abnormal or pathological rather than say, an issue of personal growth and learning or difficult social circumstances.

The scrutiny of health professionals is significant. Experiences of crises for the four men were labelled as diagnoses of personality disorder or mental illnesses ${ }^{23}$ such as schizophrenia, depression, manic-depressive, or addictions (e.g. alcoholism or other substances). Diagnosis confirmed individual faultiness or abnormality as the cause of the relationship crisis. As a result of this process, these men acquired a label that explained all the crises and distress they had experienced extending back into their school years. In addition, their diagnosis prescribed their future well-being as bleak.

As mentally disordered or ill, it was also a given that these men were irrational. Several consequences flowed from this equation; greatly emphasised for William and Podraig by their experiences of compulsory treatment. Among these were, firstly, confidence in the ability to accurately interpret experiences was questioned. The historical "reality" of events was now uncertain; the "correct" view being determined by health professionals. Secondly, irrationality was further affirmation of being not-masculine (Warren, 1983). Being irrational is anathema to the modern conception of an autonomous and successful individual. The "excessive" expressed emotionality of the crisis (except for anger which I return to shortly) are viewed as both out of control, pathological, and unmanly. Consequently, being angry was also now seen as evidence of irrationality. Likewise, being "ill" is to be unproductive, contrary to the expectation of men as economically useful (Cushman, 1990; Cushman \& Gilford, 1999). Thirdly, every thought, behaviour, and emotional response was now subject to the scrutiny of biomedicine; typically, examined against the criteria of the Diagnostic and Statistical Manual of Mental Disorders (American Psychiatric Association, 1987). Normality was subject to restoration through biochemical intervention. If this was not forthcoming, the efficacy of the biochemical treatment was questioned rather than the "fact" of the mental illness and the associated irrationality. For instance, surviving bullying, sensitiveness, academic failure, and isolation at school were pathologised as early

23 The exemplar of the classificatory system of observed behaviours is the taxonomy of mental disorders titled the Diagnostic and Statistical Manual of Mental Disorders (DSM). Crowe (2000) argues that the DSM construes normality in relationship to productivity, unity, moderation and rationality. Such values are important to the modernist project. Such values are also highly regarded as defining the hegemonic ideal of masculinity 
evidence of current mental illness rather than understood as a struggle to understand. Diagnosis, like the bullies at school, blamed the victim for their victimhood and hence, victimised them further through the diagnosis.

These encounters with health professionals provided a vast new language upon which to construct an understanding of their experiences. Scientific words and meanings were provided through which to comprehend their past and present experiences of distress. Problems were now construed as a result of an illness. Although the diagnostic labels changed over time, ${ }^{24}$ suicidality was generally thought to be the result of major depressive illness. This was viewed as either the major disorder or secondary to another disorder such as alcoholism. Feeling suicidal was seen as a sign of underlying mental illness and therefore not normal.

Being diagnosed with an illness held out some hope that intervention would produce normality. That is, normality could be biologically achieved through the ingestion of a pill or driving electrical current through the brain to restore physiology. However, the absence of distress of itself was insufficient to enable them to fit in; to be "normal". That is, treatment to bring about the absence of distress did not mean that they would then be normal. The meaning of normal was much more than the absence of distress as normal.

\section{Quelling anxiety: A matter of survival}

As the degree of difference between self evaluation and the hegemonic standard deepened, anxieties increased for these four men. In the search for the means to enhance a claim to masculinity, sport and substance abuse became pivotal means to manage anxiety. Both sport and substance use were available and accessible within the social context of school. While alcohol and drug abuse were not condoned by the school, both were easily available.

As the ideal masculinity, rugby also becomes one way of policing this demarcation between feminine and masculine. For instance, Town (1999) describes a practice of deterrence and defeminisation in which violence and emotional constrain are characteristic features. Insofar as sport is to do with the body, the test of mind over body (e.g. mastery of pain) reaffirms hegemonic masculine values (White et al., 1995;

${ }^{24}$ At the time these men were diagnosed the consensus views on both schizophrenia and personality disorder was that these were largely untreatable and intervention was substantially palliative. 
Whitson, 1990). To reject rugby, is easily equated to a rejection of dominant male values. This is not to say that a rejection of rugby leaves no claim at all to masculinity. On the contrary, efforts were made to accomplish particular attributes of the hegemonic standard. To the degree that athletics, soccer and horse riding provided a test of physical force and skill, accomplishment in these sports affirmed control of the mind over the body, congruent with dominant masculine ideals. In Foucauldian terms, any sport was an examination of masculinity, a disciplining exercise and as such, the more combative the sport the greater the test of masculinity.

While sport was discovered as being to some degree effective at ameliorating anxiety, drugs and alcohol were found to be faster. There is a clear recollection that alcohol and drugs took away the "pain". Podraig in particular described in detail the escape that marathon running provided. Drugs (generally cannabis) and alcohol were discovered very early in school life as both an available and accessible means to quell their increasing anxieties. Like sport, a key issue was that alcohol and drugs were also consistent with a number of important hegemonic values. This is evident for instance, with alcohol through in the advertising of beer linking it to highly valued aspects of male culture (Hill, 1999). The risk-taking, anti-authority, and mateship involved in alcohol and drug abuse provided a limited means to fit in. The chemical effect on their anxieties was startling. Peter stated this emphatically, in his comment that his excessive use of cannabis was for "annihilation", driven by an underlying need to stop the psychological pain. Peter is also clear that he did not regard this desire as a suicidal one. Rather than wanting to die, he wanted to get rid of intolerable psychological pain, or "psychache" as Shneidman (1993) has labelled this experience. Abusing alcohol and drugs to stop the psychological pain was not an explicit and informed choice in which a number of options were accessible and available. Nevertheless, they became a means to survive by quelling their anxieties; or at least, this was temporarily achieved.

While chemicals may temporarily remove the memory of victimisation, the experience and its effects were not erased. Furthermore, alcohol and drug abuse brought its own set of adverse consequences. As well as a physiological impact, there were social consequences. The negative impact however, did not appear to become apparent until their adult years. Andrew spoke of losing income, relationships and the anger and violence of his alcoholic bingeing. Podraig spoke explicitly of being drawn into a criminal world in which he spent a prolonged time in fear. He also became addicted to 
harder drugs and made multiple suicide attempts. These experiences too, are easily understood yet again, as further confirmation of hopelessness rekindling the experience of not fitting in and the associated feeling of angst.

Participating in sport, no matter how substantial a role this might play in everyday living at school, did not resolve the original issues. Similarly, use of chemicals to relieve anxiety did not resolve the original issues, and ultimately added further to long-standing feelings of not fitting in.

\section{Re-constructing self as "recovering"}

The four men in this study tended to use the term "recovering" rather than recovered, to describe their current state. The term conveys a sense of history in that it locates themselves temporally in relation to their experiences. It is also a cautious term in that they are uncertain about recovery. Their teenage and early adult years were not a period of unremitting distress. To the contrary, the men in this study describe periods where they felt under "control" and there was an absence of distress. Within certain contexts and relationships there were times when they felt they did "fit in". Indeed, each of these men "succeeded" at establishing or running some sort of business. However, crises returned, reminding them that enjoying life was not "deserved"; that they weren't "meant" to succeed or be happy. The return of these times of crisis was viewed as confirmation that it was the absence of distress that was unusual rather than the presence of distress.

While medicine is seen as somewhat useful to alleviate symptoms (e.g. lifting mood), it falls short of bringing about recovery. Within the medical model, recovery means a return to a disease-free state; that is, recovery is to have cured the disease. However, because "normal" is culturally defined rather than a physiological state and hence biologically determined, a return to the culturally expected norm is not possible on the basis of medication alone. That is, medication was unable to cause them to fit in. Nonetheless, where medication (and ECT) was found to be beneficial was as an enabler for something else to happen. Medication lifted energy and mood so that "work" could be done. Unfortunately, medication was also available to enable overdosing.

Resourcing themselves for survival and recovery was not straightforward; it was a process of uncertain discovery and became known only upon reflection. Recognising what was useful and what was not depended upon an ability to reflect on themselves. 
Through the sense-making of reflection and doing, what was helpful was gradually sorted from what was not helpful. In this way, what worked and what didn't was entirely idiosyncratic. This working out of understandings did not cease at times when they were suicidal. Suicidal experience was one form of doing what they understood to be who they were in the world.

Over a prolonged time their experiences with many different resources led them to become more discriminating on what was helpful and what help was needed. However, simply being exposed to many resources was insufficient. This is shown by a familiar pattern of responses to crises; for example, use of drugs or alcohol in response to stress. An important element to this "figuring out" what worked and what didn't had to do with the nature of relationships with both health professionals and significant others close to them. The nature of these relationships were themselves a substantially unfamiliar experience, and while this alone provoked anxiety and crisis, relationships nevertheless provided a wider horizon of meaning from which to comprehend themselves and the world, and hence, try new ways of understanding (and therefore new ways of responding).

Relationships that helped to create change included marriage, children, close friends, as well as health professionals. Relationships also included those charismatic people who stepped into their lives for brief moments, yet had a provocative impact (e.g. Indian gurus, spiritual guides, etc). Change was not always positive or painless. While they experienced the collapse of intimate relationships in early adulthood, they also experienced a very different kind of relationship to the fear and isolation that they had been familiar with in their early lives, and consequently expanded their range of understandings. For Peter and William, children were also a part of that changed experience. They experienced a love for their children and what it was to care for and be needed. They experienced (and grappled with) experiences of sharing, intimacy, and being accepted for who they were. Health professionals and non-professionals came into their lives and facilitated other ways of understanding their experiences to what they were familiar. With Alcoholics Anonymous (AA) Andrew experienced people who understood him and his history from an intimate level, as well as a willingness to provide readily accessible support. Accessibility was a part of being supported and being understood. As he became more involved in AA, he also experienced (perhaps for the first time) offering support to others. These experiences expanded Andrew's horizon of 
meanings. Podraig told of similar experiences when he entered drug and alcohol rehabilitation and when he joined AA, and similarly William, when he attended Adult Children of Alcoholics (ACoA). These different experiences (both "good" and "bad") brought to consciousness alternative understanding of self, and self in relationship to others. The difference between what was helpful and what was not helpful was not possible to recognise at the time. What was helpful became visible only in the later practical application of those understandings. Podraig goes as far as saying that what was helpful can only be seen in hindsight, suggesting that while what is discovered to be helpful is serendipitous, the later application of what was learnt from experience discloses its helpfulness.

In contrast to swallowing a pill or receiving ECT and simply awaiting the biological change to bring about normality, these men regarded "work" as beginning within a relational context. Reconstructing their personal histories of distress in order to understand differently entailed a degree of questioning or critical reflection that in turn could produce heightened anxiety. Such anxiety could in turn provoke familiar understandings and responses. However, relationships in which they felt affirmed and valued could also provide sufficient safety to work through different understandings. Their work entailed psychotherapy, group work, and individual counselling. It additionally, involved working on their relationships in the home as well as with many and varied non-professional people (e.g. gurus, friends, self-help groups, etc). Recovering was an application of different understandings. It was a reconstruction of their history in a way that they now identify as personal growth. This is captured in the remark that they have had to learn more about themselves than most men will ever have to learn. Rather than being able to be informed, or provided with the knowledge of what works and what doesn't and then following the logic in a rationale and instrumental fashion, the significant task before these men was to do with the context and breadth of their experience. Furthermore, it was necessary to critically reflect on their experiences both good and bad, for what had helped and what did not. However, without the means to view experiences from an expanded horizon of meaning, reflection alone was insufficient to the "work" of personal growth. Podraig provided an exemplar of the task before him, using the metaphor of peeling back the layers of an onion and once peeled back, there was nothing. Podraig needed something else; something he alone could not produce from within himself to move him forward. 
These men described this reflective reconstructive process as much more than simply dwelling on the past, but instead, as a circular revisiting, grappling with, and contemplating a different understanding of their history that in turn, is then used to return to their history at ever deeper levels to understand other parts of their history differently. In this process, present understandings of themselves, and their place in their present social context was also changed. This coming to "know myself" differently involved close scrutiny, experiences of, and knowledge about emotions that they remain aware that other men find alien. They have found that it is not possible to discuss this knowledge of themselves with other men, but can do so with women. So, for these men, they continue to be acutely aware they remain different to other men and see no future in which this will change.

In the "work" of reflecting upon their history it can also be seen that their understanding of themselves as mentally ill or disordered was challenged. At the same time, they also began to take a stand on the legitimacy of their exclusion (i.e. not fitting in to hegemonic conceptions of masculinity). This is an incomplete work, and they each state that it is an ongoing task. For these men then, there is no recovery in the sense of returning to normal, as normal has never existed for them; they have never fitted into a norm. They are unable to look back and state when the process of recovering began. Recovering therefore seems to be more to do with a productive figuring out or working through of something necessary in order to survive and offers hope of meaningful living. Their view then is that they are always in the process of recovering. That is, an ongoing process in which they grow, conscious of their difference. They do not celebrate their difference, instead they struggle to find a way to live meaningfully whilst remaining sad about the constraints that are now visible to them. 
Chapter 9

\section{DISCUSSION AND IMPLICATIONS FOR MENTAL HEALTH NURSING PRACTICE AND RESEARCH}

The exploration undertaken in this study of four men's experiences of suicidality arose from a desire to explore suicidal experience from an explicit concern with masculinities. The desire to explore these issues was prompted by my own clinical experiences of working with men who were suicidal. In undertaking this study, the aim was to inform mental health nursing practice of alternative possibilities for intervention with suicidal men informed by an awareness of the influence of masculine values on men's experiences of suicidality.

Three particular concerns have contributed to the shaping of this study. Firstly, given that mental health nurses constitute a substantial portion of the mental health workforce, it seems inconsistent that the dominant body of knowledge that informs mental health nursing practice with suicidality rests on theories and research borrowed from other disciplines. Secondly, while there is significant public and professional concern about an historically high rate of male suicide, the literature review undertaken in this thesis suggests that there is minimal research about the understanding men have of their experience of suicidality as men. Thirdly, while the core practice of mental health nursing is to "engage in relationships at a meaningful level" (Australian and New Zealand College of Mental Health Nurses, 2002, p. 6) it is only recently that models for mental health nursing in which this position is central, have been comprehensively developed (e.g. Barker, 2000). While engagement is recognised as necessary to mental health nursing, currently, it is frequently viewed instrumentally as serving the assessment process rather than as the core mode of practice through which change is effected.

A focus on engagement as a core element of practice sits within a tradition of nursing theory that holds to a person-centred focus (Peplau, 1952, 1997). As such, Gadamer's $(1965 / 1975)$ articulation of understanding in the context of human sciences, is of 
significance to mental health nursing. In drawing on Gadamer to inform a study of four men's suicidal experiences, this study parallels the relational focus of mental health nursing and hence, has the potential to inform practice insofar as practice involves dialogically understanding another's experience. Additionally, this study can inform mental health nursing practice through what it reveals about these suicidal experiences.

This study moves beyond an uncritical interpretation of men's experiences of suicidality, revisiting this understanding in order to explore the influence of masculinity in the understanding the suicidal experience of these men. An examination of the literature on masculinities made explicit an anti-essentialist lens that was then brought to bear on the transcripts of our conversations through a Gadamerian methodology.

\section{Interpreting suicidal experiences with four men}

Gadamerian hermeneutics calls attention to the dialogical participation of both people in bringing about understanding as a fusion of horizons. Drawing on Gadamer, understanding is argued here to have already occurred in conversation before analysis (or rather, an interpretation) of transcripts. In contrast to other research approaches using participant interviews, I have taken the position in this study that there are two occurrences of hermeneutic understanding that are different, yet refer to the same original conversations. This position on Gadamer has resulted in conceptualising this study as using a double hermeneutic. While participants were aware of my dual focus on masculinity and suicidality from the moment of first hearing of it, an exploration of taken-for-granted meanings can only take place after an initial understanding has occurred. This required a second process to the research. Exploration of taken-forgranteds is unable to take place in the same dialogue that seeks to genuinely reach an understanding of that person's experience of suicidality. Instead, this interpretive horizon was later brought to bear in developing an interpretation of the transcripts.

Given that a Gadamerian approach aims to make explicit the "conditions under which understanding takes place" (Gadamer, 1965/1975, p. 263), all facets of the study were conducted with their historical effect as overt as was consciously possible. These "conditions" of understanding necessarily included my motivation for the study, the literature review, the approach taken to recruitment, conduct of the conversations, interpretive processes, and the conclusions to be drawn from the study as a whole. 
While Gadamer's (1965/1975) Truth and Method is primarily concerned about the interpretation of text in the form of writings that are intended for reading, much of the nursing research drawing on Gadamer applies his ideas to transcripts of interviews as if transcripts were originally constructed to be read as writings. However, I have argued that doing so risks insufficient attention to the "conditions" in which understanding of the transcripts takes place; in particular, that of effective history. Firstly, transcripts are pale proxies of the original event. They fail to capture the situatedness of natural speech and require interpretation to make them "readable". Secondly, understanding has already occurred dialogically within the interviews or conversations that gave rise to the transcripts in the first instance. Assuming researcher and interpreter are the same person, the new understanding achieved as a result of the original dialogue forms an horizon of meaning that is then brought to bear on the transcripts. While Gadamer offers justification for considering that the transcripts have something to say of the original communicative event (as they indeed refer back to the original event), I take the position that transcripts are more properly regarded as an historical record requiring interpretation and cannot be "read" automatically as would say, a literary work (or closer to the concerns of this study, suicide notes).

In this study, my participation in the original conversations must necessarily be a significant aspect of the "conditions" under which interpretation of the transcripts then takes place. The fact that I participated in the conversations that gave rise to the transcripts cannot be set aside when making an interpretation of the transcripts. That is, as well as participating in the creation of the conversations, I also bring the experience (and personal notes, i.e. memos) of the earlier conversations to the interpretive endeavour. In this study I have made this explicit by conveying my understanding of suicidal experience as a result of the conversations or research interviews in a manner that is "readable". I do this by writing a kind of autobiographical narrative of each conversation. Through writing, I make the text available for interpretation conscious that it is to be read. Ultimately, these contribute to the historical records available for (re)interpretation whilst at the same time, making explicit the effect of history. At the same time, writing and rewriting synoptic stories of each interview, and then producing a thematic summary of all the stories, is also a form of interpretive analysis (Richardson, 1994). 
Gadamer's work shows the dependency of understanding on historical and cultural context, irrespective of whether it is understanding of a text, an experience, or another person. While Gadamer does not specifically discuss gender, it is clear that gender forms a key aspect of a person's historical situatedness. As mental health nursing is an endeavour to engage in purposeful relationships in which understanding is central to practice, Gadamer's investigation of understanding can illuminate this process and therefore enhance mental health nursing in both practice and research. Gadamer's work also calls attention to the active involvement of mental health nurses in the development of understanding, and that this is the case irrespective of whether or not nurses are aware of this. Hence, mental health nursing informed by Gadamerian hermeneutics is viewed is a situated endeavour in which history and culture (including gender) are key aspects of the interpretive horizon.

\section{Historically emergent suicidality}

My conversational understanding was gathered under eleven thematic headings, set out in Table 5, below. These are historical, overlapping, and context-dependent. Although not strictly chronological, they tend toward a developmental sequence. The overarching sense conveyed by these themes is that to understand the suicidal experiences of these four men, it is necessary to conceptualise suicidality and its meanings as situated and historically emergent in which these men were (and still are) active in the construction of a sense of self. This is a constructivist viewpoint whereby:

...particular actors, in particular places, at particular times, fashion meaning out of events and phenomena through

Table 5. Initial major themes

Family violence and abuse
Fathers and other men
Sexual assault
Unsafe schools
Becoming "different" at school
Mistrust and sexuality
Sport
Drugs and alcohol
Normalness
Finding effective help
Ongoing recovery


prolonged, complex processes of social interaction involving

history, language, and action. (Schwandt, 1994, p. 118)

That is to say that doing and understanding occur all at the same time. The doing and meaning cannot be separated. Insofar as suicidality is experienced, and therefore a form of "doing", it is constituted by and constitutive of a sense of self and the social world. Contrary to the modernist sense of self as constant and knowable, a constructivist sense of self is an ongoing situated process of becoming, in which multiple possibilities exist (Cox \& Lyddon, 1997). As historically emergent, each of the men's suicidality is not located in a cause and effect relationship to any one or number of variables, but emerges out of a personal engagement with the social world in an effort to understand.

Revisiting the transcripts through an horizon of meaning informed by a theorising of masculinities critical of essentialist approaches, showed an ongoing pivotal theme of "fitting in". The struggle to fit in was set through their early experiences of victimisation; though not of itself sufficient to produce the trajectory that emerged across their lifespan.

Each of these men related stories of experiencing being different at school as the source of a continued experience of difference. Shame and anxiety accompanied these realisations of difference. This difference was in reference to the body and in relation to norms for boys. For example, Podraig was aware of his small stature not being the norm, William was aware of his physical deformity, Andrew knew his family was poor. The surveillance of norms was institutional; by teachers, Principals, other boys, eventually internalised as an embodied reality. Insofar as their school experience echoed their victimisation at home, the horizon of meanings from which to understand new experiences was one influenced by these experiences of difference, inadequacy, powerlessness, and so forth.

That fitting in was something actively sought and struggled with, indicates a consciousness of the experiences of not fitting in. To fit in or not fit in was constructed in relation to something. This "something" however, was not articulated in the stories of these men beyond that it was not this or that. The criteria against which they were in some way not fitting in, was unseen. Suicidality appeared to emerge in an insidious manner over a prolonged period in response to increasingly unbearable pain of not 
fitting in. This viewpoint supports Shneidman's (1998) concept of "psychache", in which suicide is viewed as a solution to the problem of unbearable psychological pain. Removing themselves from the world became a solution to a problem of intolerable anguish. This interpretation of these men's stories supports Shneidman's (1985) definition of suicide as a problem for which suicide is a possible solution. However, the conclusions drawn here also suggest that these men, while active agents throughout their entire life in their struggle to make sense of themselves in their circumstances, were also constrained by largely unseen social forces.

\section{Problematising masculinity in men's suicidal experience}

Revisiting the conversations with the four men through a specific theoretical lens informed by anti-essentialist theories on masculinities produced a different set of themes shown in Table 6, below. Again, these themes are not mutually exclusive or chronological, but rather, overlapping and fluid. These themes emerge from an interaction of victimisation and masculinity in the particular context in which these men sought to make sense of their experiences and "fit in".

An interpretation of the transcripts through an anti-essentialist lens contends that the struggle to fit in was a struggle to not be different, not be excluded, and not be less than something that was expected of them. The analysis here argues that this struggle was especially problematic as fitting in was determined by gender norms that were hegemonic, and hence taken-for-granted. In their everydayness or taken-forgrantedness, these meanings were unable to be problematised. Their struggle then, at least in their early years, was with something intangible and unnameable. Nonetheless, in examining what it was that cast them as different, excluded and less than, something of

Table 6. A (re)interpretation: Disclosing masculinities in suicidal experience

Experiencing re-victimisation

Struggling to fit in

Sport

Difference and being less-than

Fathers and heteronormativity

"Irrational" men

Quelling anxiety: A matter of survival

Re-constructing self as "recovering" 
this was gradually disclosed in the process.

A (re)interpretation of the conversations with the four men in this study revealed that the process of becoming different, excluded, and less than, were targeted to the body; that is, the processes were gendered. However, masculinity was largely invisible frequently only glimpsed as a shadow cast by something else. Even so, such shadows were not questionable; the given sociocultural context provided only two gender positions: to be feminine or masculine. Hence, in their early years these men found themselves in a state of increasing awareness of contradiction, increasingly unable to fit in to the sociocultural imperatives, there was no alternative position to take.

The view taken here is that the importance of the masculine norm lies not in how this might be defined or not (e.g. as a set of roles), but in its pervasive taken-for-grantedness. Being hegemonic, the masculine norm makes available readily accessible social meanings from which to understand oneself and the lived-in world. These meanings already preexist the entry of these men into the world, and are already there as social material from which to construct oneself as masculine or not-masculine. This was the tradition in which these men made meaning of their experience. The unseen sociocultural constraints arise are constituted by the absence of alternative meanings. Alternatives cannot be freely invented, Gadamer has made clear that unsustainable understandings will fail in their practical application. For instance, unsustainable meanings may seem incongruent or irrational; yet applying such terms immediately pulls the incomprehensible into a particular tradition that makes it comprehensible. This is one way of interpreting Podraig's "nervous collapse". Podraig is unable to resolve the struggle to fit into a social context that views gender as dichotomous. In Podraig's world, it is incomprehensible to be not-masculine while at the same time be notfeminine. A "nervous collapse" appears to be how the incomprehensible "not fitting in" is made comprehensible by Podraig and others. This has an impact on the body. Understandings are put into practice, and consequently have health effects. In Podraig's example, the nervous collapse had a profound physical and mental impact.

The growing awareness of what constituted not fitting in was itself an awareness that marked them as different to their peers. In a cyclical and back and forth process, earlier understandings of failure and inadequacy became ready-to-hand meanings from which to understand future events. As inevitable crises were encountered, these were readily 
construed within their existing horizon of meanings as further failure to fit in. These additional experiences further expanded the horizon of meaning, upon which later crises would yet again facilitate a construal of self as a failure, different, or faulty. Suicidality emerged at some point within this historical momentum, not in a deterministic way, but simply because other alternatives for meaning making were not available nor readily accessible through which they could construct a different sense of self.

As they were confronted by their thinking, doing and being, that was different to the norm of other boys, they accepted that they were indeed different. However, that the meaning of this difference was then taken as being excluded and less-than, discloses the operation of what Connell (1995) has described as a hierarchy of masculinities. Connell has argued that there is a need for some form of congruence with institutional and cultural practices and institutions. This is indeed seen through the collective practice of their peers and the institutional context (including the authority) of the school. This was accomplished through the reproduction of masculine ideals, for instance, through the privileging of combative sports over other sports, and "harder" subjects over "soft" subjects in the academic curriculum.

Perhaps a more pervasive and insidious issue was that at some point during school yet another difference rose to some level of consciousness. This was that their life experiences of fear, pain, neglect, and rape were different to the norm. Their different life experiences marked them in subtle ways for others to see (e.g. being labelled as "sensitive"), but they were aware that they also saw their social world in a different way to that of normal boys. This was implicit in their descriptions of surveilling male peers at school and of the adult men around them. Like other attributes that were targeted, they could not undo how their experiences of victimisation had marked them as different from what was "normal" for boys.

To a certain degree they sought refuge from their growing existential angst in sport and nihilistic bouts of alcohol and drug abuse. However, as each crisis was encountered in their early adult years, the familiar understandings of inadequacy and failure, resulted in recurrent experiences of shame and anxiety; again, experiences they associated with being not-men. As intimate trusting relationships had been denied (or intentionally excluded), intimacy was a relatively unknown experience, so relationship crises became 
inevitable and frequently precipitated suicidality. Intimate experiences have an certain emphasis in current sociocultural meanings of masculinity, again producing a potent social site for constructing themselves as masculine or "inadequate". Insofar as homophobia underpins current constructions of masculinity (Kimmel, 1994) fear and anxiety became associated with terror of being homosexual. In these conversations, homosexuality in their early years was always to be feared.

Contact with psychiatric services (and other health professionals who informed their practice from a diagnostic model), confirmed what their past experiences of failure and inadequacy had already informed them; that they were not normal. The various diagnostic labels said this using different words: schizophrenia, antisocial, depression, addiction, personality disordered, and so forth. The necessity to take medication to alter their sense of self in order to be normal also supported their view of themselves as not being normal. It is therefore unsurprising that none of the men found diagnosis-driven health services to be helpful. Medication was both a means to lift mood in order to do the "work" or as an alternative means to suicide through overdose.

As a "doing" that is related to the body in a specific way, suicide is meaningful and meaning-making in the context of masculine norms. For these four men, suicide is not only an escape from intolerable anguish it is also a doing of masculinity as a bodyreflexive practice. Continuing the personal project of "working out" meaningfulness through practice, suicide would ultimately fulfil the demand of not fitting in. Suicide may therefore be construed as successfully accomplishing this task and exerting the ultimate control of mind over the body. Furthermore, from this perspective, "failure" can be easily associated with femininity. The care taken in the way these men were to suicide demonstrates a deliberateness and an exercise of agency that is full of meaning. Children and partners were carefully considered as to how they were intended to comprehend his death. To contrive death to be perceived as an accident or not was important. The possibility of discovery, and who should discover the body were considered. In bringing about their own death was an opportunity to shape how they were to be seen (or not) by others. The action to bring about suicide was a conscious consideration of their body in relationship to their social world. 
Suicide and suicidal experience is deeply gendered. Moreover, this interpretation of suicidal experience also discloses the taken-for-grantedness of current masculine norms as posing intolerable existential contradictions for some men.

\section{Implications for mental health nursing practice}

Mental health nursing practice with people who are suicidal is informed by practice guidelines that generally seek to establish a measure of risk that in turn, guides intervention aimed to ameliorate that risk. Practice guidelines are usually positioned as disciplinarily generic, yet being "evidence-based" privileging the scientific method and consequently those disciplines underpinned by positivist science (see Geanellos, 2004, for recent discussion in relation to mental health nursing). For instance, the recently published New Zealand evidence-based guidelines for the Assessment and Management of People at Risk of Suicide (2003) describe intervention that rests on assuring physical safety, establishing a therapeutic relationship, and instituting treatment established through diagnosis. Intermediate intervention includes developing strategies to change psychosocial stressors. While therapeutic relationships are central to intervention, such relationships are primarily for the purpose of obtaining assessment data to formulate a diagnosis and risk rating. While these guidelines suggest "engagement" is necessary, understanding the meaning of suicidality for the person is not necessary for diagnosis or intervention. As far as obtaining "history" is concerned, it is in order to establishing the bounds of predisposing, precipitating, perpetuating, and protective factors. The meaningfulness of suicidality as a human being is not considered. The person is rather, an object whose ailments are to be discovered through medical and psychological science.

Gadamer has argued that understanding occurs on the basis that "self" is a dialogical participant and open to the truth of the other person and willing to consider that the other's truth may be better. Whether the relationship is called therapy, research interview, or some other encounter, Gadamer has argued that new understandings derivative of the dialogue is a fusion of horizons. Insofar as understanding occurs at all, this necessarily means that the researcher or mental health nurse is inextricably involved in the hermeneutic of understanding whether or not this is acknowledged. Where unacknowledged, understanding occurs in an unseen way, opening up the potential for unhelpful meanings to become part of the encounter without being questioned. This was shown, for instance, in the negative meaning taken from their diagnostic labels by these four men. 
The meaning of "recovering" is a dynamic ongoing process of learning and development without an endpoint, or even a clearly defined beginning. The survival of these four men and their continuing effort to recover and grow shows that the opportunity to build new understandings of self are ongoing. The potential for change exists throughout the lifespan. As Gadamer has shown that new understandings depend on dialogue and openness, relationships that were validating and supportive became critical for the facilitation of change for these men. This perspective stands in contrast to the medical notion of cure, whereby change (e.g. medication) is believed to fix the problem in a mechanistic way in which normalness is restored.

Applying Gadamer's work to therapeutic communication shows that to facilitate different meanings, mental health nurses need first to understand meaning-making as historically and socio-culturally situated. Such an approach would require that nurses engage in psychotherapeutic encounters as:

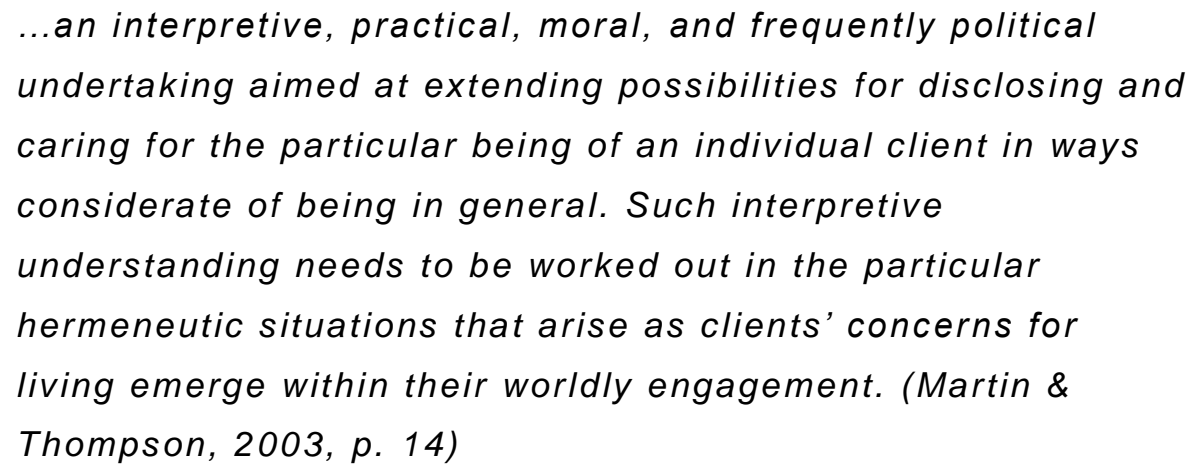

Yet in terms of understanding the impact of socio-cultural and historical meanings on the lives of mental health clients, and establishing therapeutic processes based on a constructivist position, mental health nursing research and practice frameworks are lacking. The influence of the evidence-based practice movement suggests that mental health nursing remains largely captured by mainstream psychology and biomedical psychiatry.

Nonetheless, acknowledged or not, mental health nursing does not exist outside of the social world in which we communicate and understand each other. This study suggests that without a critical awareness of the role of masculinity in men's meaning-making, diagnosis-driven intervention with men who are suicidal may further limit their choices to survive. Mental health nursing intervention is likely to be complicit with hegemonic 
constructions of boundaries between normal and not-normal when nurses unreflectively communicate within a biomedical framework.

Barker and colleagues argue that the "proper focus" of mental health nursing is about people's experiences as being meaningful (Barker et al., 1997; Barker, Reynolds, \& Ward, 1995). This posits a central role for nurses to make a deliberate use of self to facilitate helpful change. As this presumes a collaborative encounter, this position requires mental health nurses to understand the other person. In this context, "to understand" is not to be able to explain the person's troubles, but to truly understand as Gadamer has explicated the concept of understanding. Adopting Martin and Thompson's (2003) position above on the place of hermeneutics in psychotherapy, the potential for therapeutic change occurs in the fusion of horizons when nurse and client understand each other.

Adopting the "proper focus" of mental health nursing does not advocate an abandonment of biomedicine, but suggests the need to relocate the place of "treatment." Rather than the treatment itself being of central concern to nurses, it is the context in which treatment is positioned in the person's life that should be of central concern. In this study, this was clearly shown in statements by the men that discussed their view of medication as enabling the real work to be done, in contrast to medication doing the real work.

If mental health nursing intervention aims to facilitate the growth and development of the other and consequently diminish distress, Gadamer's articulation of the connection between experience and understanding is relevant. This may be as simple as bringing understandings about the "disorder" into a state of indeterminacy by asking questions and therefore beginning a process of dialogue in which the person understands differently. This shifts the notion of "doing" mental health nursing from treatment tasks to something closer to deliberate conversation. As Barker (1996) has suggested:

The most elegant nursing interventions involve asking questions: the most central of which is 'what exactly is going on here?' The extensive repertoire of questions that we might use to facilitate the person's voyage of discovery has only one proper objective: to further her relationship with her self, her world, and all those within it and to extend her appreciation of 


\section{the meanings she constructs around and about these interacting relationships [sic]. (p. 8)}

The constructivist position recognises that the relationship with a client is not from an objective position, but always stands in a tradition and thus makes therapeutic interpretations from this position (McNamee \& Gergen, 1992). Facilitation of growth and development through alternative meaning-making is what mental health nursing can bring to their situation from a constructivist position. He or she "can introduce novel or catalytic ideas" (Efran \& Clarfield, 1992, p. 214) to the encounter from which change is invited. This is suggested in those parts of the conversations in this study on what was meant by the "real work." Real work was achieved through whatever facilitated a reconstruction of self as growing, developing, and leading lives they found to be meaningful. This was not always formalised in a discrete therapy or treatment (e.g. targeting the modification of cognitions or behaviours), but could occur through books, gurus, close relationships, reflection, self help groups; only in reflection was what was useful able to be separated from what was not. This suggests that rather than being prescribed, the client "discovers" what works through the encounter.

Equally, William's example of his changed position on how he regards psychiatric admission cautions that an invitation to change would be inappropriate when the most immediate and pressing issue is to preserve life. Similarly, examples these men have shown that while some forms of counselling were regarded as helpful and some counselling was not. For these men, the "real work" did not proceed through treatment or therapy alone, but through these men working with whatever they sought out or came their way that facilitated their efforts to understand themselves and their history differently. What understandings were ultimately hindering and what were helpful was not known at the time but was worked out in the process of these efforts. Again, this calls attention to the dialogical process rather than imparting the experts knowledge as "facts".

While generic diagnosis-driven assessments have a place within the multidisciplinary team, they are unconcerned with personal meaning and situated understandings of people. This is not to argue that mental health nurses do not have a role in diagnosisoriented approaches, but that the purpose of diagnosis needs to be interpreted within a mental health nursing practice framework that has a focus on situated understanding, relationship, and personal meaning. Similarly, risk assessments premised on population 
risk, while informative for other members of the multidisciplinary team, should be interpreted within a mental health nursing framework. Again, if the contribution of mental health nursing is to understand risk as it relates to the individual concerned (i.e. situated, relational, and meaningful), then a different conceptualisation of risk assessment to that developed from population data is required for nursing. This is not to say risk and safety is not of central concern of mental health nursing, but as with diagnosis, that it should be located within a framework of situated understanding of the person. It follows that a different assessment process and protocol from that of diagnosis or risk factor driven processes is required. There is however, an absence of practice models for mental health nursing that have understanding and meaning-making as a central philosophical tenet. The closest practice model consistent with the focus here, would be the Barker's (2000) Tidal Model, in which the person's narrative, language, and meanings are central to the assessment process and shape the approach to therapeutic relationship.

The exploration here of four men's experiences of suicidality shows that the potential for survival and recovery lies in reconstructing an understanding of self and personal history differently in order to grow. In a Gadamerian sense, to acquire an expanded horizon of meaning. Insofar as this can be generally applied to a broader range of mental health nursing issues, it supports Barker, Reynolds and Ward's (1995) assertions that the proper focus of mental health nursing is with the way in which people make meaning from their life experiences, having regard to the sociocultural and historical situatedness of meanings; including that which the nurse brings to the encounter. The proper focus of mental health nursing intervention then is to engage in human relationships in a conscious way to facilitate bringing into possibility the potential for different understandings of their troubles. This differs from the "nursing process" in which the nurse is the expert who defines (e.g. diagnosing) the meaning of the person's experiences and then intervenes (i.e. treatment). Hence, the aim is not to treat, but to invite. It is also an advocacy process for an ethics of nursing practice that recognises nurses, and the people we work with as clients or patients to construct meaning through every encounter. Hence, what the nurse brings as a person to the process is important. This calls attention to the fact that we and the people we work with, bring ourselves and our worldview to each encounter. A critical awareness of this fact is necessary in order to be fully aware that through what we introduce, especially the taken-for-granteds, to the encounter may also limit the possibilities for growth and development. 


\section{Implications for mental health nursing research}

An initial exploration of the literature on suicidality showed it to be predominantly informed from research measuring sex-differences in population data. Although nursing textbooks were aetiologically eclectic, discussion of nursing intervention for suicidality was rarely explicitly located within a nursing framework, theory, or philosophy other than the application of the nursing process and functions (e.g. Gallop \& Stamina, 2003; Kniesl, Wilson \& Trigoboff, 2004; Shives, 2004; Townsend, 2003). Hence, mental health nursing intervention was substantially generic, bringing little to intervention that was specific to the discipline. While texts advocated the role of nursing to be underpinned by the therapeutic relationship, the current approach does not attend to the process of understanding, and the situatedness of suicidal experience. In particular, within the current universalist approach to risk assessment and risk-driven intervention, suicidality is not regarded as a gendered experience; yet at the same time, the same texts clearly state that men are at higher risk.

There is however, a growing body of nursing research that explores the suicidal person's experiences (Cutcliffe \& Barker, 2002; Duffy, 2003; Moore, 1997; Raingruber, 2002; Samuelsson, Wiklander, Asberg, \& Saveman, 2000; Talseth, Gilje, \& Norberg, 2003; Talseth, Lindseth, Jacobsson, \& Norberg, 1999; Talseth, Jacobsson, \& Norberg, 2001; Wiklander, Samuelsson, \& Asberg, 2003), the experiences of their family (Demi \& Howell, 1991; Fielden, 2003; Talseth, Gilje, \& Norberg, 2001), and the experiences of mental health nurses (Dearden, 2004; Duffy, 1995; McLaughlin, 1999; Thompson \& Brooks, 1990; Valente, 2003; Yonge \& Stewin, 1992) and that of other professionals (Anderson, Standen, Nazir, \& Noon, 2000; Anderson, Standen, \& Noon, 2003; Lindseth, Marhaug, Norberg, \& Uden, 1994). Despite this body of nursing research, recent guidelines aimed at informing practice by all mental health clinicians produced by the New Zealand Guidelines Group (2003) did not cite research on suicidality sourced from nursing journals. ${ }^{25}$ That guidelines for risk assessment and management of suicide risk, for which nurses are a substantial part of the workforce, are not informed by nursing research should be of great concern to mental health nursing practice and mental health nursing researchers. Additionally, current nursing research tends to ignore the participation of researcher (and clinician) in the construction of meaning in the

\footnotetext{
25 This was established by examining the reference list in cited in the guidelines and noting whether or not the article was sourced from a nursing journal.
} 
social context of suicidality and therefore neglects the impact that gendered meanings have, including the process of intervention by the nurse. This current study begins to address this gap.

While there is a general recognition that mental health nurses have ongoing contact with clients who are suicidal, and in inpatient settings as a staff group, have 24-hour responsibility for the safekeeping of suicidal people, there seems minimal literature that provides nurses with a nursing framework to guide therapeutic practice with suicidal clients. Mental health nursing practice is in need of frameworks or models that translate nursing research that explores the meaningfulness of client experience into a structure that may be implemented in nursing settings with people who are suicidal. Cardell and Horton-Deutsch (1994) developed a model for assessing suicide potential based on the notion of ambivalence in the interactional context of a psychiatric admission. Rickelman and Houfek (1995) have proposed an interactional model based on a cognitive therapy framework for "nurse psychotherapists". More recently Cutcliffe and Barker (2000, 2002) have proposed a "hopeline" model, premised on a notion of engagement rather than observation of people who are suicidal. Much more work is needed for research to clarify the therapeutic processes and to define appropriate ways to evaluate the nursing outcomes of these models. Additionally, an overarching mental health nursing framework is needed in which such approaches to suicidality are philosophically and theoretically congruent. As nurses have a critical role in the administration of medication, such approaches must account for the meaning that biomedical interventions (e.g. medication) have within the broad scope of mental health nursing practice.

Appropriate research methodologies, congruent with the core precepts of mental health nursing are needed. If the core of mental health nursing practice is to do with working within meaningful relationships and the meaningfulness of experiences in which mental health nurses participate to facilitate growth and development, then the approach used in this study provides such an approach. A research approach drawing on Gadamer explicitly attends to the participation of the mental health nurse in the creation of new understandings. The approach taken here makes explicit the involvement of the researcher in producing new understandings through the research dialogue. The methodical approach taken in this study seems particularly useful for mental health nursing researchers where, the phenomena of interest inextricably involves both the 
client and nurse engaged in conversation. This parallels the central role of conversation in mental health nursing practice in which mental health nurses engage and work with clients and their families. Just as the researcher first engages with participants in order to understand, and then later, this understanding is further examined, mental health nurses similarly enter a relationship to understand the client and later reflect on this in order to be able to offer alternative possibilities. This study shows that a method drawing on Gadamer, such as described in this study, provides the opportunity to explore the many different aspects of mental health nursing relationship, engagement, and working with clients.

\section{Conclusion}

This study has explored the understanding of four men's suicidal experiences using a methodology informed by Gadamerian hermeneutics to arrive at an interpretation that also explicitly considers anti-essentialist theorising on masculinities. By drawing on Gadamer's work on the nature of understanding this study has made the interpretive horizon of the researcher an overt aspect of the interpretive process. Conclusions are therefore made standing within the tradition of mental health nursing in New Zealand and Australia.

A methodological position is developed that approaches the understanding of suicidality as being initially produced through the hermeneutic fusion of horizons of myself (as researcher) and each of the participants. The result is suicidal experience interpreted as an historical trajectory, not predetermined by circumstances but instead, insidiously shaped over a prolonged time through childhood and adolescence, that at the same time, are limited by the means to comprehend those experiences. Additionally, the picture derived from the fusion is one in which each of these men recollect struggling alone with their effort to make sense of their experiences of victimisation.

Again, drawing upon Gadamer, this study then moves beyond the initial point of understanding within the conversations with the study participants, to further examine the influence of masculinities upon the shaping of the understandings developed in the dialogue. Methodologically, this move takes the position that understanding and interpretation have already occurred within the conversations and that an examination of transcripts (and any other records) cannot be collapsed into a single interpretative effort, in which transcripts alone are assumed to be a sufficient proxy for the original 
dialogue. The assumption that the analysis of transcripts is a proxy for the original researcher-participant dialogue is a common feature of hermeneutic studies. However, such an assumption fails to sufficiently account for the "conditions of understanding" that a Gadamerian approach demands.

Through an explicit consideration of anti-essentialist theorising on masculinities, this (re)interpretation explores the potent influence of unquestioned and taken-for-granted social norms for boys and men in shaping the understanding of their experiences of victimisation as a boy. In a social world that locates gender as a dichotomy of men and women, and in which men can only be "not-women", these men were thrown into a struggle to meet the required sociocultural expectations to fit in as best they could as boys and teenagers. In a hierarchical masculine social context, transgression of the dominant worldview met with further experiences of victimisation that echoed prior experiences. Furthermore, being a victim in itself was a transgression of dominant masculine norms.

A potent claim to a masculine identity in New Zealand through participation in rugby was not available to these men. Alternative means of enacting violence and competitiveness (e.g. school ground fighting, gay bashing, etc.) as a means of making a claim to the dominant forms of masculinity was similarly not available, as these men already knew the consequences of their physical vulnerability from their childhood at home and school. Instead, sport, and then drugs and alcohol were accessible and an acceptable means of both quelling the growing psychological pain and ameliorating social isolation.

Gadamerian hermeneutics locates the pathway to suicidality in an historical and sociocultural context, showing the way in which early understandings can be carried through from the past in a continual interpretation and reinterpretation of experiences. For the participants of this study, suicidal experience is not so much a result of an immediate crisis but as a way of understanding the present through a fusion with the accumulated understandings from the past. In this sense, this interpretation suggests that suicidality is socioculturally situated and historically emergent rather than an irrational response to immediate difficulties. This approach to suicidality, from the premise of understanding rather than explaining, provides mental health nursing with a different range of possibilities to engage with and provide nursing intervention. 
Furthermore, the attendance to situatedness means that nurses are also able to work with the individual uniqueness (including difference) of both themselves and the person who is suicidal; and at the same time, within the social constraints and possibilities that the current gender order affords for women and men in society. Gender is not viewed here as a universal category of either woman or man determined by biology, but rather, that in being suicidal these men were also doing their best to remain men as they understood men to be.

Significantly, a socio-cultural and historical interpretation also suggests that there is a substantial and unrealised scope for suicide prevention from having a focus on the construction and processes of understanding. For instance, along with recent research that has examined the impact of bullying and its relationship to mental disorders and suicide (Coggan, Bennett, Hooper, \& Dickson, 2003), the exploration of suicidal experiences undertaken here indicates that the struggle to comprehend experiences of victimisation would be a fruitful process to engage with. In addition, by drawing upon a Gadamerian perspective to underpin practice, the potential for a range of approaches to facilitate change begins to come into view. This potential may be realised by drawing upon recent theorising in constructivist psychology that is underpinned by Gadamerian hermeneutics in which individual agency is viewed as operating within possibilities and constraints offered by the person's particular sociocultural and historical context (Martin \& Sugarman, 1999; Martin \& Thompson, 2003).

While patient-centred practice is a commonly held premise within mental health nursing and generally accepted that this locates the nurse-client relationship at the centre of practice, (and hence reflected in practice standards), this study suggests that a constructivist mental health nursing practice emphasises relationship in such a way that current best practice is unable to achieve. A mental health nursing practice underpinned by constructivism raises a concern for human meaning and human relationship in a way that is prior to the concerns of the biomedical or behavioural sciences, rather than merely a necessary function or mechanism to facilitate biomedical or behavioural intervention.

Such a shift in focus calls attention to the place in mental health nursing of relating and relationships and what it means to understand the other person. With the current emphasis in mental health on measurable outcomes and biological intervention, this 
study argues that at the core of mental health nursing endeavours are complex (and often distressed) human beings who are more than objects of biomedical or behavioural science. This study calls for a reinvigoration of the interpersonal in mental health nursing as the centre of practice and professional identity. At the same time, this study provides a cautionary note that neglect the interpersonal may exacerbate existing distress. 


\section{REFERENCES}

Adams, P. (1997). Men. In P. M. Ellis \& S. C. D. Collings (Eds.), Mental health in New Zealand from a public health perspective (pp. 213-242). Wellington, New Zealand: Public Health Group, Ministry of Health.

Allen, L. (2002). 'As far as sex goes, I don't really think about my body': Young men's corporeal experiences of (hetero)sexual pleasure. In H. Worth, A. Paris \& L. Allen (Eds.), The life of Brian (pp. 129-138). Dunedin, New Zealand: University of Otago Press.

Amankwaa, L. (2000). Qualitative data analysis: Using NUD*IST 4 in a preliminary investigation of postpartum depression among African-American women. The Qualitative Report, 4(3 \& 4). Retrieved from http://www.nova.edu/ssss/QR/QR4-3/amankwaa.html

American Psychiatric Association. (1987). Diagnostic and statistical manual of mental disorders (3rd Rev. ed.). Washington, DC: Author.

American Psychiatric Association. (2000). Diagnostic and statistical manual of mental disorders (4th Ed., Text Revision). Washington, DC: Author.

Anderson, M., Standen, P., Nazir, S., \& Noon, J. P. (2000). Nurses' and doctors' attitudes towards suicidal behaviour in young people. International Journal of Nursing Studies, $37(1), 1-11$.

Anderson, M., Standen, P., \& Noon, J. (2003). Nurses' and doctors' perceptions of young people who engage in suicidal behaviour: A contemporary grounded theory analysis. International Journal of Nursing Studies, 40(6), 587-597.

Australian and New Zealand College of Mental Health Nurses. (1995). Standards of practice for mental health nursing in New Zealand. Auckland, New Zealand: Author.

Australian and New Zealand College of Mental Health Nurses. (2002). Competencies for advanced practice in psychiatric mental health nursing. Auckland, New Zealand: Author.

Baechler, J. (1979). Suicides (B. Cooper, Trans.). New York: Basic Books. (Original work published 1975) 
Barker, P. (1990). The philosophy of psychiatric nursing. Nursing Standard, 5(12), 28-33.

Barker, P. (2000). The Tidal Model: Theory and practice. Edinburgh, UK: Clan Unity.

Barker, P., \& Cutcliffe, J. (2000). Creating a hopeline for suicidal people: A new model for acute sector mental health nursing. Mental Health and Learning Disabilities Care, 31(6), 190-193.

Barker, P., Jackson, S., \& Stevenson, C. (1999a). The need for psychiatric nursing: Towards a multidimensional theory of caring. Nursing Inquiry, 6(2), 103-111.

Barker, P., Jackson, S., \& Stevenson, C. (1999b). What are psychiatric nurses needed for? Developing a theory of essential nursing practice. Journal of Psychiatric and Mental Health Nursing, 6(4), 273-282.

Barker, P. J. (1996). The logic of experience: Developing appropriate care through effective collaboration. Australian and New Zealand Journal of Mental Health Nursing, 5(1), 3-12.

Barker, P. J. (1997). Assessment in psychiatric and mental health nursing: In search of the whole person. Cheltenham, United Kingdom: Nelson Thornes.

Barker, P. J., \& Reynolds, B. (1996). Rediscovering the proper focus of nursing: A critique of Gournay's position on nursing theory and models. Journal of Psychiatric and Mental Health Nursing, 3(1), 76-80.

Barker, P. J., Reynolds, W., \& Stevenson, C. (1997). The human science basis of psychiatric nursing: Theory and practice. Perspectives in Psychiatric Care, 34(1), 5-15.

Barker, P. J., Reynolds, W., \& Ward, T. (1995). The proper focus of nursing: A critique of the "caring" ideology. International Journal of Nursing Studies, 32(4), 386-397.

Barnes, L. S., Ikeda, R. M., \& Kresnow, M. J. (2001). Help-seeking behavior prior to nearly lethal suicide attempts. Suicide and Life-Threatening Behavior, 32(Suppl.), 6875.

Barraclough, B. M. (1985). Clinical and epidemiological studies on suicide. Unpublished doctoral thesis, University of Otago, Dunedin, New Zealand.

Battersby, M. W., O'Mahoney, J. J., Beckwith, A. R., \& Hunt, J. L. (1996). Antidepressant deaths by overdose. Australian and New Zealand Journal of Psychiatry, 30(2), 223228. 
Beck, A. (1996). Beyond belief: A theory of modes, personality, and psychopathology. In P. Salkovkis (Ed.), Frontiers of cognitive therapy (pp. 1-25). New York: Guilford Press.

Berman, A. (1993). Forensic suicidology and the psychological autopsy. In A. A. Leenaars (Ed.), Suicidology: Essays in honor of Edwin S. Shneidman (pp. 248-266). Northvale, NJ: Jason Aronson.

Beumont, P. (1997). Mental disorders, psychopathology and classification. In P. Beumont, G. Andrews, P. Boyce \& V. Carr (Eds.), Psychological medicine: A companion to management of mental disorders (pp. 17-41). Sydney, Australia: World Health Organisation Collaborating Centre for Mental Health and Substance Abuse.

Beumont, P., Andrews, G., Boyce, P., \& Carr, V. (1997). Preface. In P. Beumont, G. Andrews, P. Boyce \& V. Carr (Eds.), Psychological medicine: A companion to management of mental disorders (pp. xiv-xv). Sydney, Australia: World Health Organisation Collaborating Centre for Mental Health and Substance Abuse.

Beynon, J. (2001). Masculinities and culture. Philadelphia, PA: Open University Press. Biddulf, S. (1995). Manhood: An action plan for changing men's lives (2nd ed.). Sydney, Australia: Finch.

Bleicher, J. (1980). Contemporary hermeneutics: Hermeneutics as method, philosophy and critique. London: Routledge \& Kegan Paul.

Bly, R. (1990). Iron John: A book about men. Reading, MA: Addison-Wesley.

Brent, P. A. (1989). The psychological autopsy: Methodological considerations for the study of adolescent suicide. Suicide and Life-Threatening Behaviour, 19(1), 43-57.

Broom, D. (1995, 17-19 November). Gendering health, sexing illness. Paper presented at the 3rd National Women's Health Conference, Canberra, Australia.

Broverman, I. K., Broverman, D. M., Clarkson, F. E., Rosenkrantz, P. S., \& Vogel, S. R. (1970). Sex-role stereotypes and clinical judgements of mental health. Journal of Counselling and Clinical Psychology, 34(1), 1-7.

Bryson, L. (1987). Sport and the maintenance of masculine hegemony. Women's Studies International Forum, 10(4), 349-360. 
Buckley, N. A., Dawson, A. H., Whyte, I. M., Hazell, P., \& et al. (1996). An analysis of age and gender influences on the relative risk for suicide and psychotropic drug self-poisoning. Acta Psychiatrica Scandinavica, 93(3), 168-171.

Busfield, J. (1982). Gender and mental illness. International Journal of Mental Health, 11(1), 46-66.

Busfield, J. (1986). Managing madness: Changing ideas and practice. London: Unwin Hyman.

Campbell, H., Law, R., \& Honeyfield, J. (1999). 'What it means to be a man': Hegemonic masculinity and the reinvention of beer. In R. Law, H. Campbell \& J. Dolan (Eds.), Masculinities in Aotearoa/New Zealand (pp. 166-186). Palmerston North, New Zealand: Dunmore Press.

Canetto, S. S. (1991). Gender roles, suicide attempts, and substance abuse. Journal of Psychology, 125(6), 605-620.

Canetto, S. S. (1992). She died for love and he for glory: Gender myths of suicidal behavior. Omega: Journal of Death and Dying, 26(1), 1-17.

Canetto, S. S. (1994). Gender issues in the treatment of suicidal individuals. Death Studies, 18(5), 513-527.

Canetto, S. S. (1995). Men who survive a suicidal act. In D. Sabo \& D. F. Gordon (Eds.), Men's health and illness: Gender, power, and the body (pp. 292-304). Thousand Oaks, CA: Sage.

Canetto, S. S. (1997). Meaning of gender and suicidal behavior during adolescence. Suicide and Life-Threatening Behaviour, 27(4), 339-351.

Canetto, S. S., \& Sakinofsky, I. (1998). The gender paradox in suicide. Suicide and LifeThreatening Behavior, 28(1), 1-23.

Cantor, P. (1993). The roots and legacy of violence. In A. A. Leenaars (Ed.), Suicidology (pp. 63-72). Northvale, NY: Jason Aronson.

Caplan, P. (1987). Introduction. In P. Caplan (Ed.), The cultural construction of sexuality (pp. 1-30). London: Routledge.

Cardell, R. \& Horton-Deutsch, S. (1994). A model for assessment of inpatient suicide potential. Archives of Psychiatric Nursing, 8(6), 366-372. 
Carter, G. (1997). Suicide. In P. Beumont, G. Andrews, P. Boyce \& V. Carr (Eds.), Psychological medicine: A companion to management of mental disorders (pp. 184-187). Sydney, Australia: World Health Organisation Collaborating Centre for Mental Health and Substance Abuse.

Cavan, R. S. (1965). Suicide. New York: Russell \& Russell. (Original work published 1928)

Chesler, P. (1972). Women and madness. New York: Four Walls Eight Windows.

Chesler, P. (1978). About men. New York: Simon and Schuster.

Clark, D. C., \& Fawcett, J. (1992). Review of empirical risk factors for evaluation of the suicidal patient. In B. Bongar (Ed.), Suicide: Guidelines for assessment, management, and treatment (pp. 16-48). New York: Oxford University Press.

Clark, D. C., \& Horton-Deutsch, S. (1992). Assessment in abstentia: The value of the psychological autopsy method for studying antecedents of suicide and predicting future suicides. In R. Maris, A. Berman, J. Maltsberger \& R. Yufit (Eds.), Assessment and prediction of suicide (pp. 144-182). New York: Guildford Press.

Clarke, J. N. (1991). Media portrayal of disease from the medical political economy, and life-style perspectives. Qualitative Health Research, 1(3), 287-308.

Coggan, C., Bennett, S., Hooper, R., \& Dickson, P. (2003). Association between bullying and mental health status among a sample of 3,265 New Zealand adolescents. International Journal of Mental Health Promotion, 5(1), 16-22.

Collinson, D., \& Hearn, J. (2001). Naming men as men: Implications for work, organization and management. In S. M. Whitehead \& F. J. Barrett (Eds.), The masculinities reader (pp. 144-169). Malden, MA: Polity Press.

Comaroff, J. (1997). The Empire's old clothes: Fashioning the colonial subject. In L. Lamphere, H. Ragoné \& P. Zavella (Eds.), Situated lives: Gender and culture in everyday life (pp. 400-419). New York: Routledge.

Connell, R. W. (1983). Dr Freud and the course of history. In Which way is up? Essays on sex, class and culture (pp. 3-16). Sydney, Australia: Allen \& Unwin.

Connell, R. W. (1985). Theorising gender. Sociology, 19(2), 260-272. 
Connell, R. W. (1987). Gender and power: Society, the person and sexual politics. Sydney, Australia: Allen \& Unwin.

Connell, R. W. (1990). An iron man: The body and some contradictions of hegemonic masculinity. In M. A. Messner \& D. F. Sabo (Eds.), Sport, men, and the gender order: Critical feminist perspectives (pp. 83-96). Champaign, IL: Human Kinetics Books.

Connell, R. W. (1991). Live fast and die young: The construction of masculinity among young working-class men on the margin of the labour market. Australian and New Zealand Journal of Sociology, 27(2), 141-171.

Connell, R. W. (1994). Psychoanalysis on masculinity. In H. Brod \& M. Kaufman (Eds.), Theorizing masculinities (pp. 11-38). Thousand Oaks, CA: Sage.

Connell, R. W. (1995). Masculinities. Berkeley, CA: University of California Press.

Connell, R. W. (1996). New directions in gender theory, masculinity research, and gender politics. Ethnos, 61(3-4), 157-176.

Connell, R. W. (2000). The men and the boys. Berkeley, CA: University of California Press.

Connell, R. W., Schofield, T., Walker, L., Wood, J., Butland, D. L., Fisher, J., et al. (1998). Men's health: A research agenda and background report (Report No. 2527). Canberra, Australia: Commonwealth Department of Health and Aged Care.

Cox, L. M., \& Lyddon, W. J. (1997). Constructivist conceptions of self: A discussion of emerging identity constructs. Journal of Constructivist Psychology, 10(3), 201-220.

Crosset, T. (1990). Masculinity, sexuality, and the development of early modern sport. In M. A. Messner \& D. F. Sabo (Eds.), Sport, men, and the gender order: Critical feminist perspectives (pp. 45-54). Champaign, IL: Human Kinetics Books.

Crotty, M. (1998). The foundations of social research: Meaning and perspective in the research process. Sydney, Australia: Allen \& Unwin.

Crowe, M. (2000). Constructing normality: A discourse analysis of the DSM-IV. Journal of Psychiatric and Mental Health Nursing, 7(1), 69-77.

Cushman, P. (1990). Why the self is empty. American Psychologist, 45(5), 599-612.

Cushman, P., \& Gilford, P. (1999). From emptiness to multiplicity: The self at the year 2000. Psychohistory Review, 27(2), 15-31. 
Cutcliffe, J. R., \& Barker, P. (2002). Considering the care of the suicidal client and the case for "engagement and inspiring hope" or "observations." Journal of Psychiatric and Mental Health Nursing, 9(5), 611-621.

Cutcliffe, J. R., \& Goward, P. (2000). Mental health nurses and qualitative research methods: A mutual attraction? Journal of Advanced Nursing, 31(3), 590-598.

Cutcliffe, J. R., Joyce, A., \& Cummins, M. (2004). Building a case for understanding the lived experiences of males who attempt suicide in Alberta, Canada. Journal of Psychiatric and Mental Health Nursing, 11(3), 305-312.

David, D. S., \& Brannon, R. (1976). The male sex role: Our culture's blueprint of manhood, and what it's done for us lately. In D. S. David \& R. Brannon (Eds.), The forty-nine percent majority: The male sex role (pp. 1-45). Reading, MA: AddisonWesley.

Dearden, G. (2004). When things go wrong: The experiences of mental health nurses who have had a patient die through suicide. Unpublished Master of Arts (Applied) thesis, Victoria University of Wellington, Wellington, New Zealand.

Demi, A. S., \& Howell, C. (1991). Hiding and healing: Resolving the suicide of a parent or sibling. Archives of Psychiatric Nursing, 5(6), 350-356.

Depner, C. E., Leino, E. V., \& Chun, A. (1992). Interparental conflict and child adjustment: A decade review and meta-analysis. Family and Conciliation Courts Review, 30(3), 323-341.

Diekstra, R. F. (1989a). An international perspective on suicide and its prevention. In S. D. Platt \& N. Kreitman (Eds.), Current research on suicide and parasuicide: Selected proceedings of the Second European Symposium on Suicidal Behaviour (pp. 2-21).

Edinburgh, Scotland: Edinburgh University Press.

Diekstra, R. F. (1989b). Suicide and attempted suicide: An international perspective. Acta Psychiatrica Scandinavica, 80(354, Suppl.), 1-24.

Diekstra, R. F. W. (1998). Reflections on the state of suicidology. In D. De Leo, A. Schmidtke \& R. F. W. Diekstra (Eds.), Suicide prevention: A holistic approach (pp. 113). Dordrecht, The Netherlands: Kluwer Academic. 
Donald, R. R. (2001). Masculinity and machismo in Hollywood's war films. In S. M. Whitehead \& F. J. Barrett (Eds.), The masculinities reader (pp. 170-183). Malden, MA: Polity Press.

Donaldson, M. (1993). What is hegemonic masculinity? Theory and Society, 22(5), 643-657.

Douglas, J. D. (1967). The social meanings of suicide. Princeton, NJ: Princeton University Press.

Drummond, M. J. N. (2002). Sport and images of masculinity: the meaning of relationships in the life course of "elite" male athletes. The Journal of Men's Studies, 10(2), 129-142.

Durkheim, E. (1952). Suicide: A study in sociology (J. A. Spaulding \& G. Simpson, Trans.). London: Routledge \& Kegan Paul. (Original work published 1897)

Duroche, L. (1990). Male perception as social construct. In J. Hearn \& D. Morgan (Eds.), Men, masculinities and social theory (pp. 170-185). London: Unwin Hyman.

Duffy, D. (1995). Out of the shadows: a study of the special observation of suicidal psychiatric in-patients. Journal of Advanced Nursing, 21(5), 944-950.

Duffy, D. (2003). Exploring suicide risk and the therapeutic relationship: a case study approach. NT Research, 8(3), 185-199.

Easlea, B. (1987). Patriarchy, scientists, and nuclear warriors. In M. Kaufman (Ed.), Beyond patriarchy: Essays by men on pleasure, power, and change (pp. 195-215). Toronto, Canada: Oxford University Press.

Edley, N., \& Wetherell, M. (1997). Jockeying for position: The construction of masculine identities. Discourse and Society, 8(2), 203-217.

Efran, J. S., \& Clarfield, L. E. (1992). Constructionist therapy: Sense and nonsense. In S. McNamee \& K. J. Gergen (Eds.), Therapy as social construction (pp. 200-217). London: Sage.

Ellard, J. (1999). What's love got to do with it? Male victims and the Family Court. In K. Biber, T. Sear \& D. Trudinger (Eds.), Playing the man: New approaches to masculinity (pp. 161-170). Annandale, Australia: Pluto Press.

Erickson, M. F., Egeland, B., \& Pianta, R. (1989). The effects of maltreatment on the development of young children. In D. Cicchetti \& V. Carlson (Eds.), Child 
maltreatment: Theory and research on the causes and consequences of child abuse and neglect (pp. 647-684). Cambridge, United Kingdom: Cambridge University Press.

Farber, M. L. (1968). Theory of suicide. New York: Funk \& Wagnalls.

Fee, D. (1992). Masculinities, identity and the politics of essentialism: A social constructionist critique of the men's movement. Feminism and Psychology, 2(2), 171-176.

Fielden, J. M. (2003). Grief as a transformative experience: Weaving through different lifeworlds after a loved one has completed suicide. International Journal of Mental Health Nursing, 12(1), 74-85.

Fitzclarence, L., \& Hickey, C. (2001). Real footballers don't eat quiche: Old narratives in new times. Men and Masculinities, 4(2), 118-140.

Fleming, V., Gaidys, U., \& Robb, Y. (2003). Hermeneutic research in nursing: Developing a Gadamerian-based research method. Nursing Inquiry, 10(2), 113120.

Foucault, M. (1979). Discipline and punish: The birth of the prison (A. Sheridan, Trans.). Harmondsworth, England: Penguin Books. (Original work published 1975)

Fougere, G. (1987). Sport, culture and identity: The case of rugby football. In D. Novitz \& B. Willmott (Eds.), Culture and identity in New Zealand (pp. 110-122).

Wellington, New Zealand: GP Books.

Frankl, V. E. (1984). Man's search for meaning (Revised ed.). New York: Washington Square Press.

Freeman, A., \& Reinecke, M. A. (1993). Cognitive therapy of suicidal behavior: A manual for treatment. New York: Springer.

Fremouw, W. J., de Perczel, M., \& Ellis, T. E. (1990). Suicide risk: Assessment and response guidelines. New York: Pergamon.

French, S. (1999). Masculinity and violence in the school playground. In K. Biber, T. Sear \& D. Trudinger (Eds.), Playing the man: New approaches to masculinity (pp. 137149). Annandale, Australia: Pluto Press.

Freud, S. (1925). Mourning and melancholia. In J. Riviere (Ed. \& Trans.), Collected papers (Vol. 4, pp. 152-170). London: Hogarth Press. (Original work published 1917) 
Freud, S. (1955). From the history of an infantile neurosis. In J. Strachey (Ed. \& Trans.), The standard edition of the complete psychological works of Sigmund Freud (Vol. 17, pp. 3122). London: Hogarth. (Original work published 1918)

Freud, S. (1955). Notes upon a case of obsessional neurosis. In J. Strachey (Ed. \& Trans.), The standard edition of the complete psychological works of Sigmund Freud (Vol. 10, pp. 155-249). London: Hogarth. (Original work published 1909)

Freud, S. (1986). Three essays on the theory of sexuality (J. Strachey, Trans.). In A. Freud (Ed.), The essentials of psycho-analysis (pp. 281-375). London: Hogarth. (Original work published 1905)

Gadamer, H.-G. (1975). Truth and method (G. Barden \& J. Cumming, Trans.). New York: Continuum. (Original work published 1965)

Gadamer, H.-G. (1976). Philosophical hermeneutics (D. E. Linge, Trans.). Berkeley, CA: University of California Press.

Gadamer, H.-G. (1980). The universality of the hermeneutical problem (D. E. Linge, Trans.). In J. Bleicher (Ed.), Contemporary hermeneutics: Hermeneutics as method, philosopby and critique (pp. 147-158). London: Routledge \& Kegan Paul. (Original work published 1966)

Gadamer, H.-G. (1985). The discrediting of prejudice by the enlightenment (G. Barden, J. Cumming \& J. Dibble, Trans.). In K. Mueller-Vollmer (Ed.), The hermeneutics reader: Texts of the German tradition from the Enlightenment to the present (pp. 257-292). Oxford, United Kingdom: Basil Blackwell. (Original work published 1965)

Gadamer, H.-G. (1987). The problem of historical consciousness (J. L. Close, Trans.). In P. Rabinow \& W. M. Sullivan (Eds.), Interpretive social science: A second look (Rev. ed., pp. 82-140). Berkeley: University of California Press. (Original work published 1963)

Gadamer, H.-G. (1988). On the circle of understanding. In J. M. Connolly \& T. Keutner (Eds. \& Trans.), Hermeneutics versus science? Three German views (pp. 68-78). Notre Dame, IN: University of Notre Dame Press. (Original work published 1959)

Gadamer, H.-G. (1989). Text and interpretation (D. J. Schmidt \& R. Palmer, Trans.). In D. P. Michelfelder \& R. E. Palmer (Eds.), Dialogue and deconstruction: The GadamerDerrida encounter (pp. 21-51). Albany, NY: State University of New York. (Original work published 1984) 
Gadamer, H.-G. (1990). Truth and method (G. Barden \& J. Cumming, Trans.). In G. L. Ormiston \& A. D. Schrift (Eds.), The hermeneutic tradition: From Ast to Ricoeur (pp. 198-212). Albany, NY: State University of New York Press. (Original work published 1965)

Gadamer, H.-G. (1996). The enigma of health: The art of healing in a scientific age (J. Gaiger \& N. Walker, Trans.). Palo Alto, CA: Stanford University Press.

Gallop, R., \& Stamina, E. (2003). The person who is suicidal. In P. Barker (Ed.), Psychiatric and mental health nursing: The craft of care (pp. 227-235). London: Arnold.

Geanellos, R. (1997). Explicating practice knowledge: A hermeneutic inquiry into adolescent mental health nursing. Unpublished doctoral thesis, Australian Catholic University, Ascot Vale, Australia.

Geanellos, R. (1999). Hermeneutic interviewing: an example of its development and use as research method. Contemporary Nurse, 8(2), 39-45.

Geanellos, R. (2004). Nursing based evidence: Moving beyond evidence-based practice in mental health nursing. Journal of Evaluation in Clinical Practice, 10(2), 177-186.

Gilbert, P. (1994). Male violence: Towards an integration. In J. Archer (Ed.), Male violence (pp. 352-389). London: Routledge.

Gilligan, J. (2004). Culture, gender, and violence: "We are not women". In M. S. Kimmel \& A. Aronson (Eds.), The gendered society reader (2nd ed., pp. 427-436). New York: Oxford University Press.

Glick, B., \& Goldstein, A. P. (1987). Aggression replacement training. Journal of Counselling and Development, 65(7), 356-362.

Gold, M. (1958). Suicide, homicide, and the socialization of aggression. American Journal of Sociology, 63(6), 651-661.

Gournay, K. (1995). What to do with nursing models. Journal of Psychiatric and Mental Health Nursing, 2(5), 325-327.

Gournay, K. (1997). Commentary. Responses to: "What to do with nursing models" - a reply from Gournay. Journal of Psychiatric and Mental Health Nursing, 4(3), 227-231.

Griffiths, T. (1993). Fight/flight: Violence alcohol and denial. In Men's health: The forgotten issue (pp. 55-62). Melbourne, Australia: Ausmed. 
Grondin, J. (2002). Gadamer's basic understanding of understanding. In R. J. Dostal (Ed.), Cambridge companion to Gadamer (pp. 36-51). Cambridge, United Kingdom: Cambridge University Press.

Grondin, J. (2003). Hans-Georg Gadamer: A biography (J. Weinsheimer, Trans.). New Haven, CT: Yale University Press.

Guba, E. G., \& Lincoln, Y. S. (1994). Competing paradigms in qualitative research. In N. K. Denzin \& Y. S. Lincoln (Eds.), Handbook of qualitative research (pp. 105-117). Thousand Oaks, CA: Sage.

Hall, W. (1996). Substance abuse. In A. F. Jorm (Ed.), Men and mental health (pp. 36-44). Canberra, Australia: National Health and Medical Research Council.

Harvey, L. (1992). Science and technology. In G. Lupton, P. M. Short \& R. Whip (Eds.), Society and gender: An introduction to sociology (pp. 267-286). South Melbourne, Australia: Macmillan.

Hassan, R. (1995). Suicide explained: The Australian experience. Melbourne, Australia: Melbourne University Press.

Hawton, K., \& Catalan, J. (1987). Attempted suicide: A practical guide to its nature and management (2nd ed.). Oxford, United Kingdom: Oxford University Press.

Hearn, J. (1987). The gender of oppression: Men, masculinity, and the critique of Marxism. Sussex, United Kingdom: Wheatsheaf Books.

Hearn, J. (1992). The personal, the political, the theoretical: The case of men's sexualities and sexual violences. In D. Porter (Ed.), Between men and feminism (pp. 161-181). London: Routledge.

Heidegger, M. (1962). Being and time (J. Macquarrie \& E. Robinson, Trans.). London: SCM.

Heise, L. L. (1994). Violence against women: The bidden health burden (Discussion Paper No. 255). Washington, DC: World Bank.

Hekman, S. J. (1984). Action as text: Gadamer's hermeneutics and the social scientific analysis of action. Journal for the Theory of Social Behaviour, 14(3), 333-354.

Hekman, S. J. (1986). Hermeneutics and the sociology of knowledge. Notre Dame, IN: University of Notre Dame Press. 
Henry, A. F., \& Short, J. F., Jr. (1954). Suicide and homicide: Some economic, sociological and psychological aspects of aggression. London: Free Press.

Herek, G. M. (1987). On heterosexual masculinity: Some psychical consequences of the social construction of gender and sexuality. In M. S. Kimmel (Ed.), Changing men: New directions in research on men and masculinity (pp. 68-82). Newbury Park, CA: Sage.

Hill, L. (1999). What it means to be a Lion Red man: Alcohol advertising and Kiwi masculinity. Women's Studies Journal, 15(1), 65-85.

Hjelmeland, H., \& Knizek, B. L. (1999). Conceptual confusion about intentions and motives of nonfatal suicidal behavior: A discussion of terms employed in the literature of suicidology. Archives of Suicide Research, 5(4), 275-281.

Holmes, J. (Ed.). (2000). Gendered speech in social context. Wellington, New Zealand: Victoria University Press.

Horsfall, J., \& Stuhlmiller, C. M., (with Champ, S.). (2000). Interpersonal nursing for mental bealth. Sydney: MacLennan \& Petty.

Hutchins, B., \& Mikosza, J. (1998). Australian rugby league and violence 1970 to 1995: A case study in the maintenance of masculine hegemony. Journal of Sociology, 34(3), 246-263.

Ikeda, R. M., Kresnow, M. J., Mercy, J. A., Powell, K. E., Simon, T. R., Potter, L. B., et al. (2001). Medical conditions and nearly lethal suicide attempts. Suicide and LifeThreatening Behavior, 32(Suppl.), 60-67.

Jackson, P. (Director), \& B. Osbourne (Producer). (2001). Lord of the rings: Fellowship of the ring [DVD]. United States: New Line Home Entertainment.

Jackson, S., \& Stevenson, C. (2000). What do people need psychiatric and mental health nurses for? Journal of Advanced Nursing, 31(2), 378-388.

James, B., \& Saville-Smith, K. (1994). Gender, culture, and power: Challenging New Zealand's gendered culture (Rev. ed.). Auckland, New Zealand: Oxford University Press.

Kaplan, H. I., \& Sadock, B. J. (1991). Synopsis of psychiatry (6th ed.). Baltimore: Williams \& Wilkins. 
Kaufman, M. (1994). Men, feminism, and men's contradictory experiences of power. In H. Brod \& M. Kaufman (Eds.), Theorizing masculinities (pp. 142-163). Thousand Oaks, CA: Sage.

Kerfoot, D. (2001). The organization of intimacy: Managerialism, masculinity and the masculine subject. In S. M. Whitehead \& F. J. Barrett (Eds.), The masculinities reader (pp. 233-252). Malden, MA: Polity Press.

Kerkhof, A. J. F. M., \& Diekstra, R. F. W. (1995). The prevention of suicidal behaviour: A review of effectiveness. In R. F. W. Diekstra, W. Gulbinat, I. Kienhorst \& D. D. Leo (Eds.), Preventive Strategies on Suicide (pp. 207-229). Lieden, The Netherlands: E. J. Brill.

Kessler, R. C., Brown, R. L., \& Broman, C. L. (1981). Sex differences in psychiatric helpseeking: Evidence from four large-scale surveys. Journal of Health and Social Behavior, 22(1), 49-64.

Kidd, B. (1987). Sports and masculinity. In M. Kaufman (Ed.), Beyond patriarchy: Essays by men on pleasure, power, and change (pp. 250-265). Toronto, Canada: Oxford University Press.

Kimmel, M. S. (1994). Masculinity as homophobia: Fear, shame, and silence in the construction of gender identity. In H. Brod \& M. Kaufman (Eds.), Theorizing Masculinities (pp. 119-141). Thousand Oaks, CA: Sage.

Kimmel, M. S. (2000). The gendered society. New York: Oxford University Press.

Kimmel, M. S., \& Kaufman, M. (1994). Weekend warriors: The new men's movement. In H. Brod \& M. Kaufman (Eds.), Theorizing masculinities (pp. 259-288). Thousand Oaks, CA: Sage.

Kirkman, A. (2001). Ethics and the politics of research: Where gender and sexuality still matter. In M. Tolich (Ed.), Research ethics in Aotearoa New Zealand: Concepts, practice, critique (pp. 53-63). Auckland, New Zealand: Pearson Education.

Klerman, G. L. (1987). Clinical epidemiology of suicide. Journal of Clinical Psychiatry, 48(Suppl.), 33-38.

Kneisl, C. R., Wilson, H. S. \& Trigoboff, E. (2004). Contemporary psychiatric-mental health nursing, Pearson/Prentice Hall, Upper Saddle River, NJ. 
Kotch, J. B., Chalmers, D. J., Fanslow, J. L., Marshall, S., \& Langley, J. D. (1993).

Morbidity and death due to child abuse in New Zealand. Child Abuse and Neglect, 17(2), 223-247.

Kral, M. J., \& Sakinofsky, I. (1994). A clinical model for suicide risk assessment. In A. A. Leenaars, J. T. Maltsberger \& R. A. Neimeyer (Eds.), Treatment of suicidal people (pp. 19-31). Washington, DC: Taylor \& Francis.

Kushner, H. I. (1985). Women and suicide in historical perspective. Signs, 10(3), 537-552.

Leahey, T. H. (1987). A history of psychology: Main currents in psychological thought (2nd ed.). Englewood Cliffs, NJ: Prentice-Hall.

Leenaars, A. A. (Ed.). (1993). Suicidology: Essays in honor of Edwin Shneidman. Northvale, NJ: Jason Aronson.

Lego, S. (1997). A critique of Gournay's position on nursing theory and models. Journal of Psychiatric and Mental Health Nursing, 4(1), 64-66.

Lester, D. (1972). Self-mutilating behavior. Psychological Bulletin, 78(2), 119-128.

Lester, D. (1989). The study of suicide from a feminist perspective. Crisis: Journal of Crisis Intervention and Suicide, 11(1), 38-43.

Lester, D. (1996). On the relationship between fatal and nonfatal suicidal behavior. Homeostasis in Health and Disease, 37(3), 122-128.

Lester, D. (2000a). Alcoholism, substance abuse, and suicide. In R. W. Maris, A. L. Berman \& M. M. Silverman (Eds.), Comprehensive textbook of suicidology (pp. 357375). New York: Guilford Press.

Lester, D. (2000b). Why people kill themselves: A 2000 summary of research on suicide (4th ed.). Springfield: IL: Charles C. Thomas.

Lester, D. (2001). Association of alcohol use and suicide in 27 nations of the world. Psychological Reports, 88(3), 1129.

Lindseth, A., Marhaug, V., Norberg, A., \& Uden, G. (1994). Registered nurses' and physicians' reflections on their narratives about ethically difficult care episodes. Journal of Advanced Nursing, 20(2), 245-250.

Linehan, M. M. (1971). Toward a theory of sex differences in suicidal behavior. Crisis Intervention, 3(4), 93-101. 
Linehan, M. M. (1973). Suicide and attempted suicide: Study of perceived sex differences. Perceptual and Motor Skills, 37(1), 31-34.

Long, J. L., Jr. (1986). Reason versus causes as explanations of human behavior. International Forum for Logotherapy, 9, 93-99.

Long, J. L., Jr. (1997). Logotherapeutic transcendental crisis intervention. International Forum for Logotherapy, 20(2), 104-112.

Lövdahl, U., Riska, Å., \& Riska, E. (1999). Gender display in Scandinavian and American advertising for antidepressants. Scandinavian Journal of Public Health, 27(4), 306-310.

Lövdahl, U., \& Riska, E. (2000). The construction of gender and mental health in Nordic psychotropic-drug advertising. International Journal of Health Services, 30(2), 387-406.

Mac an Ghaill, M. (1994). The making of men: Masculinities, sexualities and schooling. Buckingham, England: Open University Press.

Mac an Ghaill, M. (1996). 'What about the boys?' Schooling, class and crisis masculinity. Sociological Review, 44(3), 381-397.

Maris, R. W. (1981). Pathways to suicide: A survey of self-destructive behaviors. Baltimore, MD: Johns Hopkins University Press.

Maris, R. W. (1992). How are suicides different? In R. W. Maris, A. L. Berman, J. T. Maltsberger \& R. I. Yufit (Eds.), Assessment and prediction of suicide (pp. 65-87). New York: Guilford Press.

Maris, R. W. (1997). Social suicide. Suicide and Life-Threatening Behavior, 27(1), 41-49.

Marks, A., \& Abernathy, T. (1974). Towards a sociocultural perspective on means of self-destruction. Suicide and Life-Threatening Behavior, 4(1), 3-17.

Martin, J., \& Dawda, D. (1999). Beyond empathy: A hermeneutically inspired inquiry into interpersonal understanding in psychotherapy. Theory and Psychology, 9(4), 459-481.

Martin, J., \& Sugarman, J. (1999). The psychology of human possibility and constraint. Albany, NY: State University of New York Press. 
Martin, J., \& Thompson, J. (2003). Psychotherapy as the interpretation of being: Hermeneutic perspectives on psychotherapy. Journal of Constructivist Psychology, 16(1), 1-16.

May, T. (1997). Social research: Issues, methods and process (2nd ed.). Buckingham, United Kingdom: Open University Press.

McCann, R. (1999). Fatherless sons: The experiences of New Zealand men. Auckland, New Zealand: Harper Collins.

McCloskey, L. A., \& Walker, M. (2000). Posttraumatic stress in children exposed to family violence and single-event trauma. Journal of the American Academy of Child and Adolescent Psychiatry, 39(1), 108-115.

McIntosh, J. L. (1992). Methods of suicide. In R. W.Maris, A. L. Berman, J. T.

Maltsberger \& R. I. Yufit (Eds.), Assessment and Prediction of Suicide (pp. 381-397). New York: Guilford Press.

McIntosh, J. L. (2002). Quantitative methods in suicide research: Issues associated with official statistics. Archives of Suicide Research, 6(1), 41-54.

McLaughlin, C. (1999). An exploration of psychiatric nurses' and patients' opinions regarding in-patient care for suicidal patients. Journal of Advanced Nursing, 29(5), 1042-1051.

McMorran, S. (1998, 22 April). Tunstall promises fight against women boxers. The Dominion, p. 48.

McNamee, S. (1992). Reconstructing identity: The communal construction of crisis. In S. McNamee \& K. J. Gergen (Eds.), Therapy as social construction (pp. 186-199). London: Sage.

McNamee, S., \& Gergen, K. J. (Eds.). (1992). Therapy as social construction. Thousand Oaks, CA: Sage Publications.

Menninger, K. A. (1938). Man against bimself. New York: Harcourt Brace.

Messner, M. A. (1991). Masculinities and athletic careers. In J. Lorber \& S. A. Farrell (Eds.), The social construction of gender (pp. 60-75). Newbury Park, CA: Sage.

Messner, M. A. (2001). Friendship, intimacy, and sexuality. In S. M. Whitehead \& F. J. Barrett (Eds.), The masculinities reader (pp. 253-265). Malden, MA: Polity Press. 
Midlefort, H. C. (1981). Heartland of the witchcraze: Central and northern Europe. History Today, 31, 28.

Mills, M. (2001). Challenging violence in schools: An issue of masculinities. Buckingham, United Kingdom: Open University Press.

Minichiello, V., Aroni, R., Timewell, E., \& Alexander, L. (1990). In-depth interviewing: Researching people (2nd ed.). Melbourne, Australia: Longman.

Ministry of Health. (1998). Guidelines for clinical risk assessment and management in mental health services. Wellington, New Zealand: Author.

Ministry of Justice. (1999). Response to crime: Annual review 1999. Wellington, New Zealand: Author.

Moore, S. L. (1997). A phenomenological study of meaning in life in suicidal older adults. Archives of Psychiatric Nursing, 11(1), 29-36.

Morgan, D. H. J. (1994). Family, gender and masculinities. Family Sociology and Social Change(18), 55-66.

Morin, M., Longhurst, K. R., \& Johnston, L. (2001). (Troubling) spaces of mountains and men: New Zealand's Mount Cook and Hermitage Lodge. Social and Cultural Geography, 2(2), 117-140.

Neale, J. M., \& Liebert, R. M. (1973). Science and behaviour: An introduction to methods of research (3rd ed.). Englewood Cliffs, NJ: Prentice-Hall.

Neame, P. (1997). Suicide and mental health in Australia and New Zealand. Brisbane, Australia: Author.

New Zealand Guidelines Group. (2003). The assessment and management of people at risk of suicide. Wellington, New Zealand: Author.

Nicholls, M. (1999). Some thing for the man who has everything: Melancholia and the films of Martin Scorsese. In K. Biber, T. Sear \& D. Trudinger (Eds.), Playing the man: New approaches to masculinity (pp. 39-51). Annandale, Australia: Pluto Press.

Nightingale, S., Beatrais, A., Joyce, P., \& Mulder, R. (1994). Antisocial behaviour and alcohol and drug disorders in suicides and suicide attempters. In P. R. Joyce, R. T. Mulder, M. A. Oakley-Browne, J. D. Sellman \& W. G. A. Watkins (Eds.), Development personality and psychopathology. Otago, New Zealand: University of Otago Press. 
Novaco, R. W. (1994). Anger as a risk factor for violence among the mentally disordered. In J. Monahan \& H. J. Steadman (Eds.), Violence and mental disorder: Developments in risk assessment (pp. 21-59). Chicago, IL: University of Chicago Press.

Nursing Council of New Zealand. (1998). Code of conduct for nurses and midwives. Wellington, New Zealand: Author.

O'Carroll, P. W. (1989). A consideration of the validity and reliability of suicide mortality data. Suicide and Life-Threatening Behavior, 19(1), 1-16.

Palmer, R. E. (1969). Hermeneutics: Interpretation theory in Schleiermacher, Dilthey, Heidegger, and Gadamer. Evanston, IL: Northwestern University Press.

Palmer, S. (1968). Murder and suicide in forty non-literate societies. In J. P. Gibbs (Ed.), Suicide (pp. 246-254). New York: Harper \& Row.

Pascoe, E. (1996). The value to nursing research of Gadamer's hermeneutic philosophy. Journal of Advanced Nursing, 24(6), 1309-1314.

Paton-Simpson, G. R. (1999). Towards an inclusive understanding of alcohol and drug problems in New Zealand. Wellington, New Zealand: Alcohol Advisory Council of New Zealand.

Pease, B. (1997). Understanding men's lives: From mythopoetic to sociopolitical perspectives. In Men and sexual politics: Towards a profeminist practice (pp. 45-56). Adelaide, Australia: Dulwich Centre.

Peplau, H. E. (1952). Interpersonal relations in nursing: A conceptual frame of reference for psychodynamic nursing. New York: Putnam.

Peplau, H. E. (1997). Peplau's theory of interpersonal relations. Nursing Science Quarterly, 10(4), 162-167.

Peteet, J. (2002). Male gender and rituals of resistance in the Palestinian intifada: A cultural politics of violence. In R. Adams \& D. Savran (Eds.), The masculinity studies reader (pp. 318-335). Malden, MA: Blackwell.

Peterson, D. (1998). Ethical research with mental health consumers. Wellington, New Zealand: Mental Health Commission.

Philbin, M. (1997). What to do with certainty: A response to Kevin Gournay. Journal of Psychiatric and Mental Health Nursing, 4(1), 63-64. 
Phillips, G. M. (1986). Men talking to men about their relationships. American Behavioral Scientist, 29(3), 321-341.

Phillips, J. (1980). Mummy's boys: Pakeha men and male culture in New Zealand. In P. Bunkle \& B. Hughes (Eds.), Women in New Zealand society (pp. 217-243). Sydney, Australia: Allen \& Unwin.

Phillips, J. (1996). A man's country? The image of the pakeha male: A history (Revised ed.). Auckland, New Zealand: Penguin Books.

Phoenix, A., \& Frosh, S. (2001). Positioned by "hegemonic" masculinities: A study of London boys' narratives of identity. Australian Psychologist, 36(1), 27-35.

Piekarska, A. (2000). Child abuse and neglect. In L. Bird \& W. J. Drewery (Eds.), Human development in Aotearoa: A journey through life (pp. 85-87). Sydney, Australia: McGraw-Hill.

Pinar, W. F. (1997). Regimes of reason and the male narrative voice. In W. G. Tierney \& Y. S. Lincoln (Eds.), Representation and the text: Reframing the narrative voice (pp. 81 113). Albany, NY: State University of New York Press.

Plass, C., \& Schetsche, M. (2000). The analysis and archiving of heterogeneous text documents: Using support of the computer program NUD*IST 4. Forum: Qualitative Social Research, 1(3). Retrieved from http://www.qualitativeresearch.net/fqs-texte/3-00/3-00plassschetsche-e.pdf

Plummer, D. (1999). One of the boys: Masculinity, homophobia, and modern manhood. New York: Harrington Park Press.

Pringle, R. (2002). Living the contradictions: A Foucauldian examination of my youthful rugby experiences. In H. Worth, A. Paris \& L. Allen (Eds.), The life of Brian (pp. 57-72). Dunedin, New Zealand: University of Otago Press.

Qualitative Solutions \& Research. (2000). NUD*IST (Version 6) [Computer software]. Melbourne, Australia: Author.

Raingruber, B. (2002). Client and provider perspectives regarding the stigma of and nonstigmatizing interventions for depression. Archives of Psychiatric Nursing, 16(5), 201-207. 
Rich, C. L., Ricketts, J. E., Fowler, R. C., \& Young, D. (1988). Some differences between men and women who commit suicide. American Journal of Psychiatry, 145(6), 718722.

Richardson, L. (1994). Writing: A method of inquiry. In N. K. Denzin \& Y. S. Lincoln (Eds.), Handbook of qualitative research (pp. 516-529). Thousand Oaks, CA: Sage.

Rickelman, B. L., \& Houfek, J. F. (1995). Toward an interactional model of suicidal behaviors: Cognitive rigidity, attributional style, stress, hopelessness, and depression. Archives of Psychiatric Nursing, 9(3), 158-168.

Ricoeur, P. (1971). The model of the text: Meaningful action considered as a text. Social Research, 38(3), 529-562.

Rolfe, G. (1996). What to do with psychiatric nursing? Journal of Psychiatric and Mental Health Nursing, 3(5), 331-333.

Roper, C. M., (Chair), Guest, M. R. D., Tia, A., McGeorge, A. P., Diamond, B., \& Perry, N. (1987). Report of Ministerial Committee of inquiry into violence. Wellington, New Zealand: Ministry of Justice.

Rout, B. (1992). Being 'staunch': Boys hassling girls. In S. Middleton \& A. Jones (Eds.), Women and education in Aotearoa 2 (pp. 169-180). Wellington, New Zealand: Bridget Williams Books.

Rudd, M. D. (2000). The suicidal mode: A cognitive-behavioral model of suicidality. Suicide and Life-Threatening Behavior, 30(1), 18-33.

Rutherford, J. (1992). Men's silences: Predicaments in masculinity. New York: Routledge.

Samuelsson, M., Wiklander, M., Asberg, M., \& Saveman, B. I. (2000). Psychiatric care as seen by the attempted suicide patient. Journal of Advanced Nursing, 32(3), 635-643.

Sanborn, C. J. (1990). Gender socialization and suicide: American Association of Suicidology Presidential Address, 1989. Suicide and Life-Threatening Behavior, 20(2), 148-155.

Schacht, S. P. (1996). Misogyny on and off the "pitch": The gendered world of male rugby players. Gender and Society, 10(5), 550-565.

Schwandt, T. A. (1994). Constructivist, interpretivist approaches to human inquiry. In N. K. Denzin \& Y. S. Lincoln (Eds.), Handbook of qualitative research (pp. 118-137). Thousand Oaks, CA: Sage. 
Sear, T. (1999). Playgirl executives: Images of men and work in early 1960s Australian pulp fiction. In K. Biber, T. Sear \& D. Trudinger (Eds.), Playing the man: New approaches to masculinity (pp. 200-213). Annandale, Australia: Pluto Press.

Seidler, V. J. (1987). Reason, desire, and male sexuality. In P. Caplan (Ed.), The cultural construction of sexuality (pp. 82-112). London: Routledge.

Seidler, V. J. (1989). Rediscovering masculinity: Reason, language and sexuality. London: Routledge.

Seidler, V. J. (1992). Rejection, vulnerability, and friendship. In P. Nardi (Ed.), Men's friendships (pp. 15-34). Thousand Oaks, CA: Sage.

Seidler, V. J. (1994). Unreasonable men: Masculinity and social theory. London: Routledge.

Seidler, V. J. (1997). Man enough: Embodying masculinities. London: Sage.

Shives, L. R. (2004). Basic concepts of psychiatric-mental health nursing. Lippincott Williams \& Wilkins, Philadelphia, PA.

Shneidman, E. (1968). Classifications of suicidal phenomena. Bulletin of Suicidology, 1, 119.

Shneidman, E. (1985). Definition of suicide. New York: John Wiley \& Sons.

Shneidman, E. S. (1992). What do suicides have in common? Summary of the psychological approach. In B. Bongar (Ed.), Suicide: Guidelines for assessment, management, and treatment (pp. 3-15). New York: Oxford University Press.

Shneidman, E. S. (1993). Suicide as psychache. Journal of Nervous and Mental Disease, 181(3), 145-147.

Shneidman, E. S. (1998). Further reflections on suicide and psychache. Suicide and LifeThreatening Behavior, 28(3), 245-250.

Shneidman, E. S. (1998). The suicidal mind. New York: Oxford University Press.

Shneidman, E. S. (2001). Comprehending suicide: Landmarks in 20th century suicidology. Washington, DC: American Psychiatric Press.

Simpson, J. A., \& Weiner, E. S. C., (Eds.). (1989, 2004). OED Online. Retrieved 5 June, from Oxford University Press http://dictionary.oed.com

South, B. (1996, 27 October). Women in boxing might make it a pretty sport again. Sunday Star Times, p. 9. 
Sparkes, A. C., \& Smith, B. (2002). Sport, spinal cord injury, embodied masculinities, and the dilemmas of narrative identity. Men and Masculinities, 4(3), 258-286.

Spender, D. (1980). Man made language. London: Routledge \& Kegan Paul.

Spierenburg, P. (1998). Masculinity, violence, and honor: An introduction. In P. Spierenburg (Ed.), Men and violence: Gender, honor, and rituals in modern Europe and America (pp. 1-29). Columbus, OH: Ohio State University Press.

St. John, W., \& Johnson, P. (2000). The pros and cons of data analysis software for qualitative research. Journal of Nursing Scholarship, 32(4), 393-397.

Steinman, J. (1993). Objects in the rearview mirror may appear closer than they are [Recorded by Meatloaf]. On Bat Out of Hell II [Audio CD]. New York: Virgin Records.

Stengel, E. (1969). Suicide and attempted suicide (Rev. ed.). Middlesex, England: Penguin Books.

Stern, K. (1985). The flight from woman. New York: Paragon House. (Original work published 1965)

Stoltenberg, J. (1992). Pornography, homophobia and male supremacy. In C. Itzin (Ed.), Pornography: Women, violence and civil liberties (pp. 145-165). Oxford, United Kingdom: Oxford University Press.

Sumich, H., Andrews, G., \& Hunt, C. (1995). The management of mental disorders: Vol. 1. Handbook of management skills. Sydney, Australia: World Health Organization Training and Reference Centre for CIDI.

Swain, J. (2002). The resources and strategies boys use to establish status in a junior school without competitive sport. Discourse, 23(1), 91-108.

Szasz, T. S. (1970). The myth of mental illness. In Ideology and insanity: Essays on the psychiatric debumanisation of man (pp. 12-24). Garden City, NY: Anchor Books.

Talseth, A.-G., Gilje, F., \& Norberg, A. (2001). Being met: A passageway to hope for relatives of patients at risk of committing suicide: A phenomenological hermeneutic study. Archives of Psychiatric Nursing, 15(6), 249-256.

Talseth, A.-G., Gilje, F., \& Norberg, A. (2003). Struggling to become ready for consolation: Experiences of suicidal patients. Nursing Ethics, 10(6), 614-623. 
Talseth, A.-G., Lindseth, A., Jacobsson, L., \& Norberg, A. (1999). The meaning of suicidal psychiatric in-patients' experiences of being cared for by mental health nurses. Journal of Advanced Nursing, 29(5), 1034-1041.

Talseth, A., Jacobsson, L., \& Norberg, A. (2001). The meaning of suicidal psychiatric inpatients' experiences of being treated by physicians. Journal of Advanced Nursing, 34(1), 96-106.

Tanney, B. L. (1992). Mental disorders, psychiatric patients, and suicide. In R. W.Maris, A. L. Berman, J. T. Maltsberger \& R. I. Yufit (Eds.), Assessment and prediction of suicide (pp. 277-320). New York: Guilford Press.

Tanney, B. L. (2000). Psychiatric diagnoses and suicidal acts. In R. W. Maris, A. L. Berman \& M. M. Silverman (Eds.), Comprehensive textbook of suicidology (pp. 311341). New York: Guilford Press.

Taylor, C. (2002). Gadamer on the human sciences. In R. J. Dostal (Ed.), Cambridge companion to Gadamer (pp. 126-142). Cambridge, United Kingdom: Cambridge University Press.

Thompson, J., \& Brooks, S. (1990). When a colleague commits suicide: How the staff reacts. Journal of Psychosocial Nursing and Mental Health Services, 28(10), 6-11.

Thompson, J. L. (1990). Hermeneutic inquiry. In L. E. Moody (Ed.), Advancing nursing science through research (Vol. 2, pp. 223-280). Newbury Park, CA: Sage.

Toch, H. (1998). Hypermasculinity and prison violence. In L. H. Bowker (Ed.), Masculinities and violence (pp. 168-178). Thousand Oaks, CA: Sage.

Tolich, M. (2001). Beyond an unfortunate experiment: Ethics for small-town New Zealand. In M. Tolich (Ed.), Research ethics in Aotearoa New Zealand: Concepts, practice, critique (pp. 1-12). Auckland, New Zealand: Pearson Education.

Town, S. J. (1998). Is it safe to come out now? Unpublished doctoral thesis, Victoria University of Wellington, Wellington, New Zealand.

Town, S. J. (1999). Queer(y)ing masculinities in schools: Faggots, fairies and the First XV. In R. Law, H. Campbell \& J. Dolan (Eds.), Masculinities in Aotearoa/New Zealand (pp. 135-152). Palmerston North, New Zealand: Dunmore Press.

Townsend, M. C. (2003). Psychiatric mental health nursing: Concepts of care. F.A. Davis, Philadelphia, PA. 
Travelbee, J. (1971). Interpersonal aspects of nursing (2nd ed.). Philadelphia, PA: F.A. Davis.

Valente, S. M. (2003). Aftermath of a patient's suicide: A case study. Perspectives in Psychiatric Care, 39(1), 17-22.

van Hoof, A. J. L. (2000). A historical perspective on suicide. In R. W. Maris, A. L. Berman \& M. M. Silverman (Eds.), Comprehensive textbook of suicidology. New York: Guilford Press.

Wachterhauser, B. (2002). Getting it right: Relativism, realism, and truth. In R. J. Dostal (Ed.), Cambridge companion to Gadamer (pp. 52-78). Cambridge, United Kingdom: Cambridge University Press.

Walby, S. (1989). Theorising patriarchy. Sociology, 23(2), 213-234.

Walsh, K. (1996). Philosophical hermeneutics and the project of Hans Georg Gadamer: Implications for nursing research. Nursing Inquiry, 3(4), 231-237.

Warnke, G. (1987). Gadamer: Hermeneutics, tradition and reason. Cambridge, United Kingdom: Polity Press.

Warren, L. W. (1983). Male intolerance of depression: A review with implications for psychotherapy. Clinical Psychology Review, 3(2), 147-156.

Watson, J. M. (1983). Male body image and health beliefs: A qualitative study and implications for health promotion practice. Health Education Journal, 52(4), 246252.

West, C., \& Zimmerman, D. H. (1991). Doing gender. In J. Lorber \& S. A. Farrell (Eds.), The social construction of gender (pp. 13-37). Newbury Park, CA: Sage.

White, H., \& Stillion, J. M. (1988). Sex differences in attitudes toward suicide: Do males stigmatize males? Psychology of Women Quarterly, 12(3), 357-366.

White, P. G., Young, K., \& McTeer, W. G. (1995). Sport, masculinity, and the injured body. In D. Sabo \& D. F. Gordon (Eds.), Men's health and illness: Gender, power, and the body (pp. 158-182). Thousand Oaks, CA: Sage.

Whitehead, S. (2001). Man: The invisible gendered subject? In S. M. Whitehead \& F. J. Barrett (Eds.), The masculinities reader (pp. 351-368). Malden, MA: Polity Press. 
Whitson, D. (1990). Sport in the construction of masculinity. In M. A. Messner \& D. F. Sabo (Eds.), Sport, men, and the gender order: Critical feminist perspectives (pp. 19-29). Champaign, IL: Human Kinetics Books.

Wiklander, M., Samuelsson, M., \& Asberg, M. (2003). Shame reactions after suicide attempt. Scandinavian Journal of Caring Sciences, 17(3), 293-300.

Wilkin, P. (2003). The craft of psychiatric-mental health nursing practice. In P. Barker (Ed.), Psychiatric and mental health nursing: The craft of caring (pp. 26-33). London: Arnold.

World Health Organization. (1975). International classification of diseases (9th ed.). Geneva, Switzerland: Author.

World Health Organization. (1978). International classification of diseases: Clinical modification (9th ed.). Geneva, Switzerland: Commission on Professional and Hospital Activities.

World Health Organization. (1993). International statistical classification of diseases and related health problems (10th ed.). Geneva, Switzerland: Author.

Yonge, O., \& Stewin, L. L. (1992). What psychiatric nurses say about constant care. Clinical Nursing Research, 1(1), 80-90. 


\section{APPENDICES}

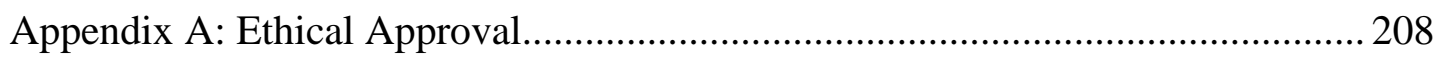

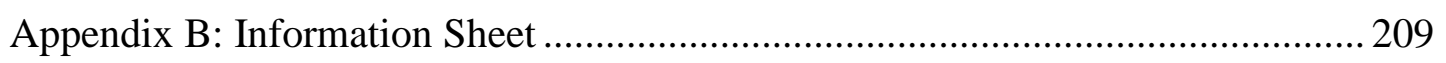

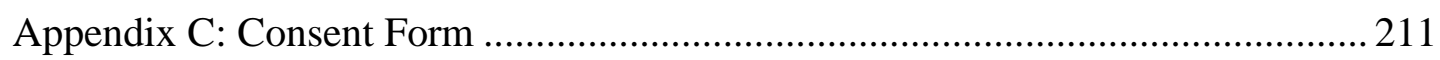

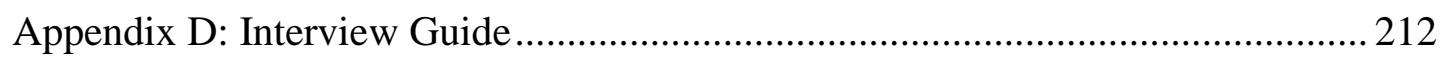


APPENDIX A: ETHICAL APPROVAL

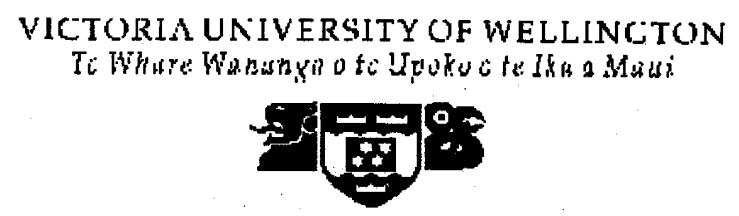

MEMORANDUM

TO: $\quad$ Brian Phillips

Nursing \& Midwifery

FROM: Graeme Kennedy

Convener, Human Ethics Committee

DATE: $\quad 22$ March 2001

SUBJECT: APPLICATION FOR ETHICAL APPROVAL: AN EXPLORATION OF THE IMPACT OF MASCULINITY IN PREVIOUS SUICIDAL EXPERIENCE

Thank you for making the amendments requested by the Human Ethics Committee.

Your application, as revised, is approved. Approval is given for the period 22 March 2001 to 31 December 2002.

With best wishes for your research.

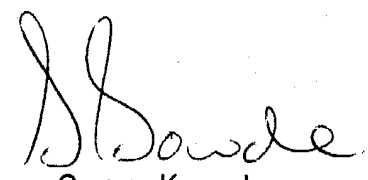

Graeme Kennedy

$\rho f$. Convener, Human Ethics Committee 

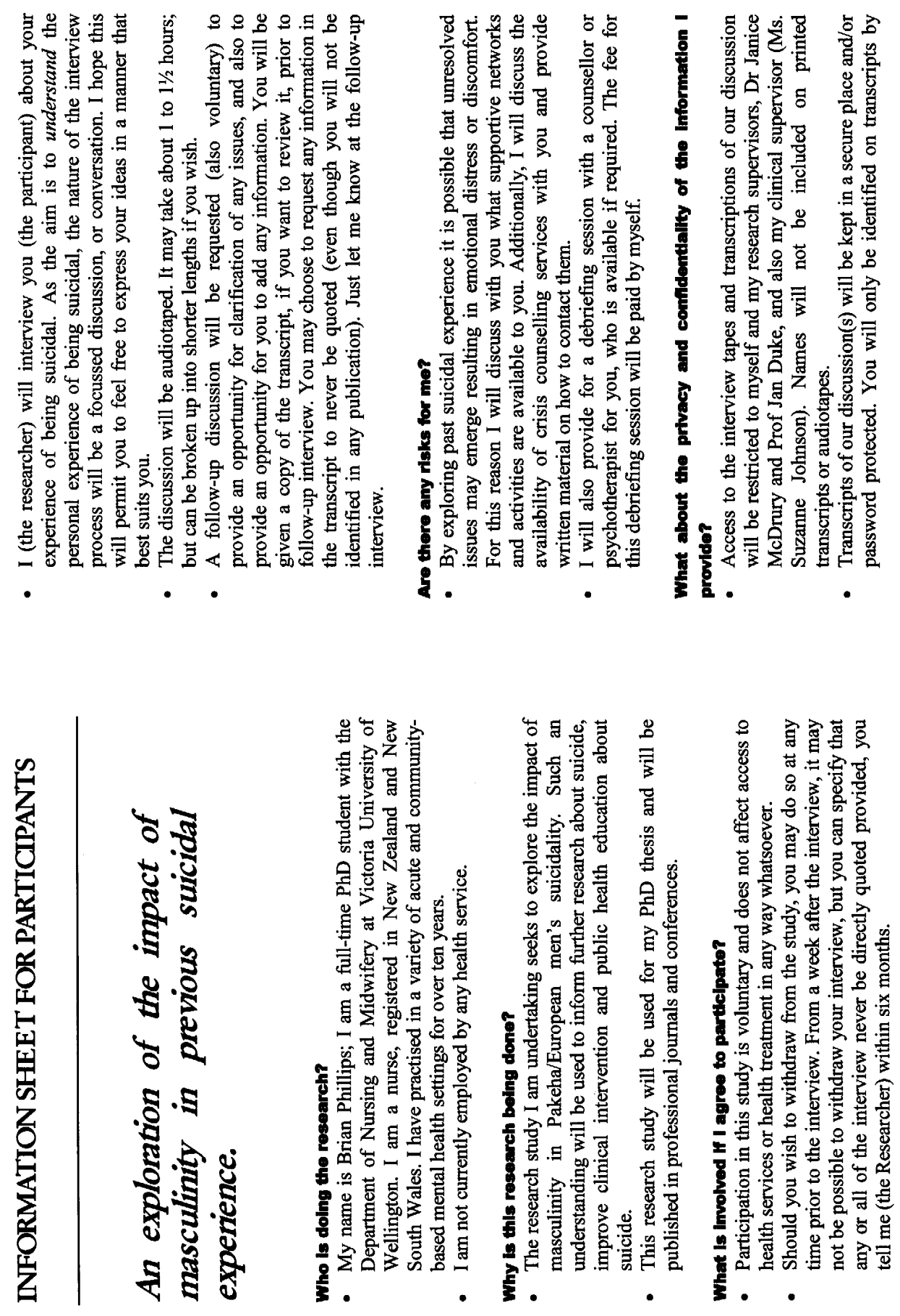

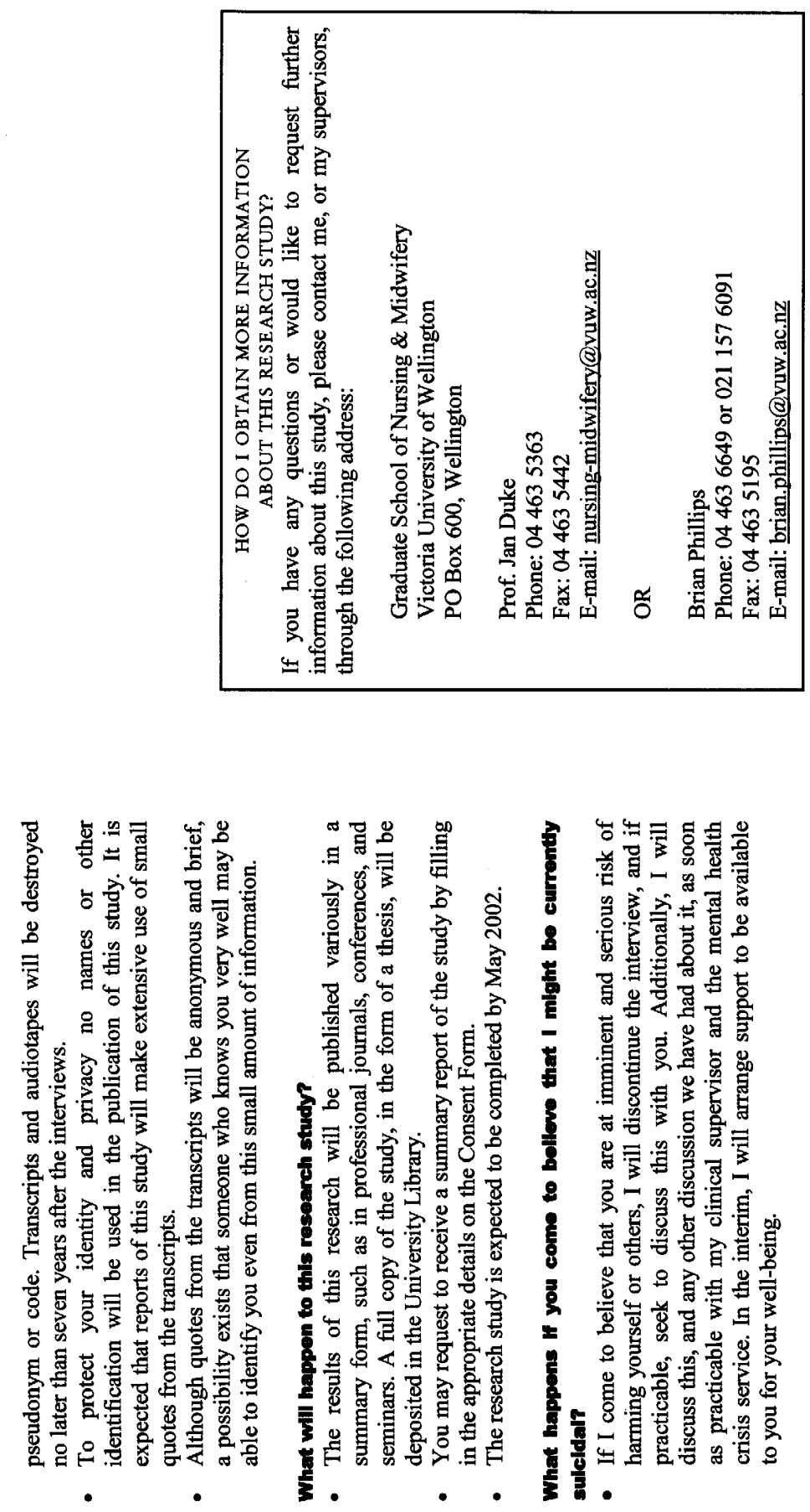


\section{Consent for Participation in Research \\ Title of Project An exploration of the impact of masculinity in previous suicidal experience.}

I

have been given, and have understood, an explanation of this research project. I understand that: a) prior to the first interview I can withdraw completely from the study without having to give reasons or penalty; b) that within a week following the interview, I will be unable to withdraw my interview, but after that the interview would become part of the research data; c) up to six months after the interview I can specifiy that any or all of my interview never be directly quoted.

I understand that any information I provide will be kept confidential to the Researcher (Brian Phillips), his supervisors, Dr. Janice McDrury and Prof. Jan Duke, his clinical supervisor (Ms Suzanne Johnson), and the person who transcribes the tape recordings of our interview. The published results will not use my name, information identifying location of events will be disguised or removed, and that no opinions will be attributed to me in any way that will identify me.

I also understand that the audiotapes, transcripts (electronic and printed) will be destroyed no later than a period of seven years after the interview takes place.

I understand that in the event of disclosure to the Researcher of information that may indicate a serious risk of physical self-harm, or physical harm to others, the Researcher will discuss this as soon as practicable with Mental Health Crisis Services.

$\square$ I would like a copy of the tape-recorded session(s).

I would like to receive a summary of the results of this research sent to the following address, when it is completed (The research is expected to be written up by May 2002):

I understand that the data I provide will not be used for any other purpose or released to others without my written consent.

I agree to take part in this research.

Signed:

Name of participant:

Date:

(Please print clearly) 


\section{APPENDIX D: INTERVIEW GUIDE}

\section{Intervlew Guide}

\section{The Interviews}

The meanings of masculinity in the context of suicidal thinking, and the dynamics of their impact, will be explored through the analysis of interviews of men talking about their past suicidal experience(s).

\section{Interview Procese}

- Interviewing and preliminary analysis will inform each other. That is following the initial interview, interview focus topics will be continuously refined and developed in the light of preliminary analysis.

- Interview process is therefore a priority for the Researcher-Interviewer. Interviews will be conducted in a conversational style so that the interviewee is facilitated to tell his story using his own words.

- The interview process will be recursive and open-ended, the purpose being as follows: 1) to maintain a focus on the topics of interest that are listed below, 2) to facilitate increasingly greater detail and clarity about the focus topic, 3) to check understandings, and 4) to elicit greater contextual data. Interview data will therefore be in a narrative form.

- Interviews will include an introduction that: recaps purpose of interviews; that it will be audiotaped; and that emotional supports, both formal and informal, are considered . Additionally, an offer of a debriefing session with counsellor/psychotherapist, if it is required, for any distress or discomfort.

- To bring about closure, the conclusion of the interviews will include: an offer for the interviewee to add further ideas and an opportunity for the interviewee to reflect on the experience of the discussion.

- After the interview, interviewees will be provided with time for open-ended talk over coffee or tea; given a reminder of arrangements for debriefing session if required and and given a reminder of support that is available. Additionally, arrangements for the follow-up interview will be discussed, if agreeable.

\section{Interviow Focus Topics}

- Thoughts of suicide and suicidality; including describing suicidal experience.

- Ideas on masculinity; including social context and history, relationships, ideas of embodiment, values, and meanings.

- Reflections on masculinity and suicidality; including the impact of suicidal experience on masculinity.

- Reflection on survival; including intervention experience, and suggestions for other men.

- Reflection on discussion; including possible links and connections. 